


\title{
A CURATED CACOPHONY: IMPLEMENTING AN INTANGIBLE
}

\author{
BY \\ OLIVER WRIGHT \\ A thesis submitted to Victoria University of Wellington in fulfilment of the requirements for the \\ degree of Master of Architecture (Professional) \\ Victoria University of Wellington, 2017 \\ School of Architecture
}




\section{ACKNOWLEDGMENTS}

I am very grateful for discussions and guidance from Natasha Perkins, Michael Donn and Christina Mackay - supervisors at the Victoria University of Wellington School of Architecture and Design.

Thank you to my parents, whose support and love has grounded this research. Thank you also to my good friends Hayley and Charlotte for their support and patience - even when listening to tales of strange animal-named programmes.

This project would not have been possible without the continuing support of Miklin Halstead and the team at Marshall Day Acoustics LTD. 


\title{
PREFACE
}

This document is the thesis output for a Master of Architecture (Professionall) project investigating the synthesis of architectural acoustics (a passion of mine) and parametric design (an immerging field I was curious about, yet, had little exposure to). This research produced a case study design of a café

building as a medium for exploring the potential influence of acoustics on architecture and its possible implications for the wider design industry.

\begin{abstract}
This research investigates a progression away from acoustics formed by spaces and towards spaces that are driven by target acoustics. Despite architecture and acoustics' shared consideration of form, materiality and inhabitation, too often acoustics is neglected from design and so is treated remedially, nullifying creativity. A case study project was undertaken to investigate the opportunities and limitations of two parametric tools, Galapagos (a generative solver) and Pachyderm (an acoustic simulation tool), to develop acoustic qualities in early architectural design. Yet, what are these acoustic qualities and how could they be measured? Testing of cafes in the Wellington CBD was undertaken to investigate these questions.
\end{abstract}

Six cafes were acoustically tested and five patrons from each of these completed a subjective survey. The café testing suggested that Reverberation Time (RT) could be an effective acoustic measure to direct architectural design. The café with the lowest patron enjoyment rating also recorded the longest RT and highest Sound Pressure Level (SPL), reinforcing the relationship between these three elements. Through these findings, patron enjoyment was concluded to be dependent on SPL and SPL was concluded to be dependent on RT (Whitlock and Dodd, 424). In order to increase patron enjoyment, Galapagos was utilised to explore possible forms that met a target design RT of 0.7 seconds. An RT of 0.7 seconds was chosen as it was shorter than the AS/NZS 2107 (2000) maximum and was comparable to the cafés with the two highest subjective enjoyment ratings.

Through a parametric and analogue design methodology, Galapagos and Pachyderm were used to investigate how acoustic goals could shape a café design. The case study project produced a design that not only meets this acoustic criterion but harnesses form to sculpt sound. Instead of applying absorption to flat surfaces, the convex curves on the north and east facades disperse sound, producing both a diffuse environment and an engaging architectural element. This integrated investigation demonstrated that a parametric and analogue design process can be implemented to create a acoustically and architecturally effective design. 

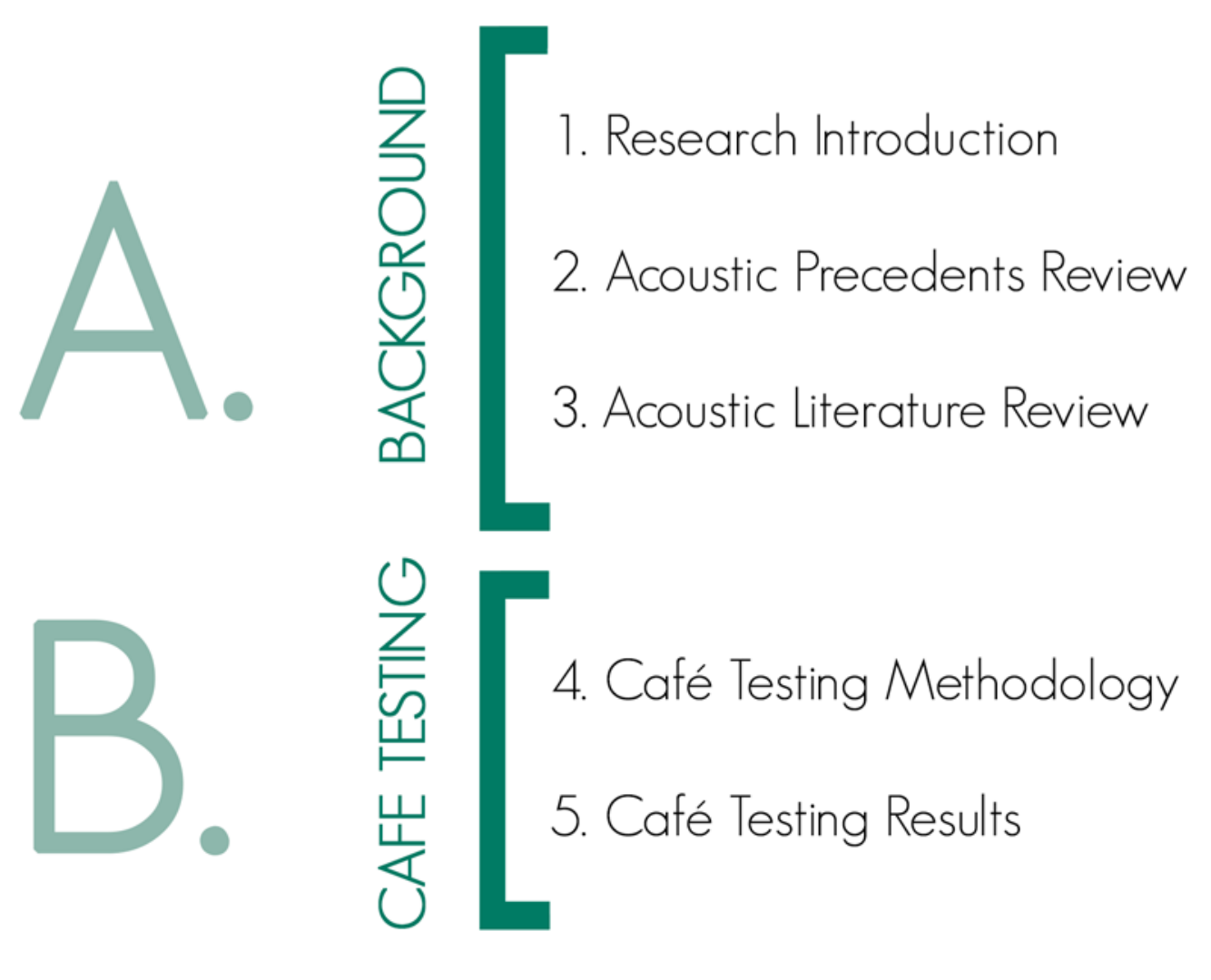

6. Existing Site and Context Analysis

7) Existing Cafe Function Analysis

8. Case Study Project Design Brief Formation

9. Case Study Project Design Methodology

10. Case Study Project Design Experiments - Preliminary Design

11. Case Study Project Design Elements

- Developed Design

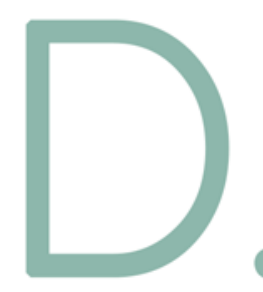

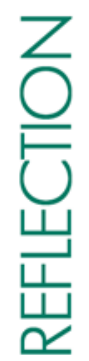




\section{KEY TERMS}

Decibel (dB):

A logarithmic unit used to describe a ratio between the measured level and a reference or threshold level of OdB.

Decibel A-weighting (dBA):

The decibel unit filtered to be comparable to the response of the human ear.

Reverberation Time (RT):

T60 - the time it takes for the Sound Pressure Level (SPL) to fall by $60 \mathrm{~dB}$ after the sound has been turned off.

Note: the 60 in "T60" indicates the number of decibels that the SPL decays by.

Speech Transmission Index (STI):

The ability for easy words to be clearly recognised. It is directly dependent on the level of background noise, Reverberation Time and the shape of the room (Gracey).

Sound Pressure Level (SPL):

The difference between the pressure produced by a sound wave and the ambient pressure at the same point in space, symbol P or $p$ (Gracey).

Signal to Noise Ratio (SNR):

The difference between the signal SPL and the noise floor (ambient) in $\mathrm{dB}$

See Appendix A - Terminology for further explanation of acoustic principles. 

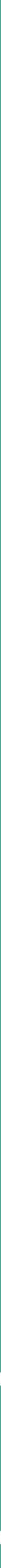


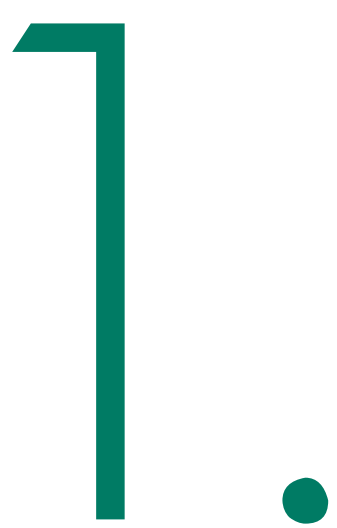


This research responds to a call from the acoustic industry for a shift away "from developing acoustics from given spaces to developing spaces from given acoustics" (Schmidt and Kirkegaard, 95). It investigates a gap between the architectural and acoustic design disciplines, conducting a "Research through Design" project to establish a case study for an implementation of acoustics into early architectural design. The findings of this research are communicated in this thesis through four sections:

\section{A background into acoustics and architec-} ture,

2. Acoustic testing of a sample group of Wellington cafes to identify what makes them effective, or otherwise, acoustic spaces,

3. Implementation of acoustic design in a case study design of a café

4. Critical reflection upon the success of the design, methodology and wider implications of the research for the industry.

This first thesis chapter introduces Architectural Acoustics, addressing what it is, why it is needed within the industry, where it could be implemented and how.

WHY SHOULD ARCHITECTURAL ACOUSTICS BE IMPLEMENTED?

"Architecture is the thoughtful making of space" - Louis Kahn (2)

Both architecture and acoustics respond to the same design issues of form, materiality and inhabitation. These shared foundations provide the two disciplines the potential to collaborate. Despite this, too often poor acoustics still occur within design - heard as, clangy, loud or sparse spaces by their patrons. The case study explores the thoughtful making of architectural space when acoustics is the starting point (Kahn, 2).
The case study project developed from a pilot study conducted by the author in 2016 that assessed whether inefficiencies within the architect and acoustician relationship led to increased acoustic remedial action. The study surveyed 51 employees of one acoustics firm and found that delays in the commencement of acoustic consultation corresponded to an increase in remedial action required for several building types (figure 1.1) (Wright et al., 780)

The pilot study revealed that acoustic design was absent from the sketch design phase of small projects. Instead, acoustics was often responded to remedially when the space did not fulfil its programmatic requirements. Given this situation, the current industry practice is to view acoustic "solutions" as application of porous sheet absorption to walls and ceilings, focusing on the removal of sound. This thesis asks: is this the best that we, as the design industry, can do? This project askes:

Can parametric design add acoustic quality to an architectural design: a case study of a cafe in Wellington?

WHEN COULD ARCHITECTURAL ACOUSTICS BE IMPLEMENTED?

"You can use an eraser on the drafting table or a sledge hammer on the construction site" - Frank Lloyd Wright atd. in Mandel.

The fluidity of change in early design allows for a level of creativity that is difficult to achieve in resolved design stages. Exploration of design expression is vital to a project's development, however, acoustics is seldom explored as a design tool in early design (Wright et al. 780; Vlaun, 9). The current focus on acoustic nullification is to the detriment of architecturally-crafted acoustics, reducing the potential for acoustic expression within a design outcome. Yet, how can, as Frank Lloyd Wright says, a shift be made back to the "eraser" phase? 


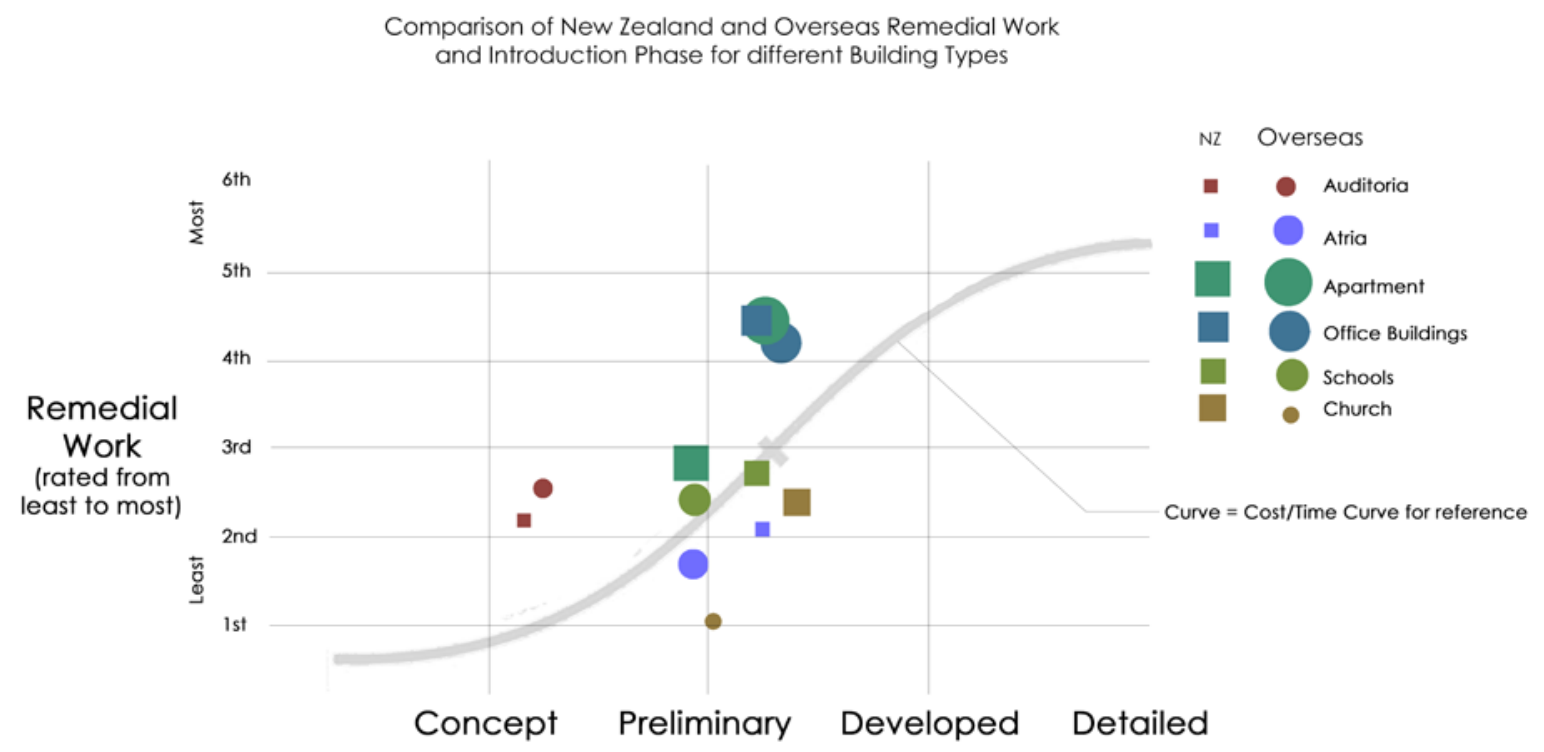

Design Phase that Acoustic Consultancy was Introduced

Figure 1.1: The graph suggests that the early intervention of acoustics could limit the need for post-construction remedial work where shape indicates the project location, colour indicates the typology and position indicates the phase of Acoustician introduction ( $X$ axis) and amount of remedial work (Y axis). Size of the shape represents the standard deviation of answers, where a small standard deviation is illustrated by a large shape. A connection between a later introduction of an acoustician and an increase in remedial action can be seen by comparing the squares. Acousticians were introduced early into auditoria (red) and had less remedial action than projects that they were introduced later into, such as Office Buildings

(green) (Wright et al., 791).

Parametric design is a design approach centred on carrying quantifiable factors such as building performance, human comfort or geometric restrictions back into the design stage. This "Deep Relationality" is an immersion of the environment, context, and interior organisation into design through parameters (Schumacher). These quantifiable factors define an outcome, carrying human comfort and performance criteria into early design. This project hypothesised that acoustics could be implemented into sketch design as one of these criteria.

WHERE COULD ARCHITECTURAL ACOUSTICS BE IMPLEMENTED?

This research explored a case study implementation of acoustics into a café design. The outwardly mundane selection of a cafe as a case study was chosen to examine a space where acoustics would not necessarily be considered in detail. Despite this lack of design attention, many cafes are often considered "too loud or undesirable acoustically for occupants from an objective point of view" (Christie and Bell-Booth, 14). This indicates a gap in the industry knowledge.

HOW COULD ARCHITECTURAL ACOUSTICS BE IMPLEMENTED?

This research explored how a concurrent parametric and analogue design methodology could add acoustic qualities to an architectural design. In this thesis the term "parametrics" is used to communicate digital design methods through Galapagos and Pachyderm. Similarly, "analogue" was used to describe more traditional design techniques such as sketching and modelling. 
The case study project established and parametrically implemented café acoustic performance criteria through Galapagos (Rutten), an evolutionary solver, and Pachyderm, an acoustic simulation software (Van Der Harten). Pachyderm simulated room acoustics by projecting sound rays out from a source and gathering them at a listener (or receiver) position. The path of the rays are simulated through raytracing and image source simulation software, the success of which, has been well established by the industry (Vorländer; Pelzer, Aretz, and Vorländer).
Galapagos was used, within the Rhino/ Grasshopper platform, as a form finding tool through Evolutionary Algorithms. This platform altered the form of the design, within geometric constraints, to optimise towards a targeted acoustic result. The amalgamation of these two tools created real-time optimisation towards a design outcome, converting the potential hindrance of acoustics into a design driver.

\section{THESIS STRUCTURE}

Three driving objectives were established to direct the research and, alongside the chapters of this thesis, established a platform for this research. Objectives (in green) and chapters (capitals) are illustrated in figure 1.2. 
Acoustic mirrors - Unknown Architect

The Blue Frog Acoustic Lounge - Serie Architects

The Cave Restaurant - Koichi Takada Architects

\section{RESEARCH INTROD}

\section{ACQUSTIC PRECEDENTS REVIEW \\ 4. CAFE TESTING METHODOLOGY}

Quantitative Acoustic

Measurements

5. SAFE TESTING RESUITS Survey Results Sualitative Data:

Reverberation Time (RT)

Signal to Noise Ratio

Sound Transmitting Index (STI)

Quantitative Data:

Clarity (C50)

Definition (D50).

Identify key objective acoustic parameters that influence the creation of effective café space

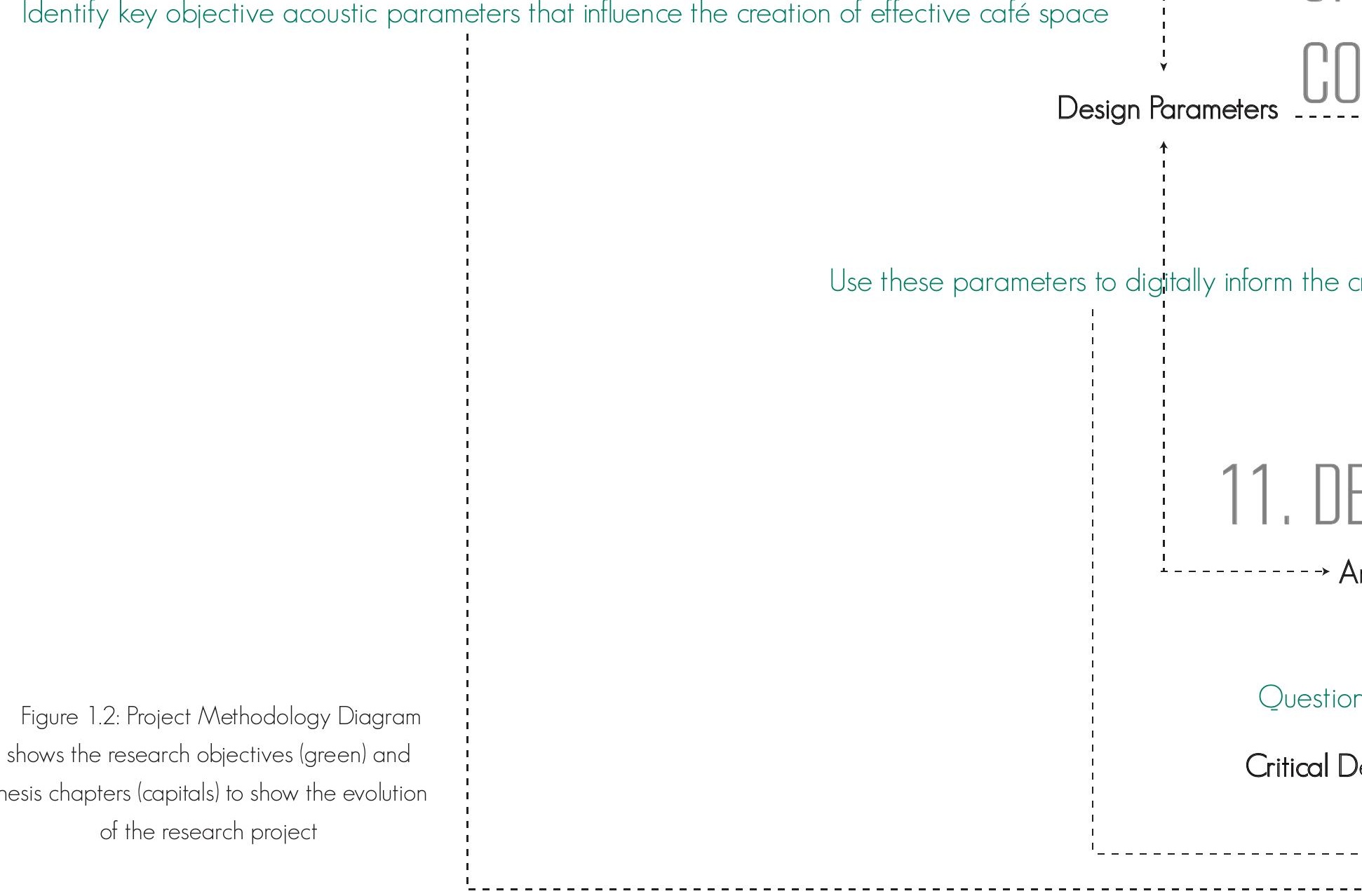

6. 
"Acoustics in the Hospitality Industry" - Christie and Bell-Booth "Spaces speak, are you listening?" - Blesser and Salter "Architectural acoustic and structural form" - Echenagucia et al "Sound working environments" - Vlaun "Understanding the Lombard Effect" - Whitlock "The Daily Grind" - Legge et al.

\section{ACOUSTIL LITERATURE REVIEW}

6 Cafés of origirial 44 elected

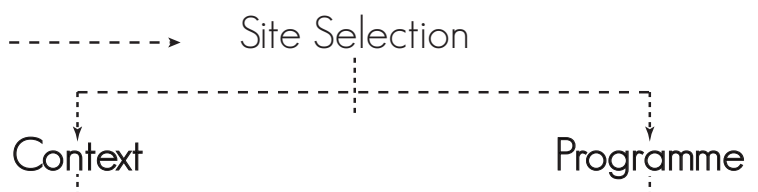

6. EXISTING SITEAND 7. EXISTSING CAFE

CONTEXT ANALYSIS FUNCTION ANALYSIS

Brief Formation

8. DESIGN BRIEF FORMATION

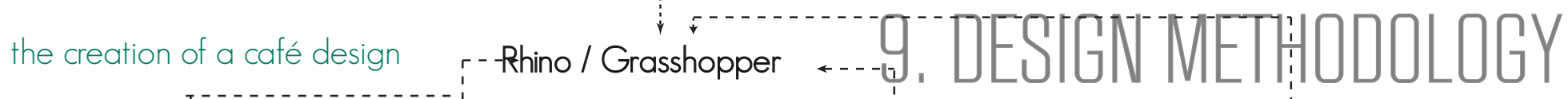

DEVELPPED DESIGN

$\rightarrow$ Analogue, Exploration

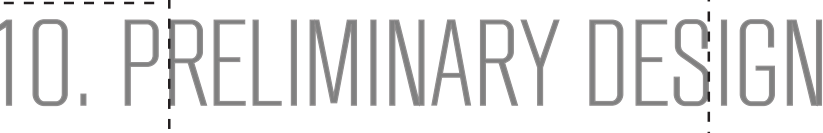

Pachyderm

Acoustic Simulations

Jestion if current parametric software produces meaningful information for the designer

ical Design Outcome Reflection 1 ' C 


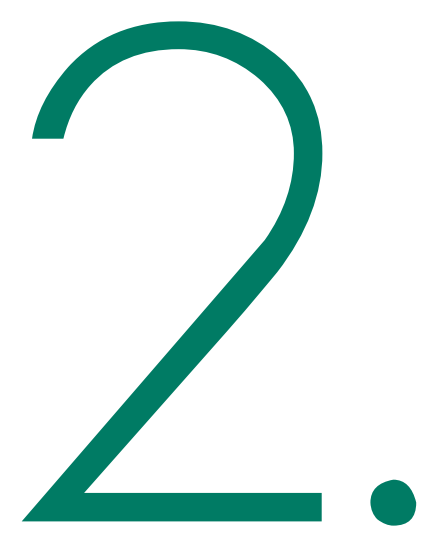

Acoustic Precedents Review 
"The technology of noise control both inside and outside buildings is well developed today.

The problem is that it is too seldom used."

- Robert Newman gtd. in Egan 
This section compares and contrasts three existing architectural acoustic projects to assess the body of work already completed and identify two of the most apt strategies for crafting architectural acoustics through form and materiality.

CRAFTING SOUND:

ACOUSTIC MIRROR (FIGURE 2.1)

\section{ACOUSTICS AND FORM}

The mirror is concrete - reflective, durable, and easily moulded. Figure 2.2 and 2.3 illustrate these material properties in terms of sound.

\section{ACOUSTICS AND MATERIALITY}

Concrete's ability to be cast in-situ meant that the design could be efficiently assembled on site. Concrete's ability to be moulded maximises the coverage of the microphone allowing significantly more sound rays to be captured. The durability of the concrete allowed for these structures to be resilient to the exterior conditions, reducing maintenance.

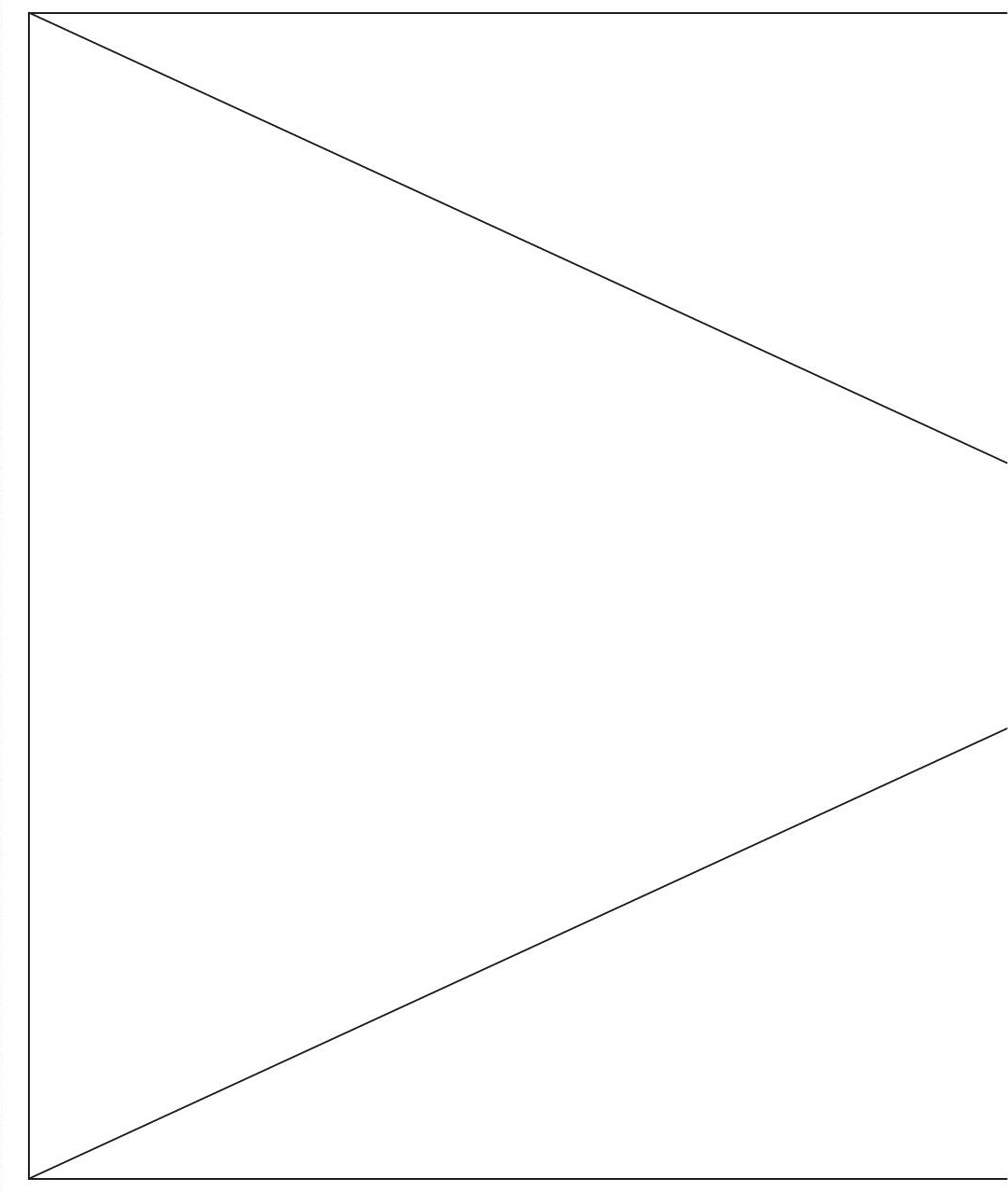



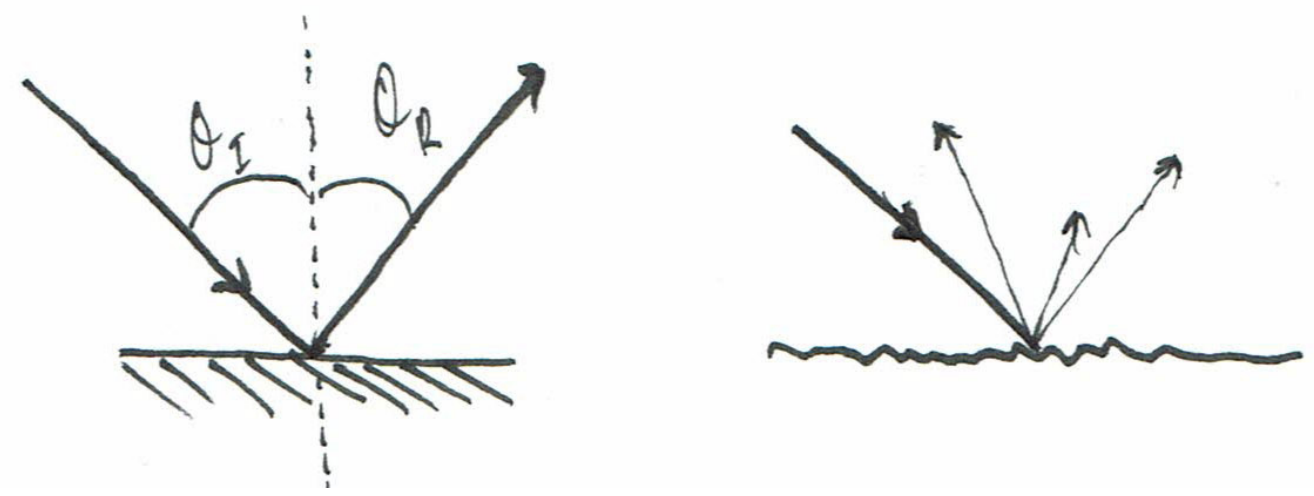

Figure 2.2 Smooth concrete produces a predictability reflection where the angle of the incoming ray is the same as the outgoing angle (left). If the material was rough or porous, sound rays scatter (right) and the signal recorded by the microphone would not be as strong 

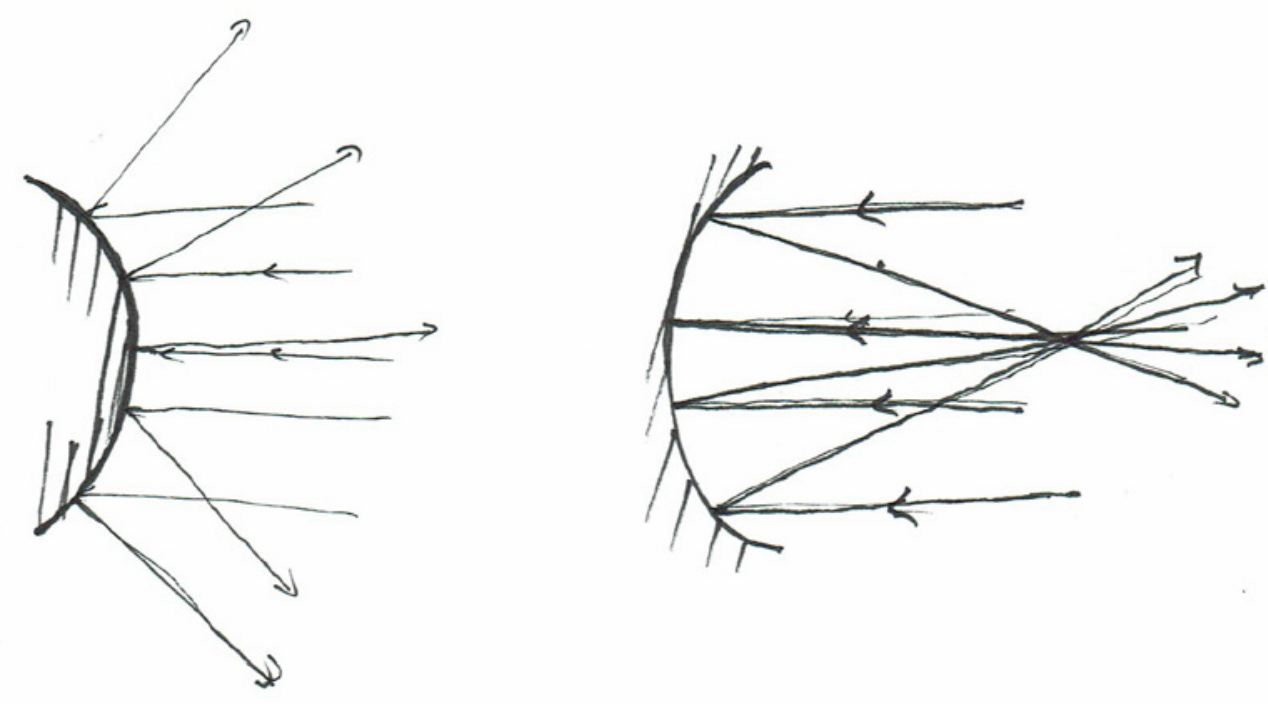

Figure 2.3 The Mirror's concave form, alongside its smooth surface, converges sound towards a strategically placed microphone at the focal point. Concrete outside of the curve is rough and porous however, consideration has been giving to the curve of the mirror to ensure a smooth and even treatment. The redirected sound rays were captured by the microphone and relayed to a control desk 
DESIGNING THROUGH SOUND:

The Blue Frog acoustic lounge and studios

by Serie Architects (figure $2.4-2.6$ ).

\section{ACOUSTIC IDEAS}

The project's location within a recording studio network informed a design goal to stage an "acoustic experience par excellence" (Dezeen). Acoustics were considered through roof absorption and bumped plasterboard wall linings (figure 2.5).

\section{CRITICAL REFLECTION}

More consideration appears to have been given to the booths than the acoustically designed walls, questioning the project's acoustic focus. According to the architects: the undulating booths were the "primary challenge of the project"; however, their acoustic performance is not mentioned in the architect's project description. The convolving surfaces are aesthetically successful, breaking free of horizontal and vertical planes and overshadowing the acoustically effective wall linings.

The bumped plasterboard is acoustically functional but visually disengaging. The convex form would successfully scatter high frequency sound and aid the creation of a diffuse environment. However, the lining is restricted to a vertical plane and so further consideration of form on acoustic performance could have better articulated the design concept (figure 2.6).
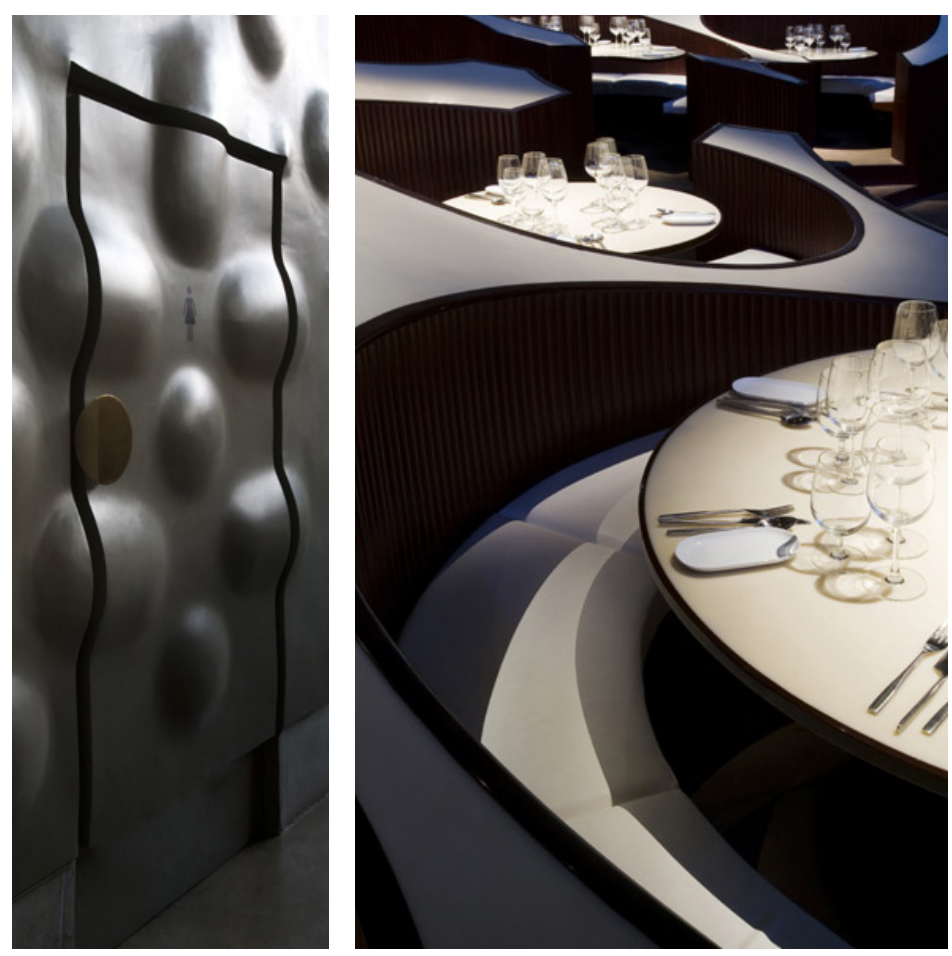


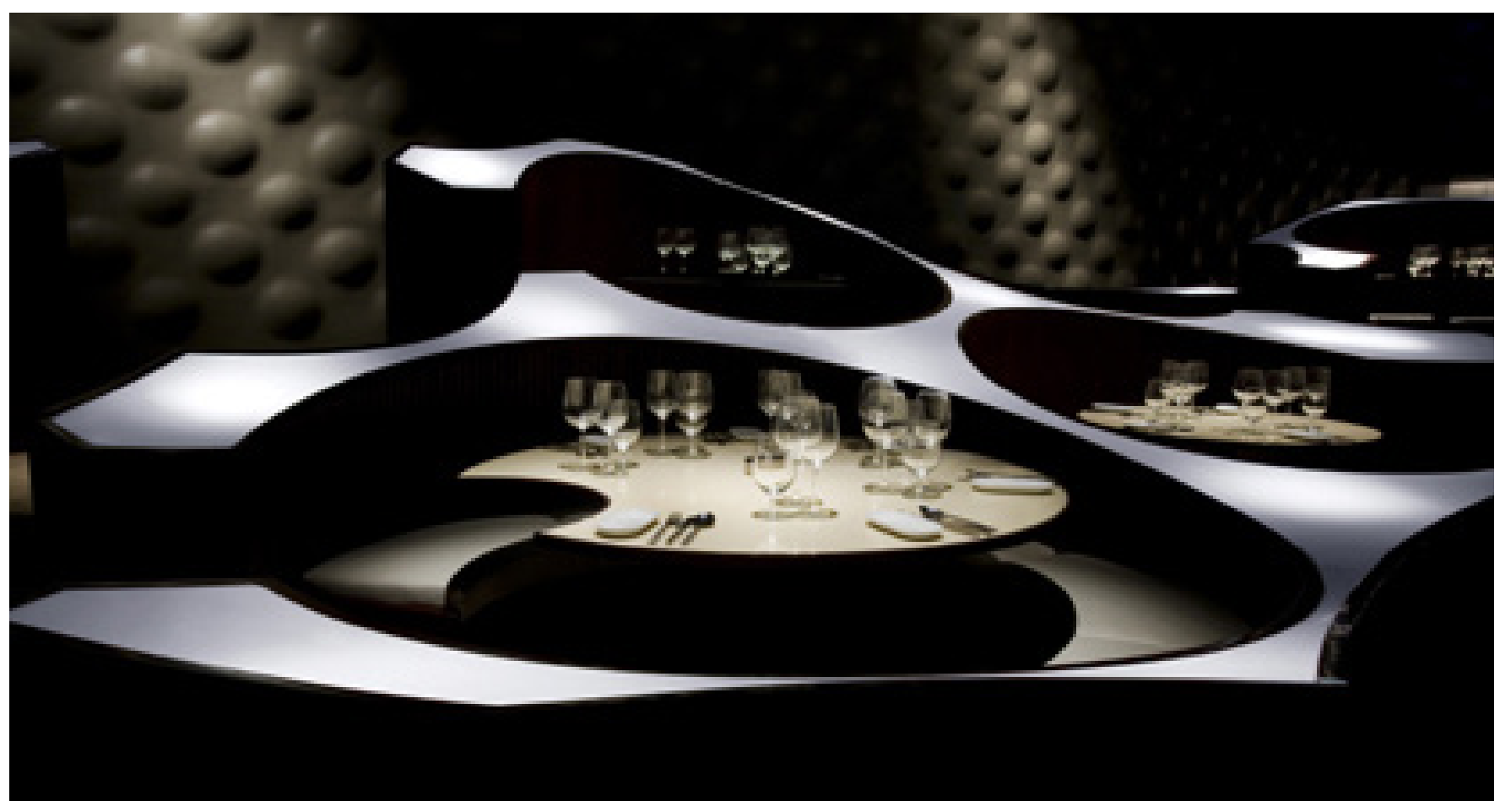

Figure 2.4 The Blue Frog acoustic lounge and studios by Serie in Mumbai, India is a redesigned warehouse completed in 2008. The lounge functions as a music venue, restaurant, bar and live music stage within a network of sound recording studios (Petit). 


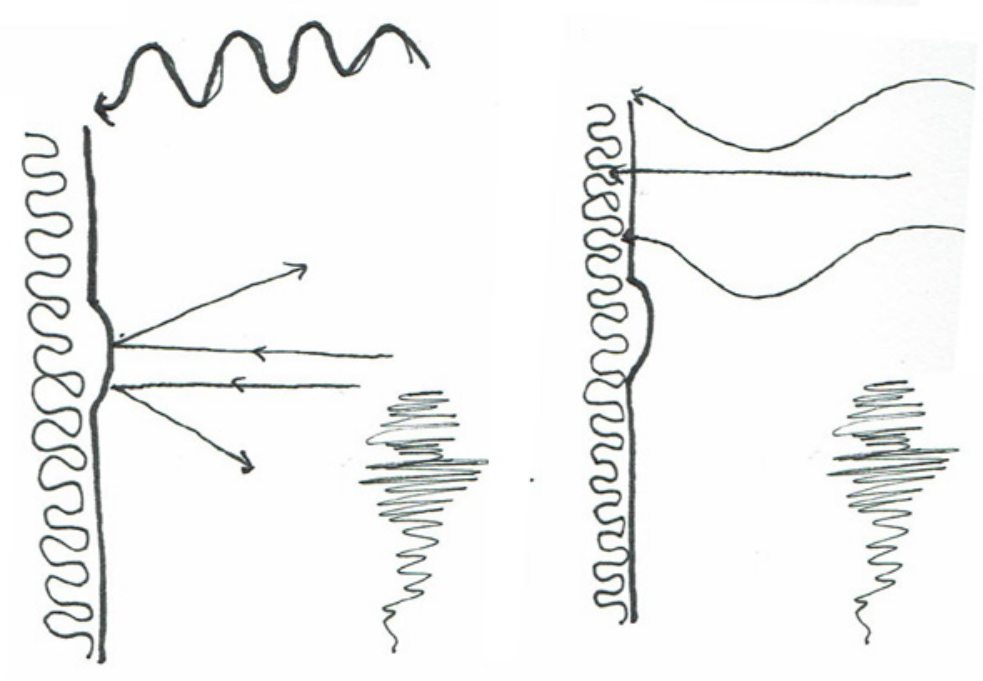

Figure 2.5 The bumped plasterboard wall paneling scattered high frequency sound waves (left) while absorbing low frequencies that penetrate the lining (right) (Dezeen). 

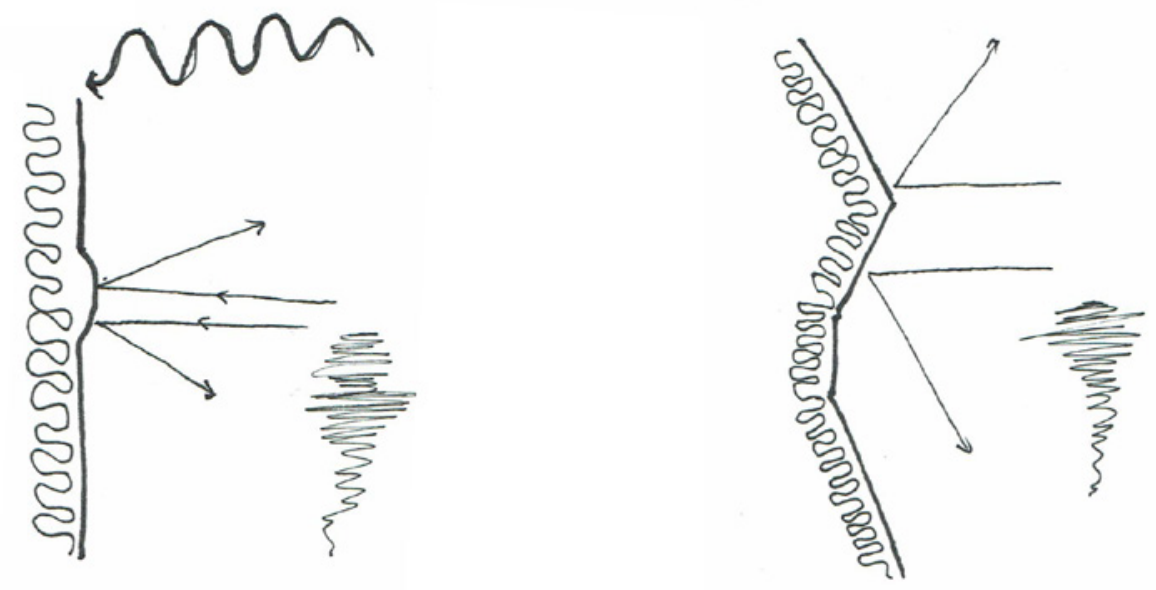

Figure 2.6 The Blue Frog Lounge links architectural and acoustic thinking, yet, highlights a hesitation of breaking free of the traditional vertical planes. Unlike Acoustics Mirrors, the lounge places absorption on the walls rather than exploring how the form of the wall itself could scatter, focus or redirect sound. This change of focus could have occurred due to the restriction of working within an existing shell. 
THE CAVE RESTAURANT BY

KOICHI TAKADA ARCHITECTS (FIGURE 2.7)

\section{ACOUSTIC IDEAS}

The Cave Restaurant aimed to "change the way we eat and chat in restaurants" with the acoustic quality of the restaurant contributing to the "comfort and enjoyment of a dining experience" (ArchDaily). The design was grounded in the experimentation of patron comfort zones at different noise levels.

\section{CRITICAL REFLECTION}

The validity of acoustic performance claims made by Koichi Takada Architects is decreased by a lack of information presented in the design outcome. The architects claim that the "timber profiles generate a sound studio atmosphere and a pleasant 'noise' of dining conversation" (ArchDaily), which appear to be contradictory ideas. The design does use significant amounts of timber, an acoustically reflective material, and few absorptive surfaces (figure 2.8), yet, these reflective materials suggest an extended RT, increasing ambient dining noise (see Appendix A - Cafe Effect) and decreasing speech intelligibility (STI). This result causes a slurring of words, very different to a "sound studio atmosphere" that is known for its stark acoustics.

The limited acoustic information presented by the architect was surprising considering the acoustic focus of the project. Visually engaging elements, such as the beams are discussed in the output, however no comments are made about absorption. This lack of information potentially suggests that acoustics is seen as a tool to justify visually engaging elements and that the organic ro of has the appearance of an effective acoustic environment, but not necessarily the performance of one.

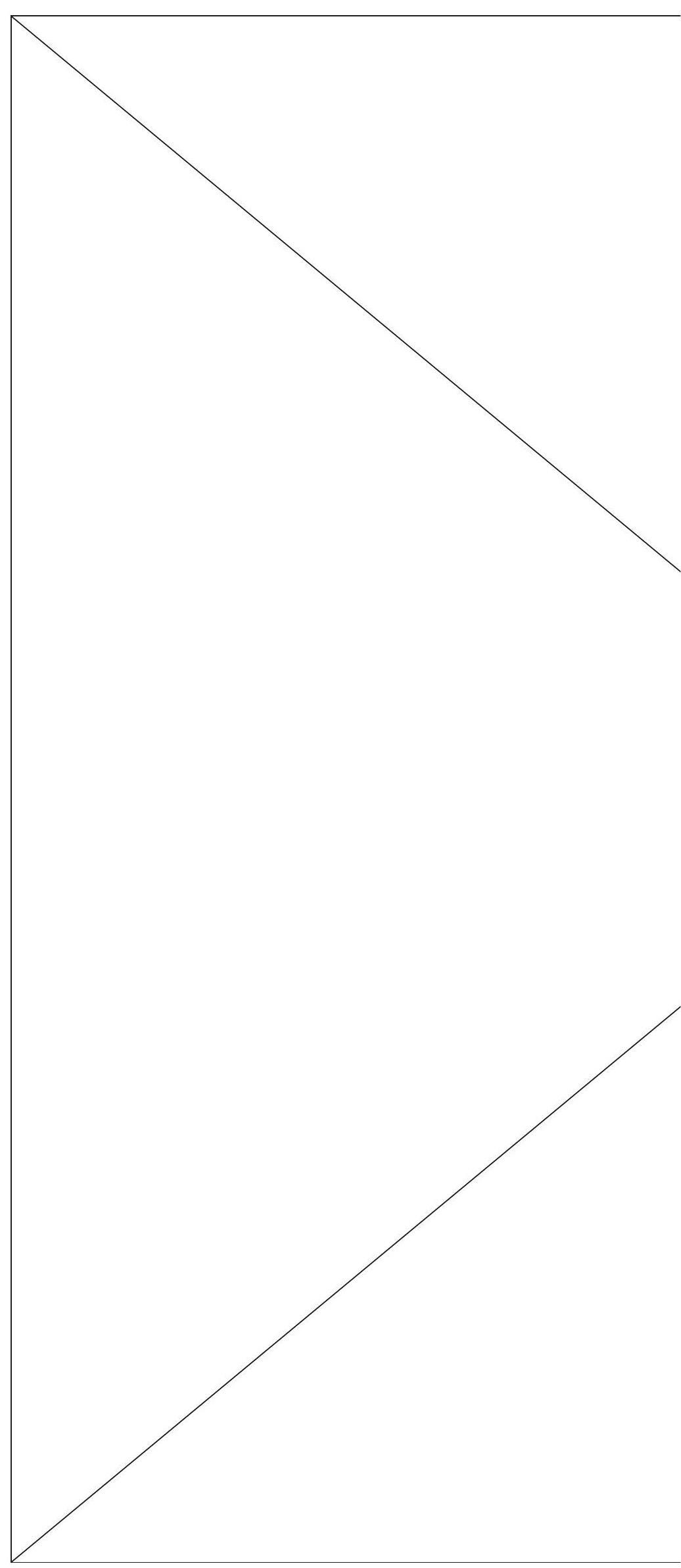




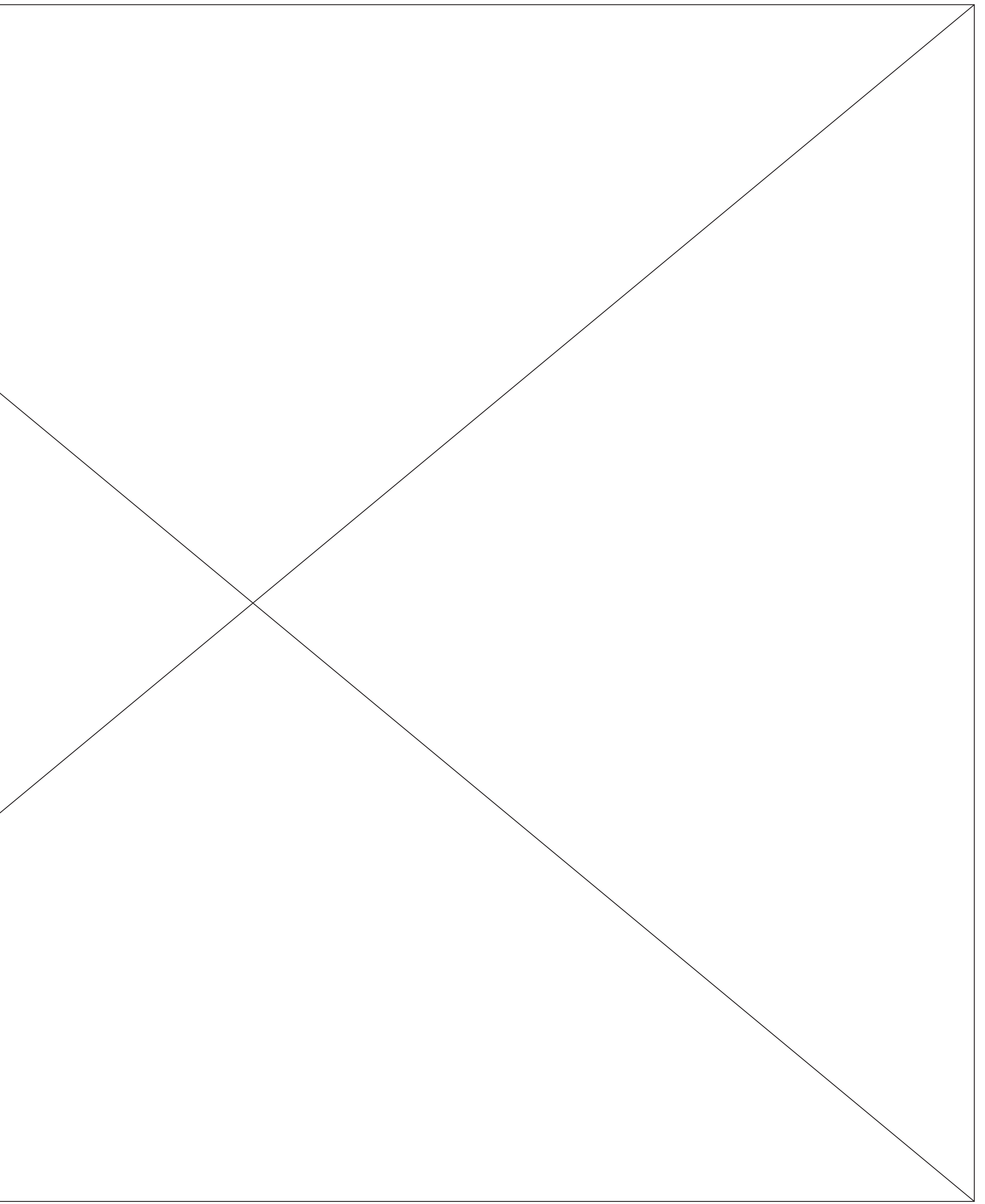

\begin{tabular}{|c|}
\hline Figure 2.7 The Cave Restaurant by Koichi Takada Architects in Sydney, Australia was completed in 2009. \\
\hline Image redacted for online submission, see physical submission for image \\
\hline
\end{tabular} 


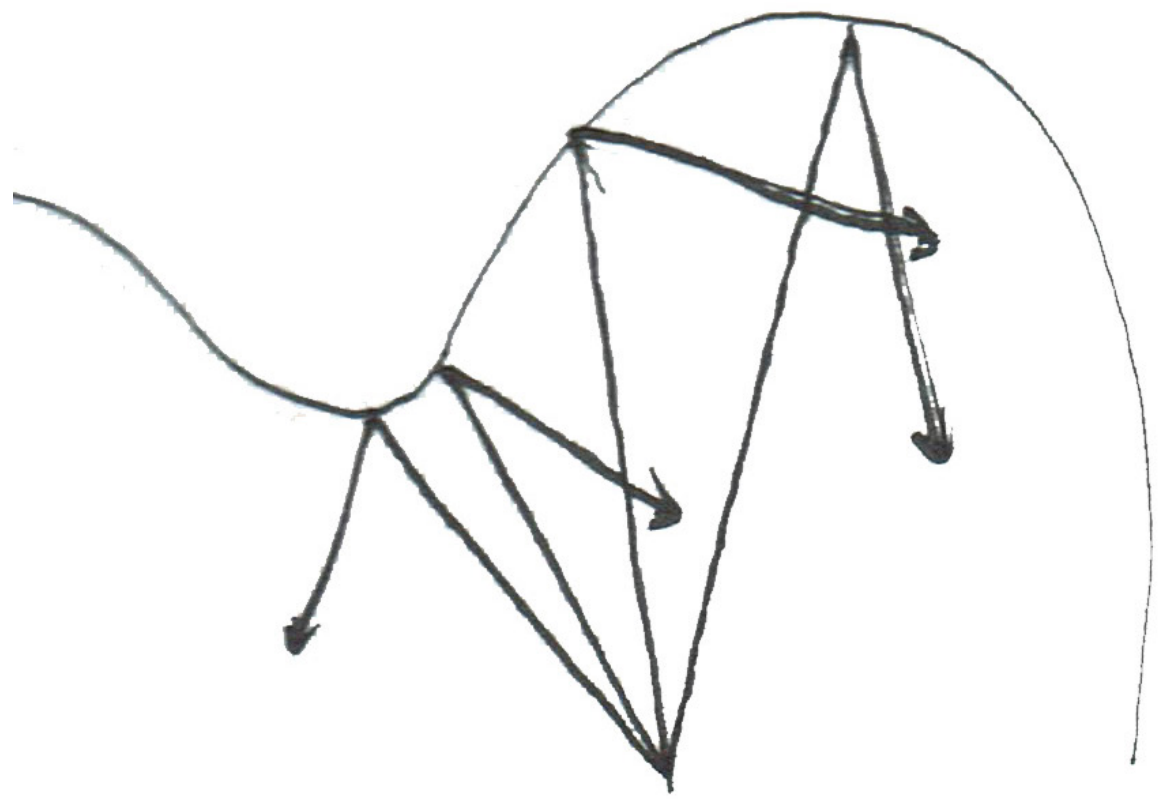

Figure 2.8 The timber profiles would create slightly more diffusion within the space, scattering the sound energy and breaking the flutter effect between parallel surfaces. However, this style of beam works more successfully when reflecting sound into absorption between the slats as seen in the SupaSlat Maxi Beam system below. Image redacted for online submission, see physical submission for image

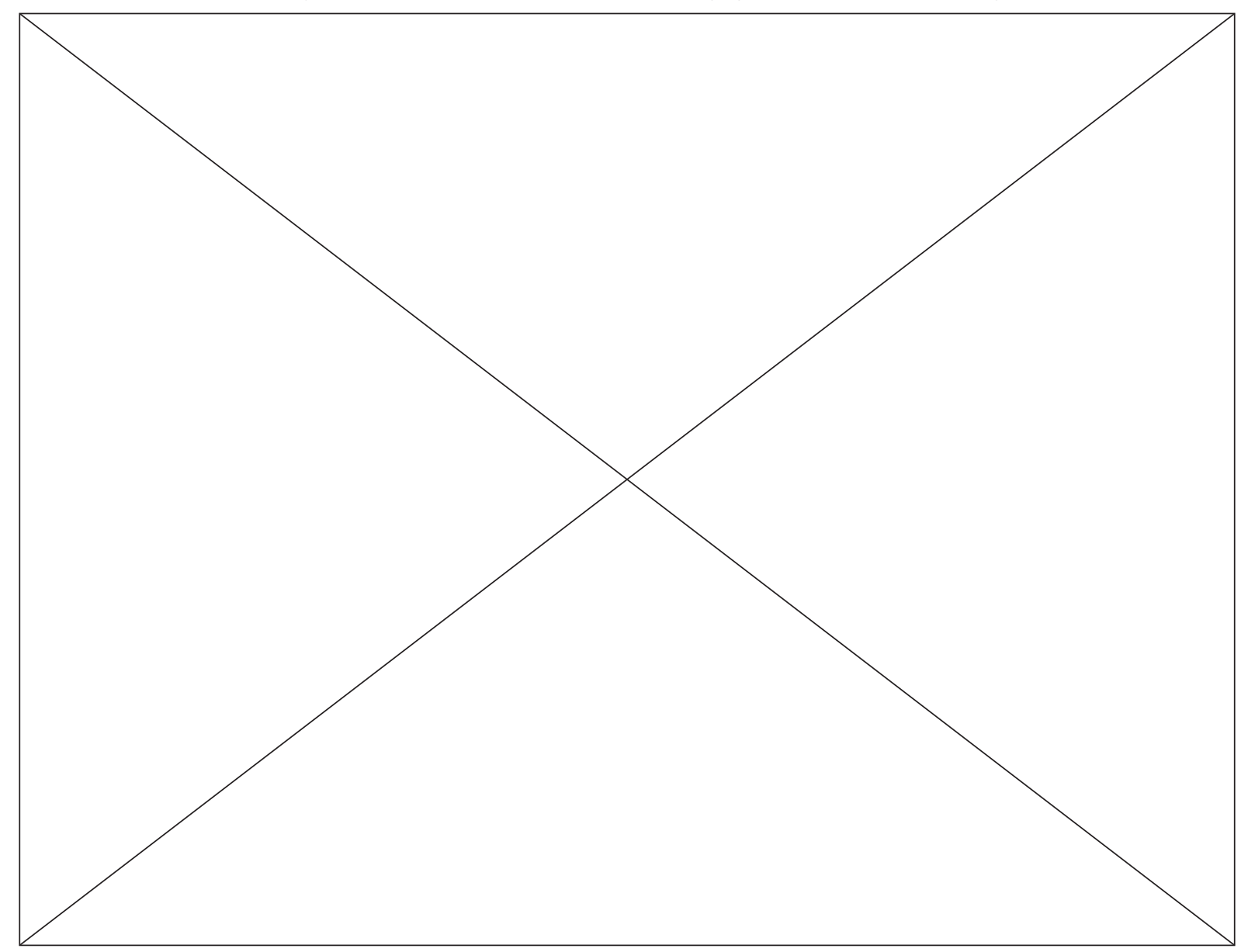




\section{IMPLICATIONS FOR DESIGN}

These three precedents centred on the design of acoustics through form and materiality. The design strategies taken from the Project Review include the use of form and materiality to converge, scatter or absorb sound.

\section{FORM}

The Acoustic Mirror project used form to converge sound rays at a point. Concave forms were used. The Blue Frog acoustic lounge and Cave Restaurant used form to scatter sound and create a diffuse environment. Convex or "organic" forms were used.

\section{MATERIALITY}

The Acoustic Mirror and Cave Restaurant used materiality as an aesthetic element through an expression of concrete or curved timber beams. In contrast, the Lounge concealed acoustic materiality, backing its plasterboard lining with Rockwool to absorb bass frequencies, while maintaining a reflective finish.

\section{ATMOSPHERE}

Both the Blue Frog Lounge and Cave Restaurant gave the atmosphere of effective acoustics, but not necessarily the performance of one. The Blue Frog acoustic lounge placed absorption on the walls, rather than analysing how the form of the wall itself, could scatter, focus or redirect sound. This limit in expression reduces the communication of the design idea.
Similarly, the timber profiles in the Cave Restaurant are a major element of this design and visually convey the design idea of a cave. However, not enough information was presented by the architects to effectively conclude if they impact the space acoustically.

\section{COMFORT}

The Cave Restaurant was derived around acoustic measures of comfort, showing a focus on the human occupation from the early design phase, however, these comfort

findings would be more convincing if they were explicitly communicated in the final design outcome. This case study project design has been centred on similar values of human comfort in cafes but presents its acoustic information to give the design validity and cohesion

\section{CONCLUSIONS}

The Acoustic Mirror was centred on acoustic expression within the formal realisation of the design. In contrast, the other projects appear to consider acoustics for the oculocentric atmosphere that it creates.

Furthermore, the Blue Frog Lounge added treatment rather than addressing the underlying form. This reaction could have been due to the restriction that working within an existing shell placed on the design. The Case Study project was not limited to a building interior in order to progress past remedial treatment of poor acoustic symptoms into defining the form itself. It is hypothesised that in a breaking free of the vertical plane, the case study project's acoustic treatment can be expressed in a way that creates a synthesis of architectural acoustics. 


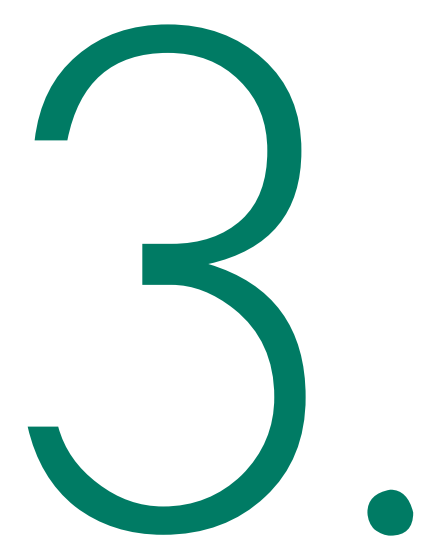

Acoustic Literature Review 
This section discusses the Project Review conclusions with analysis of previous acoustic literature. Past literature advocates for architectural acoustics, while suggesting ways to implement a Testing Methodology for cafe research.

\section{ADVOCATING FOR ARCHITECTURAL ACOUSTICS}

The importance of acoustics within concert hall architecture is well established, but less so for smaller designs. Several publications have been produced on the subtleties of concert hall design, examining subjective users' responses, the architectural features that cause these reactions and correct testing methodologies for examining them (Barron; Beranek). However, this is not true for acoustics implemented in "everyday" architecture like offices, houses and cafes.

Everyday architecture incorporates inherent acoustic qualities that allow the user to understand the space (Blesser and Salter, 16). Blesser and Salter position their argument on an allusion of the soundwave from a handclap reflecting from a distant wall. The reflection is heard as a discernible echo and as the user approaches the wall, the sound changes (16). The distance to the wall determines the delay for the arrival of the echo, the area of the wall determines the intensity, and the material of the wall's surface deter- mines the frequency content (16). Thus, from a simple reflection it is possible to understand the properties of a space, its form and one's position inside of it. This is one simple allusion, yet, extrapolated to the built environment, the richness formed by multi-facetted surfaces is apparent. With each scattering or grouping, absorbing or transmitting of sound, a cacophony is formed. This symphony of overtones is not restricted to scripted concert halls, yet occurs in urban streets, offices and cafes.

\section{IMPLEMENTATION OF ARCHITECTURAL ACOUSTICS}

Room acoustics is often perceived within a design as a potential hindrance; however, a hindrance considered early enough can become an influence. Tomas Echenagucia et al. suggested that acoustics can become an influence through the use of "Rhinoceros" (Rhino) software. Echenagucia et al.'s thesis project, completed in 2008, proposed a load-bearing ro of that sculpted early reflections towards the audience (figure 3.1).

In converting acoustics to a form driver, Echenagucia et al. shifted complications into considerations using Galapagos to optimise towards a fitness (or acoustic goal) (figure 3.2).

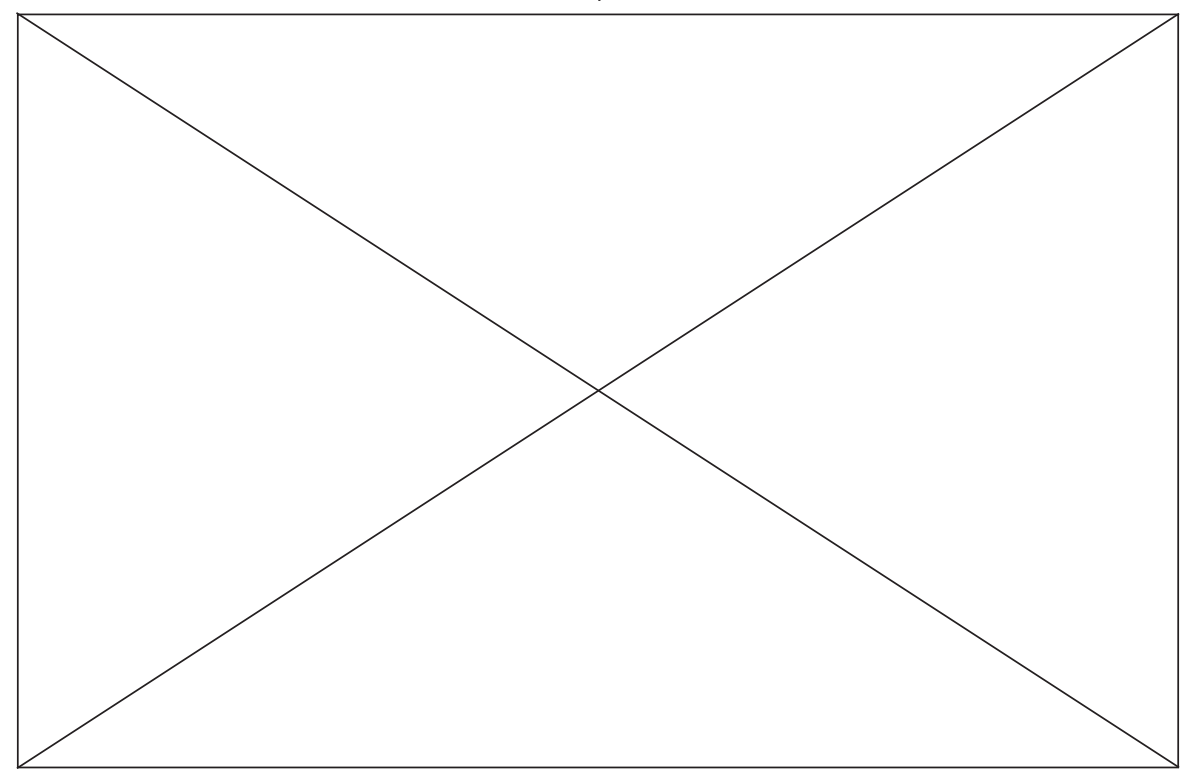

Figure 3.1 Early model of the reflections from roof form. The uniformity of sound distribution from an architectural intervention was found to increase the clarity and reinforce the music tone (Echenagucia et al., 181 ).

Image redacted for online submission, see physical submission for image 


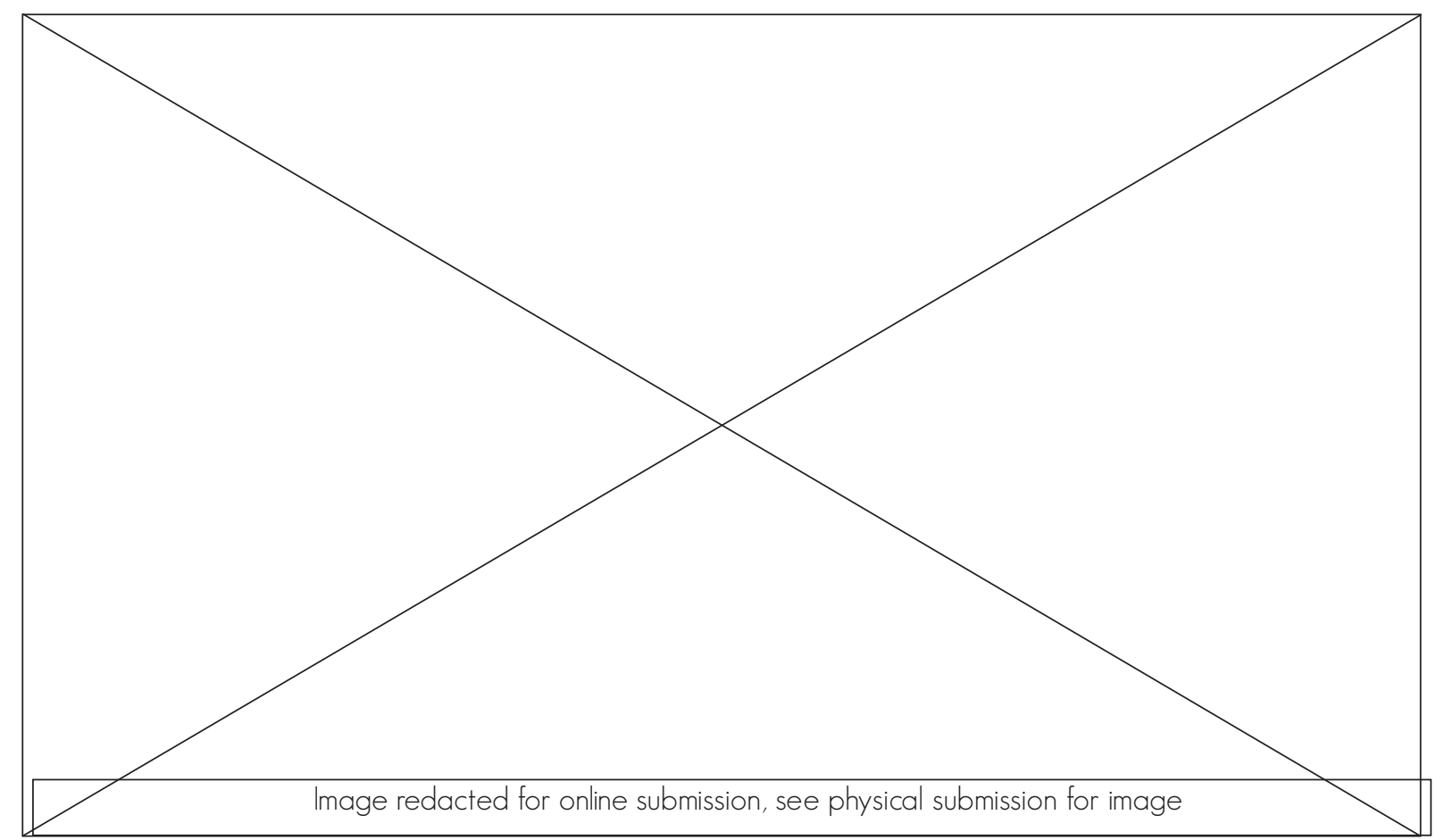

Figure 3.2 Echenagucia et al. explored three design options (blue, green and red roofs). The graph illustrates an overall increasing trend for the fitness (where an increase in the $Y$ axis represents more reflections on the ground plane) with each new generation ( $X$ axis). The three fitness levels increase across the generations as the roofs are optimised to produce more floor reflections. The three finesses stop around after the 20th generation as there becomes less variance possible, at this stage the blue design option has the highest amount of floor reflections (Echenagucia et al., 184).

N. J. V. Vlan, a Building Technology graduate from Delft University of Technology, advocated in his 2015 thesis for further acoustic consideration in open plan office work design (figure 3.3). Vlaun asserts that in current practice acoustic analysis is "not naturally integrated into the design process of office spaces" and that the transition between traditional geometric modelling programs and analysis software costs time and prevents seamless iteration of design proposals (9).

Echenagucia et al. and Vlaun address similar themes differently due to their architectural specialisations. Echenagucia et al., completing a Master of Architecture qualification, explored how acoustics can craft form to create an architecturally-engaging outcome. In contrast, Vlaun, completing a Master of Building Science qualification, focused on how to optimise an already existing office design using ceiling panels. Vlaun aimed for the creation, implementation and verification of a custom grasshopper ray tracing definition, whereas, Echenagucia et al. used pre-existing software to inform an architecturally-engaging design. Contrasting Echenagucia and Vlaun's projects, a similar comparison to the "Acoustic Mirror" and "Blue Frog Lounge" projects can be seen. Like the Blue Frog Lounge, Vlaun's project was centred within an existing structure and looked to explore how a change of materiality can alter the acoustic environment. In contrast, Echenagucia's and the Acoustic Mirror project explored how crafting of form can impact the acoustic performance of the space. The latter aspires towards an architectural-acoustic outcome and set a precedent for this case study project.

Echenagucia et al. drive architectural form from acoustic consideration, stepping deeper in acoustic expression than the Blue Frog Lounge (figure 3.4). Echenagucia et al. evalvated iterations of roofs using Galapagos, reversing the architectural process and converting acoustic performance's "burden" to architectural design. 


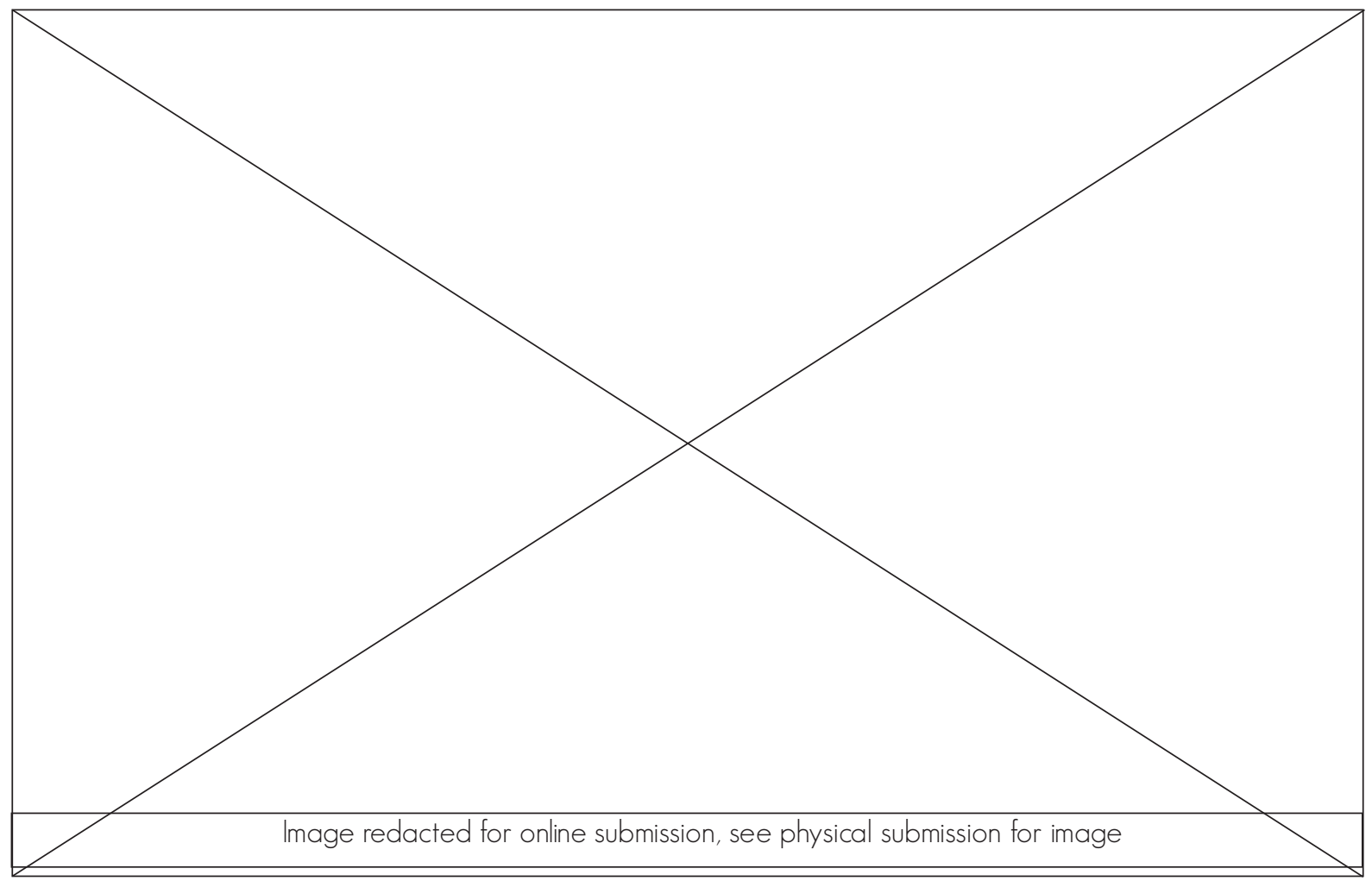

Figure 3.3 Similarly to Echenagucia et al, Vlan proposed the use of a parametric Grasshopper script as a solution to ineffective acoustic design. The optimized solutions are visualized in the table with the darkness of the panel indicating its absorption coeffiocent. Various outcome were found for different conditions, such as Most Economic or Minimum Screen Area (Vlaun, 80).

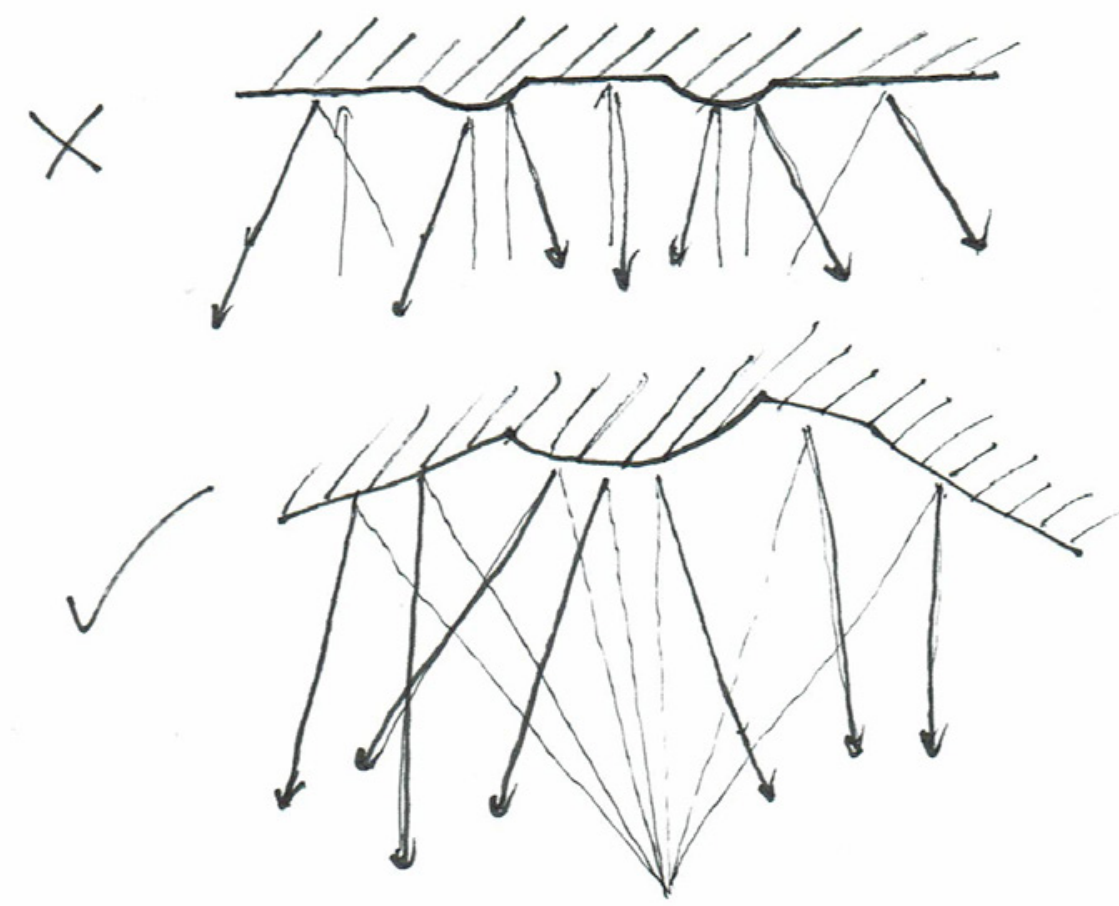

Figure 3.4 Echenagucia et al.'s architectural acoustic ro of expression is an effective example of how architecture can be driven by acoustic performance to produce an aesthetic outcome. The roof breaks free of a conventional ro of plane to create a fractal design element. This design intervention was possible because of the focus on architectural acoustics in the early design phase. 
INFORMING A CAFÉ TESTING METHODOLOGY

Cafés have a unique acoustic problem that leads to excessive noise: the Cafe Effect. The Lombard Effect, or Café Effect is when noisy spaces cause patrons to lift their voices, subsequently breeding noisy space (Whitlock and Dodd, 424). In 2012, James Whitlock and George Dodd identified the reverberation needs of children and adults and then applied this knowledge to the further design of Modern Learning Environments (MLE). Whitlock and Dodd concluded that this build-up of background noise is a critical feature in classrooms and that limiting the RT was an effective way to reduce it. While Whitlock and Dodd's research is not within cafes, their conclusion are applicable as the Cafe Effect significantly impacts cafes.

\section{THE SIGNIFICANCE OF ACOUSTICS IN CAFES - A RATIONALE}

Research from Lauren Christie and James Bell-Booth in 2006 concluded that cafes are considered too loud by their partons. Lauren Christie and James Bell-Booth published "Acoustics in the Hospitality Industry" to investigate the impact of hospitality audio environments on its patrons. Their research, focusing on three cafés, restaurants and bars, concluded that cafes are considered "too loud or undesirable acoustically for occupants from an objective [quantifiable] point of view" (14). However, they also suggested that further patron survey research should be undertaken to test if cafes are subjectively too loud, in general, or undesirable from an individual's personal experience (Christie and Bell-Booth, 14).

\section{HOW TO TEST ACOUSTICS IN CAFES}

Objective acoustic measurements and a subjective patron survey were two effective techniques for testing the human perception of café acoustics. Legge et al., from the Otago School of Medicine, measured a large sample size of 44 cafés in 2014 to explore whether noise levels in cafes determine the demographic of café patrons (1). Legge et al.'s broad study tested a large variety of Wellington cafes but with only one mea- surement, SPL. Legge et al. used six iPhones with a third-party app installed to measure the SPL of the cafes. Based on these results, cafes were divided into three SPL groups: "quiet", "medium" and "loud" (Legge et al., 7).

\section{IMPLICATIONS FOR DESIGN RESEARCH}

A need for further testing, with acoustic-specific equipment was identified for this research project. The testing aimed to identify which acoustic café environments positively and negatively impact the patrons' enjoyment. From these measurements, a set of acoustic design goals were established for the design process to aim towards.

Christie and Bell-Booth concluded that a greater sample size was required to make meaningful conclusions (14). This case study project explored the success of café acoustic environments further, expanding the three cafes sample size to six. Some strategic insights that past literature presented include:

Legge et al. were approached and agreed to share their raw data with this research project. Legge et al.'s three SPL stratify cafe groups were used throughout the case study project to get a representation of Wellington cafes.

Participating cafés that Legge et al. tested were re-tested with further acoustic measurements, such as RT, using advanced technology.

Echenagucia et al.'s research suggests that architecturally-engaging and acoustically-effective form can be crafted using Galapagos. In response, Galapagos was explored further as a form finding tool.

Based on Whitlock and Dodd's research, controlling the Cafe Effect through RT was a potential design goal 

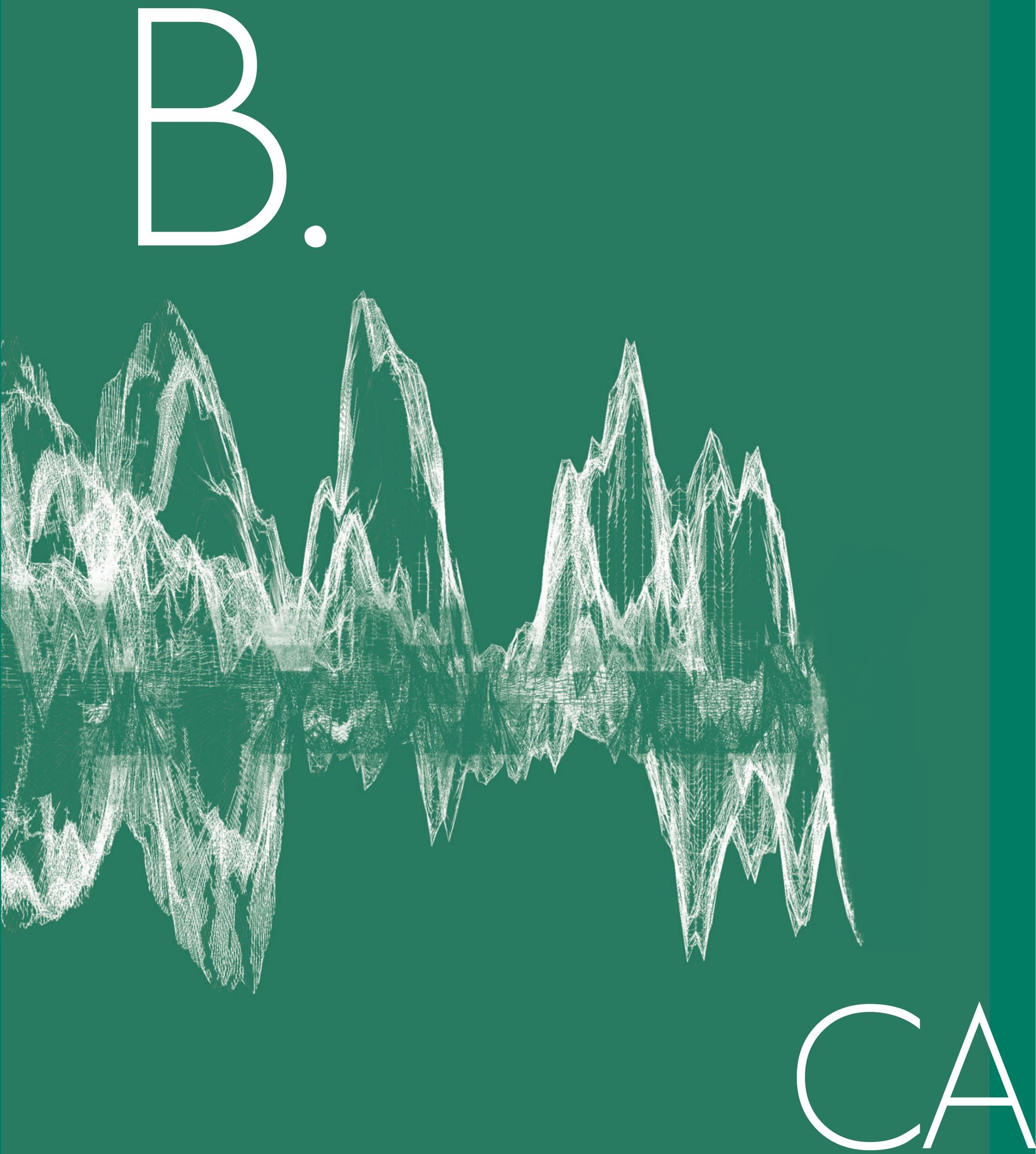


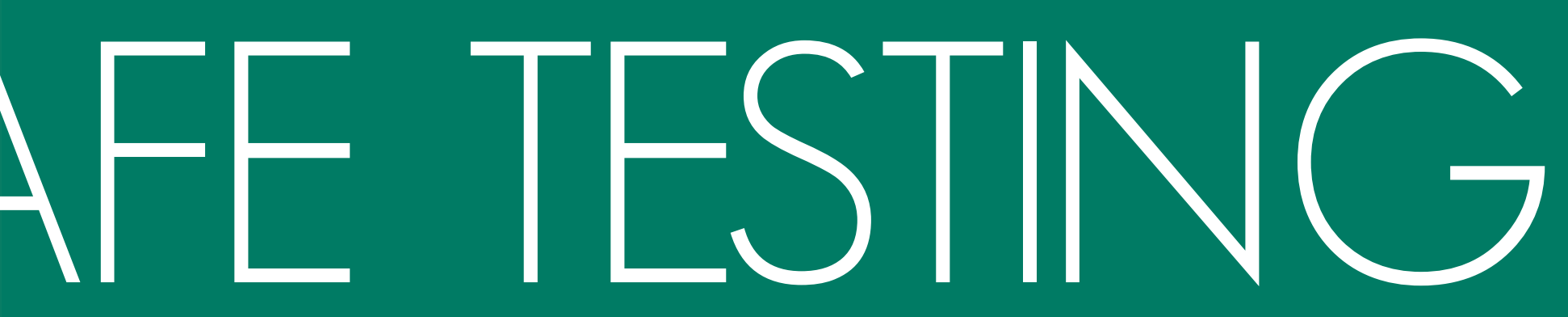




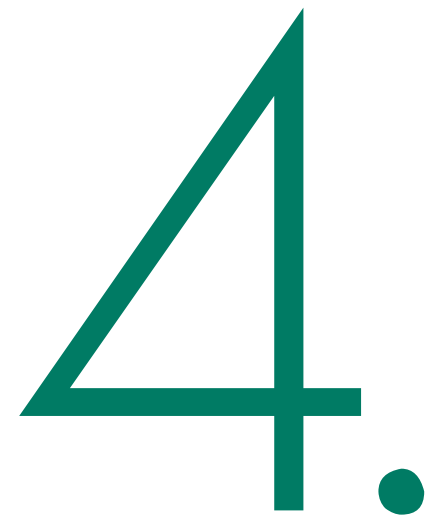

\section{Café Testing} Methodology 
"Acoustics involves both physics and psychology, and we can not separate the two"

- Robert Newman qtd. in National Research Council (U.S.). Building Research Institute, 1 
The need for further acoustic testing of the cafes was identified in the literature review. This Café Testing Methodology section discusses the café selection, qualitative and quantitative café testing. The results gathered established design goals which drove the formation of the case study project design presented later in this document.

\section{CAFÉ SELECTION}

Six cafes were selected from a stratified sample of Legge et al.'s 44 cafes to be tested (Appendix B). Cafes that were still operating were approached and managers of two cafés from each of the three SPL bands defined by Legge et al. agreed to participate within this study.

\section{CAFÉ TESTING}

The project quantitatively retested six cafes with specialist acoustic equipment and a patron survey. The further quantitative testing identified variety of acoustic measurements including RT and SPL as effective design drivers. The combination of quantitative and qualitative data informed a set of strategic design criteria that assessed acoustic influences on patron comfort.

The research project underwent a Victoria University of Wellington Ethic Approval process (Ethics Approval number: 22749) and was approved in April 2016, with all six café managers and patrons surveyed providing their consent.

\section{OUANTITATIVE DATA}

Specialist acoustic equipment, IRIS, was used in unoccupied cafes to record quantitative data including SPL, RT and three dimensional visual plots of the acoustic environment. IRIS is a measurement and analysis program that records energy produced by a speaker in a silent, unoccupied room (figure 4.1). From this signal, IRIS generates acoustic measurements including SPL and RT and three dimensional visual plots of room reflections (figure 4.2). IRIS uses a Tetramicrophone, a four microphone array, and an omnidirectional speaker to excite the room with a sine sweep (See Appendix B for methodology).
A floor plan of the cafes tested was produced, along with photographs to indicate material use, furniture, and layout (figure 5.11. All cafes were tested in the early morning before they opened for the day to record from a silent environment. However, in all of the cafés tested, staff were preparing for the day. The staff members were asked to remain still and silent while the 20 second test was conducted, however, some noise was heard on the recordings. Large amounts of background noise disturb the plot generated by IRIS. However, all readings achieved above the recommended SNR suggested by the IRIS manufacturers. If any large abrupt sounds were produced during the recording, such as a scrape of a chair on the floor, the recording was repeated.

\section{OUALITATIVE DATA}

To accompany these recordings, 30 patrons of the six cafés were surveyed. The patron survey contextualised quantitative measures with a subjective overview of how room acoustics impact patron comfort. It is acknowledged that general conclusions could not be made on such a sample size.

The anonymous survey was administered through Qualtrics survey software to protect patron anonymity. The survey (see Appendix $C$ for full questions) was arranged into four sections assessing important cafe influences, café volume, ability to communicate, and overall enjoyment level.

\section{CAFE INFLUENCES}

Patrons were asked to rank the influences such as location, price, Vibe/Atmosphere, food and coffee on their café selection. This section aimed to understand how significantly acoustics impact patron café choice and how conscious the patron is of acoustic's effect.

\section{CAFÉ VOLUME}

Patrons were asked to rate between quiet (1) and loud (10) the expected volume of the café. They were then asked to do the same for the actual experienced volume. Contrasting these two volumes identified if 

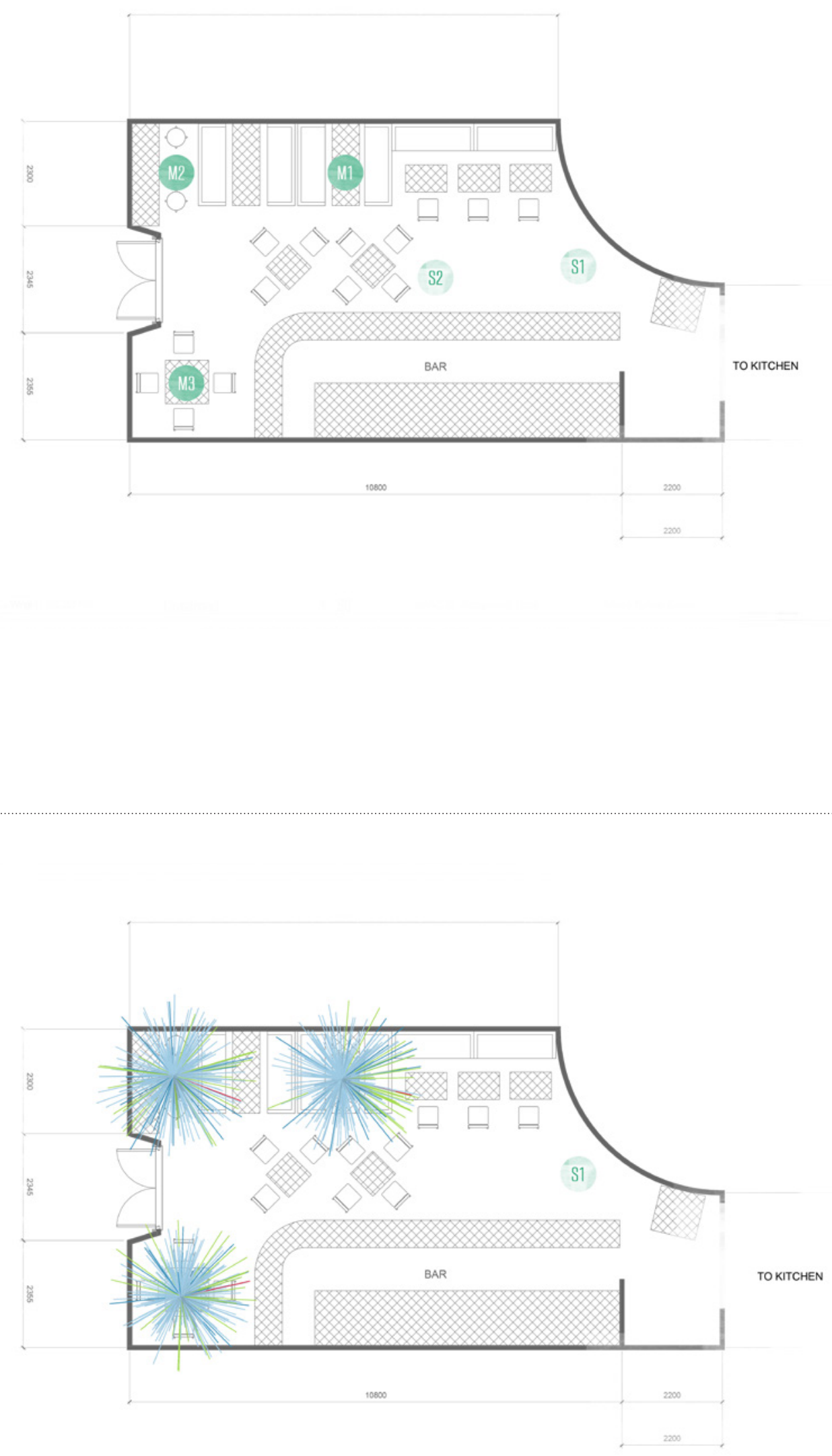

Figure 4.1 Two plans of a tested cafe shows the three microphone locations (MI, M2 and M3) and the two source locations (S1 and S2). 


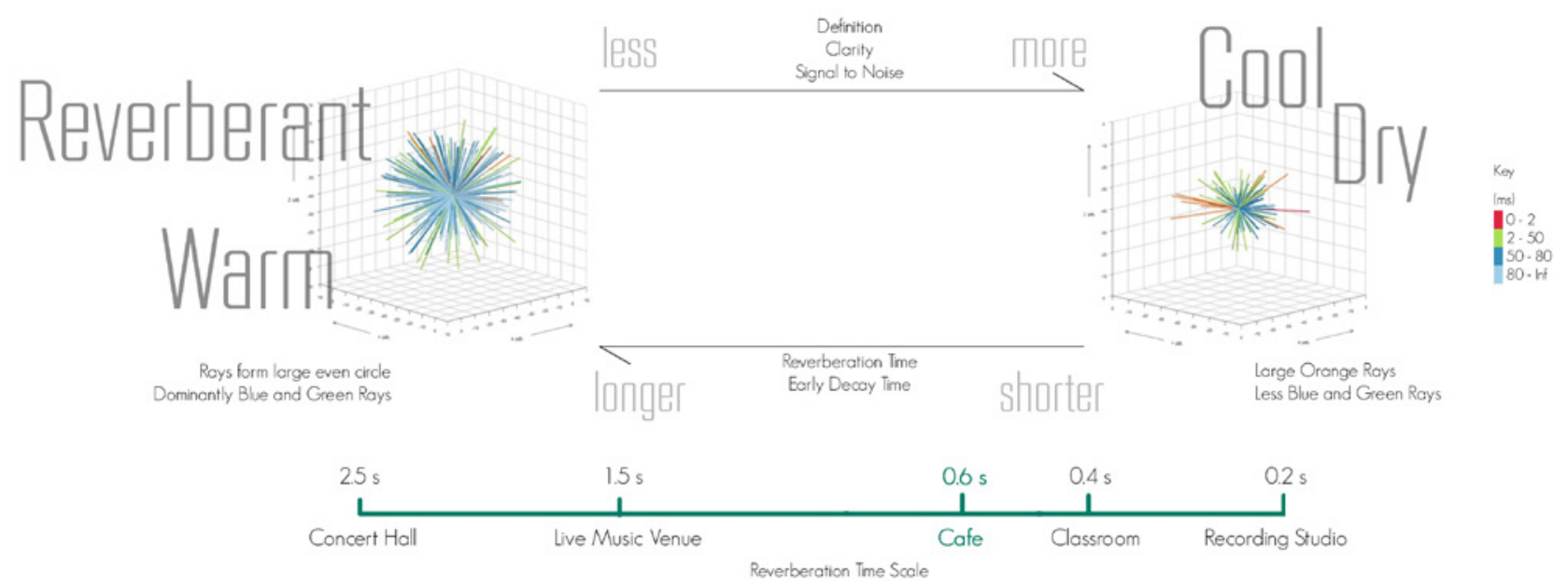

Figure 4.2 Three dimensional IRIS plots provide a visual representation of the reflections, with their directions shown by rays, their strength (by the length of the ray), and time received (by the colour). Above are two plots from opposite ends of the reverberation scale. The impact of architecture on the acoustics can be seen through the contrasting the plot's ray length, colour and direction.

the patrons" expectations were met. It was hypothesised that matching an expectation would result in a higher satisfaction level.

\section{ABILITY TO COMMUNICATE}

Patrons were asked to rank their ability to communicate on a five-level likert scale. A five-level Likert scale is a discreet range from one extreme (totally disagree) to the other (totally agree). The ability to communicate was developed through multiple questions including the ability to converse easily, hear others, be heard by others, hear themselves, have their attention diverted, and their perceived level of privacy.

\section{OVERALL ENJOYMENT}

Patrons were asked to rate their overall enjoyment of the café considering all the questions that they had answered. This question tested the overall success of the café while also analysing the importance of acoustics to the patron. If a patron answered the acoustic-specific questions negatively but the overall enjoyment positively, acoustics was suggested as an insignificant influence on enioyment for that patron. 
5. Café Testing Results 
This section discusses the results of Quantitative and Qualitative measurements through an architectural perspective to establish drivers for the case study design. RT, SPL and subjective enjoyment results were found to be most relevant for form generation and so are discussed in this section however see Appendix D for full results.

All cafes recorded long RTs with symmetrical, predominantly blue plots and subsequently low speech intelligibility. Symmetrical blue plots indicate that reflections are received from behind and to the side of the receiver as late energy (sound received after $50 \mathrm{~ms}$ threshold of human hearing for speech) (figure 5.1). Overall the IRIS plots suggest highly diffuse rooms causing a slurring of words due to the longer RT and lower speech intelligibility. These conditions are not desired for cafes as receiving reflections from a diffuse source can lead to a loss of connection to the speaker, reducing intimacy. These IRIS plots were expected due to the large volumes of the cafes and the lack of absorption in their materiality.
The results gathered by the IRIS unoccupied study align with Christie and Bell-Booth's research to suggest that the tested cafes were too loud as judged by the levels set in many codes and standards. Each tested cafe recorded a higher SPL than the recommendation in design standard AS/ NZS 2107 (2000). However, despite high SPL recordings, all of the cafes were rated as enioyable by patrons in the qualitative survey (figure 5.2).

Café 5 recorded the longest RT 10.8 seconds $-Y$ axis), highest SPL (72 dBA - $x$ Axis) and lowest Enjoyment rating (circle size) (figure 5.3). However, there is no general trend apparent between the cafes in figure 5.3 linking SPL or RT to enjoyment

The subjective ability of the patron to communicate linearly decreased as the experienced volume increased (figure 5.4). 


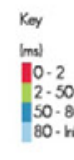
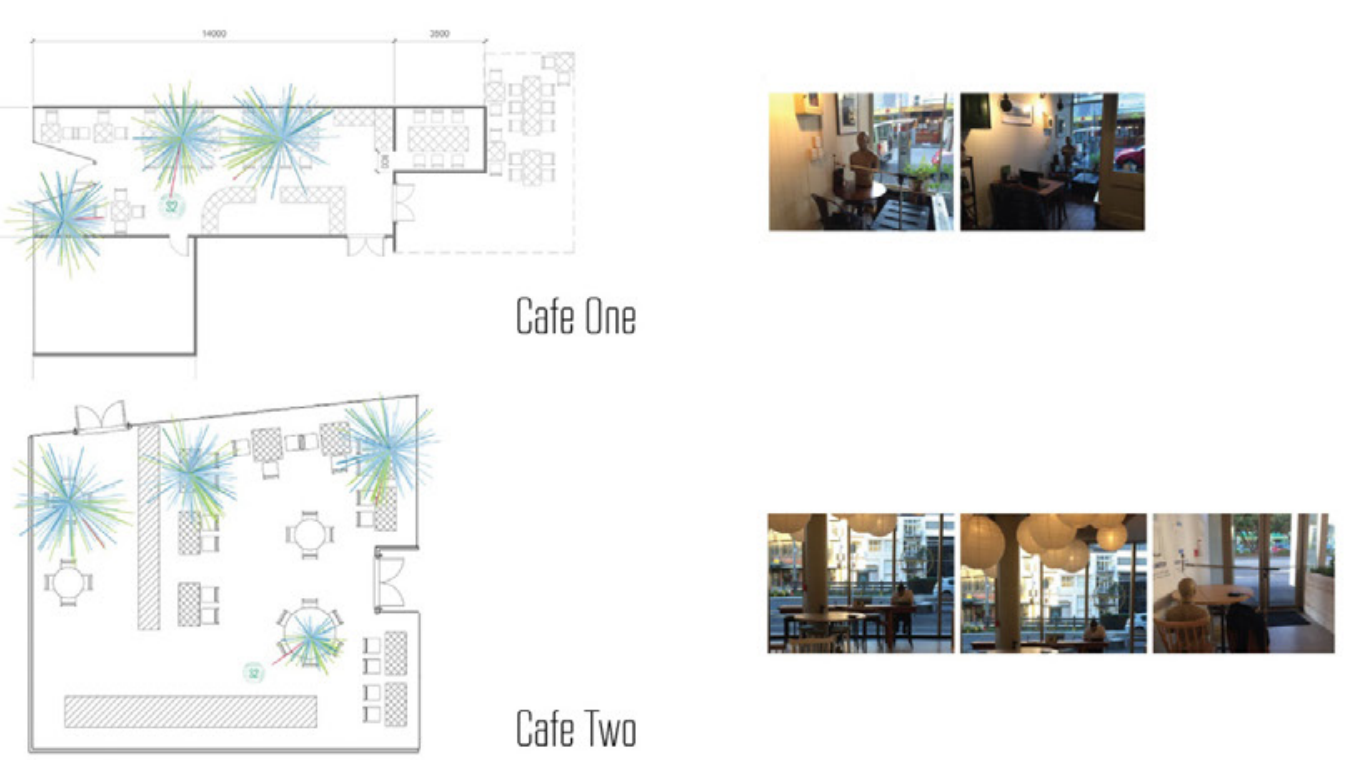

Cafe Two
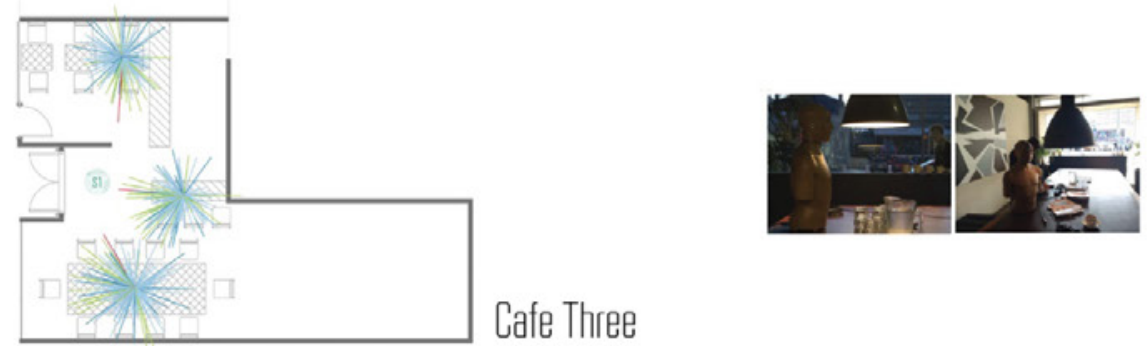

Cafe Three
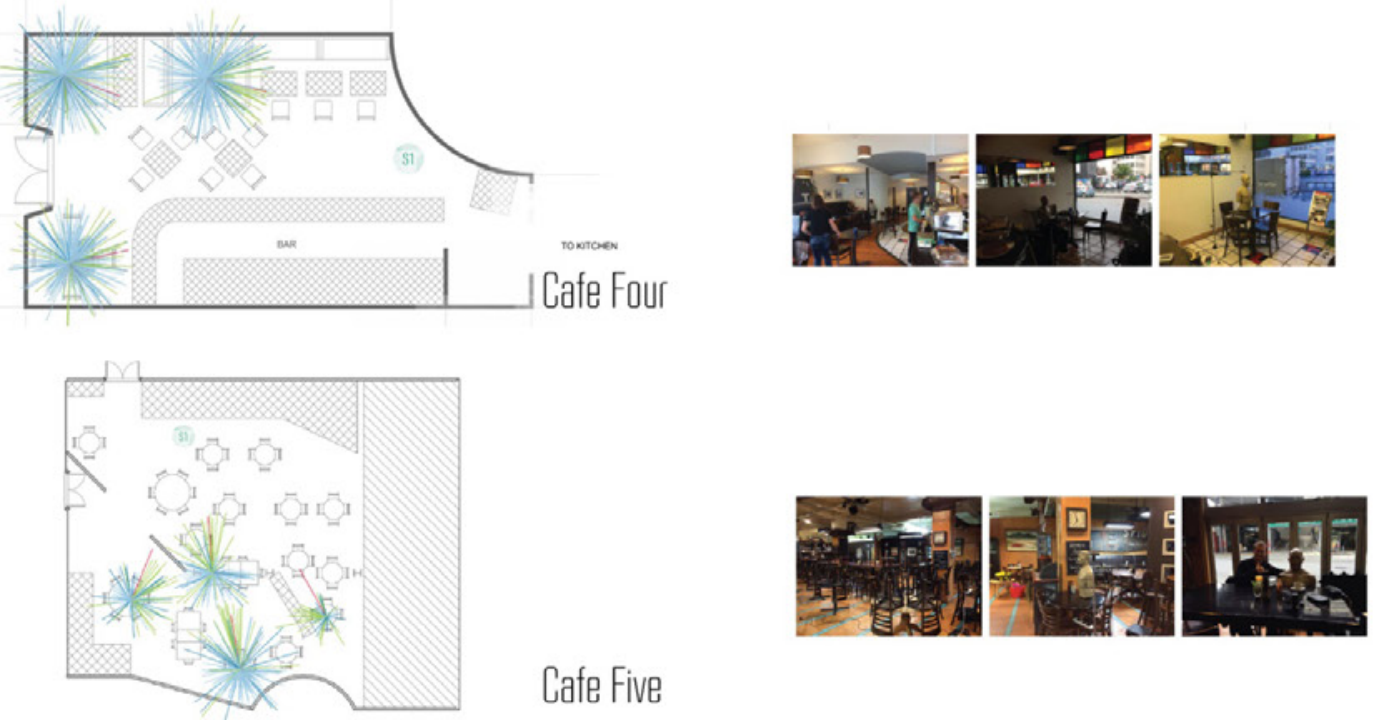

Cafe Five
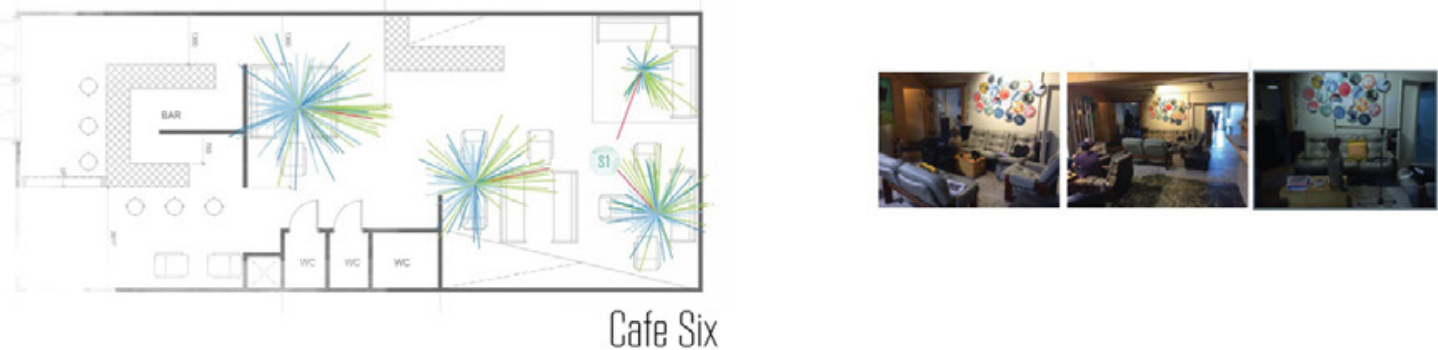

Figure 5.1 The IRIS plots results showed dominant long blue and light blue rays, representing a significant amount of late energy (after 50 and 100 milliseconds respectively). 


\section{Overall Customer Enjoyment}

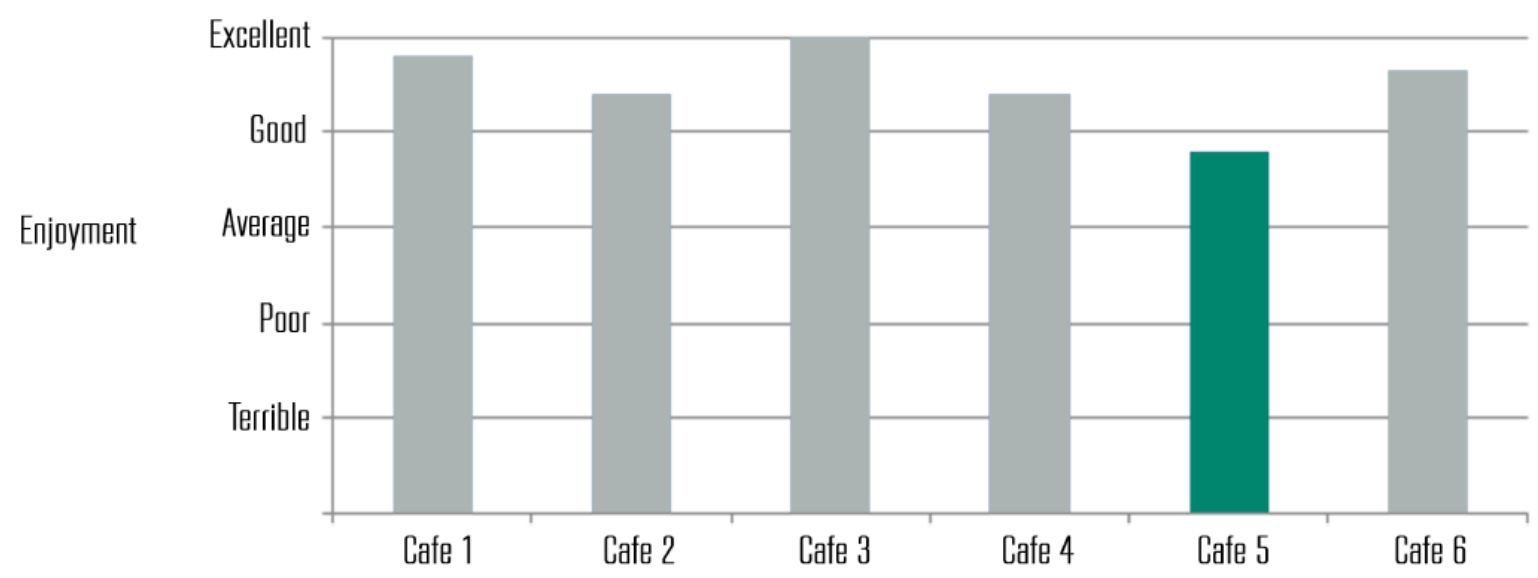

Figure 5.2 All cafes scored well above Average enjoyment, but Café 5 (shown in green) received the lowest rating.

\section{The Relationship between RT, SPL and Enjoyment}

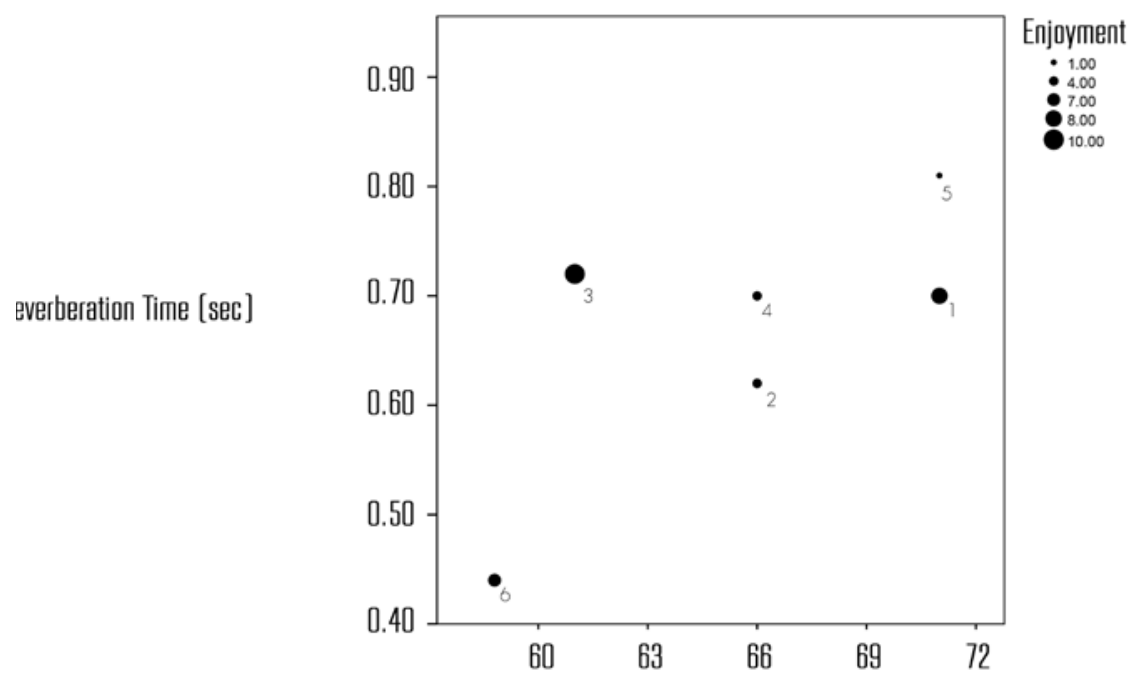

Sound Pressure Level [dBA]

[Legge et al.]

Figure 5.3 A positive correlation between RT (Y axis) and SPL ( $X$ axis) was noted. Café 5 had the longest RT, highest SPL and lowest Enjoyment rating (radius of circle where small is less enjoyment). Cafes 1 and 3 recorded the two highest enjoyments, a similar RT but different SPL. This RT of 0.7 seconds was set as a design goal. However, due to the small sample size, removing one case from this graph would alter this correlation. 
Unlike Communication, Overall Enjoyment increased and then decreased quadratically as the volume increased (figure 5.5).
The three cafes with the highest difference between Expected Volume and experienced Volume also had the three lowest overall enjoyment levels (figure 5.6).

Holistic Communication*

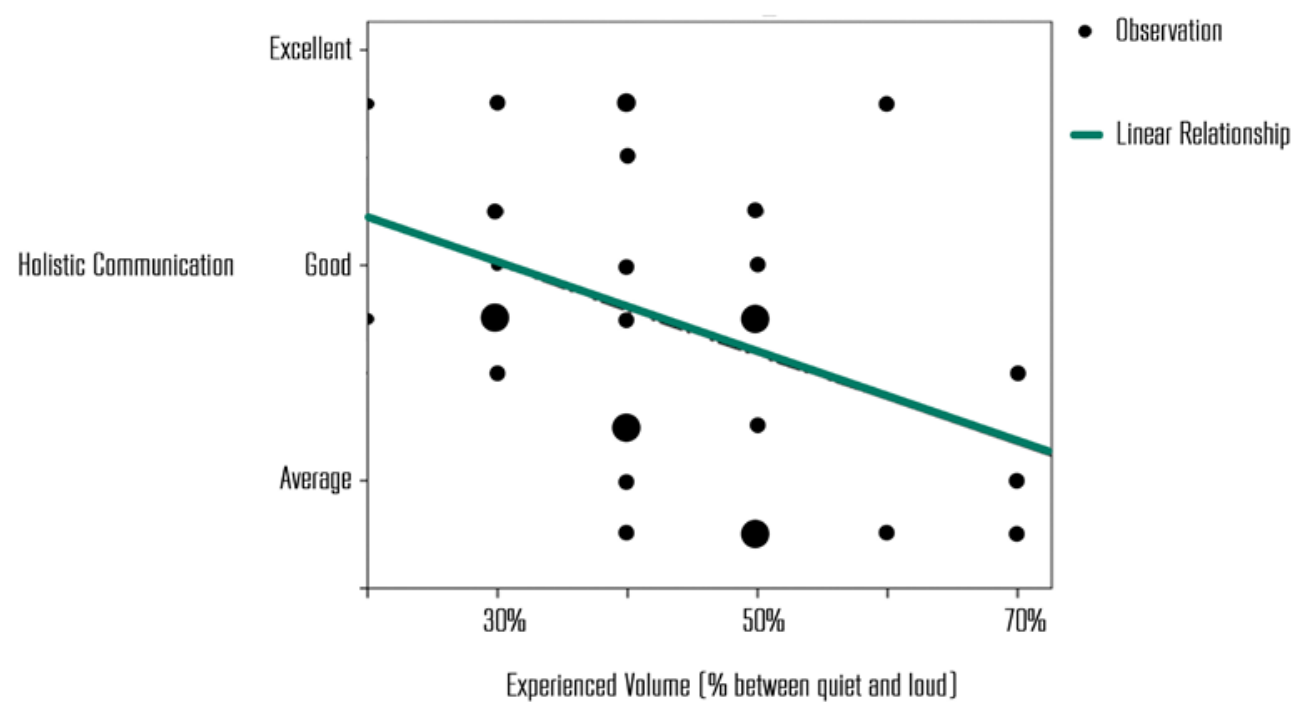

Figure 5.4 The green line indicates the negative regression while the black circles indicate the individual of patron responses where more responses are indicated by a larger circle. The frequency of a response is indicated by the circle size. "Holistic communication" is a measurement formed from three questions that tested the patron's perceived ability to hear others, hear themselves and be heard by others.

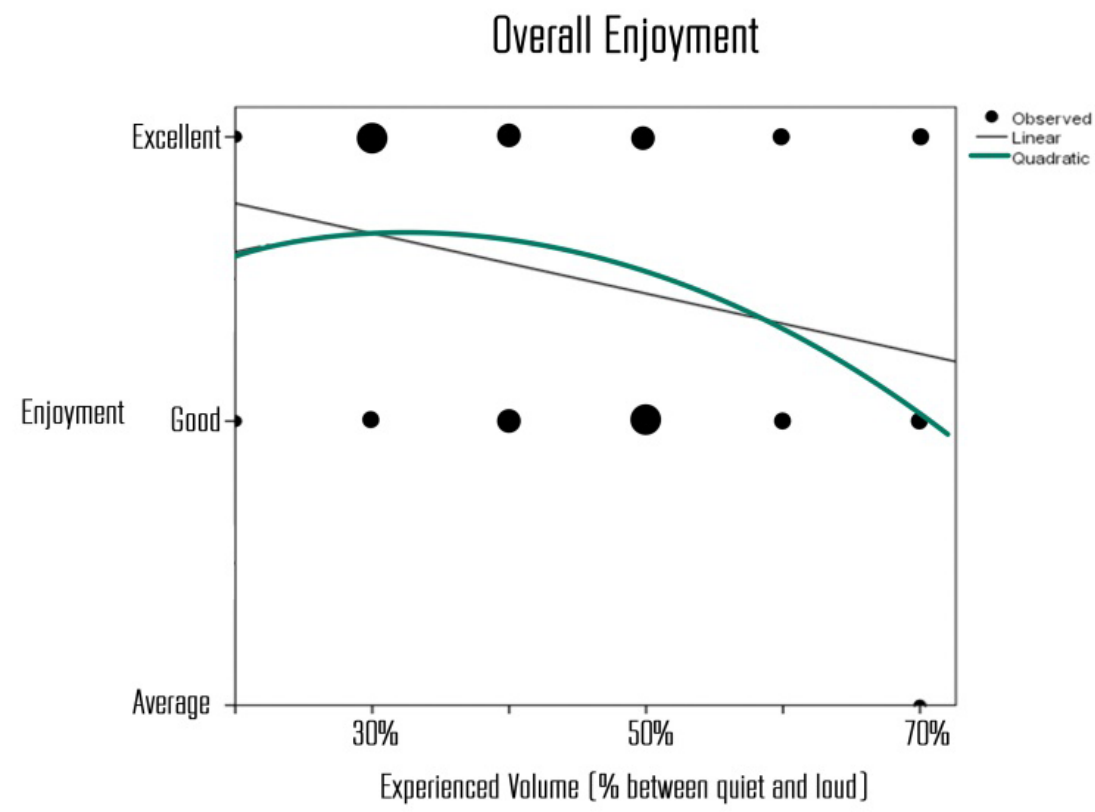

Figure 5.5 Similarly to figure 5.5, the green line indicates the quadratic regression between enioyment and volume while the black circles indicate the individual patron's response where the same responses are indicated by a larger circle. The quadratic relationship suggests a potential "peak" enjoyment volume, before which, patrons are not satisfied and afterwards which, it becomes to difficult to communicate. However, it is recommended that 38

further research should be completed on this. 


\section{Perceived Expected Volume and Perceived Experienced Volume}
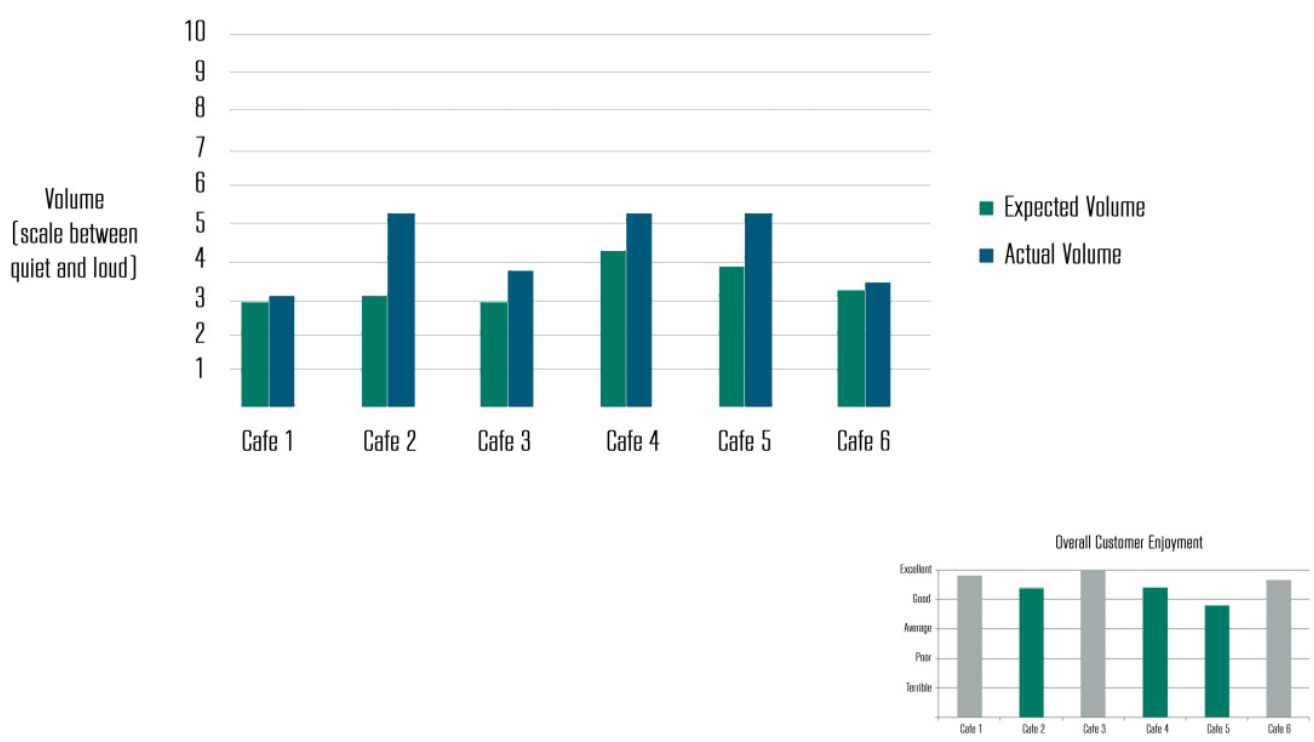

Figure 5.6 This result suggests that the patrons enter in a café knowing what they want from the acoustic environment. For example, some patrons enioy quieter cafes and some enjoy louder ones, yet if their expectations are met then they are satisfied. If, however, they do not get the experience that they desire, like cafes 2, 4 and 5, then enioyment decreases. Yet, how then can a café design cater to more than one of these patron needs or expectations?

\section{DESIGN IMPLICATIONS}

Café 5 recorded the longest RT, highest SPL, and lowest enjoyment rating, reinforcing the relationship between these three elements. Enjoyment was concluded to be influenced by SPL (figure 5.3) and SPL was concluded to be influence by RT (Whitlock and Dodd, 424). Thus, by restricting the RT to a target of 0.7 seconds, it was hypothesised that patron comfort could be increased. An RT of 0.7 seconds was chosen as it was shorter than both the AS/NZS 2107 (2000) maximum and was comparable to the cafes with the two highest enjoyments.
The need for multiple zones to cater for the patron variety was realised. This was explored through analogue design iterations presented later in this thesis. 

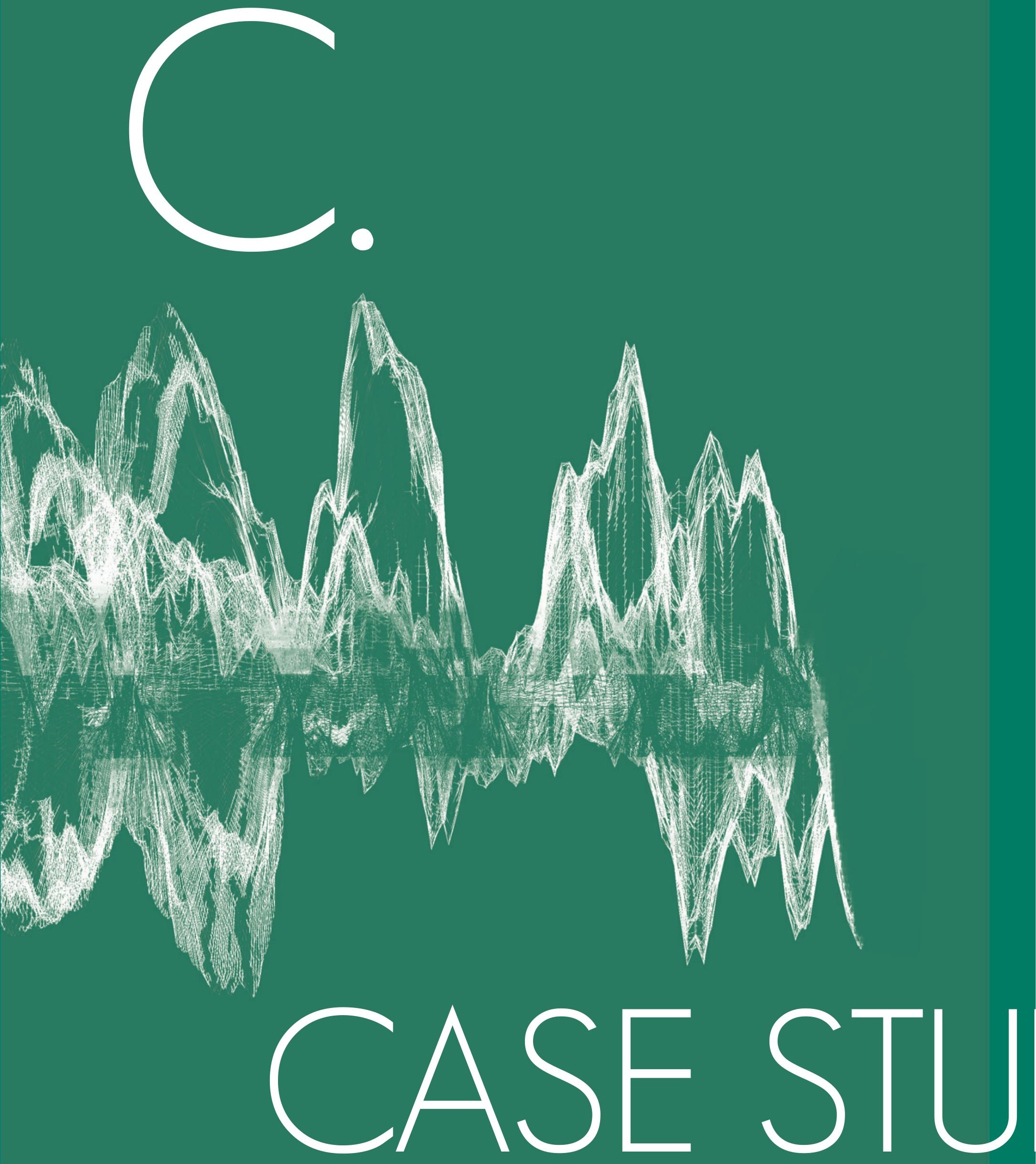


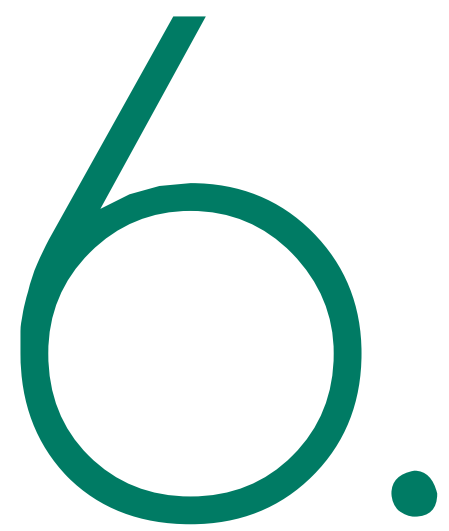

Existing Context

and Site Analysis 


\section{SITE SELECTION}

27 College Street (figure 6.1 and 6.2) was chosen as the site for this case study design as the existing café, Café 5, received the lowest patron enjoyment result. The context and site of the existing Café 5 was analysed to form a strategic set of design principles for the brief.

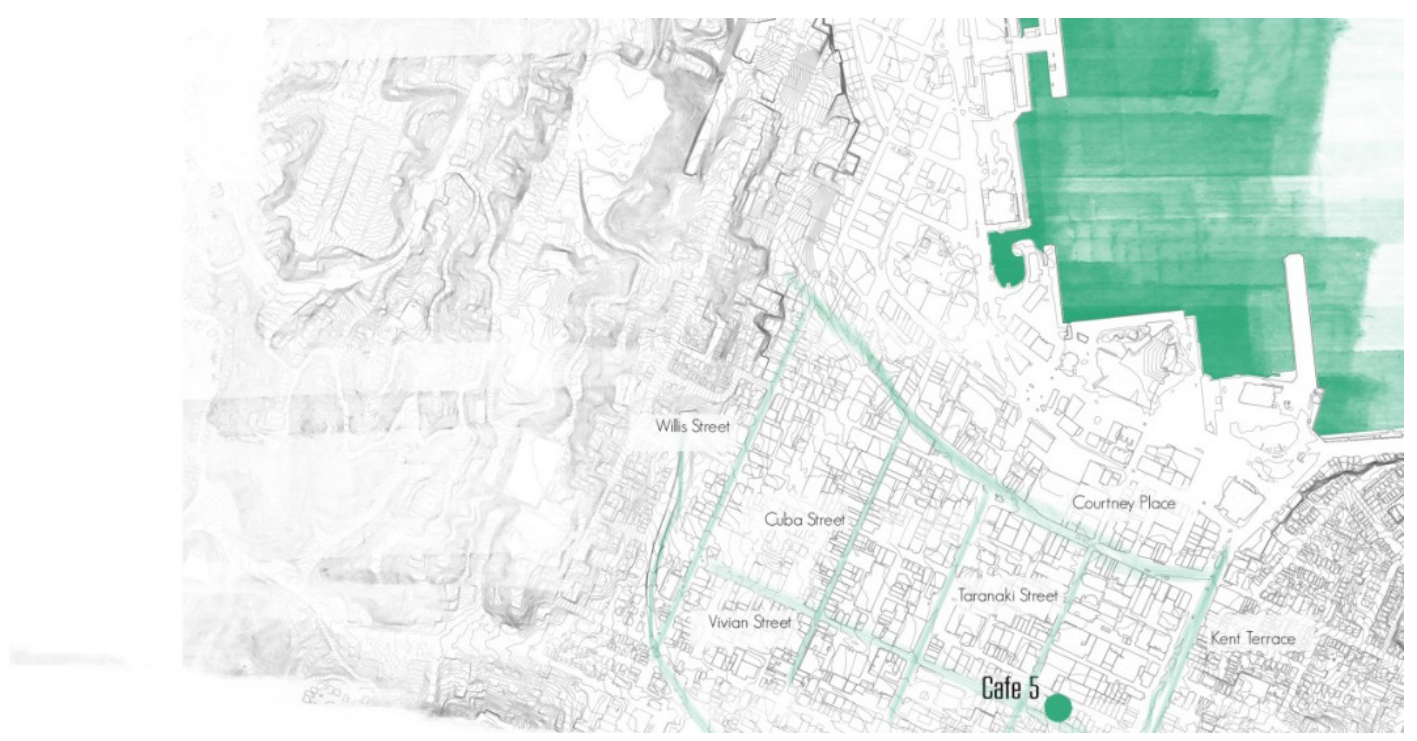

Figure 6.1 College Street is a small road off Tory Street on the edge of Wellington's CBD. 27 College Street occupies a fringe between urban and industrial areas in Wellington.

Figure 6.2 College Street's eccentric location appears to reduce the existing café's foot traffic. The site situation suggests that patrons deliberately decided to go the café. The café would be more successful if it could entice spontaneous patrons walking past the café. However, how can design help inspire more spontaneous patrons? 
Café 5 embraces its coffee roasting and distribution history forming a "sprawling, eclectic and bustling... flagship roastery and daytime eatery" (Cafe 5 Website).

IMPLICATIONS FOR THE CASE STUDY PROJECT'S DESIGN BRIEF

The Case Study project assumes an empty site within the restrictions of neighbouring buildings. This assumed empty site allows for the unrestricted exploration of architectural form including the interior and exterior thresholds.
The context and site of the existing cafe developed the design aims for the case study project. These include to:

Create a "sprawling, eclectic and bustling" design to reflect Te Aro's values

Relate the design to its location in the industrial city grain while managing the resultant industrial acoustic environment

Create quiet, reflective spaces within a hub of activity 


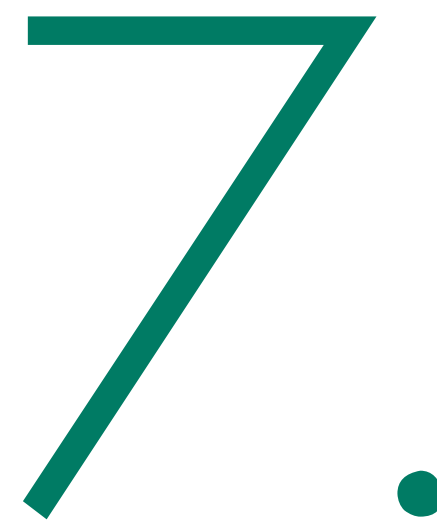

Analysis of Existing Café Function 
"Architecture is to make us know and remember who we are"

- Geoffrey Jellicoe qtd. in Besser and Salter, 361 
The cafés existing programme was observed for one weekday day to establish a framework for the functional aspect of the case study project. Despite the assumption of an empty site for the project, it was important in the design to retain a trace of Café 5's culture through a study of its operations and patrons.

\section{NUMBER OF OCCUPANTS}

The existing café's patron capacity of 120 patrons set the occupation goal for this case study project design. Patrons currently approach the existing café's counter and wait to be seated or for their order to be taken. However, it was noted that this Maitre d'system is not clearly communicated to the patron, leading to hesitation and confusion.

\section{SEATING}

Seating height and density in the existing cafe is varied to create independence. Roughly $20 \%$ of tables are high tables, looking over the lower tables, to maintain visual connection (figure 7.1). This subtle use of lines of sight maximise the effective café area.

\section{DIVERSITY}

The existing café opens at 6:30AM and closes at 3:30PM. In these seven hours a variety of patrons occupied the café, each with individual needs (figure 7.2).
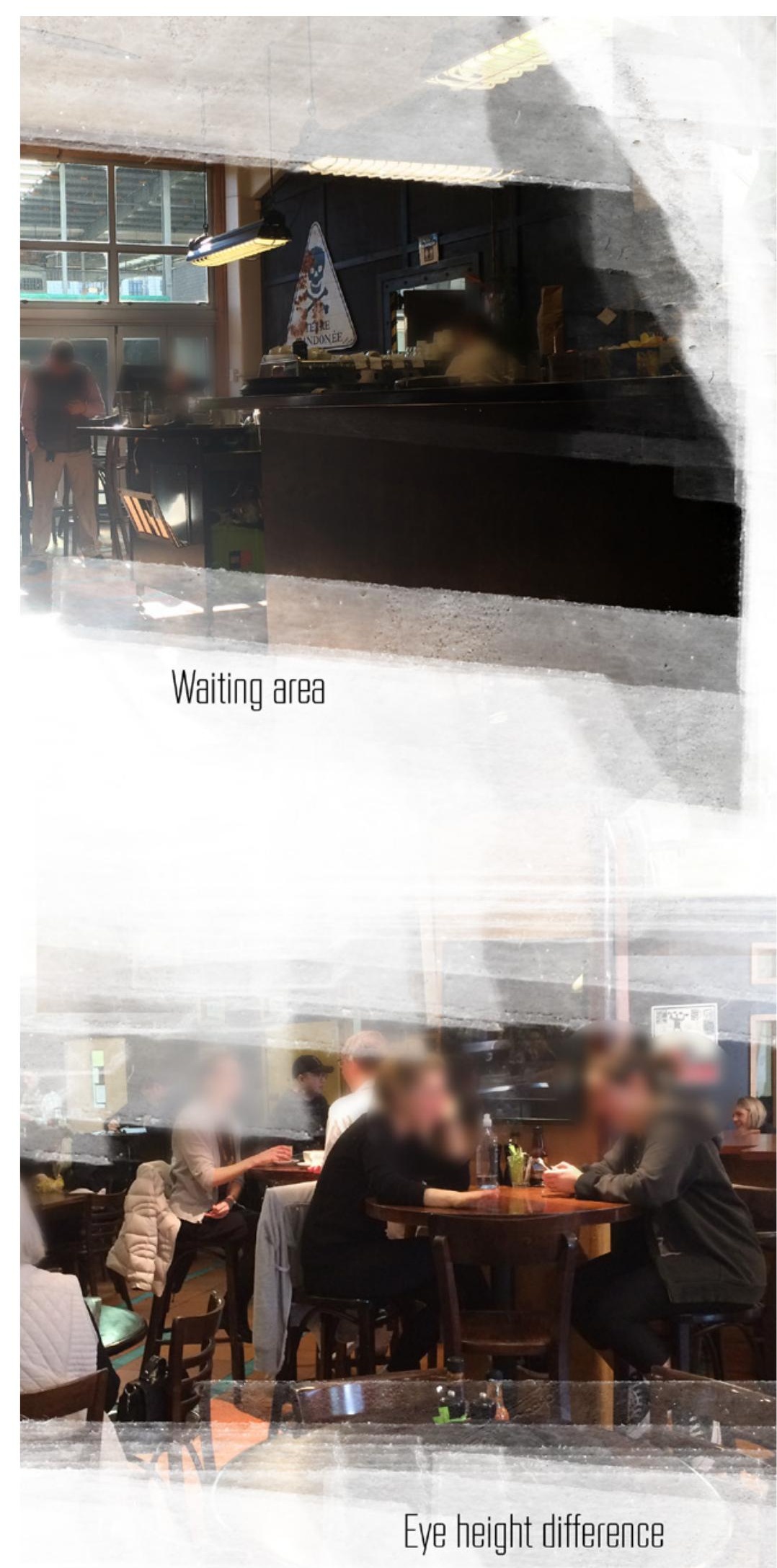

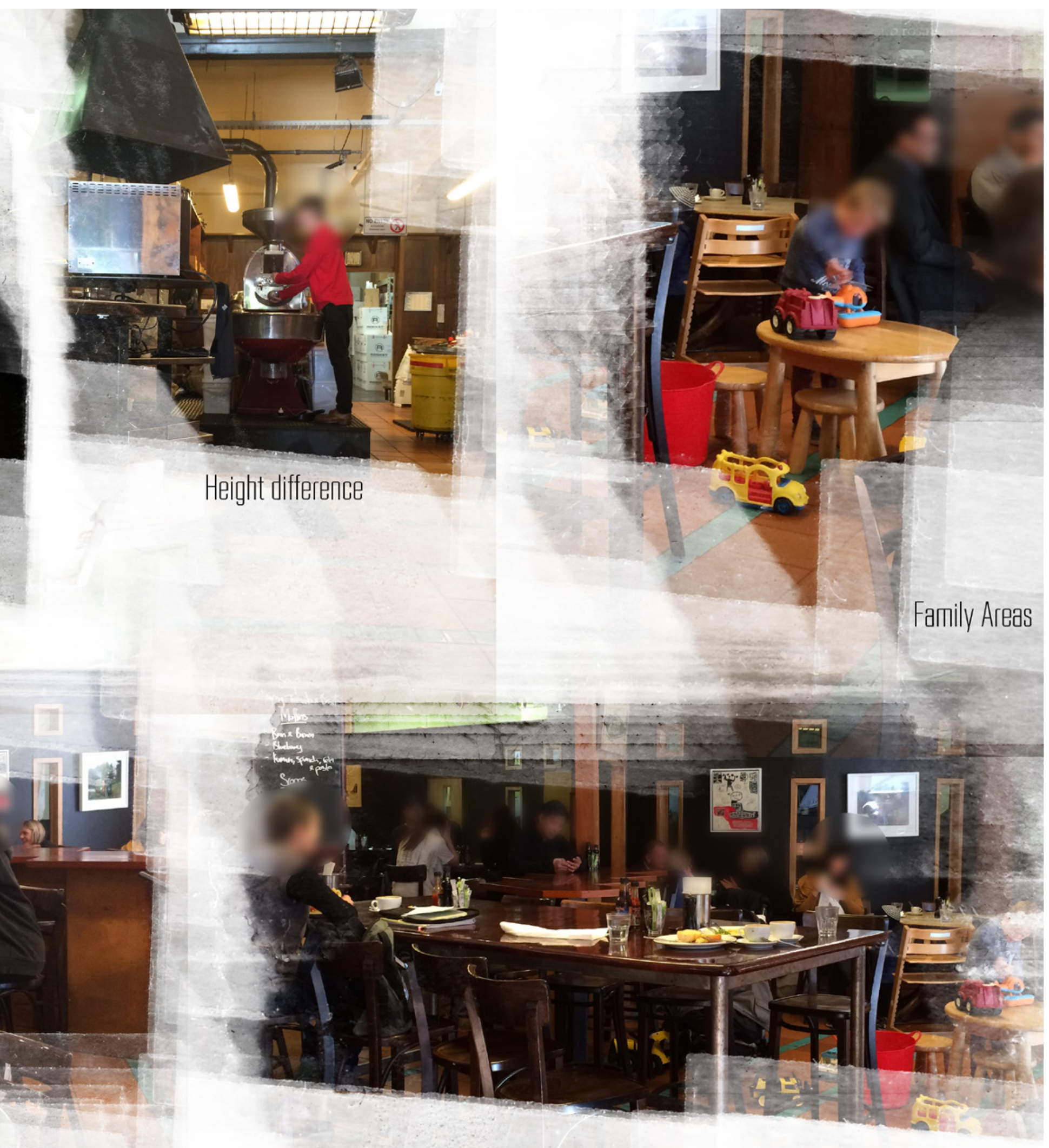

Seating number Variance

Figure 7.1 The front of house, coffee and appliance sales, offices and the workshop are all located in one space, yet each have different functions and attract different patrons. A use of varied seating heights connects the distinct parts that collaborate within Café 5's one space. Their collaboration indicates diversity in the company and was explored as a driver for the case study project. 


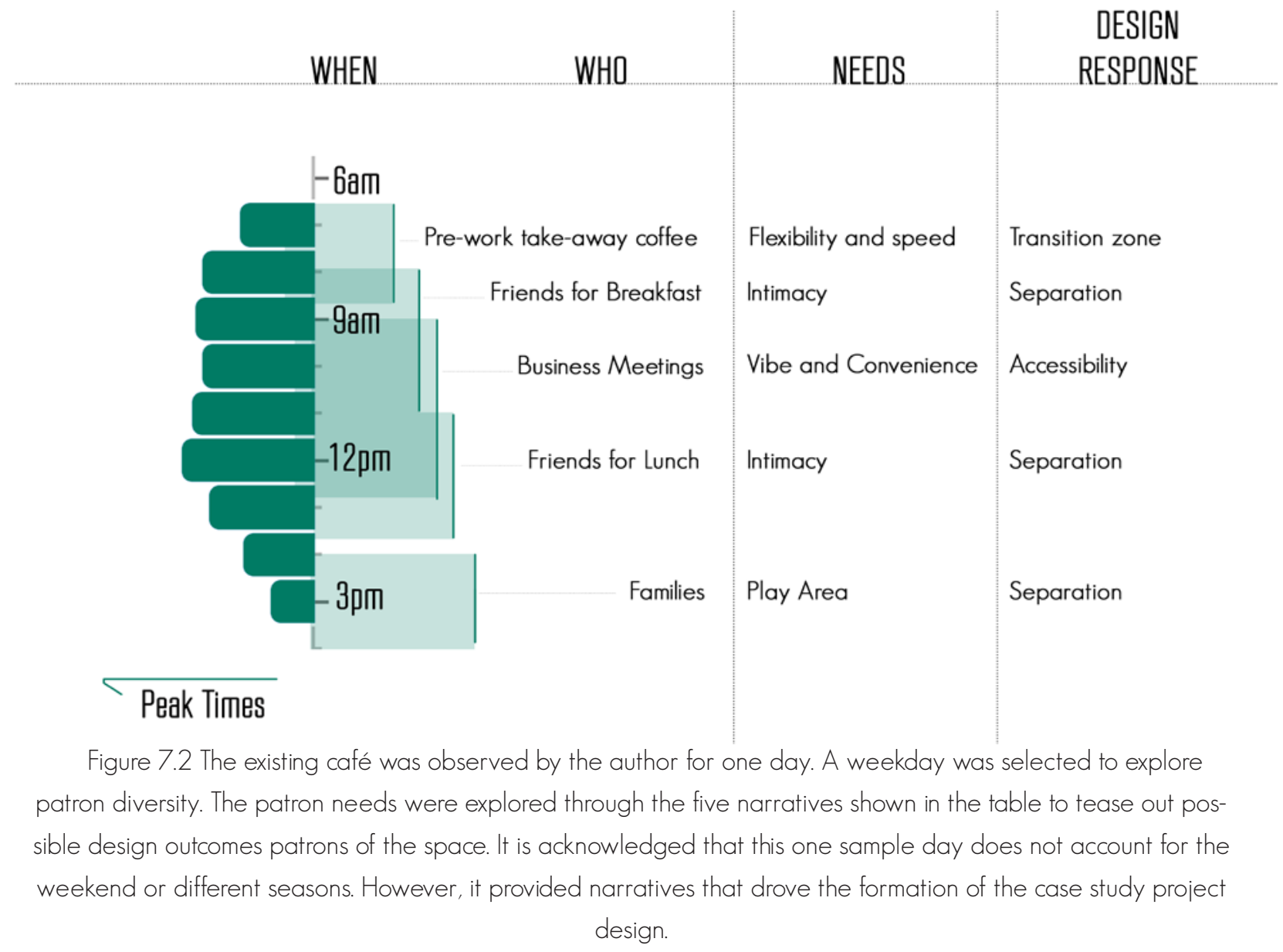

\section{TRANSPARENCY}

A transparency of the coffee-making process and the staff who make it happen is a major focus of the cafe (figure 7.3). The roaster and kitchen protrude into the main space, drawing patron awareness to the ritual of food preparation. 


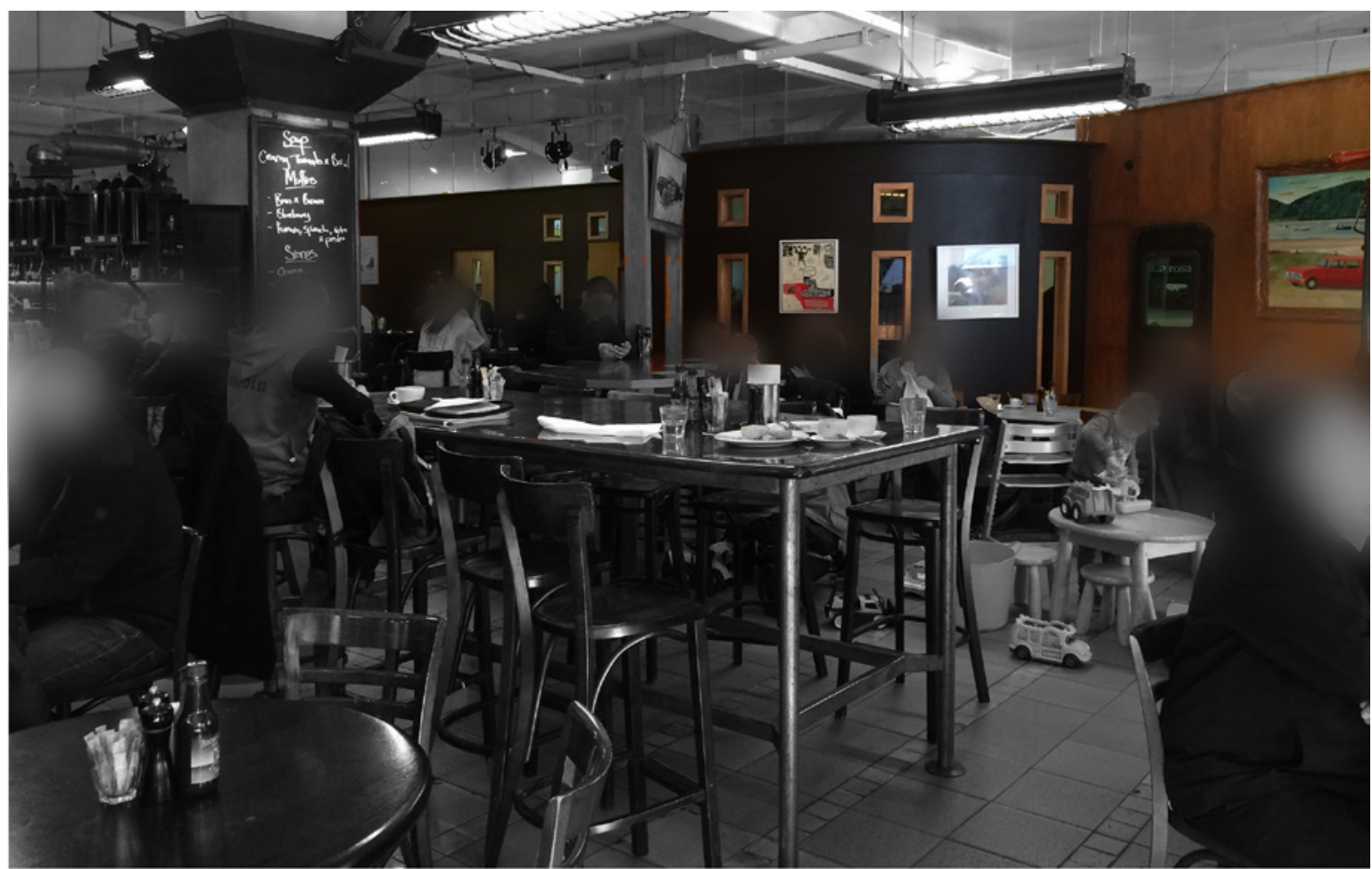

Figure 7.3 Port-hole windows between the café and the offices subtly develop connectivity. The inclusion of management staff into the café space references the connectivity of the company. This clear driver for transparency was explored in the Case Study project design.

IMPLICATIONS FOR THE CASE STUDY DESIGN BRIEF

While the design brief is not limited to the existing shell, it responds to the values of the existing culture and programme. Some design drivers that were identified from the Analysis of the Existing Cafe Function include to:

- Seat 120 patrons to match the existing cafe capacity

- Seating should be varied in height
- Service the needs of the wide range of patrons

- Incorporate the roaster and kitchen into the design as design elements that illustrate transparency

- Maintain a visual, or acoustic, connection between the staff members and patrons 


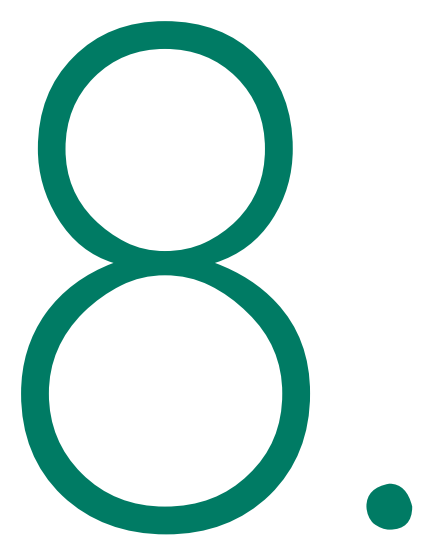

\section{Case Study}

Design Brief Formation 
This section discusses the formation of the design brief from information gained from the Site and Context Analysis and the Existing Café Function Analysis. This design process was used as a tool to research the potential of Galapagos with Pachyderm to inspire architecture that sculpts sound to achieve acoustic goals. The brief directed the design, limiting its scope and providing acoustic and design criteria that were used to assess its success.

\section{SITE}

An empty site was used to allow for the full exploration of interior and exterior thresholds without the restrictions that limited the Blue Frog Lounge precedent.

Lower amounts of foot traffic were observed on the road due to the site's large distance from the city centre. In response, the design objectives look to:

Develop a visually intriguing façade that contrast from neighbouring buildings
Create a "sprawling, eclectic and bustling" design, including:

- Exposure to the street - open façade

- Transparency of roaster present on site

- A mixture of materials

- Outdoor space

- Relate the site location in the industrial city grain to Te Aro community values

- Manipulate the industrial acoustic environment into an asset

- Create quiet space within a hub of activity

\section{PROGRAMME}

The Case Study Design aimed to:

- Seat 150 patrons

Create:

- An active area for short-term occupation

- Areas of intimacy where friends can meet

- Areas for business people

- Transitions between zones

- Use sight lines to create space

- Implement an open kitchen, services and staff to patron connection. 


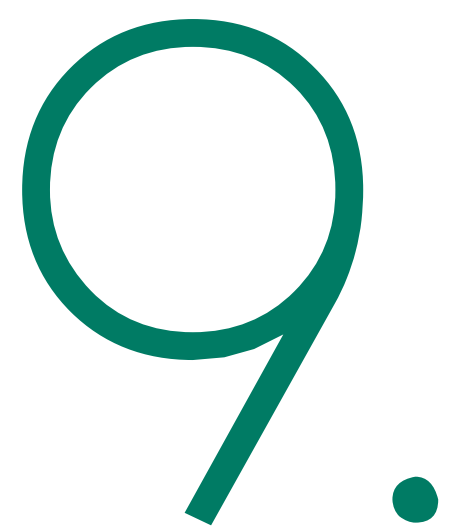

\section{Case Study Proiect} Design Methodology 
"You can use an eraser on the drafting table or a sledge hammer on the construction site"

- Frank Lloyd Wright gtd. in Mandel. 


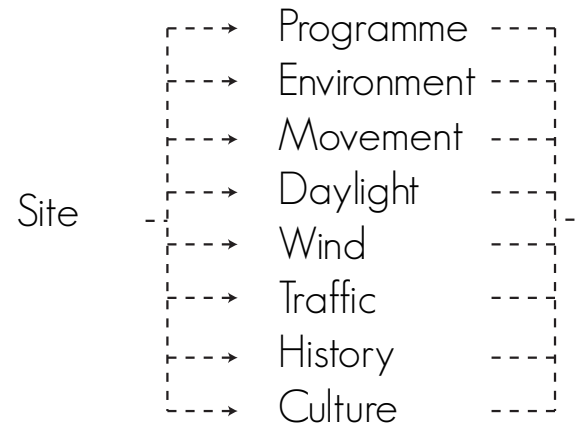

Material Properties ... $\rightarrow$ Volumetric Model

Pachyderm Acoustic Measures

Informed Model

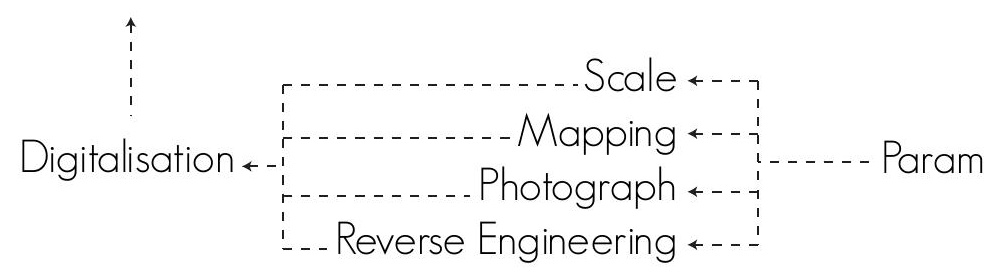

Figure 8.1 A conversation between café testing (right) and context and programme analysis (left) produced an analogue and parametric design methodology (bottom) 


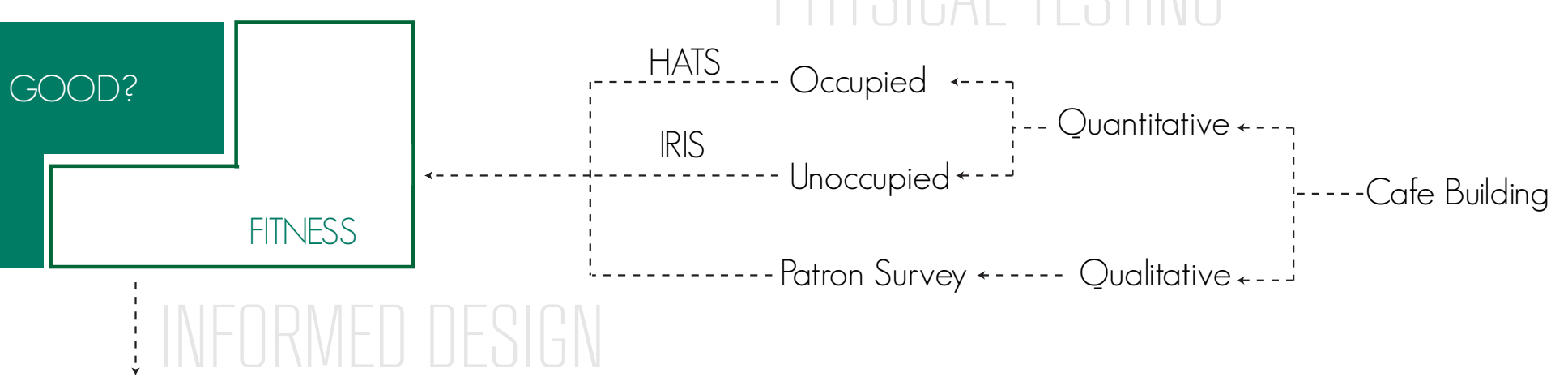

Parametric Iterations

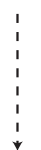

Concept Design

$$
\vdots
$$

Developed Design ...

i 
The case study project explored a concurrent analogy and parametric design methodology (figure 8.1). Parametric and analogue design methods were explored simultaneously, providing acoustic and spatial justification for design decisions. However, this process has been presented separately to discuss their individually impact on design.

\section{PART 1: PARAMETRIC EXPLORATION - GALAPAGOS}

An algorithm was written for Galapagos to alter the location of eight vertices of a cube to find forms that achieved a 0.7 second RT (figure 9.1 and 9.2).

RT, specifically $T 20$, significantly influences the Cafe Effect and can be calculated using Sabine's Equation (Whitlock and Dodd). The $R T$ is calculated with only two variables: the volume of the space (V) and its effective absorption area (A). These broad inputs allow $\mathrm{RT}$ to be effective at an early resolution level.
A T2O of 0.7 seconds was selected as it is shorter than the maximum suggested by AS/ NZS 2107 (2000) and was comparable to the cafes with the two highest enjoyments.

\section{PART 2: PARAMETRIC EXPLORATION - PACHYDERM}

Pachyderm simulated a wide range of measurements from RT to STI depending on the design resolution level. While general calculations such as RT could have been calculated through Sabine's equation, STI and other measurements that communicate the detailed acoustics for specific places rely on Pachyderm's ray tracing simulation.

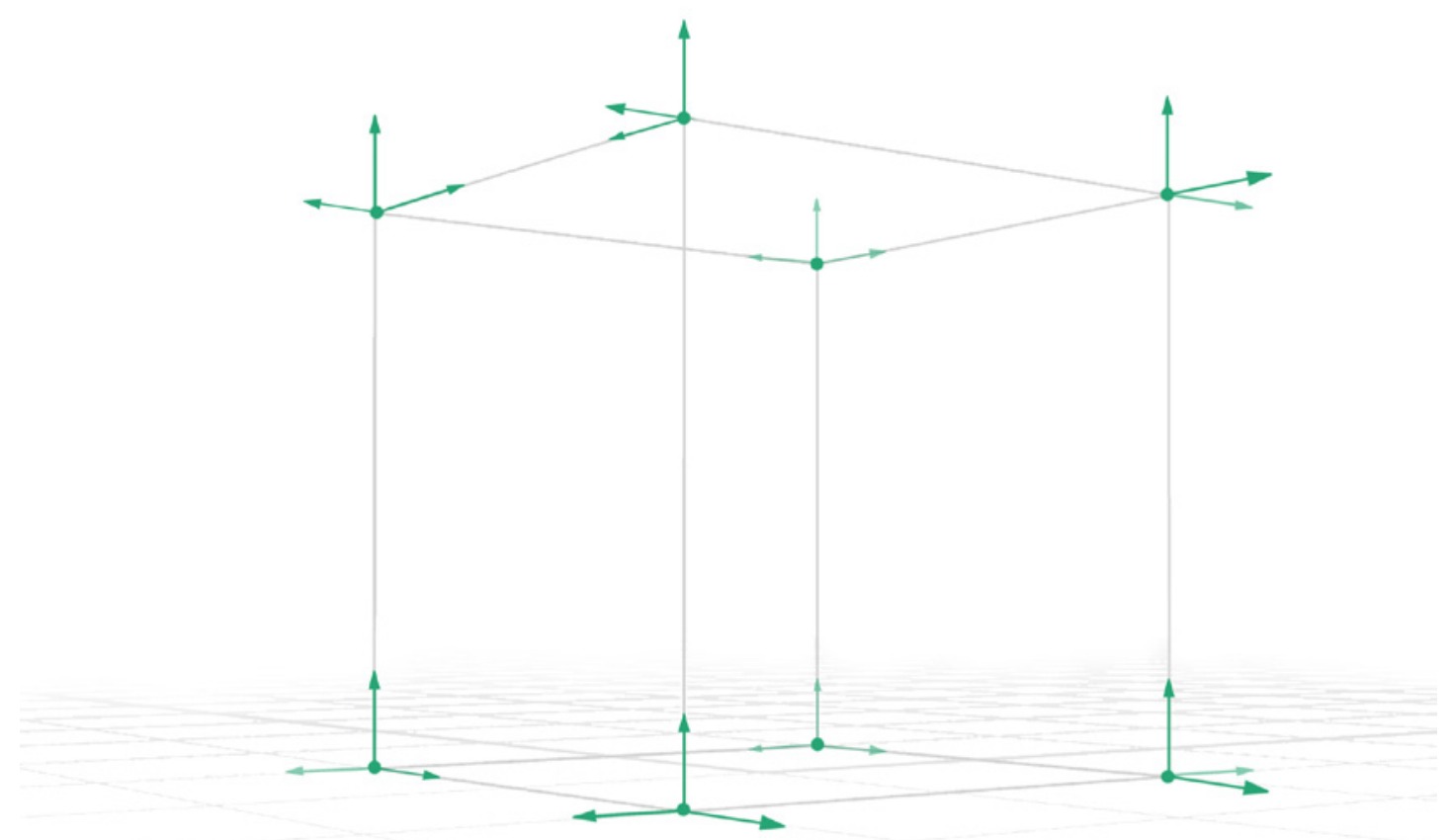

Figure 9.1 Starting from a cube, the corner locations were altered by sliders. Over 10 generations, the RT of different forms were simulated by Pachyderm and then compared to the target acoustic result to understand the form's success. 
Pachyderm's ability to realistically predict acoustic results is influenced by the number of rays, the level of detail of the model and the scattering coefficients of materials. These influences are discussed in this section to understand how to achieve the most "realistic" acoustic simulation.

\section{NUMBER OF RAYS}

An infinite number of rays would achieve the most accurate result, yet, many rays slow the system. As no suggestion on ray quantity suggestion was found within Pachyderm, CATT Acoustic's "Predict SxR" automatic ray number was utilised in this project (Dalenbäck). This automatic tool suggests the appropriate number of rays based upon the complexity of the geometry in the model. For this model's complexity, 20,000 rays were calculated.

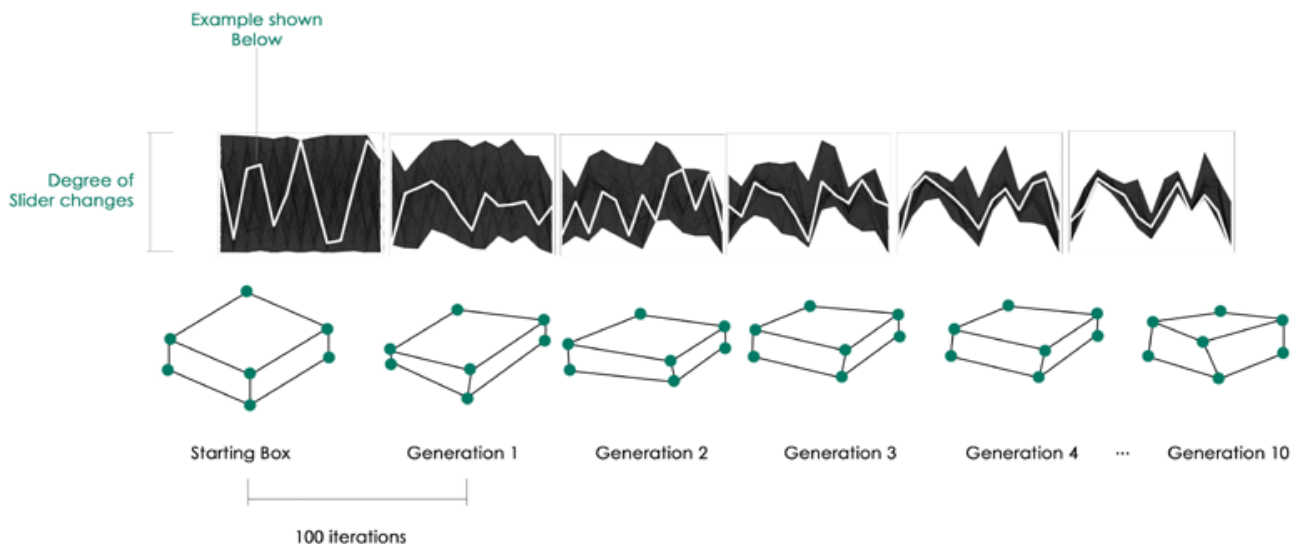

Figure 9.2 Digital Generations, just like biological ones, are markers of progress of the form towards a target acoustic goal, or fitness. In the first generation, Galapagos altered the sliders randomly, however, through the 100 iterations per generation, it detected which sliders made the most positive impact towards the fitness. The number of sliders that change, and the range that they change through, logarithmically decreases over time as Galapagos refines the form. 

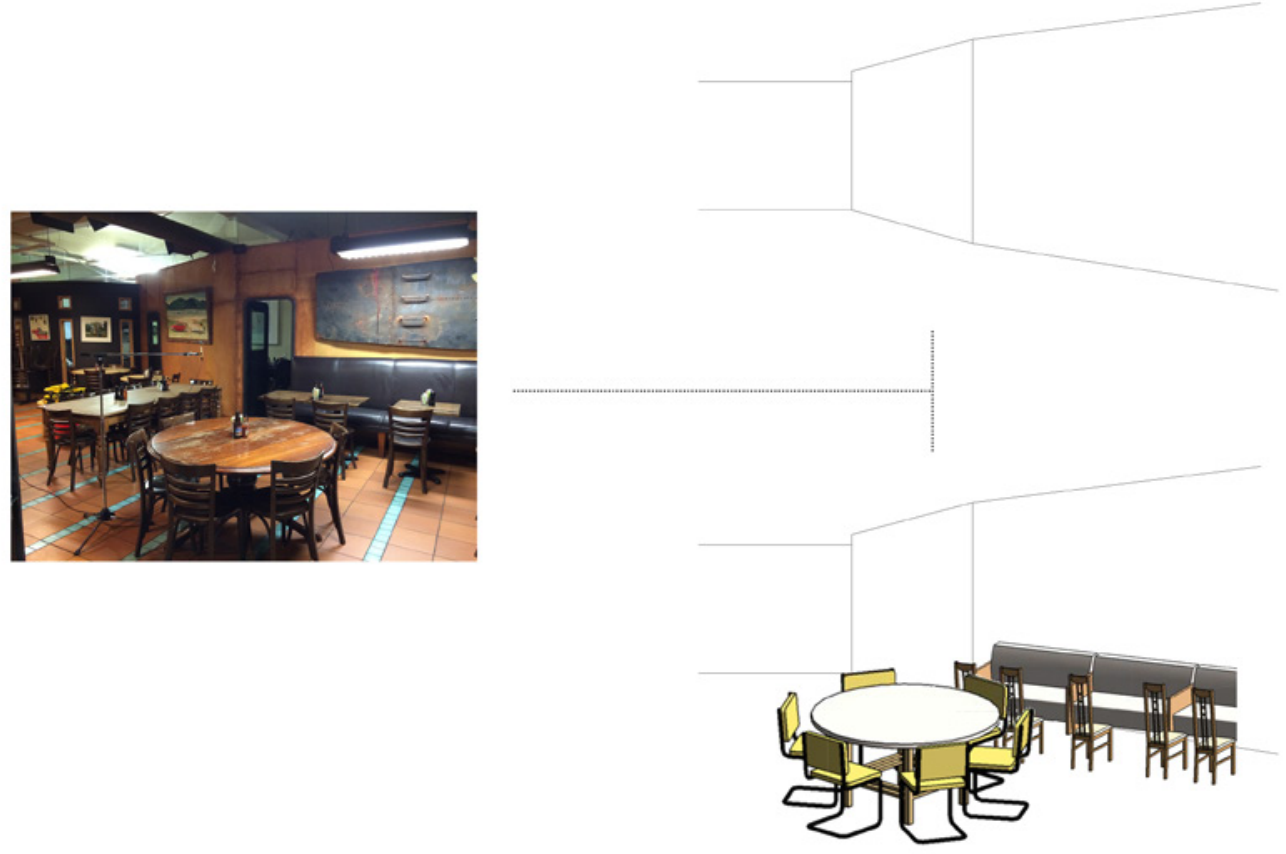

Figure 9.3 The same scene is modelled in "Low" and "High" detail. In low detail only the surfaces are modelled (top), whereas furniture is modelled in the High detail (bottom). There is an architectural preconception that higher visual detail informs realistic acoustic results. However, in ray tracing the reverse relationship is possible, as rays bypass the fine objects and do not reflect realistically.

\section{LEVEL OF DETAll}

The level of model detail significantly impacts the simulated result. This level of detail determines if simple surfaces or complex furniture are modelled (figure 9.3).

\section{SCATTERING COEFFICIENTS}

Simulated results are significantly impacted by the scattering coefficients of materials (Appendix A). This research used the CATT Acoustic chair scattering coefficients data as limmited scattering coefficient libraries are available for specific materials. Instead, a template for the expected change between frequencies was created (figure 9.4).

\begin{tabular}{|l|l|l|l|l|l|}
\hline $125 \mathrm{~Hz}$ & $250 \mathrm{~Hz}$ & $500 \mathrm{~Hz}$ & $1000 \mathrm{~Hz}$ & $2000 \mathrm{~Hz}$ & $4000 \mathrm{~Hz}$ \\
\hline 30.0 & 40.0 & 50.0 & 60.0 & 70.0 & 70.0 \\
\hline$x-30$ & $x-20$ & $x-10$ & $x$ & $x+10$ & $x+10$ \\
\hline
\end{tabular}

Figure 9.4 The scattering at $1000 \mathrm{~Hz}$ was assigned as $\mathrm{x}$ and its relationship to the other frequencies was represented by plus or minus the difference. This $x$ value was then altered for the different materials based on an informed estimate of their scattering at mid-frequencies. 
PART 2: ANALOGUE EXPLORATION

The case study project's analogue exploration focused on patron occupation of space within the shell. This method implemented the insight gained from the investigation into the patrons of the café through the methods of sketching, modelling and photographing.

Sketching inspired a fluid development of a variety of design ideas. These sketches were initially diagrammatic and increased in complexity and resolution as the design became more refined.
Physical modelling at the early design phase developed the spatial qualities of the design. The shell was formed parametrically, but then modelled in card so that its volume and floor stacking could be assessed. Photography reimagined these models to inspire further development of the design. 


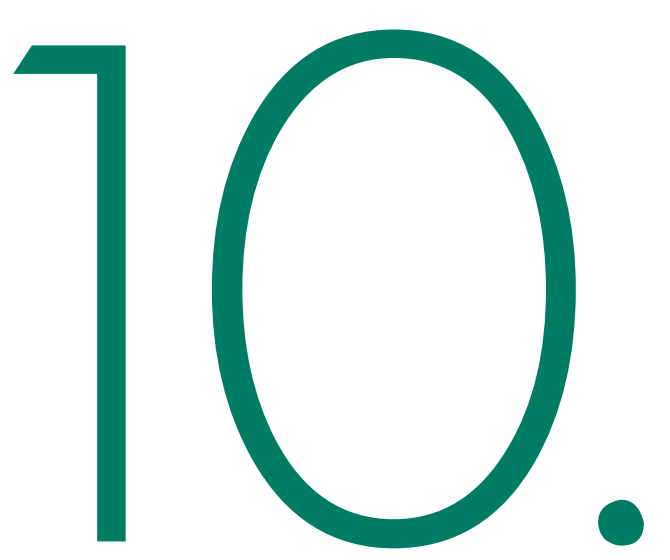

\section{Case Study Project Design

$$
\text { - Preliminary Design }
$$


"Architecture begins where engineering ends"

- Walter Gropius qtd. in Blesser and Salter, 361 
This section documents the design development of a cafe outcome through an analogue and parametric exploration of an acoustic goal.

\section{PARAMETRIC OUTCOMES}

The shell optimisation process explored 1,000 iterations over ten generations to form solutions that satisfy the acoustic brief. The shell was explored digitally and physically through printed 3D wire models (figure 10.1 and 10.2).

Figure 10.1 The 3D printed model shows the formation of the initial shell outcome. The façade's curvature is both aesthetically elegant and acoustically effective: scatting sound. 


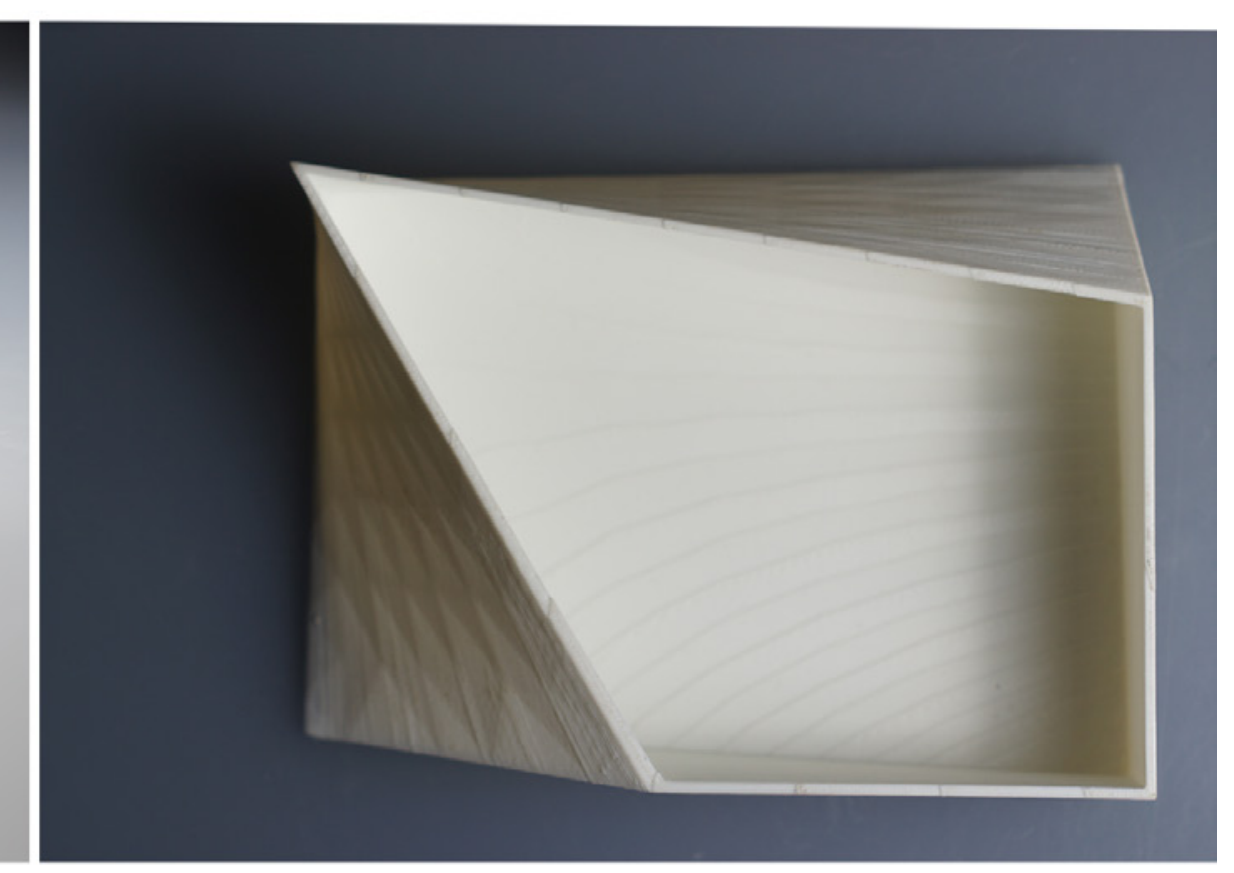



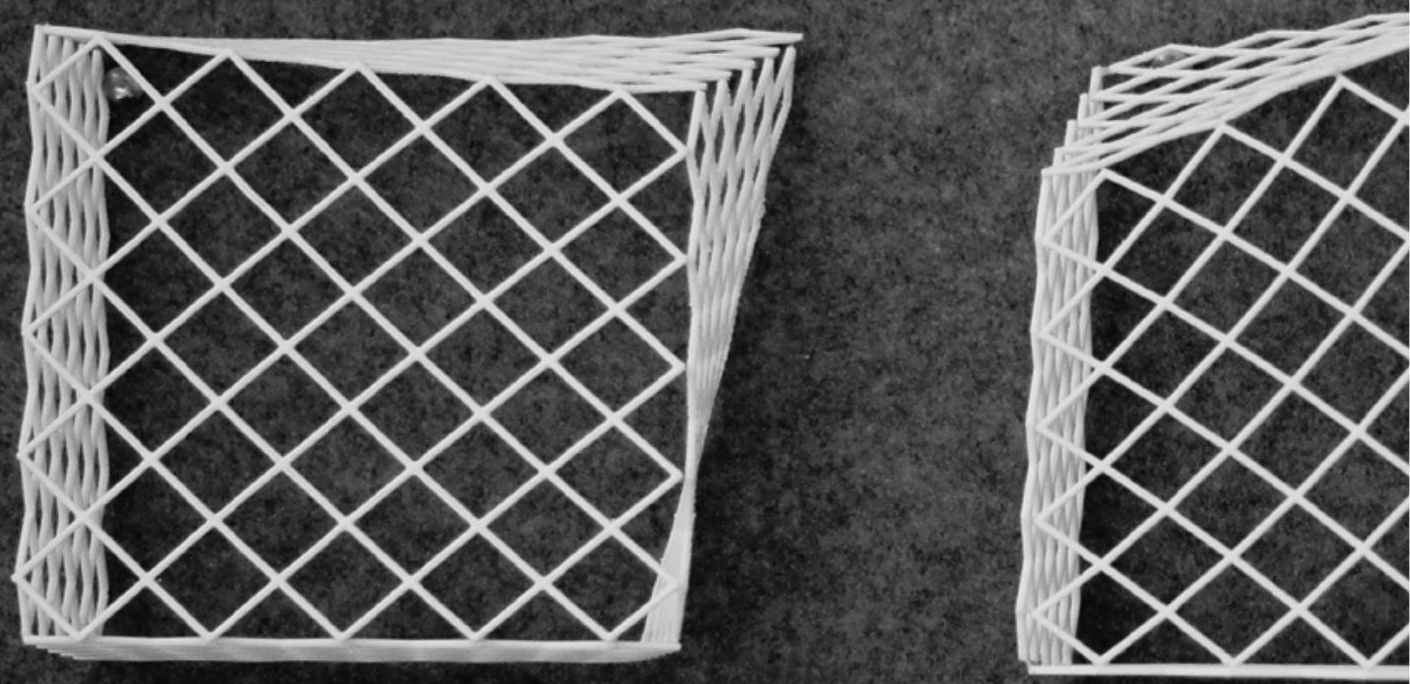

Figure 10.2 These physical wire models allowed for the formal understanding of the lines of the shell. These lines illustrate the curved facades designed to scatter sound in the café interior 
ANALOGUE OUTCOMES

A variety of acoustic environments were explored and found to be initially successful. The design was divided into different zones to allow the patrons to elect one that aligns with their needs (figure 10.3 - 10.5). This scheme, while creating potentially successful environments also divided the design and encouraged a disconnect. Further analogue investigations explored different divisions of separate zones but still promoted flow (figure 10.6 - 10.8).
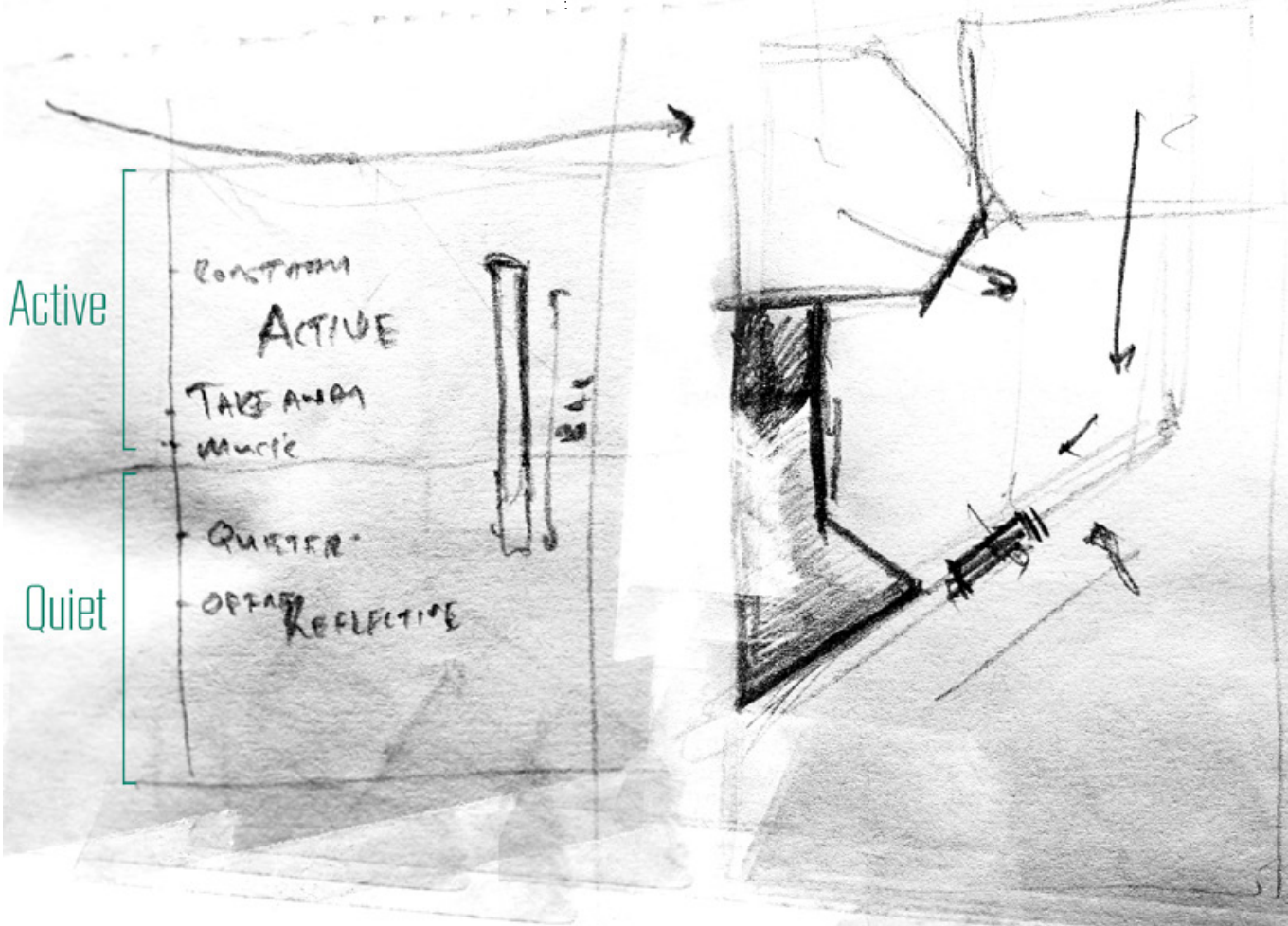

mol

1
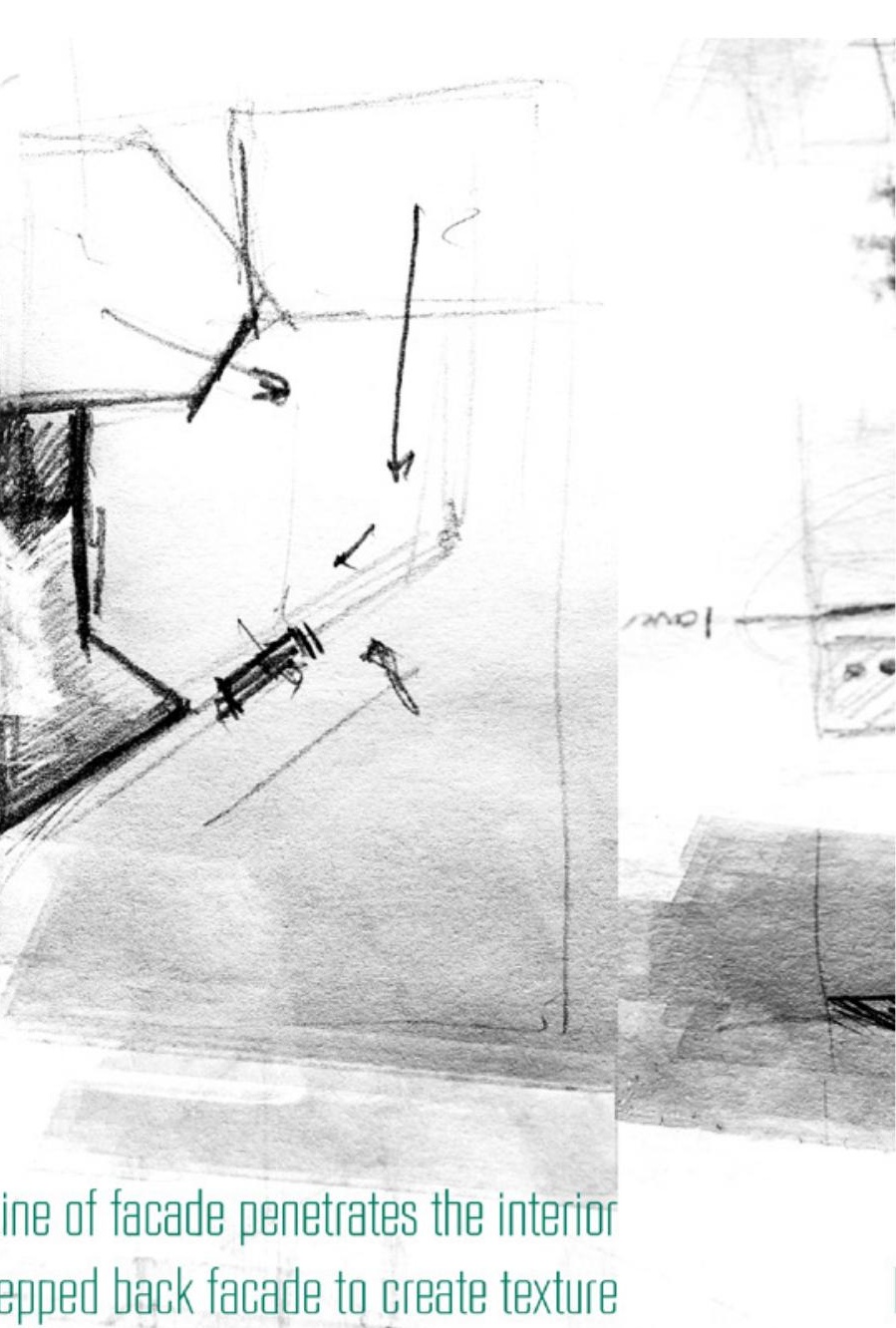

Space divided in two stepped back facade to create texture

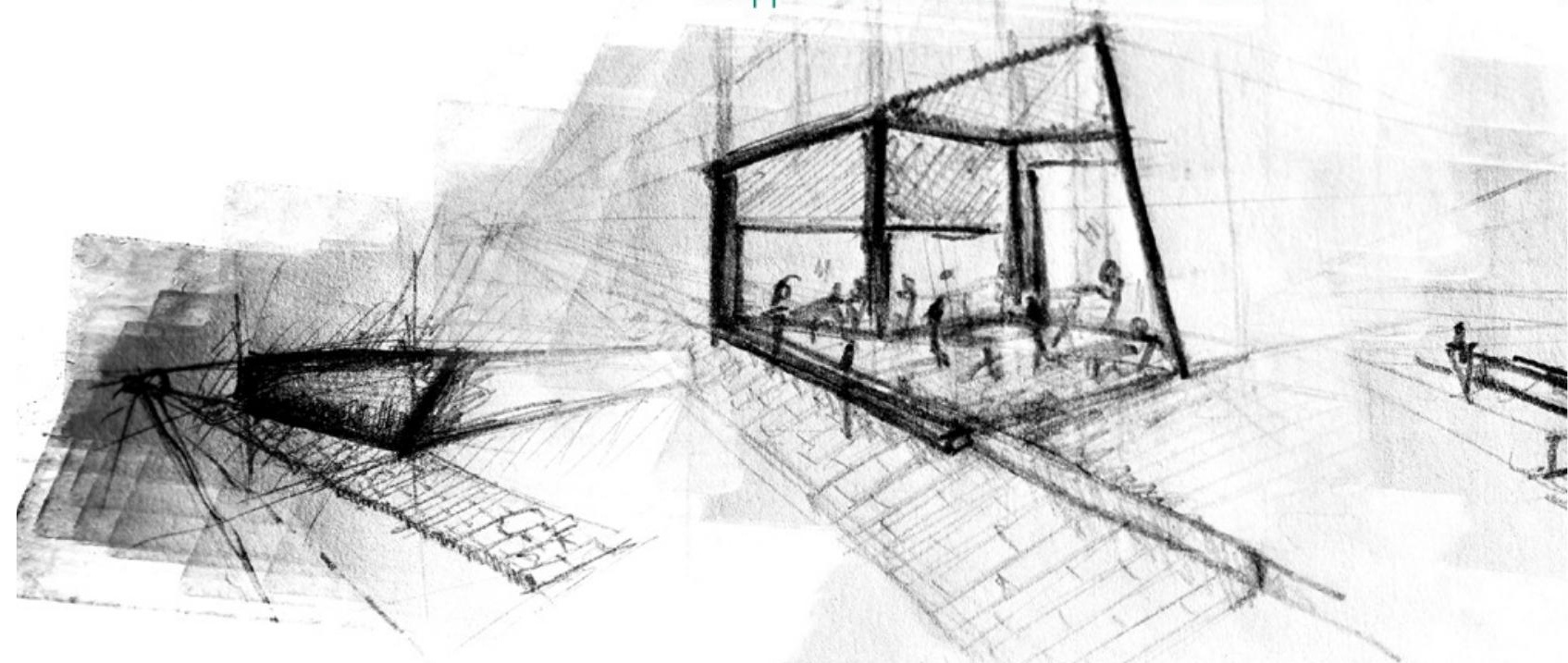

Figure 10.3 Multiple layouts were tested that allowed for the division of space and acoustic environment. A straight division was explored, following the line of the front façade (left). Forward of this threshold addressed the flow of "transition" patrons while behind was designed for the friends seeking intimate space.. 

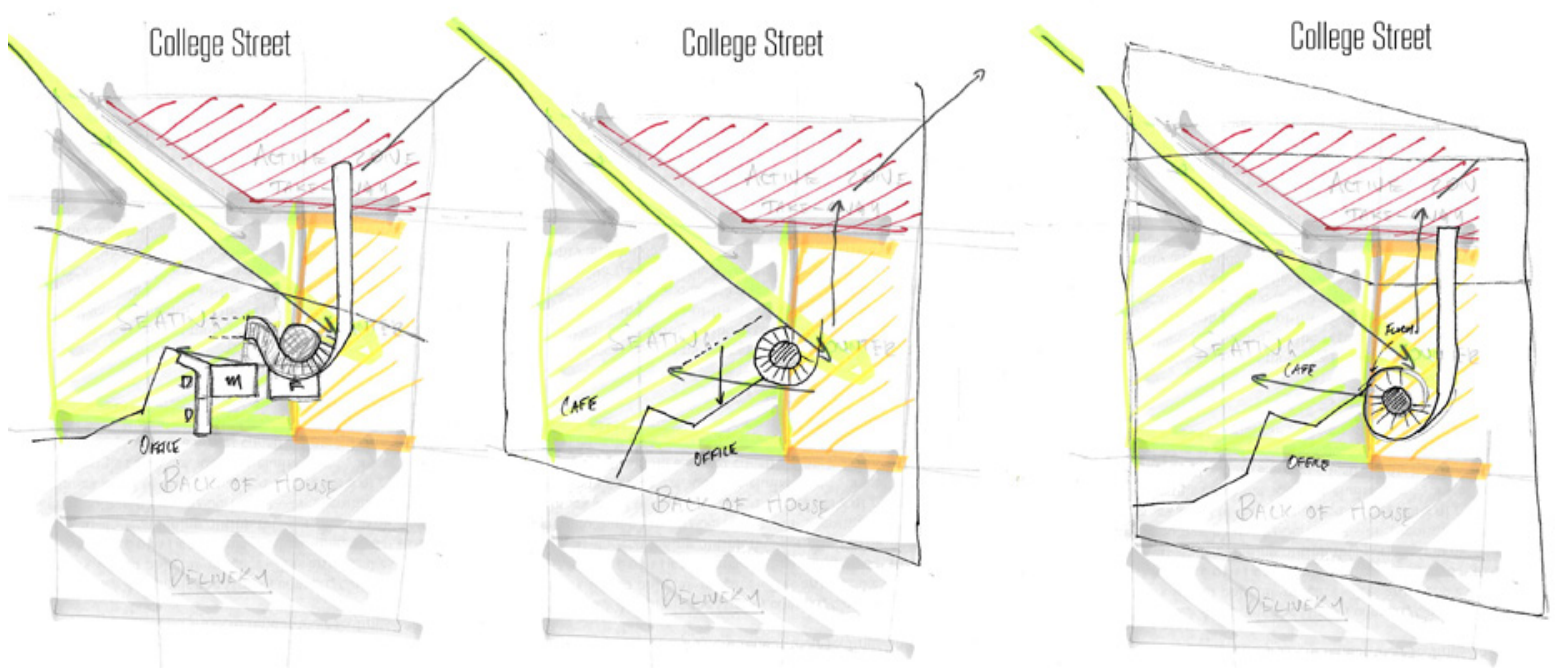

Figure 10.5 As the major entrance was on the left/front corner of the plan, design options were explored that created a line of sight from the entrance to the counter. This cut was used to divide the space into the different zones.
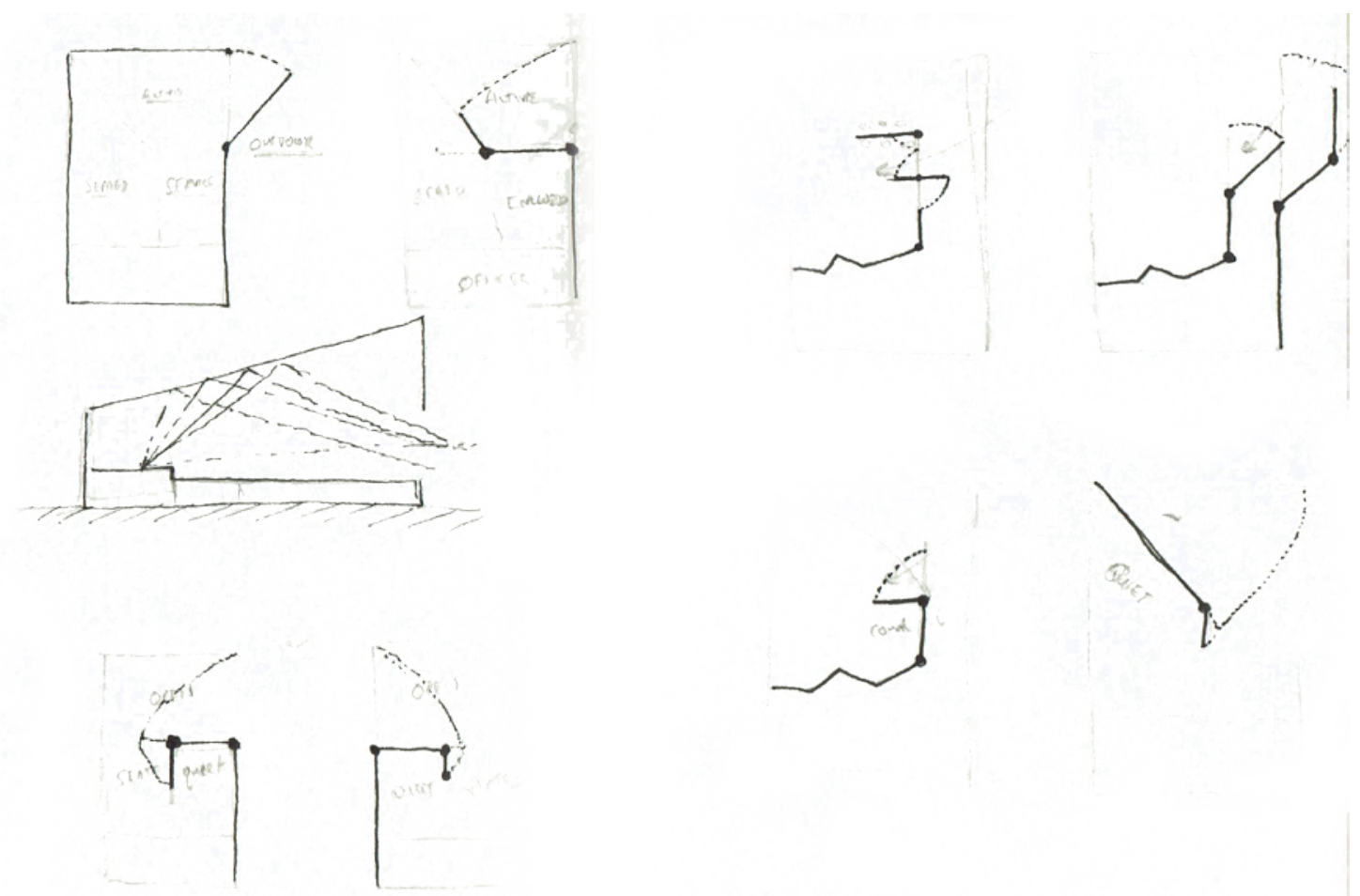

Figure 10.6 The possibility of having a dynamic wall system was explored. This design move would allow the absorption that is traditionally fixed, to shift within the room for different arrangements. 


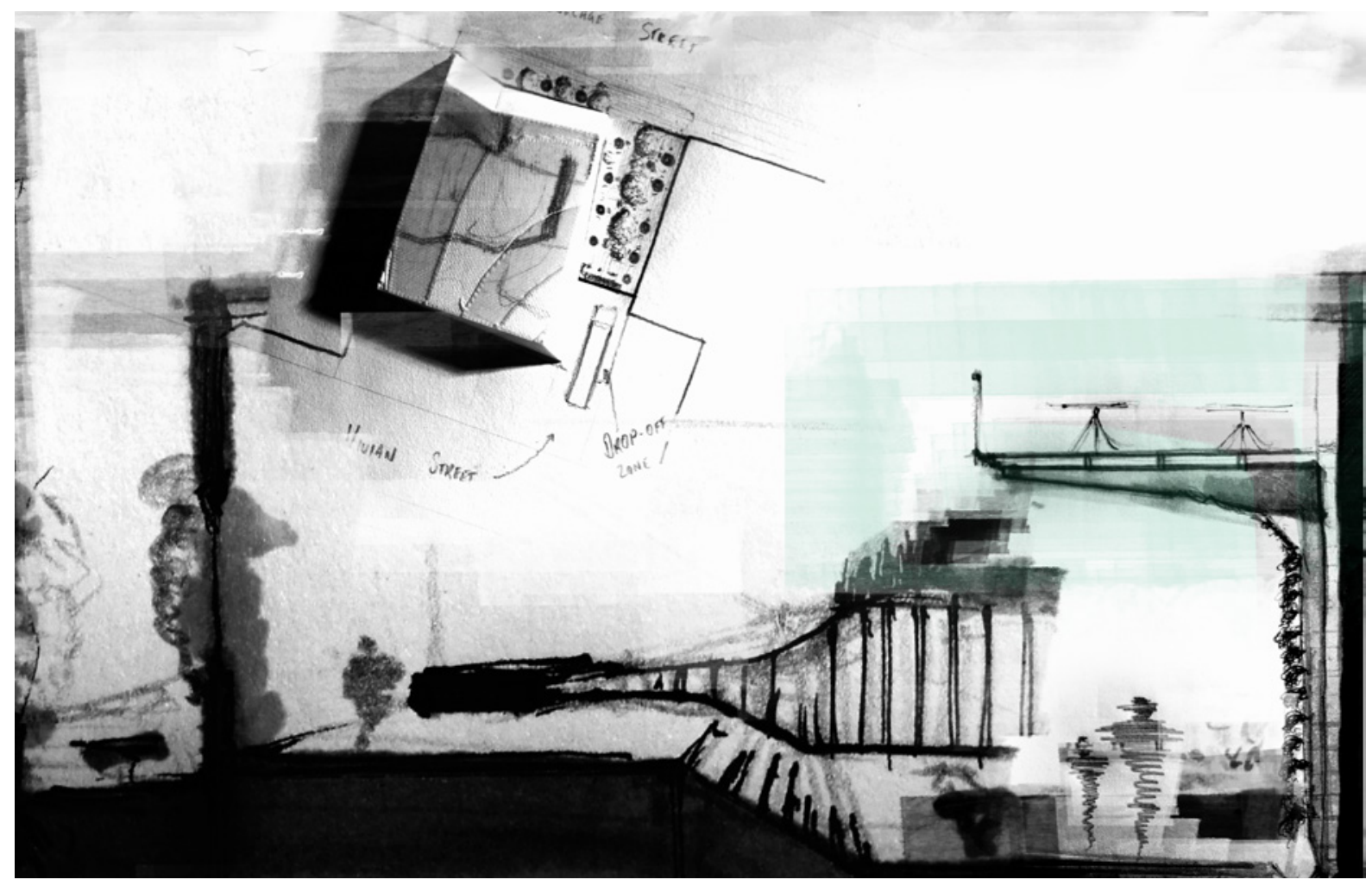

Figure 10.7 The potential of split level design was explored in section and perspective through ink and watercolour sketches. Altering the height of the zones maximises intimacy between patrons at one table, while distancing them from other groups.
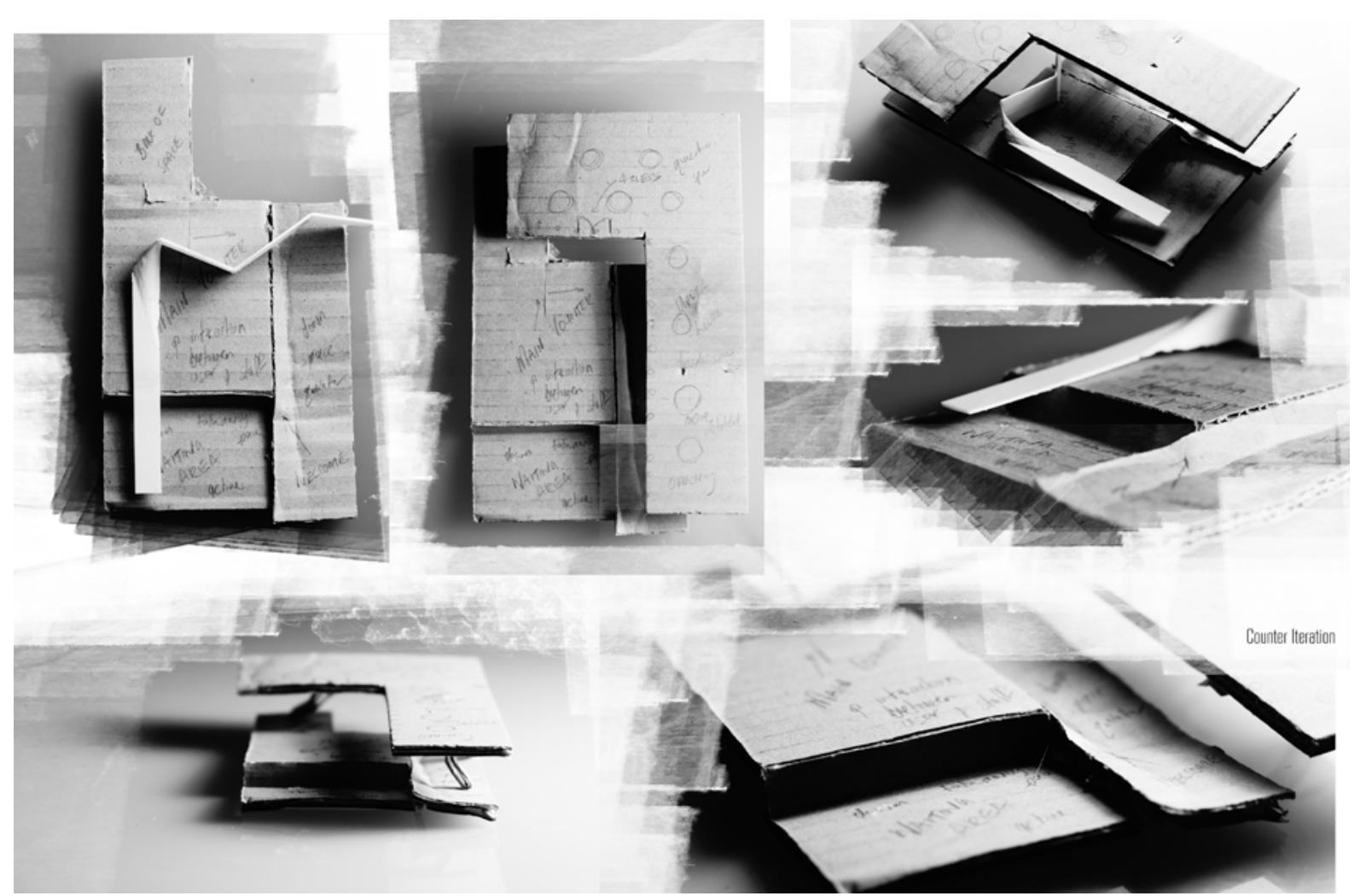

Figure 10.8 Physical modelling was utilised to explore how a counter could connect between the different zones created when dividing the plan into split levels. The counter transcends the zones to promote movement and unity within the cafe. In the main counter area, the counter acts as a sales point, flowing to become a leaner in the active zone at the street front and mezzanine stair handrail, prompting patron movement to the mezzanine level. The counter reacts to the zone's programme, providing a functional input and relieving the hesitation felt by the patrons when approaching the counter in the current café 5 design. 
The different levels were developed to prompt the patron into electing an acoustic environment. A live environment was established on the mezzanine, and patrons seeking quiet space were enticed to covered space with localised absorption sheltered by the interior wall.

\section{TRANSPARENCY:}

One key design objective was promoting the coffee roasting, brewing and drinking process to patrons. A staggered wall, designed to cross the space, forms a threshold between patrons and the back offices. This wall can be seen connecting to the counter in the physical models in figure 10.8, establishing a guide.
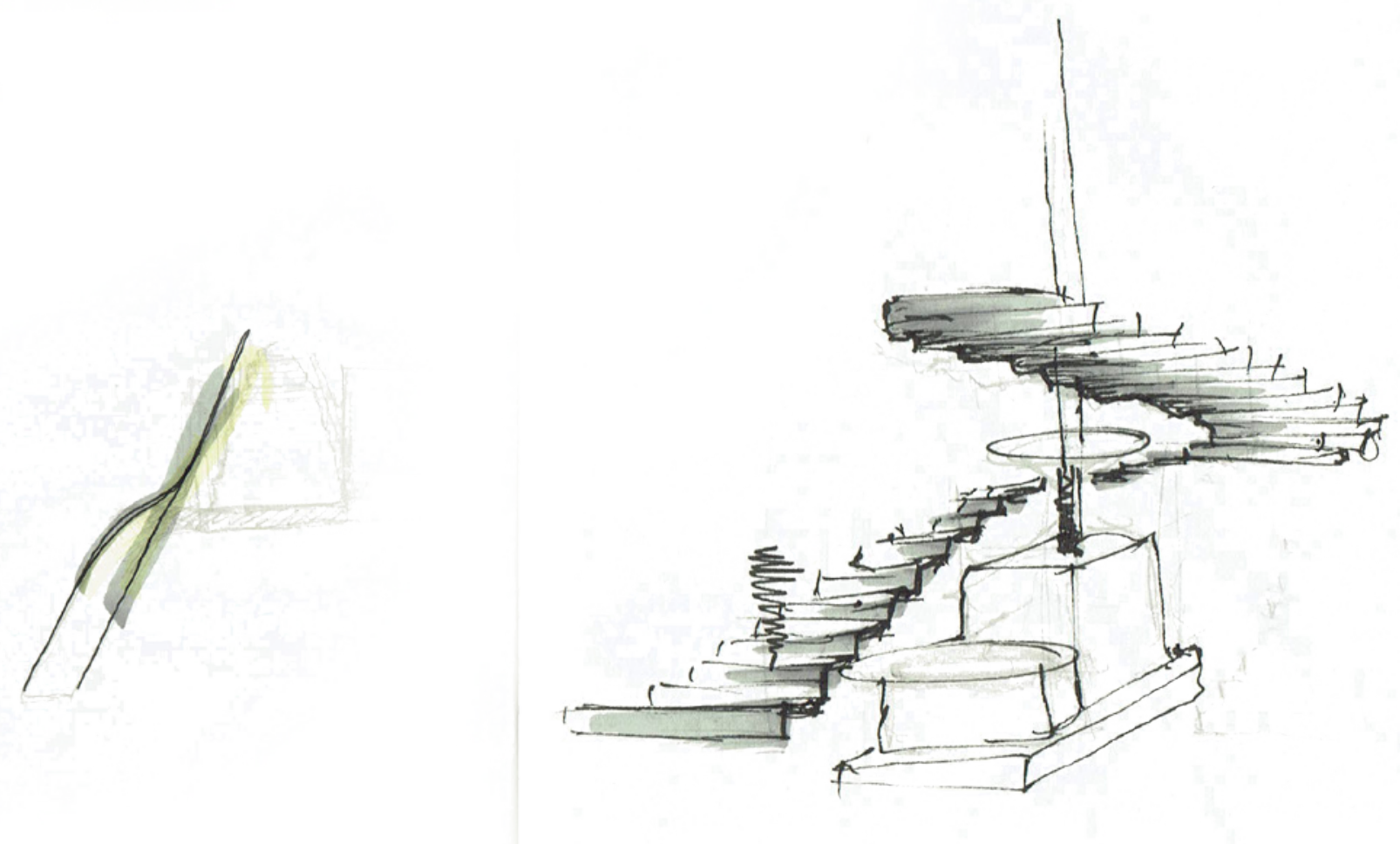

Figure 10.9 The stairs up to the Mezzanine floor circumnavigate around the grinder (right). Exposing the roaster punctuates the patron's journey, lifting its status as a major element of the coffee-making process. To aid connectivity the connection between the counter and stairs (left) was explored. 


\section{REFLECTION ON PRELIMINARY DESIGN}

The parametric and analogue techniques operate well individually (figure 10.10 10.12) however, do not form a unified design together.

Zone divisions provide an effective framework to consider architectural acoustics. This division also allows for a separation of acoustic environments with specific absorptive properties applied to a variety of surfaces (figure 10.13). Establishing different acoustic environments was hypothesized to satisfy a wider variety of patrons.

The card models were an effective spatial design tool as it investigated vertical stacking importance of sight lines. A sight line between entrance and counter responds to patron hesitation noted in the original café.

A vertical shift between zones is effective (figure 10.10), but subsequent accessibility issues require further consideration in the developed design. Furthermore, the vertical division also reduces the unity of the overall cafe and so the significance of a connecting counter is acknowledged.

The interior currently operates within the parametric shell with little connection between the concurrent methods. To strengthen this disconnect, analogue design decisions must consider how Galapagos could impact the human-scale design of interior elements. This transition into the interior of the project, could further drive parametric optimisation within analogue iterations. This combined design would better address the design question.

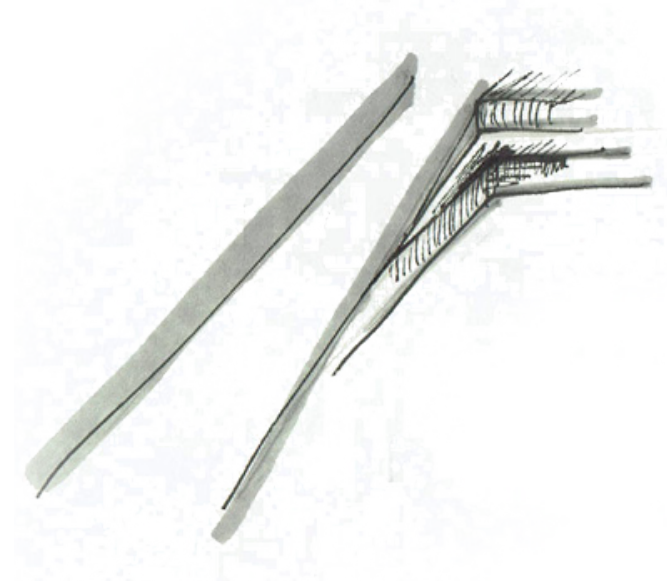

Figure 10.10 The accessibility issues established when creating a split level design were considered with a ramp positioned to emphasise the path from the entrance to the counter. 

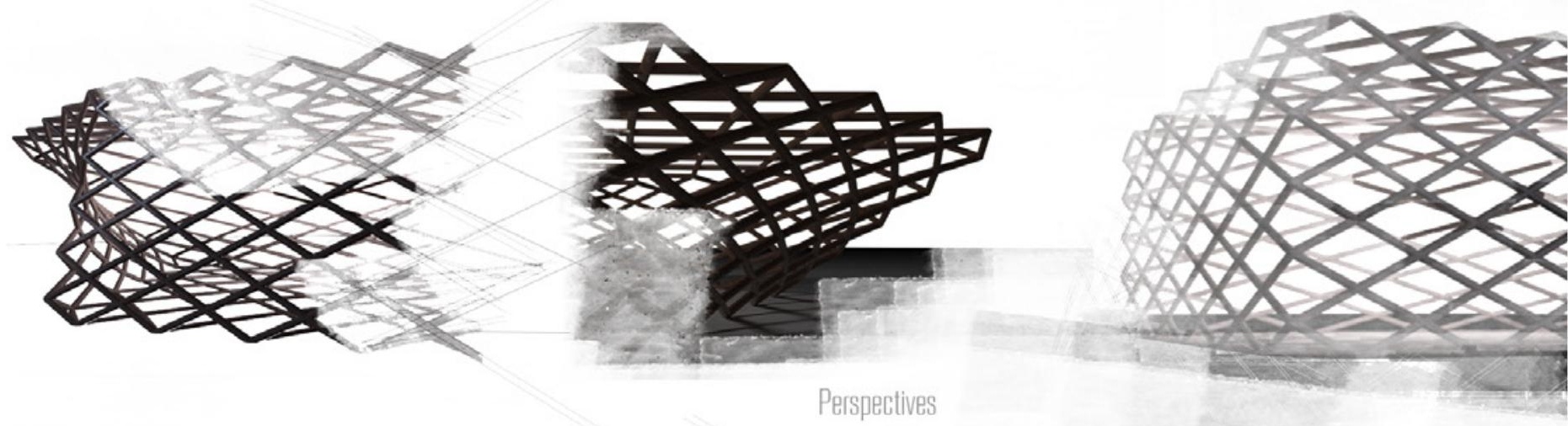

Perspectives

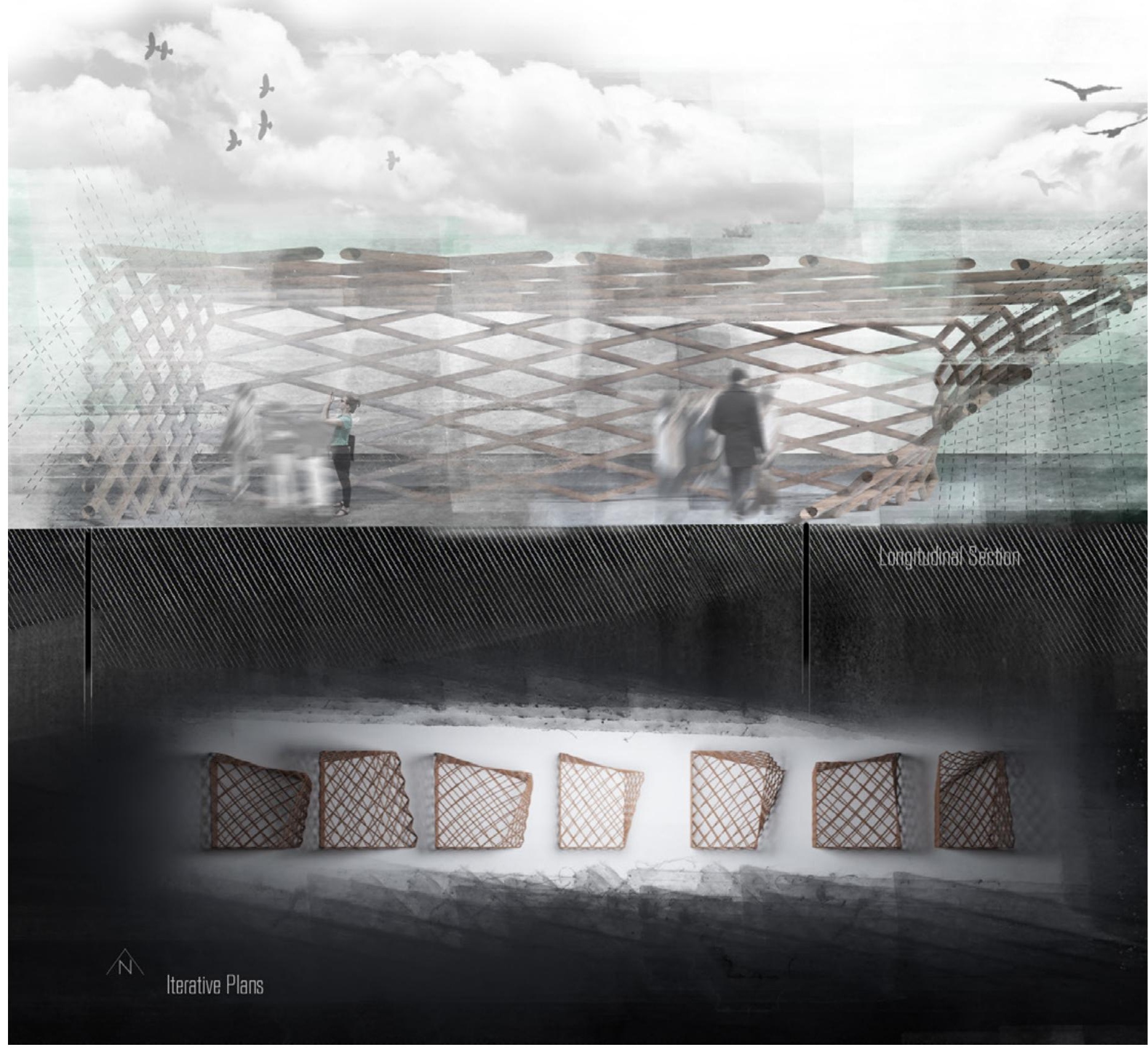

Figure 10.11 The shell's double curvature facades are visually engaging while acoustically functionally. These angles and curves suggest a dispersal of sound and a reduction of the "flutter Effect" 


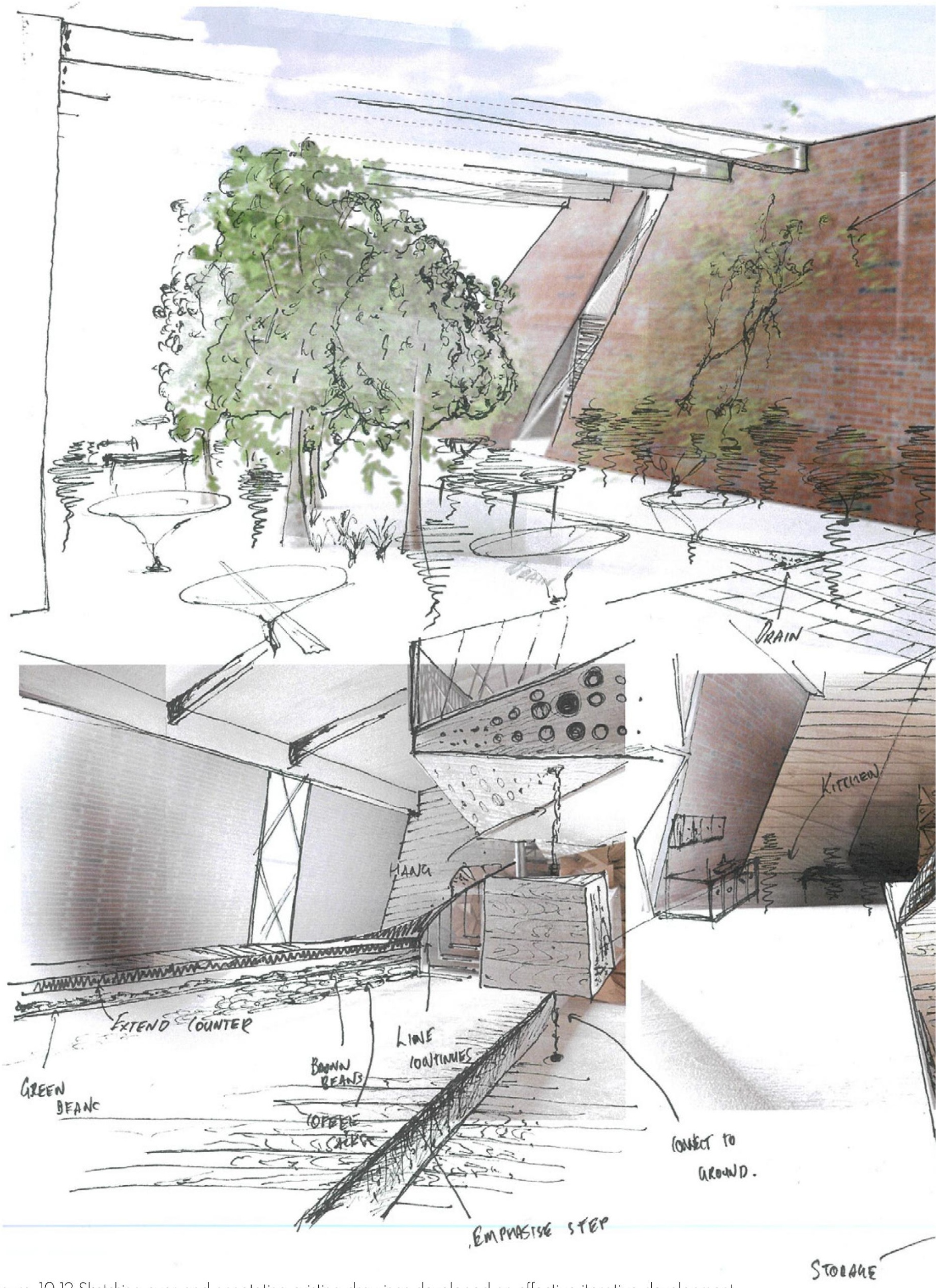

Figure 10.12 Sketching over and annotating existing drawings developed an effective iterative development loop. Materiality was explored and drawings were allowed to interrelate and inform each other 


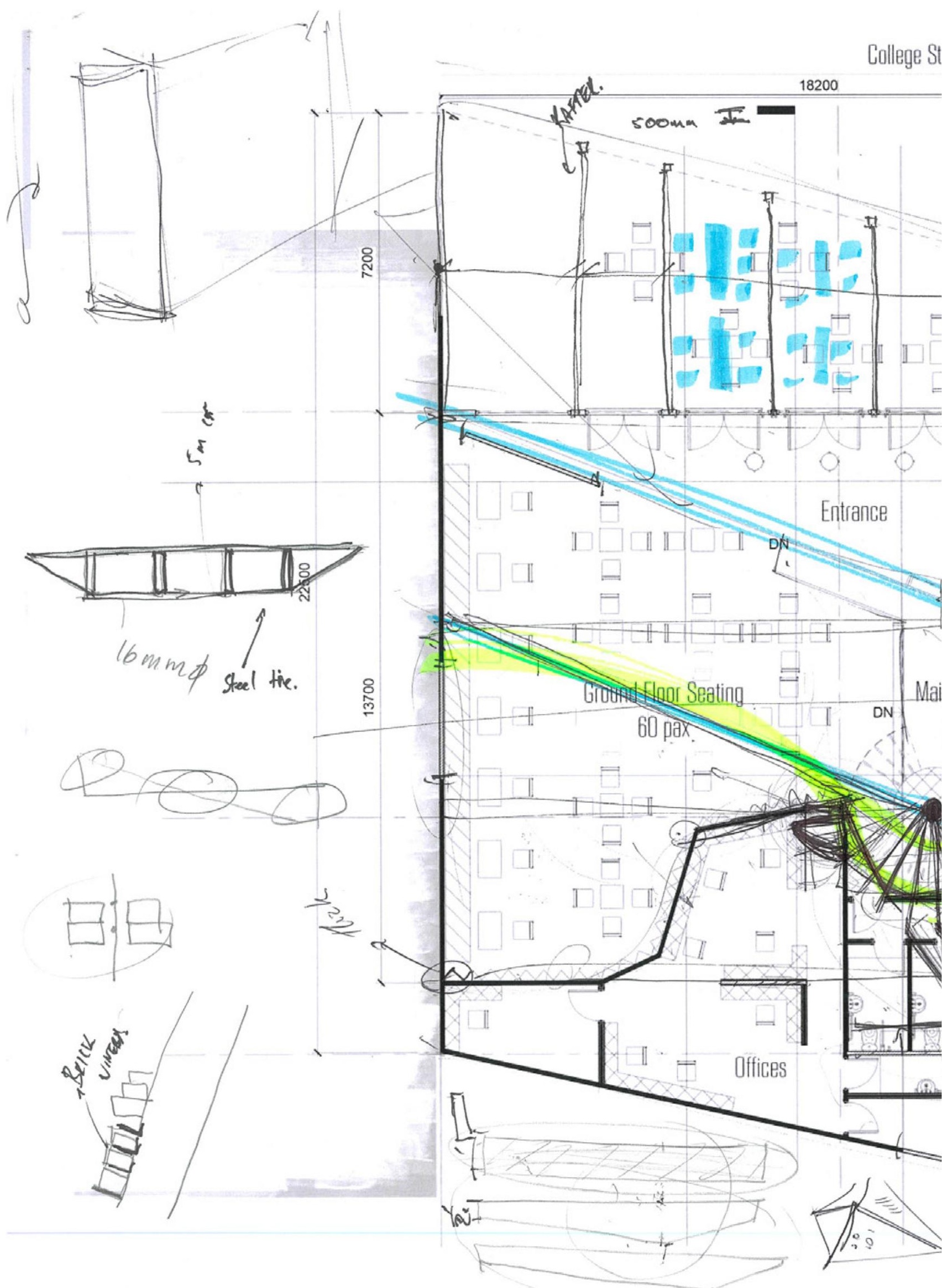

Figure 10.13 The relationship between office staff and patrons also requires further development to balance a sense of transparency with a demarcation between front and back of house. 
Ilege Street

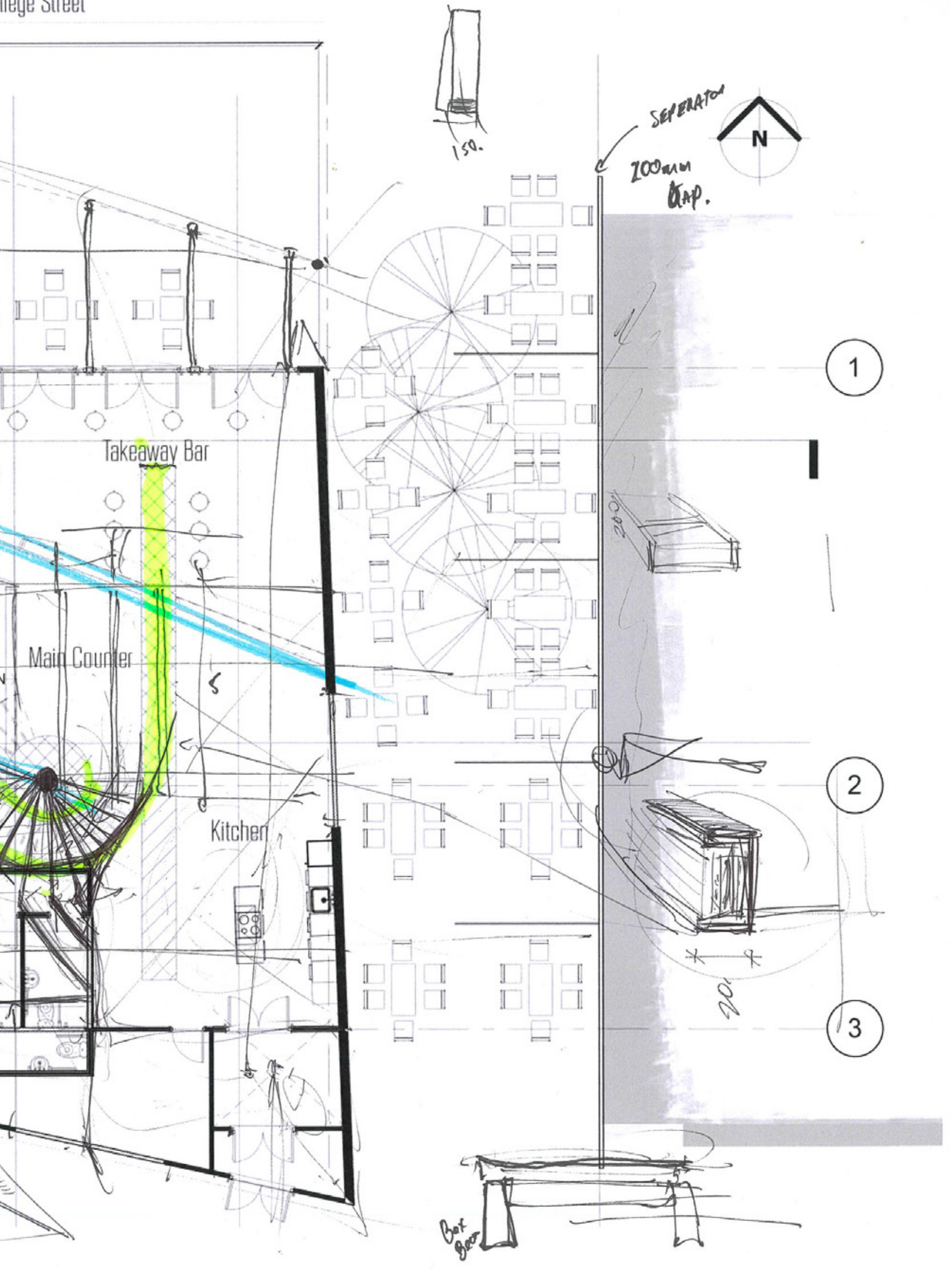




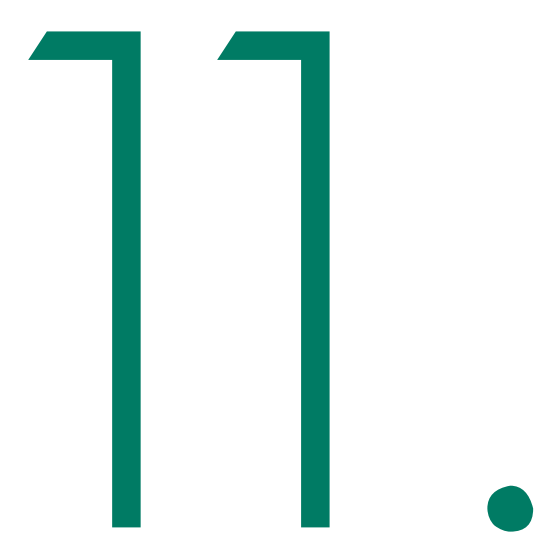

\section{Case Study Project Design \\ - Developed Design}


"We cannot escape the influence of aural architecture because we live inside it"

- Blesser and Salter, 364 
This section discusses several architectural elements that were developed through a concurrent exploration of analogue and parametric optimisation to express acoustic qualities. The selected elements presented below include the: plan, façade, structure, stair and roaster, furniture and interior wall (figure 11.1 and 11.2).

\section{PLAN}

The plan identified several patron occupation zones. These spaces are visually and acoustically different to satisfy different patron groups observed in café testing (figure 11. 1).

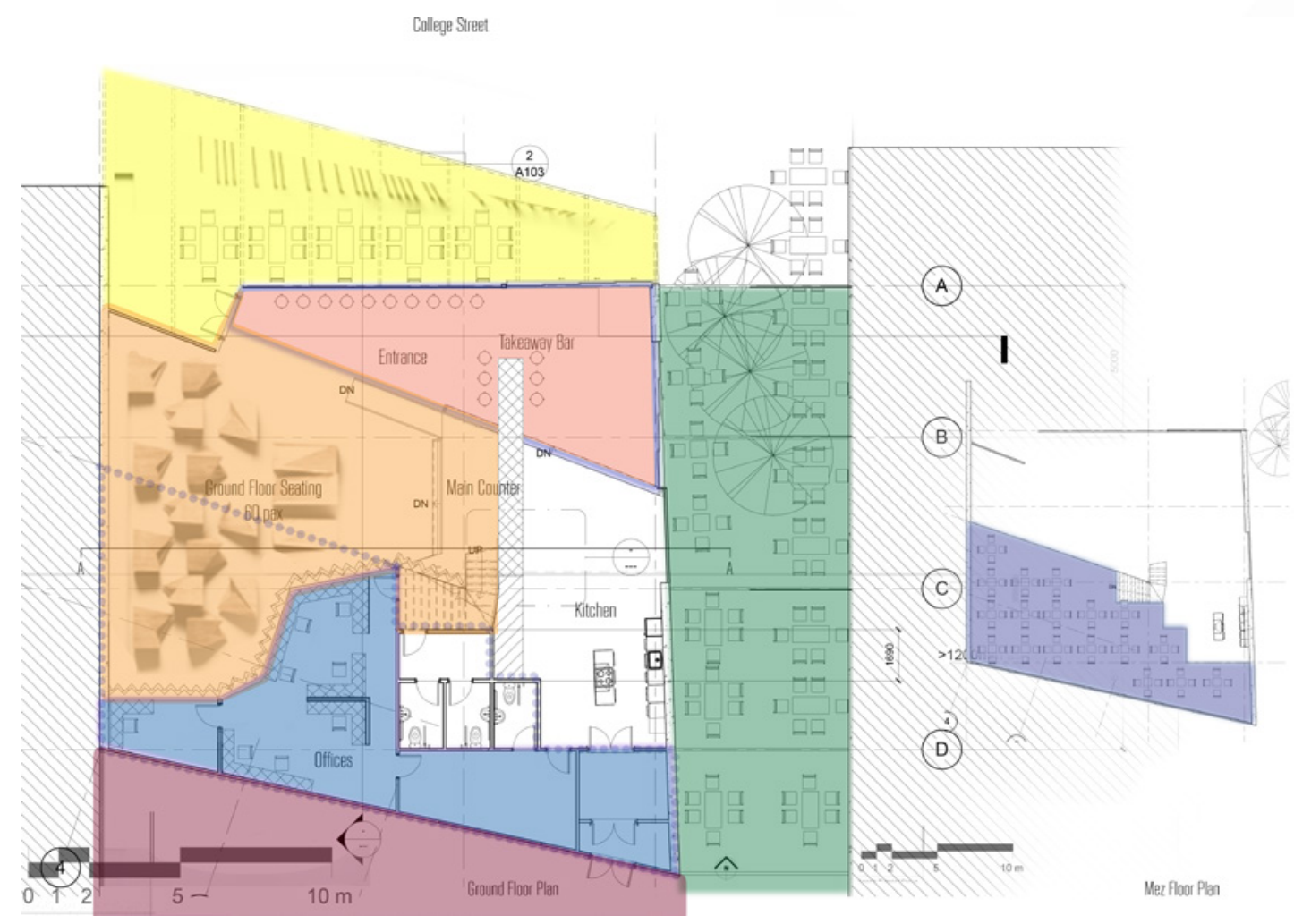




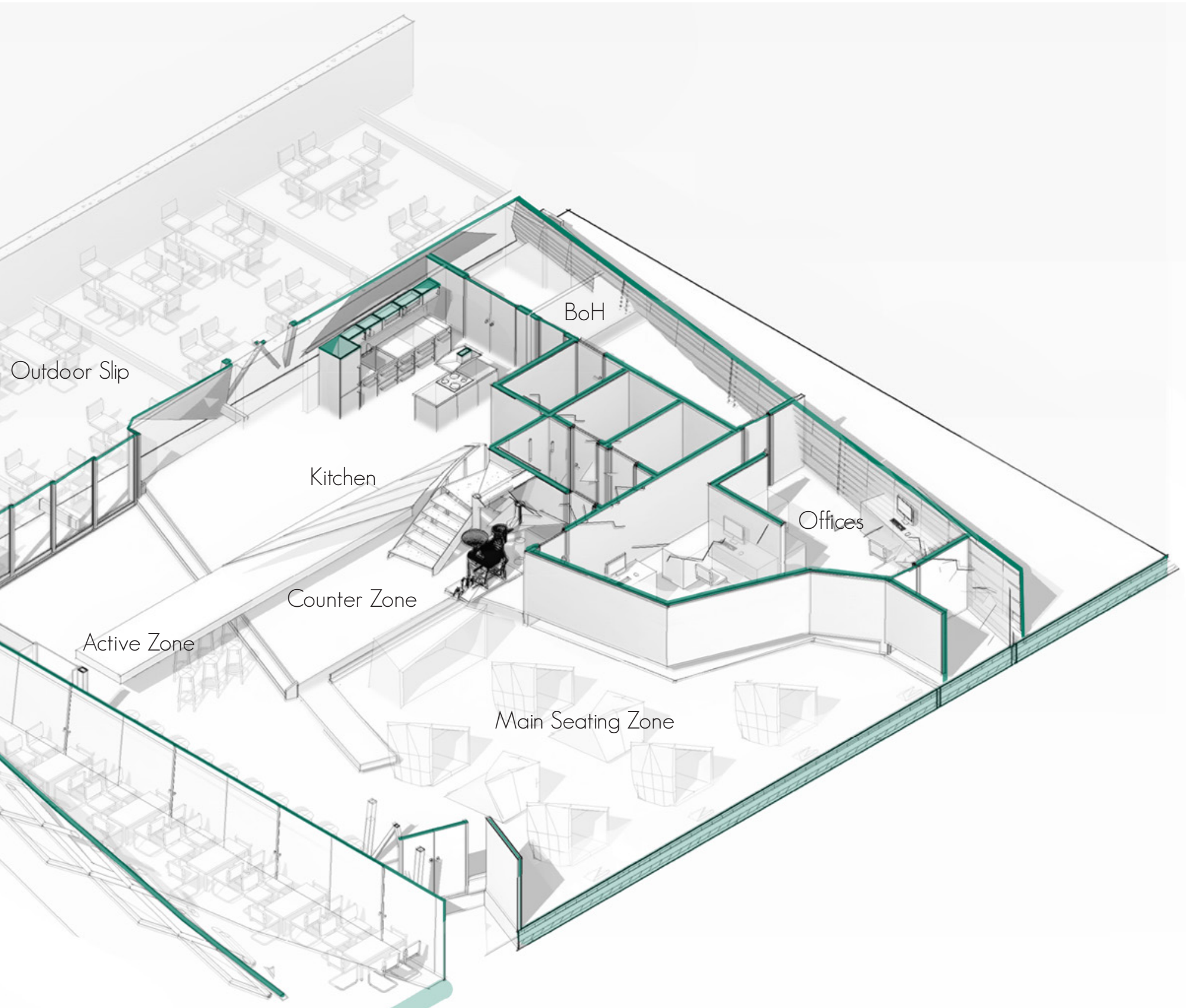

Figure 11.1 The axonometric view and coloured plan illustrate visual and acoustically different zones such as the Indoor/outdoor threshold zone (yellow), the active zone (red), the main cafe space (orange), the mezzanine (purple) and the outside courtyard (green), offices (blue) and the drop off zone (red-purple) 


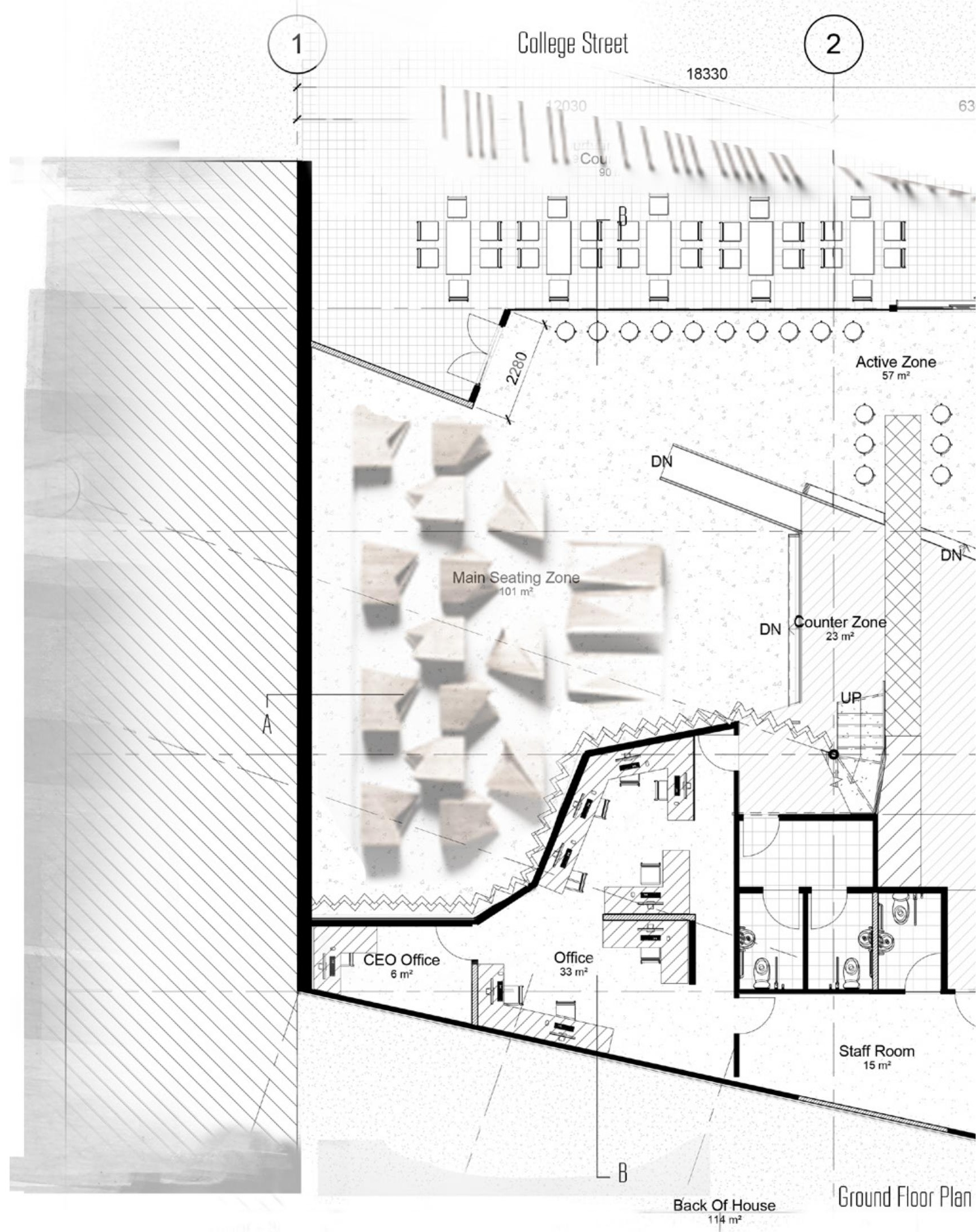

Figure 11.2 Ground floor Plan 
3

ᄉ

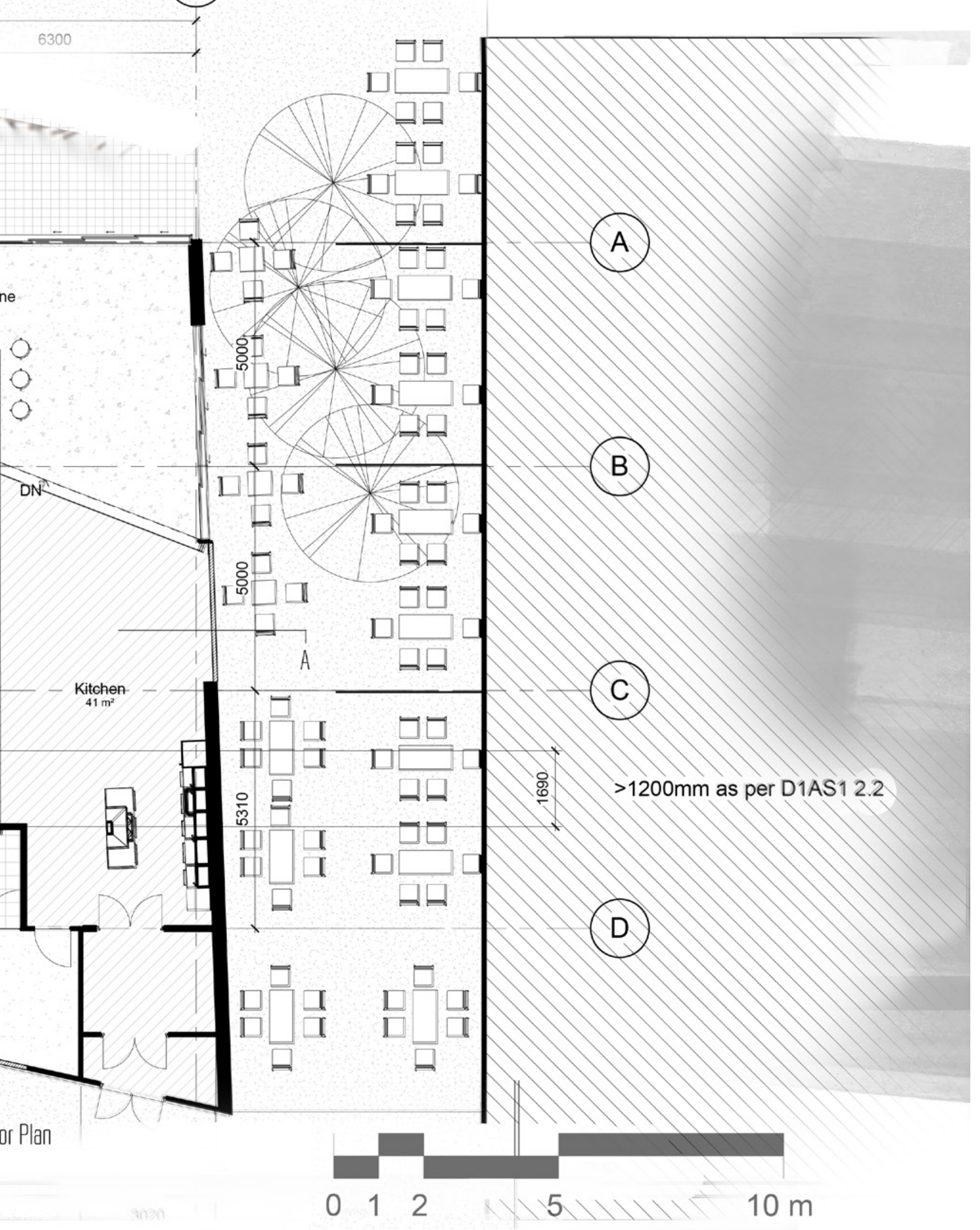


College Street

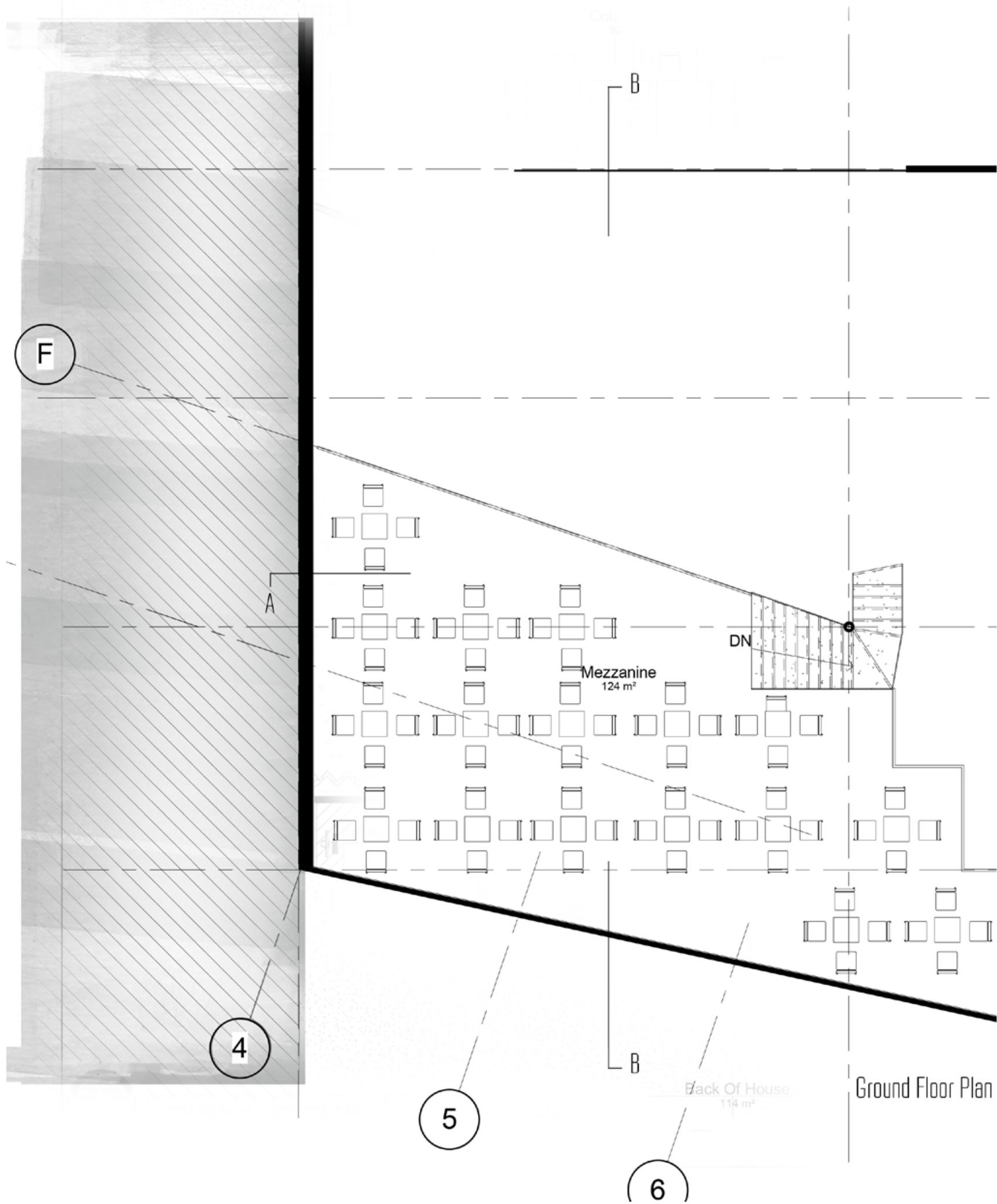

Figure 11.3 Mezzanine floor Plan 
N

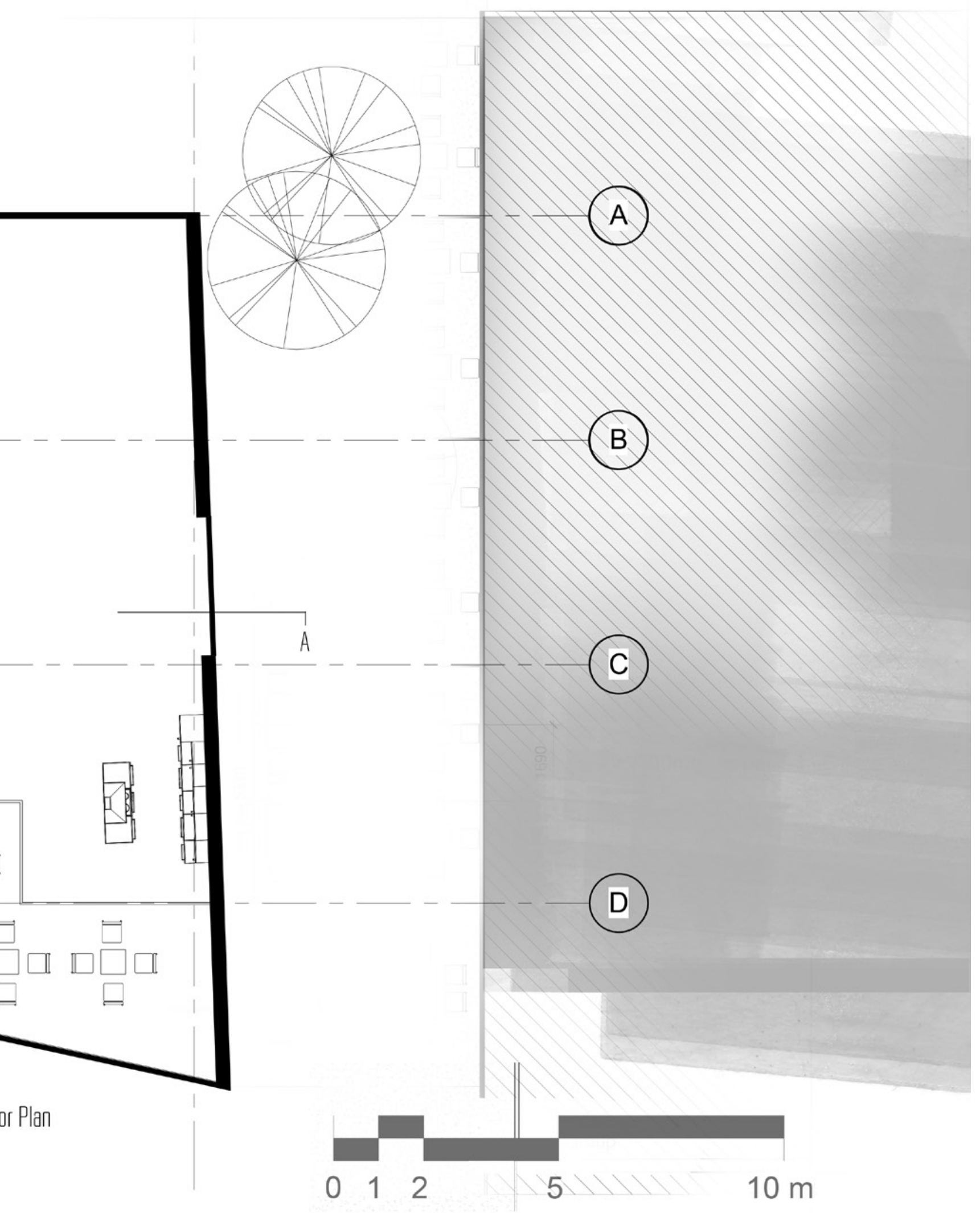




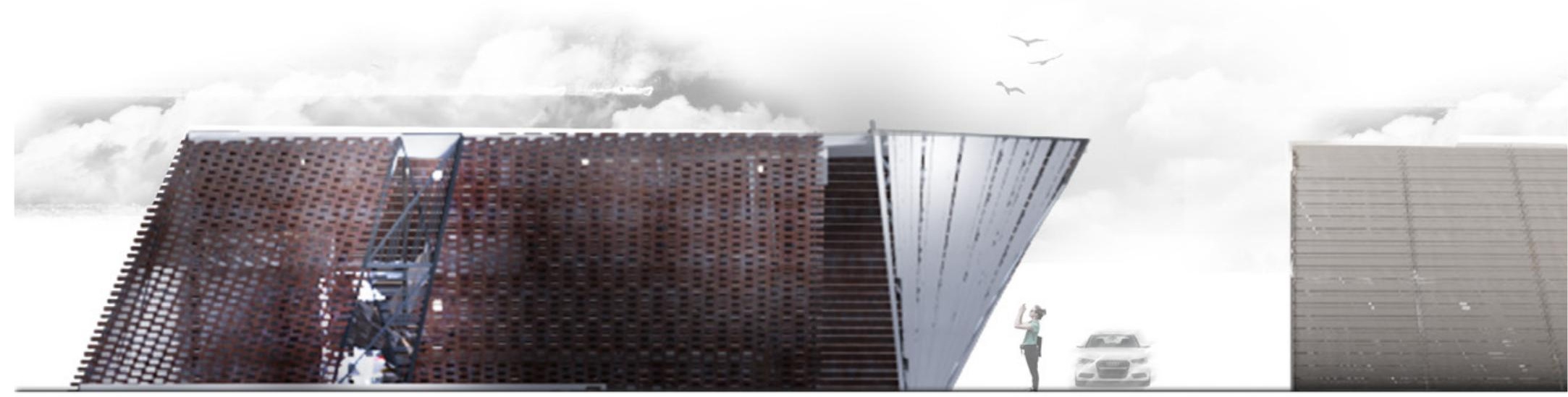

East Elevation

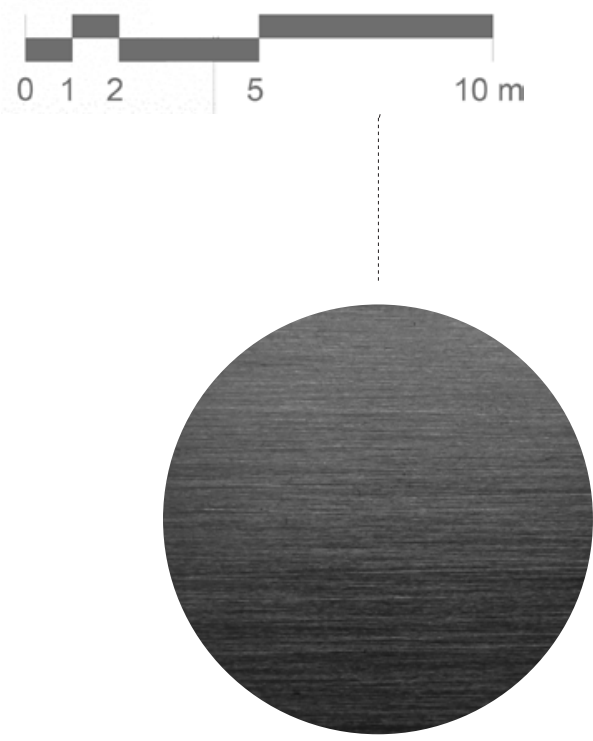

Brushed Black Steel

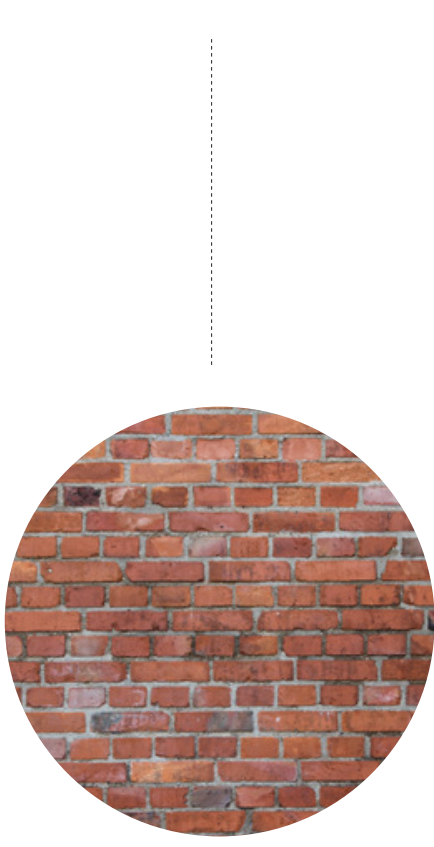

Original Bricks from

Existing building
South Elevation

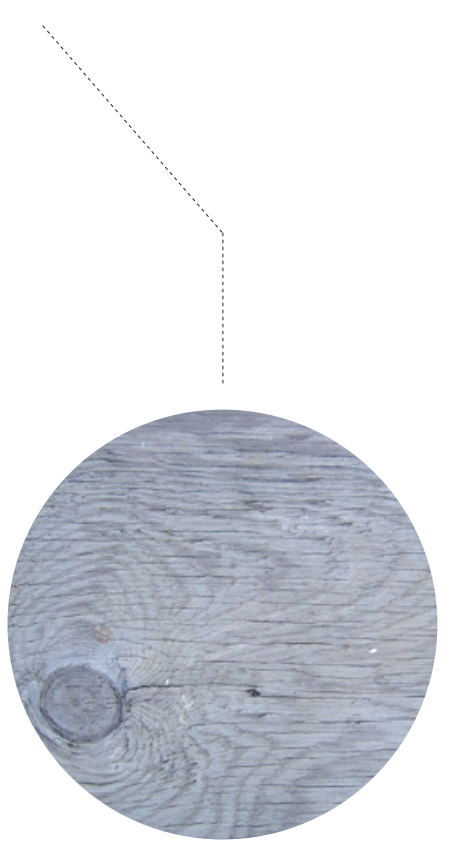

Silvered Ply

Figure 11.4 Building Elevations 


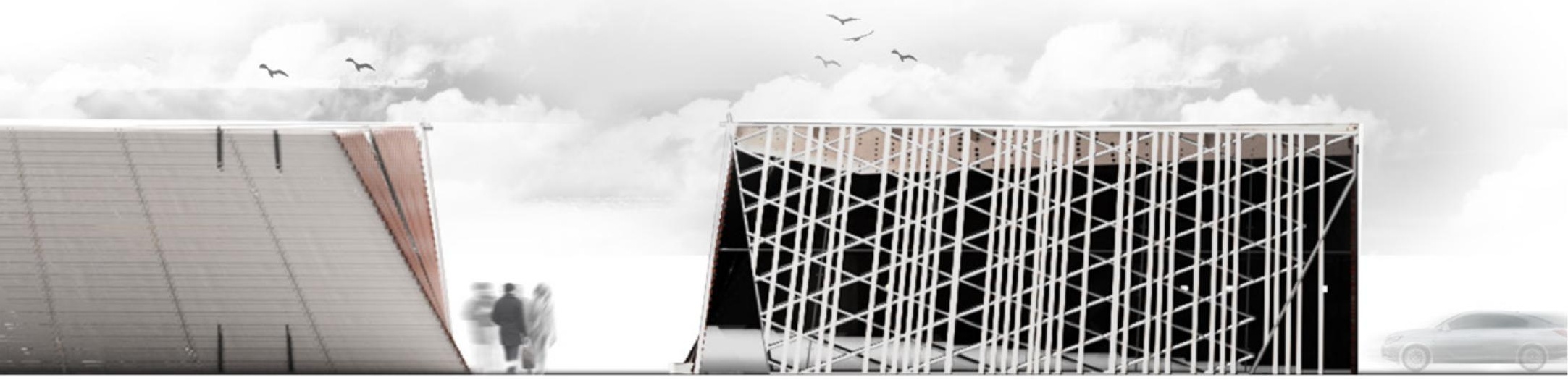


(3)

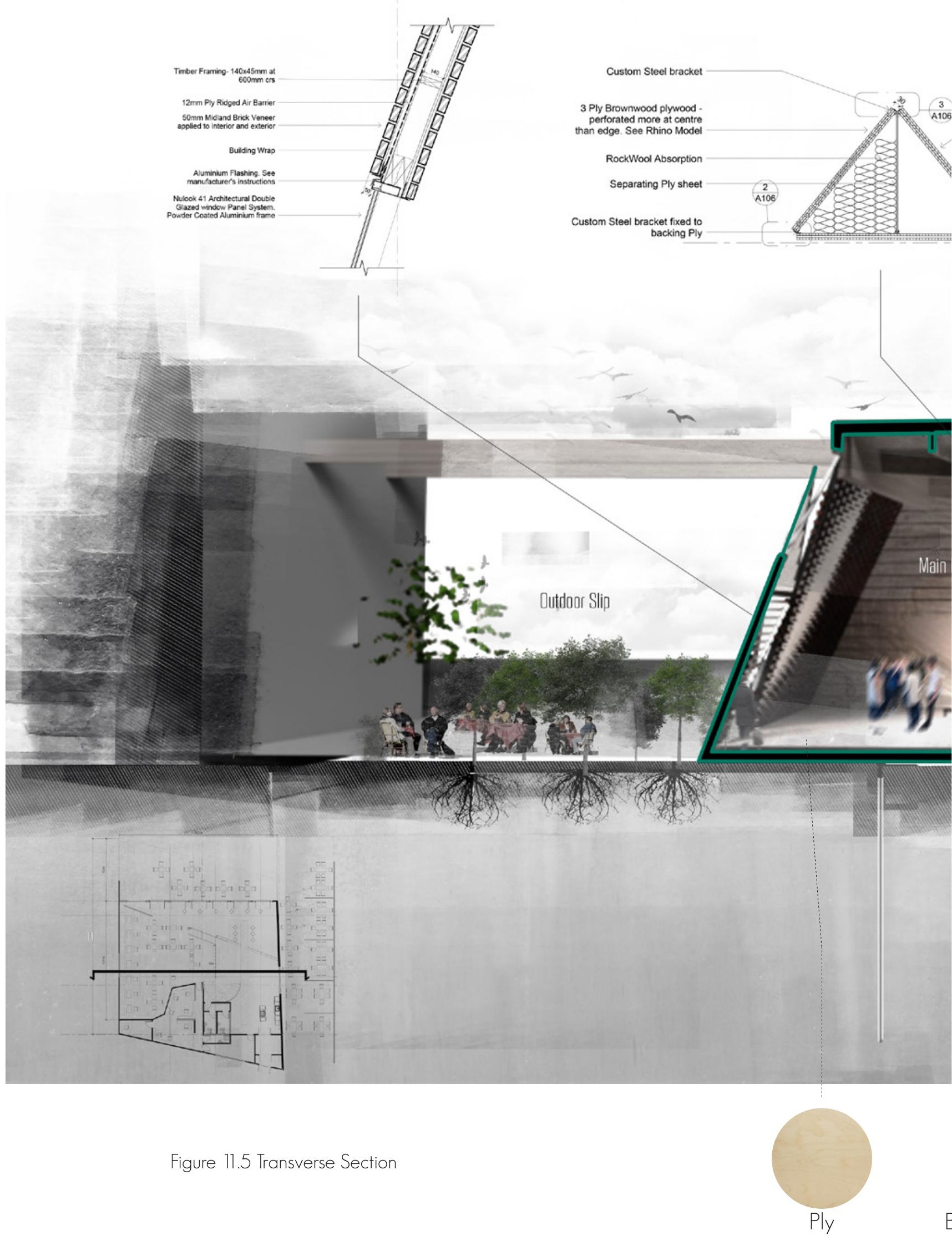


(c)
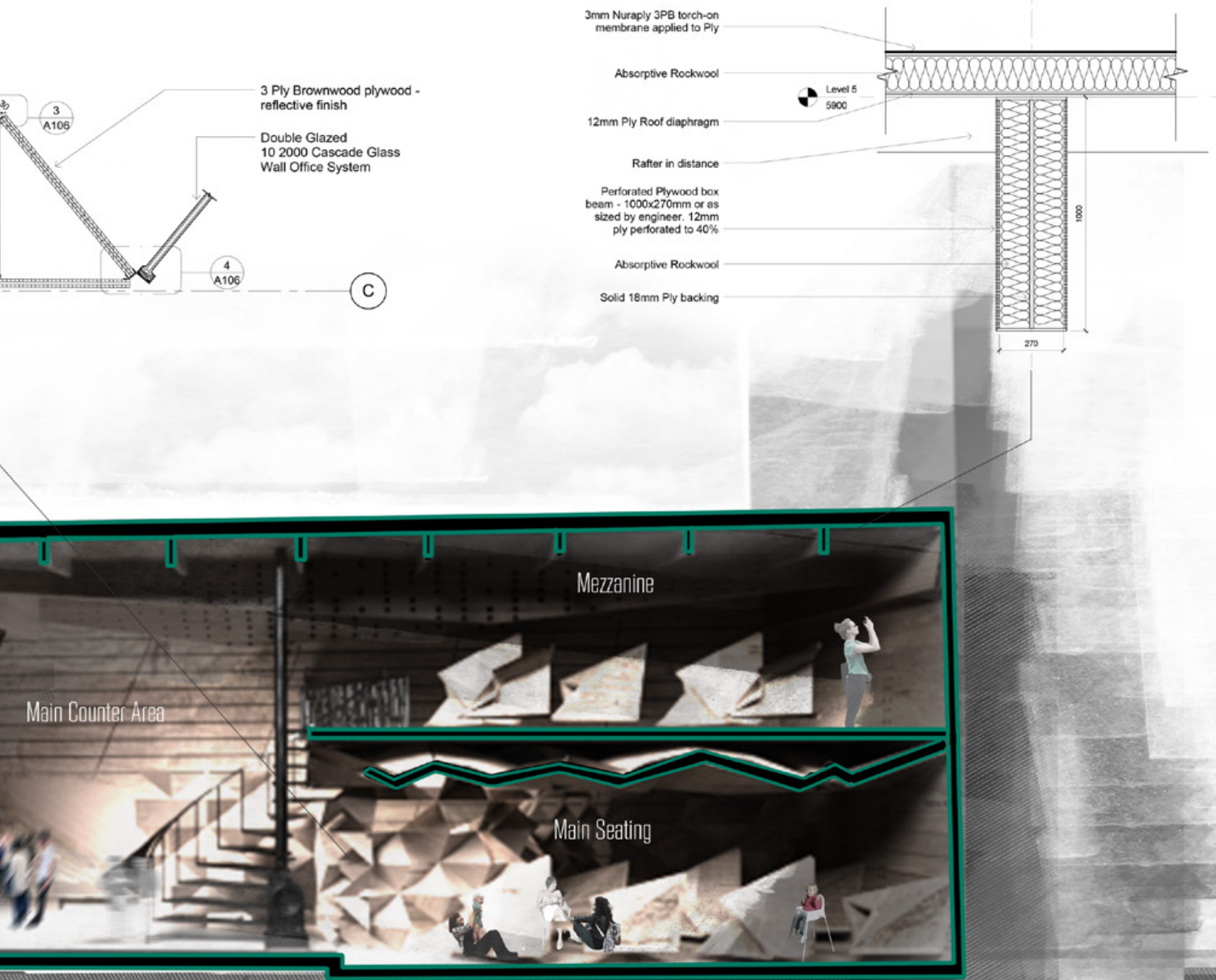

Section AA

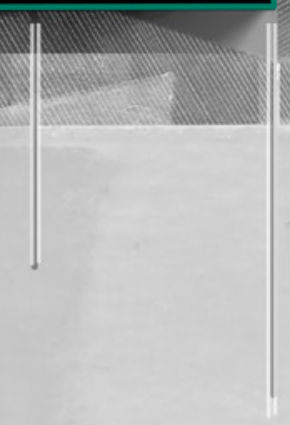

.

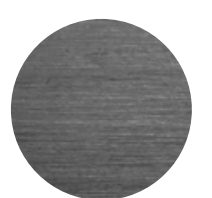

Polished Concrete

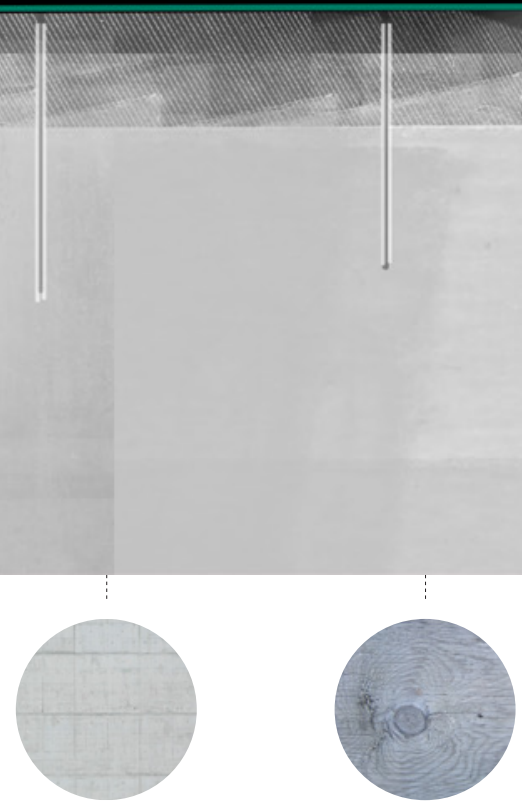

Silvered Ply 


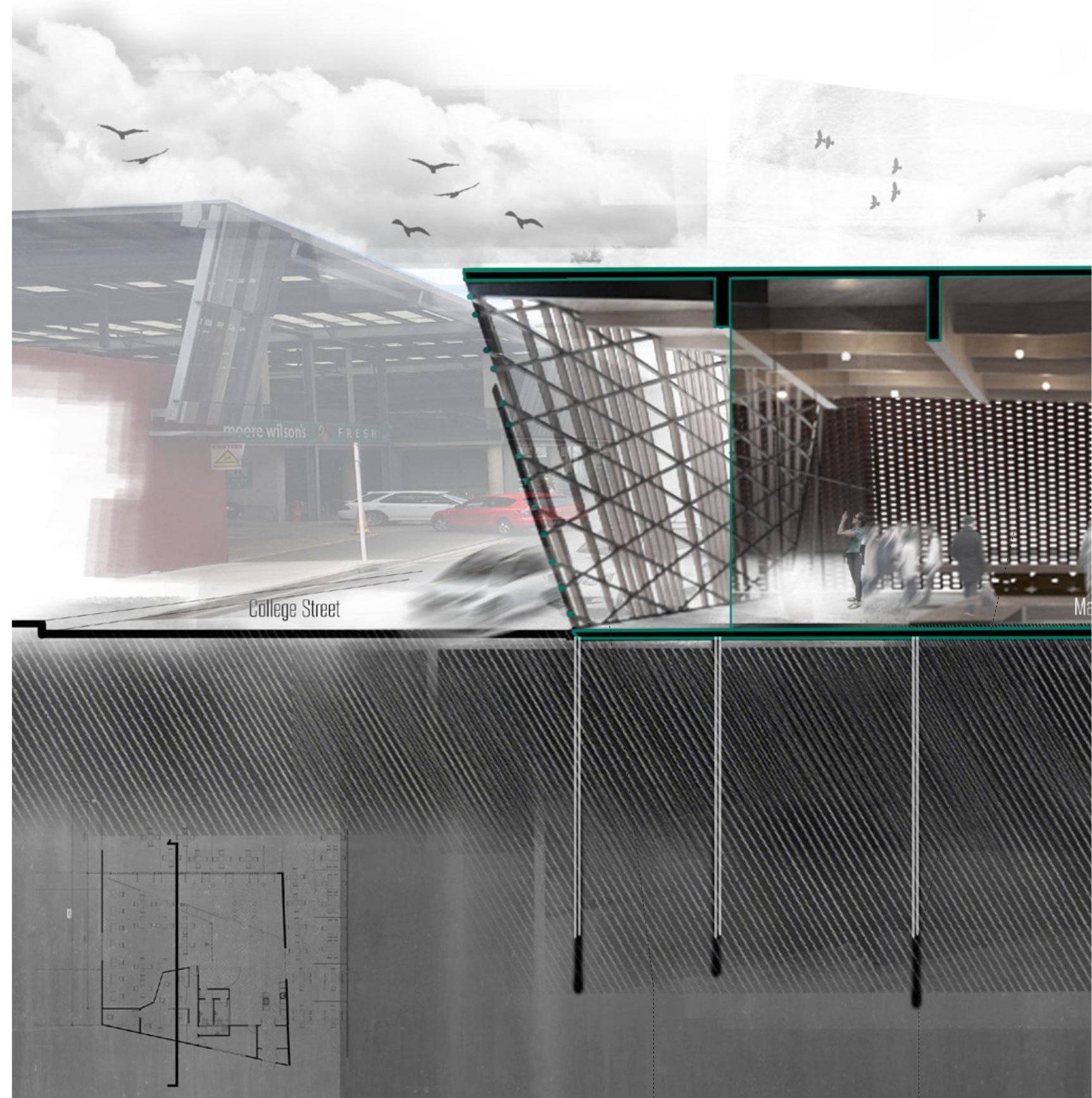

Figure 11.6 Longitudinal Section
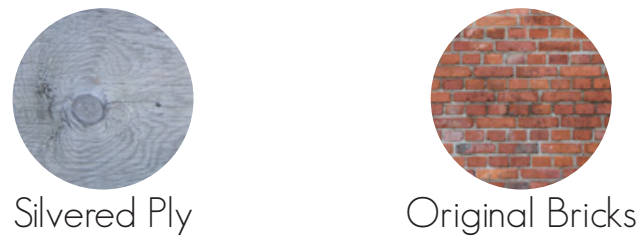

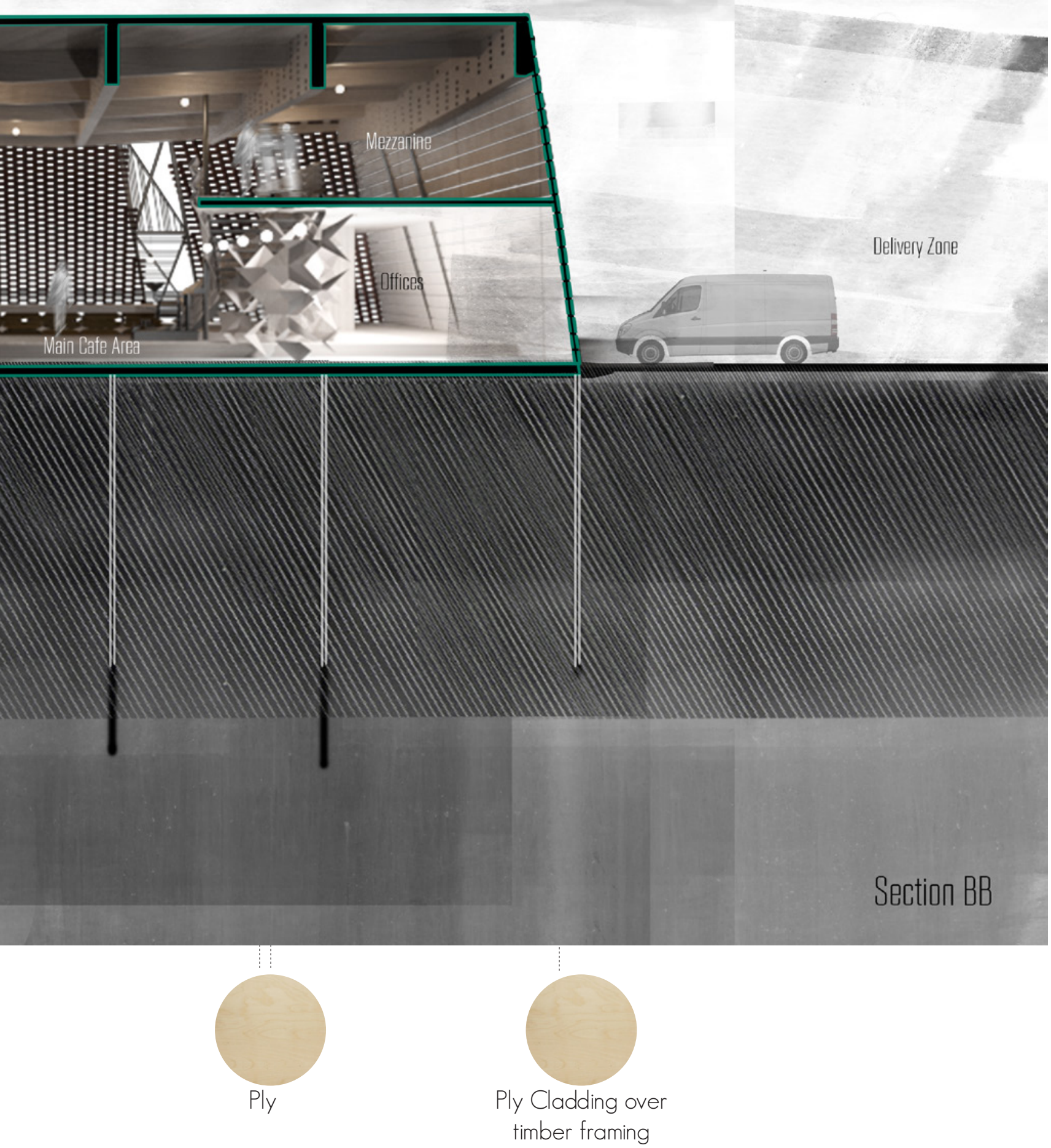


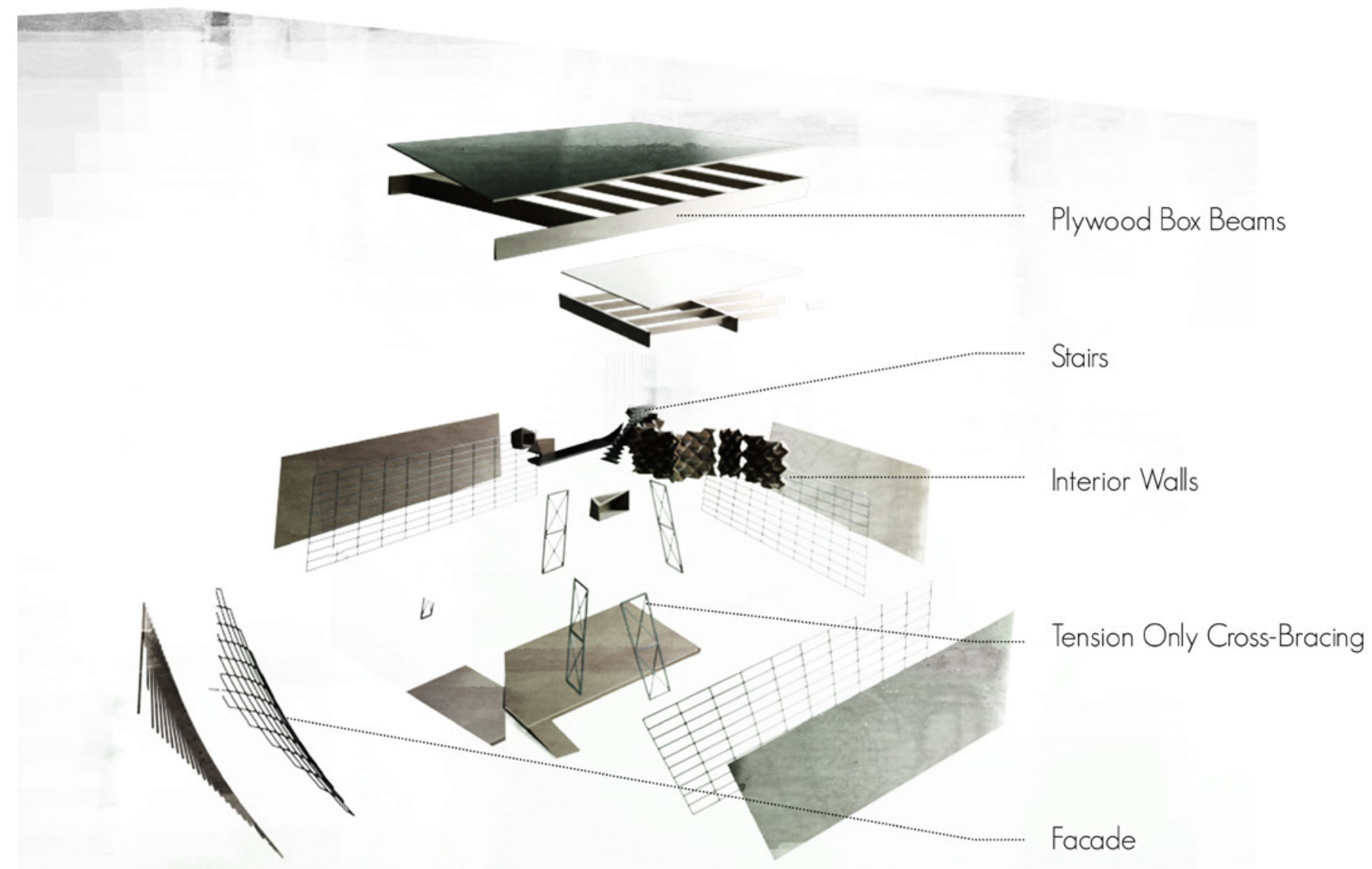

Figure 11.7 An exploded perspective indicating some of the important elements that were optimised parametrically in this case study project 
FAÇADE FORMATION

The façade was identified as a device to promote foot-traffic into the café. A double height inclined façade was designed to cantilever over the footpath and engage the pedestrians approaching from Tory Street (figure 11.8). The rhythm façade's slats was optimised to reflect the greatest SPL back to the road (figure 11.8 and 11.9).

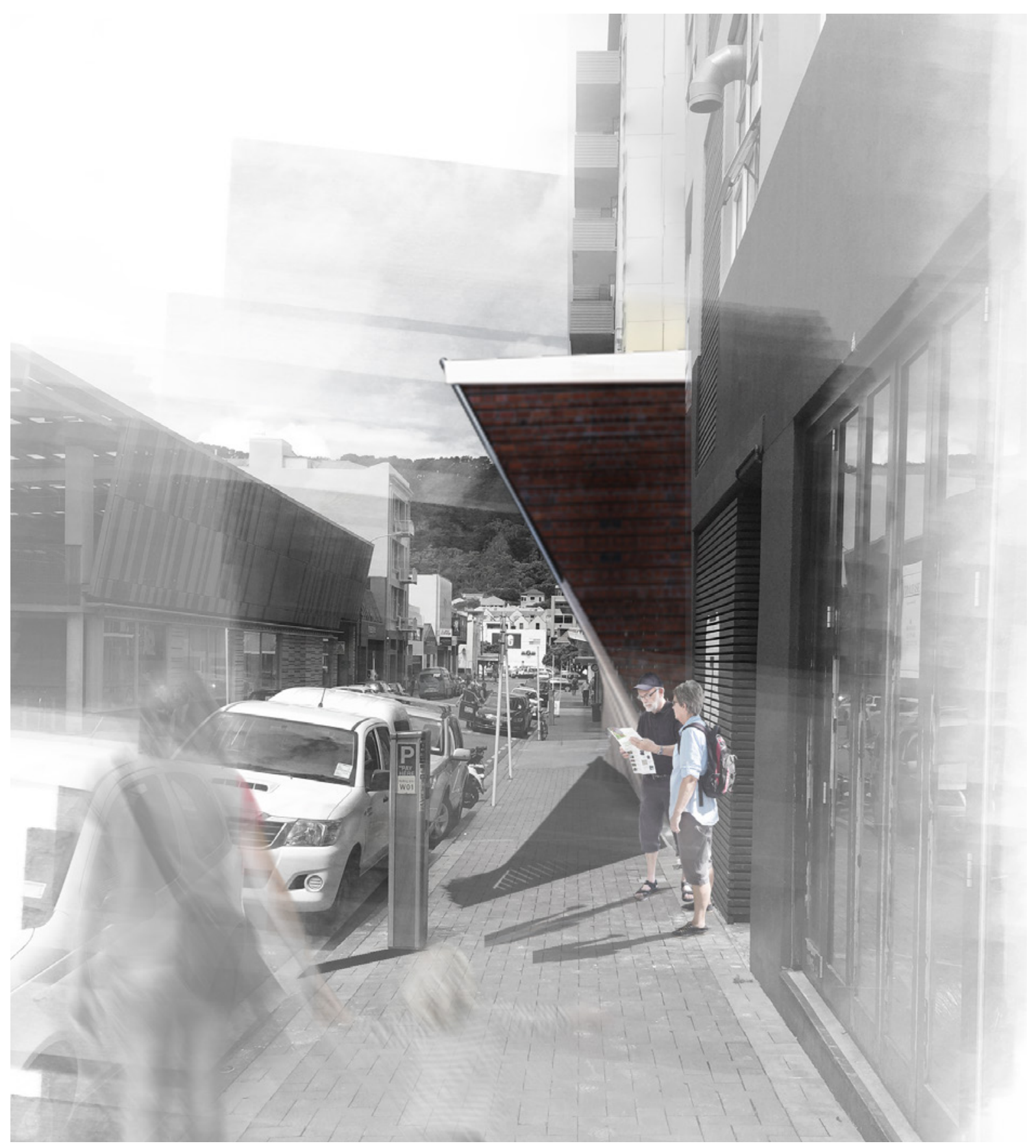

Figure 11.8 Cantilevered façade overhanging the College Street footpath 

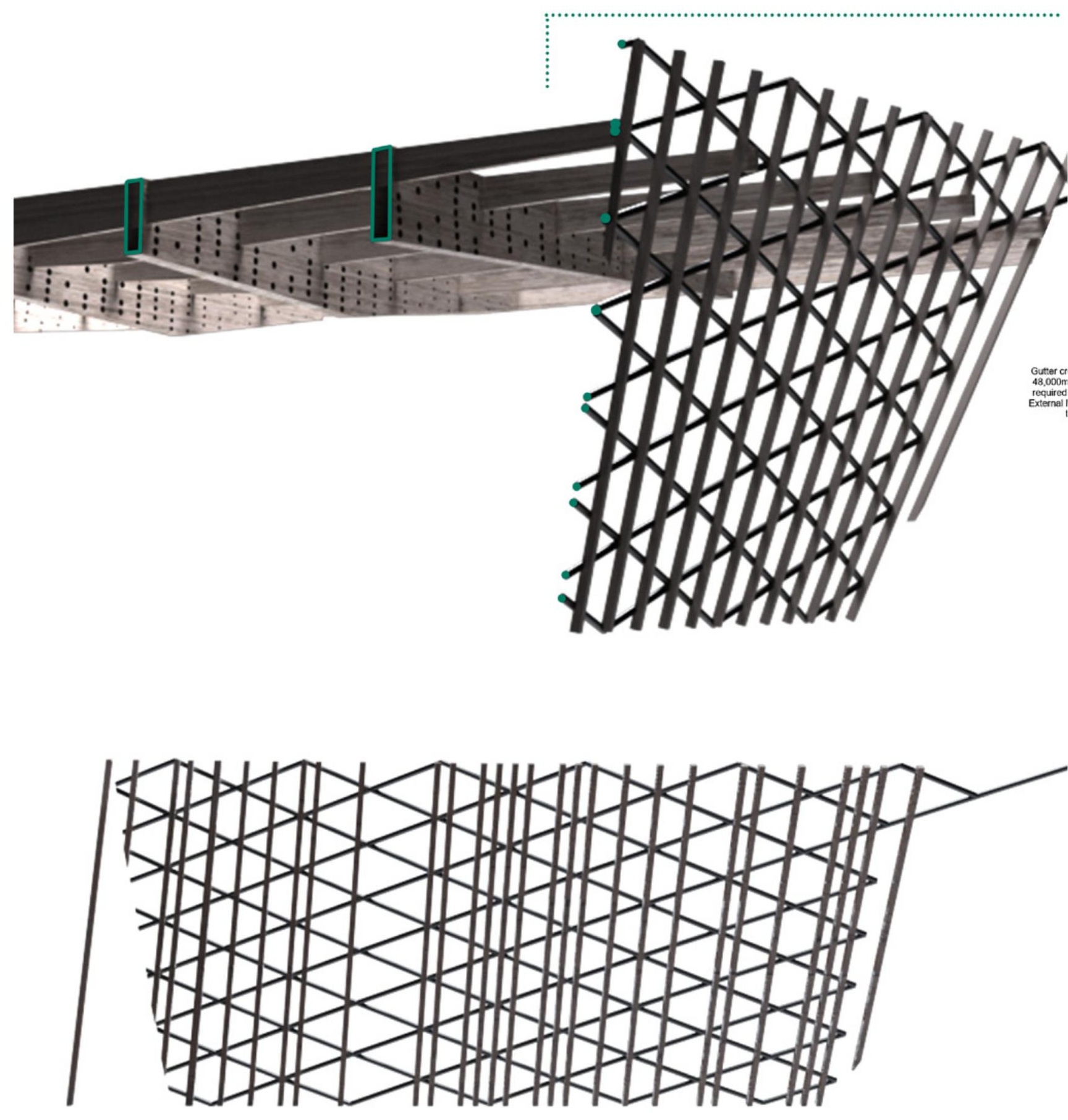

Figure 11.9 The façade created texture from the flat facades of the surrounding buildings. The elegant lines of the façade were designed to provide visual interest, but also to create a transition space between interior and exterior where patrons can enioy the comforts of being outside without the direct proximity to the road. A threshold was created through black stained plywood slats fixed to a black steel lattice. These two elements provided visual interest and texture to the design, while informing partial privacy and still maintaining an active street front. This example illustrates how an analogue design idea could be optimised through parametric simulation and design 


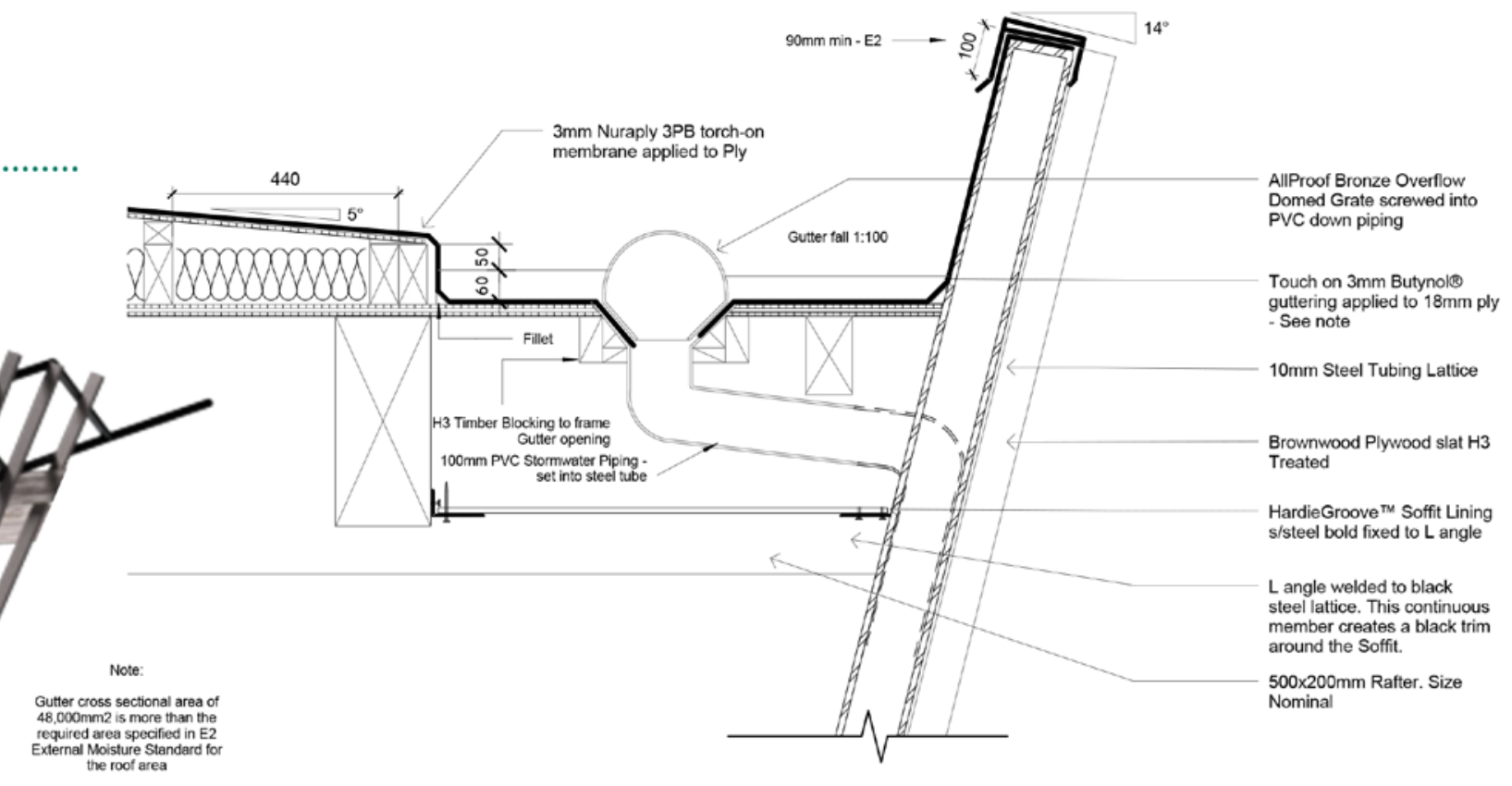

CHANGE

Width

Depth

Centres

Cut Pattern

FIND

Greatest SPL on Road 


\section{STRUCTURE}

The structural elements of the design considered gravitational and lateral loading. Each of these structural elements also contributed to optimising the acoustic environment.

\section{GRAVITATIONAL}

Plywood box beams carry the gravitational loading from the mezzanine floor and roof to the exterior and interior walls (figure 11.10).
Plywood box beams were sized to span the full width of the café, enabling a column-free space. A column-free space was important as it promotes a flexible café arrangement, enabling the ability to adapt over time or around special occasions such as performances. To span the full large width, the beam depth was 1 metre and so became a major design element. This necessary depth was seen as a design opportunity to optimise the beams acoustically as perforated absorbers.
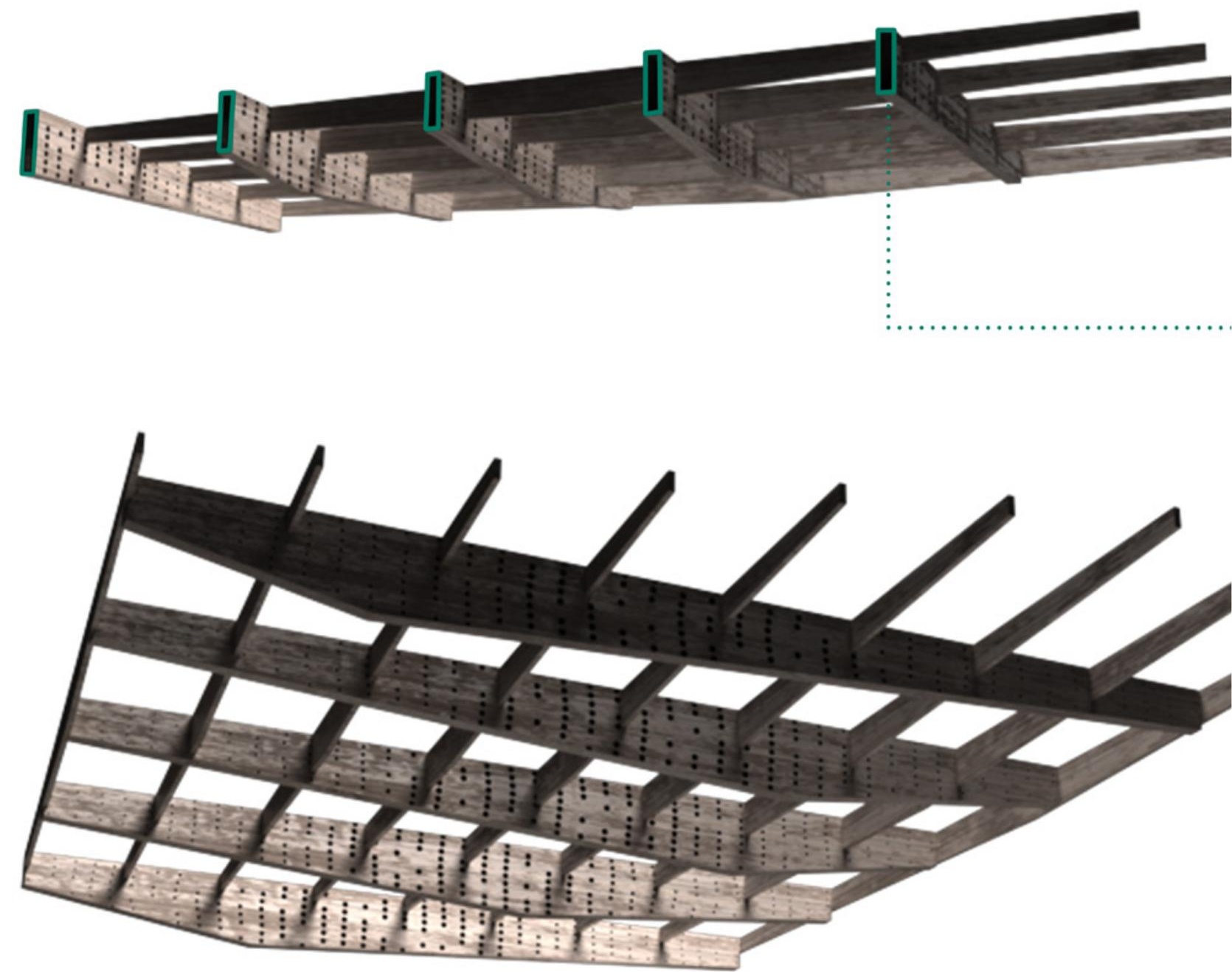

Figure 11. 10 The Plywood box beams were perforated to form perforated absorbers (figure 11.6). When a sheet material is perforated it becomes acoustically transparent. The cavities are filled with absorptive rockwool to absorb sound. The beams are specified as a $18 \mathrm{~mm}$ ply box with an additional two $18 \mathrm{~mm}$ sheets in the centre to divide the cavity in two halves. The profiles of these beams are tapered to the edges to produce a sleek aesthetic. The profile of the beams are not rectangular, instead increasing to a maximum depth of one metre near the centre of the span. The location of the deepest point of the beam varies between the beams, positioned above a sound

generating area of the cafe that requires the highest level of absorption. This example of acoustic incorporation

into design addresses the architectural acoustic design idea. 

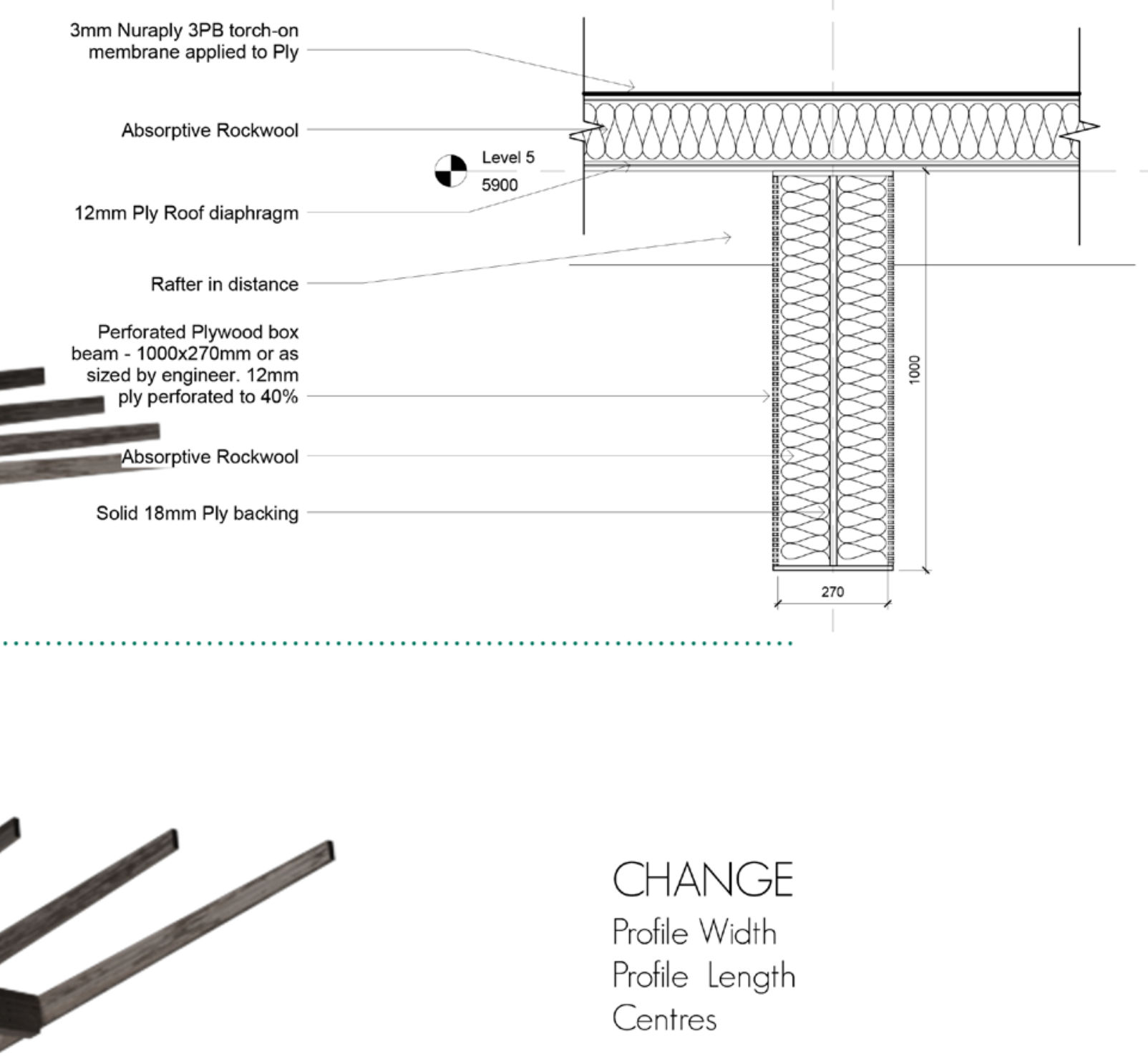

CHANGE

Profile Width

Profile Length

Centres

KEEP

Perforation size increases as distance to Centre decreases to ensure structural integerity

FIND

$0.6 \sec \mathrm{T} 2 \mathrm{O}$ 
An algorithm was written to find outcomes that reduce the maximum perforation radius closer to the end. The perforations are larger in the centre and smaller at the edges of the beam to respond to the larger shear forces at the end of the beams. The change in perforation size also alters the frequency that the beam best absorbs sound, creating a broadband absorber.

\section{LATERAL LOADING}

Lateral Loading was considered through implementation of tension-only cross braced frames. The east and west walls are easy to design because they are large solid walls and so have better design flexibility. The north façade was difficult as maintaining an open and transparent space was desired Design iterations of shear walls, moment frames and tension-only cross bracing were created and tested. The immediate choice for this requirement was a moment frame system, and they were considered in the Resist model below (Figure 11. 13).

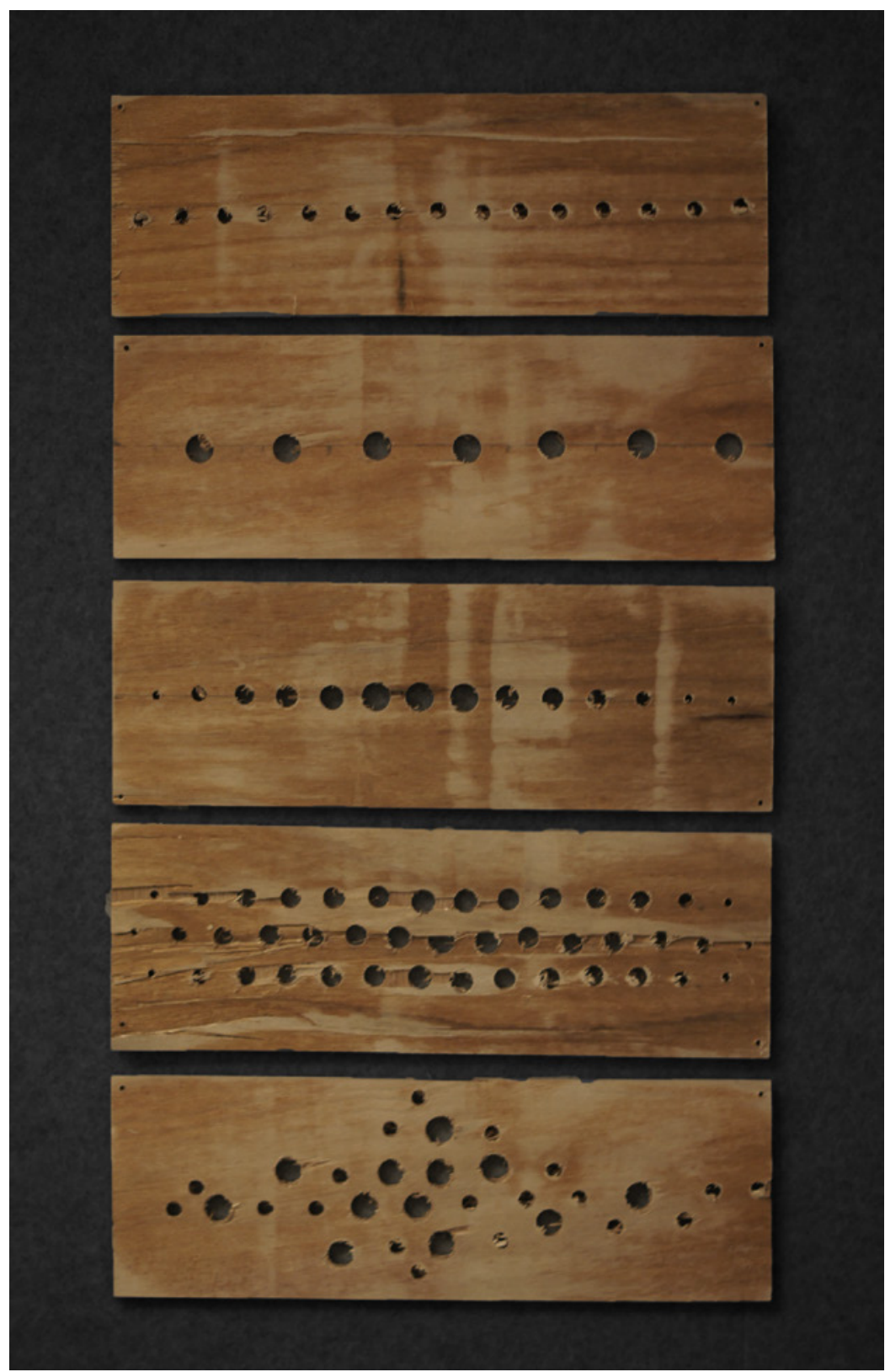

Figure 11.12 An early exploration of possible way to perforate the ply wood panels. These test panels were perforated at different centres and sizes to examine the different aesthetic and acoustic outcomes. 


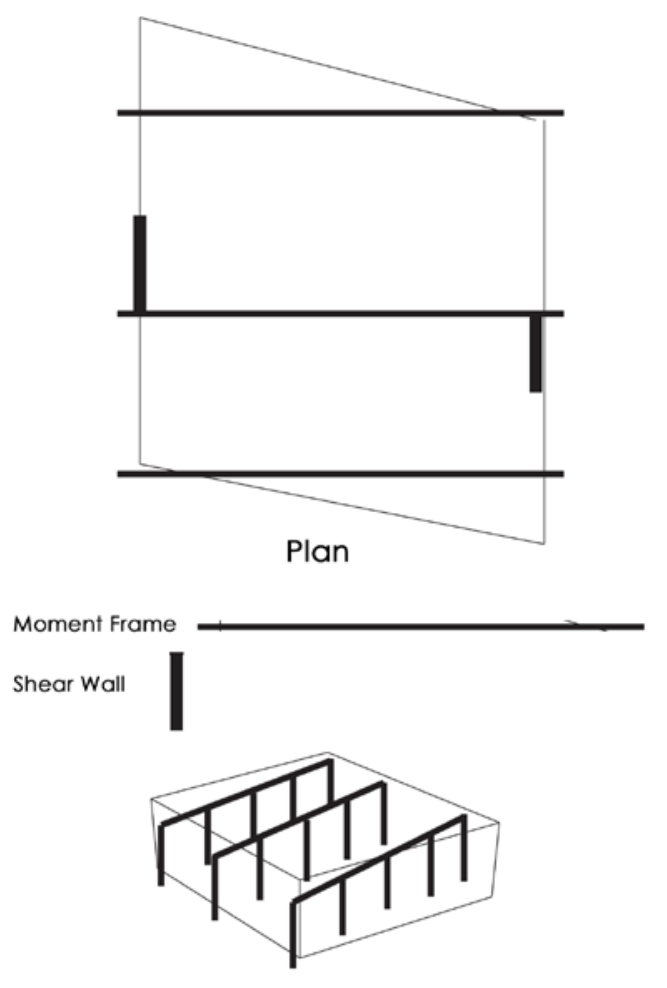

$X$ Direction Moment Frames
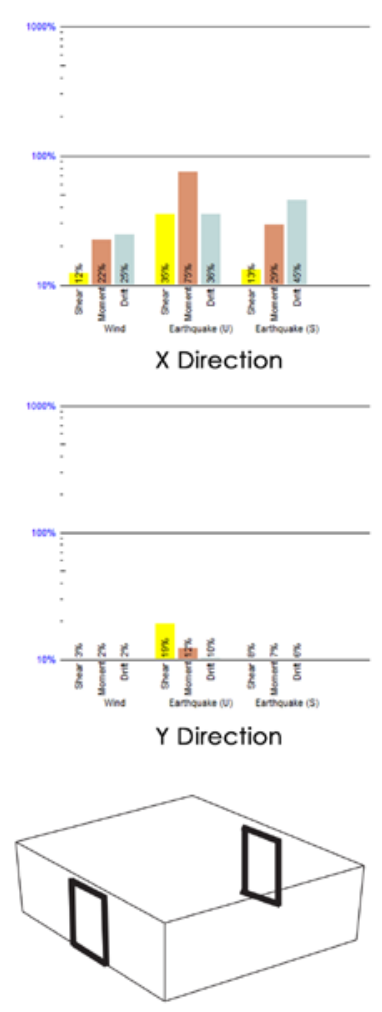

Y Direction Shear Walls

Figure 11.13 To resist lateral loading in the $x$ direction, four bays of Moment frames were suggested by RESIST. These columns divided the space, limiting the flexibility of the interior programme (Charleson). 
Lightweight cross-braced frames were also explored (figure 11.14 and 11.15). The frames were located to mimic the lines of the façade, allowing for flexibility in plan arrangements.
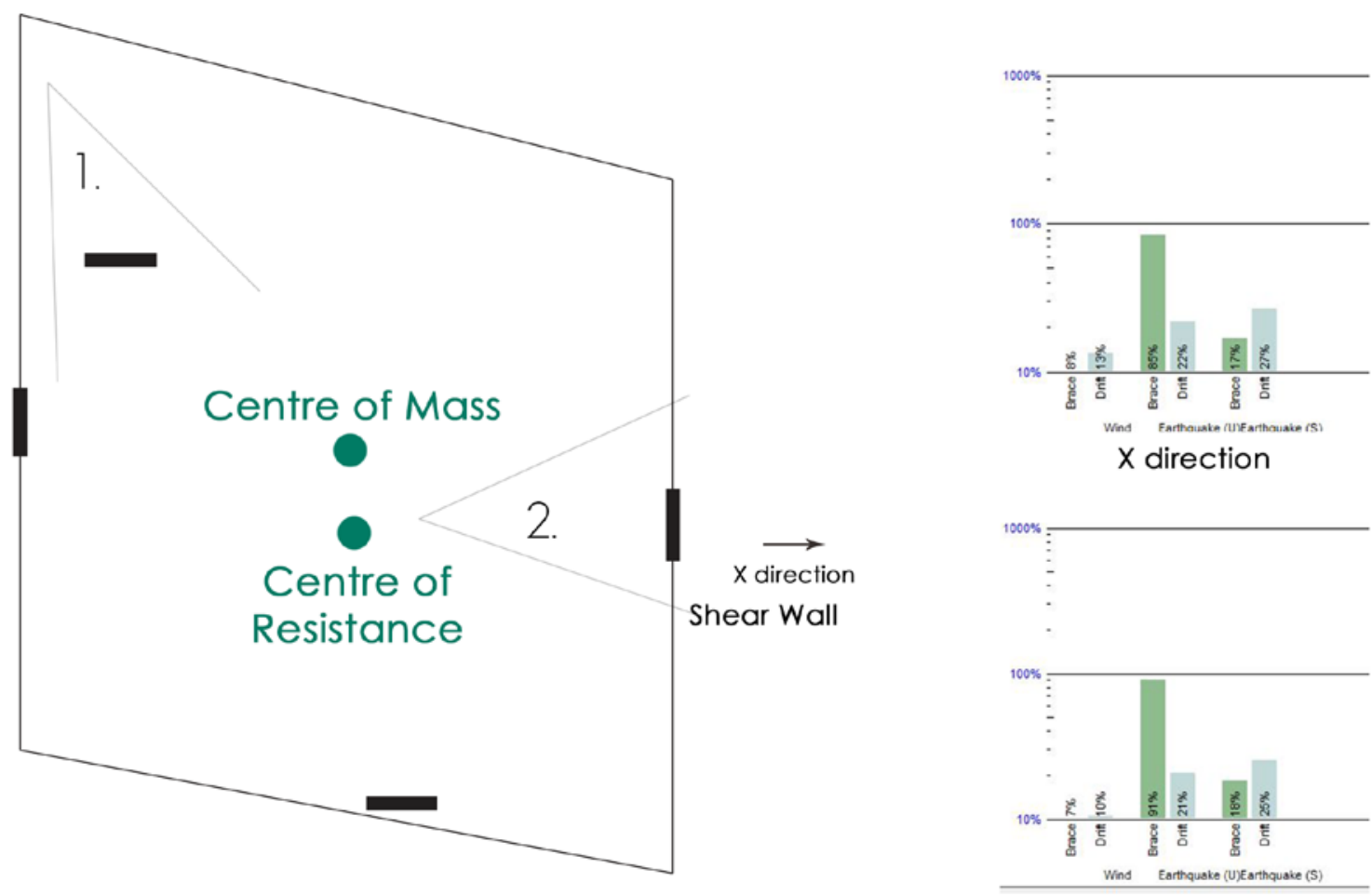

Y direction

\section{Cross Braced Frames}

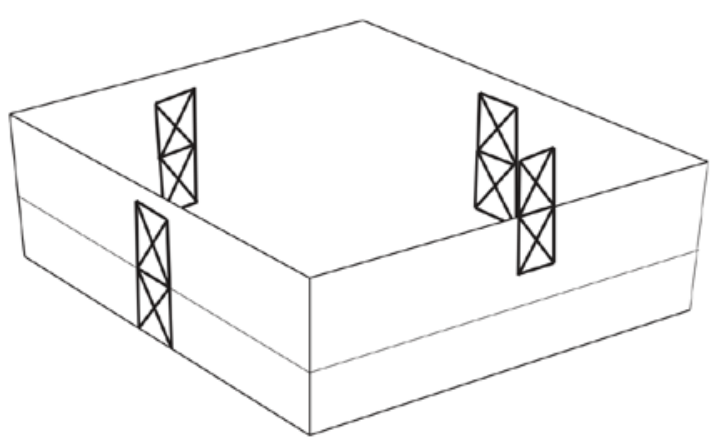

Figure 11. 14 Two frames were required in the $x$ direction, with $2.0 \mathrm{~m}$ bay lengths and $0.1 \mathrm{~m}$ brace size. These structural systems were considered early within the developed design stage to allow them to contribute towards an acoustically-driven outcome. Their even distribution avoids torsional issues as the design is balanced and so the centre of resistance is near the centre of mass. This proximity reduces the eccentricity and therefore the amount of 102 turning forces experienced by the building under lateral loading. (Charleson) 

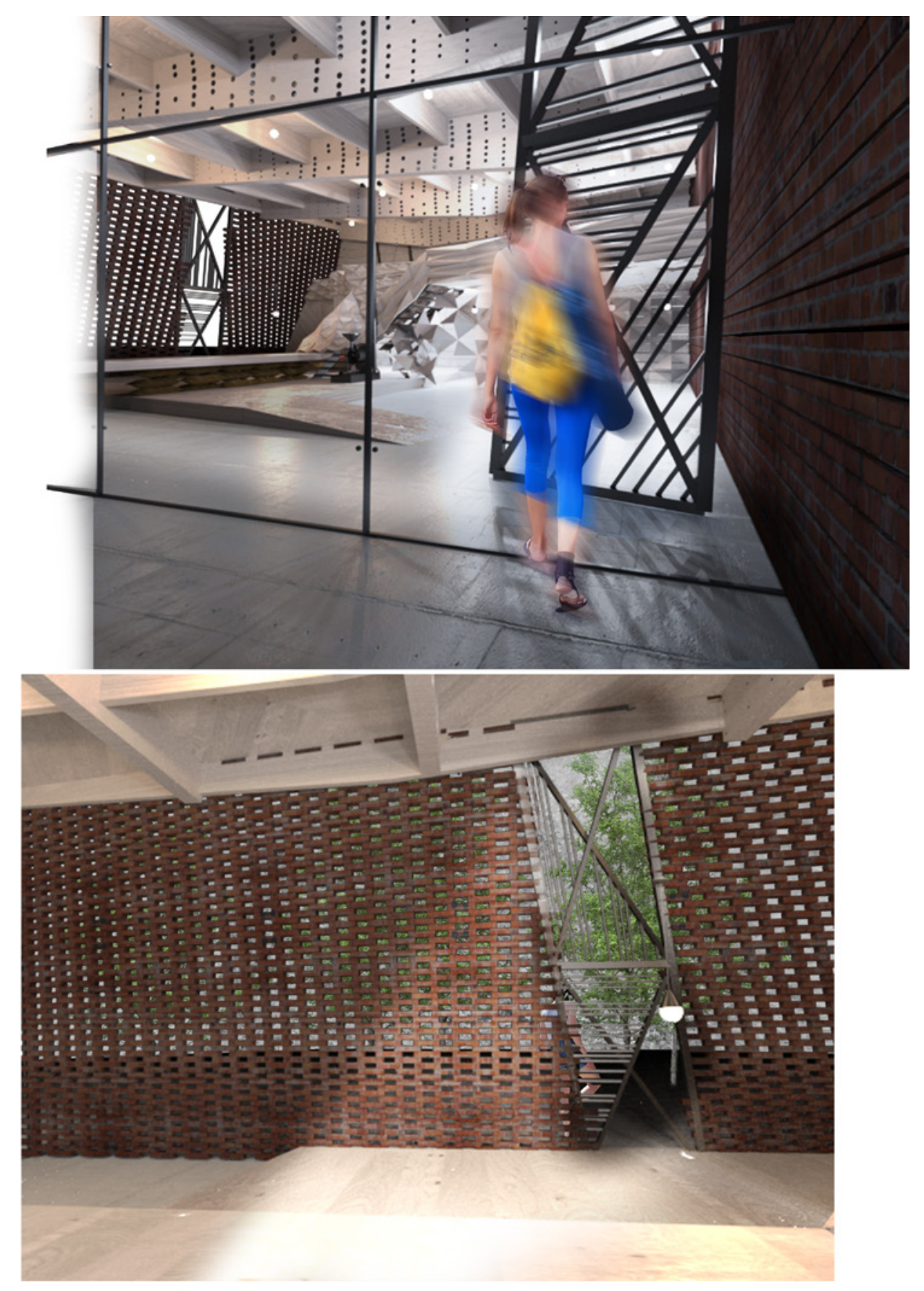

Figure 11.15 Braced frames within the design work structurally but also contribute to circulation and connection. The top image shows the street entrance framed brace and the bottom image is the view east out through the brick wall towards the outdoor seating area. Instead of adopting a perpendicular line to the west façade, the frame adopts the line of the front façade, guiding the patron visually to the counter. Its tension-only steel members allows light into the café while forming a threshold. This soft boundary preserves a sense of semi-privacy, dividing the space but maintaining visual unity and an active façade. In contrast to the north frame's threshold division, the east frame splits the brick façade between counter and courtyard. This break embraces the exterior seating, forming a connection across the threshold. The view points are indicated on figure 11.8. The braced frames have been incorporated into the design to direct the flow of people and establish a connection between the interior and exterior. The north frame has been positioned near the entrance to direct patrons towards the counter 
The frames have been placed on the perimeter of the design to maximise the amount of support against earthquake attack (figure 11. 14).
Three additional structural walls from the ground floor to the mezzanine floor were implemented so that the mezzanine floor is torsionally balanced (figure 11. 16).

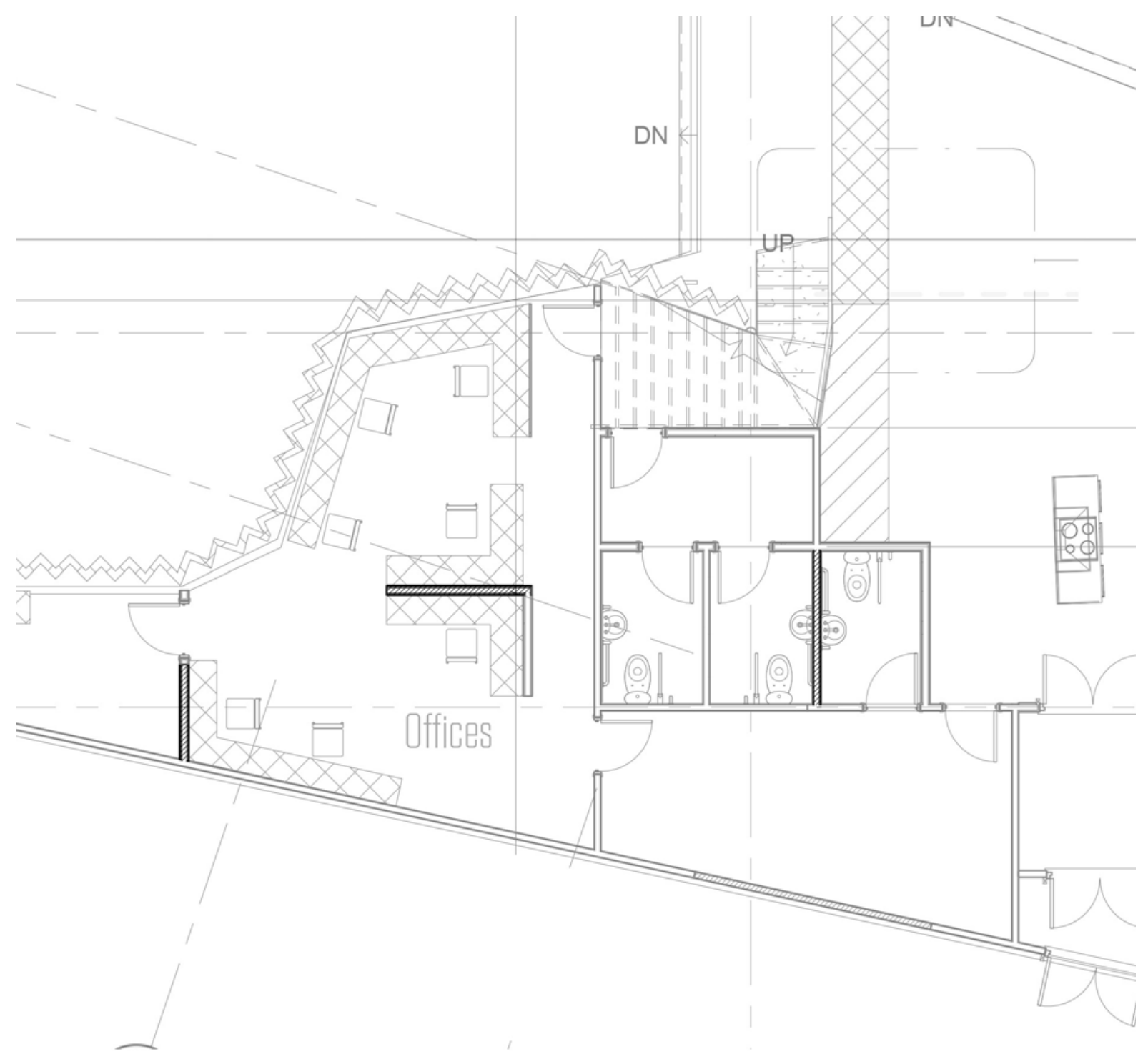

Figure 11. 16 As the mezzanine floor does not occupy the full floor plate, two out of the four braced frames did not pass through its floor diaphragm. The walls that divide the offices were specified with cross braced frames within the linings to provide lateral support. These walls do not continue to the roof as the main braced frames take 


\section{STAIR AND ROASTER}

The circulation of patrons up the stairs is enhanced by the connection to the roaster. The roaster's need for ventilation has been harnessed through the use of the steel exhaust as a steel circular hollow section support of the staircase. Incorporation of the roaster into the circulation space brings attention to the importance of the roaster and retains the industrial and process values outlined in the design brief (figure 11. 17).

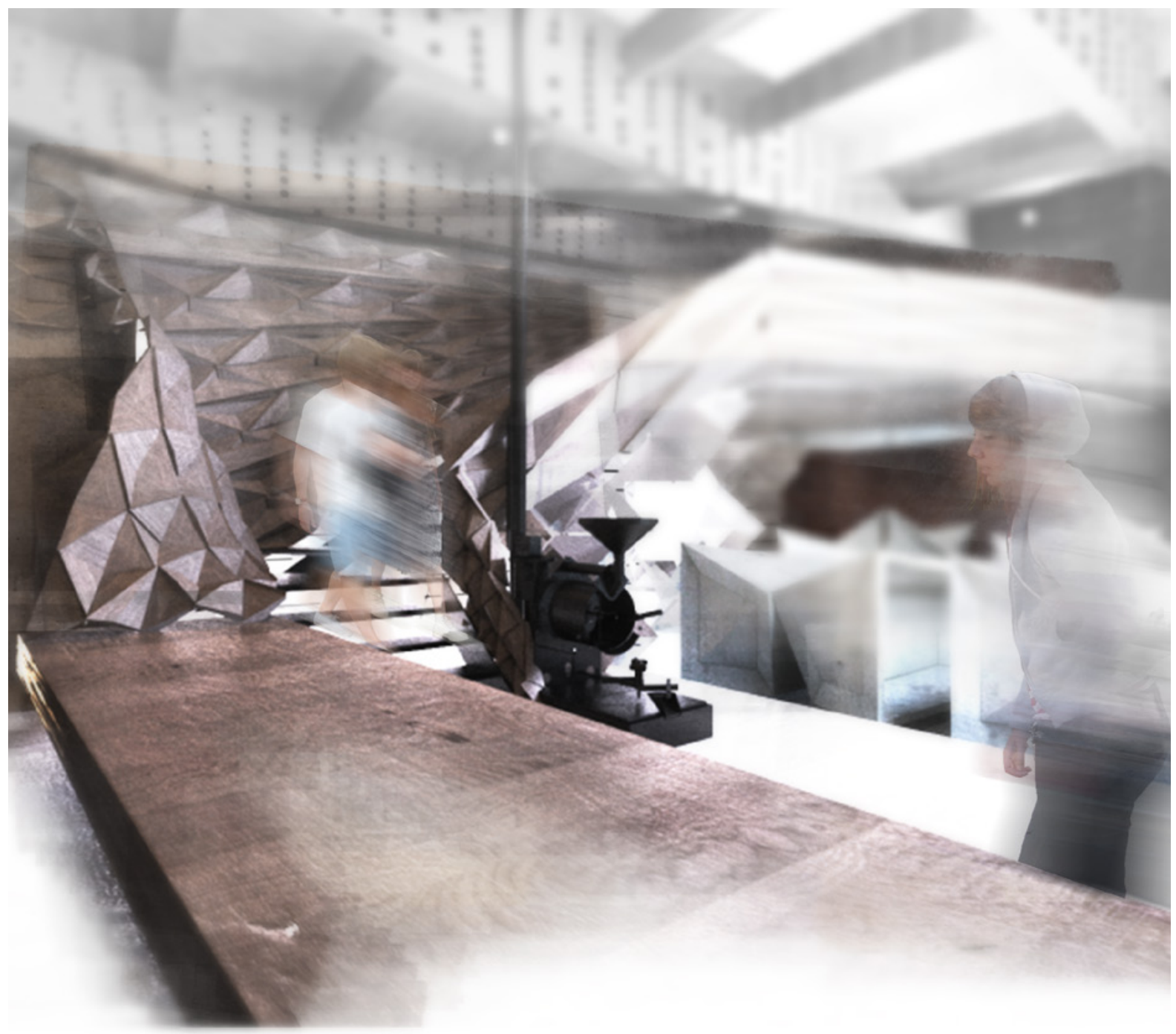

Figure 11. 17 The roaster was identified in the programme analysis as a motif to describe the transparency of the coffee-making process. The grinder's dominant visual and acoustic influence, although noisy during operation, remains a central point of the design. 
FURNITURE

The café furniture was acoustically designed and optimised from a cube to encourage projection of sound energy to an opposite seat (figure 11. 18).

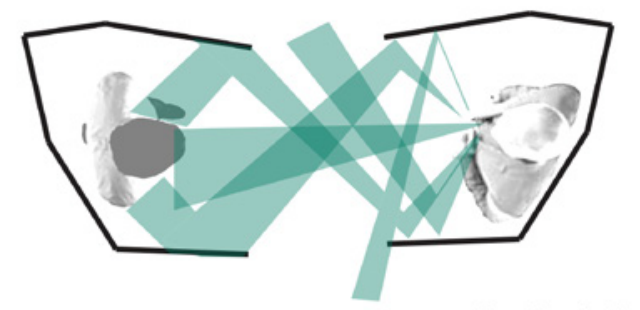

Two Single Chairs

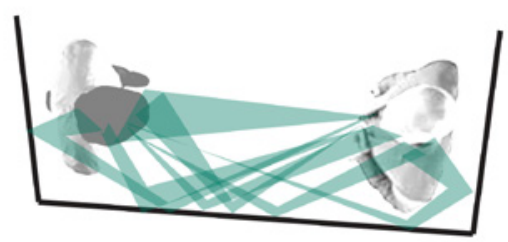

One Double Couch
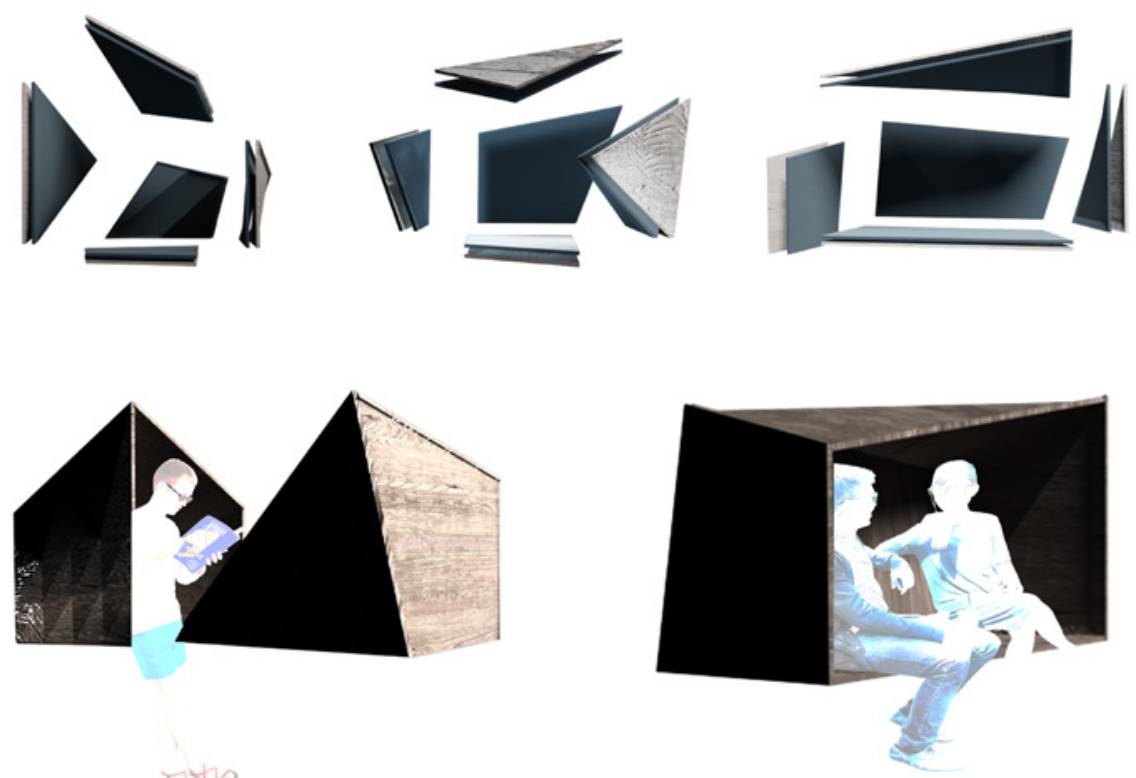

CHANGE

Locaiton of 8 corner points

FIND

Greatest SPL between seats

\section{$5+6$}

Figure 11. 18 A plywood panel system has been design for the furniture with each of the five surfaces constructed separately and then fixed together to share loading. Multiple designs including one seater chairs, and two person couches were undertaken. To test the individual forms, a sound source was positioned inside the cube and a receiver located outside of it. Galapagos was then used to optimise the surfaces of the cube to shape sound towards the receiver. The success of this was observed as an increase of SPL received by the receiver. A understanding of form's ability to shape sound was explored, extending from the principles taken from the Acoustic Mirror 106 
The concept furniture hangs from the roof to allow for simple alteration of height - a development of the successful use of high and low tables in the original design (11. 19).

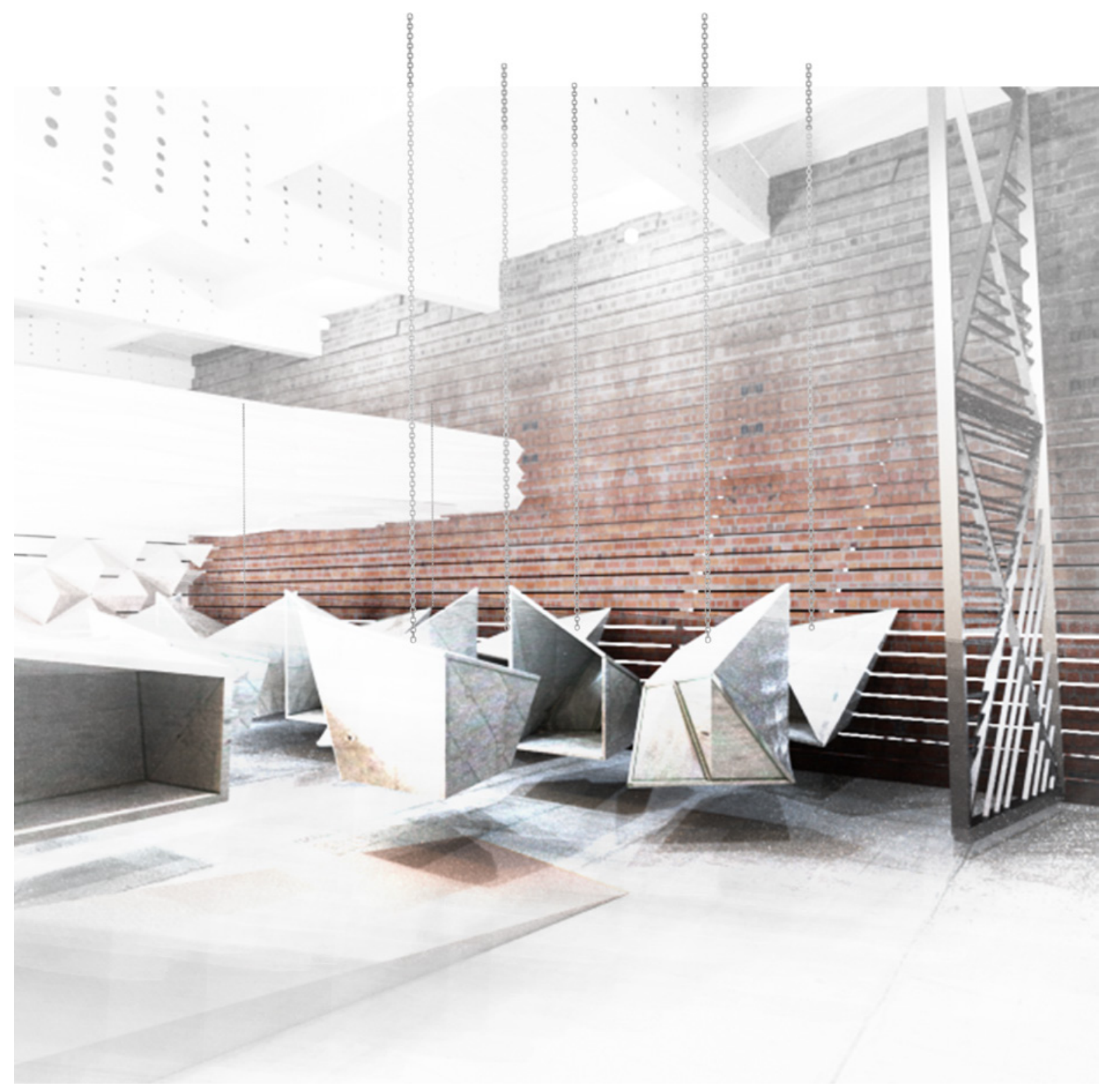

Figure 11. 19 Hanging furniture to promote different lines of sight 
INTERIOR WALL

The front and back of house was divided by an interior wall that establishes a threshold while facilitating a dialogue between patrons and staff (figure 11.20).

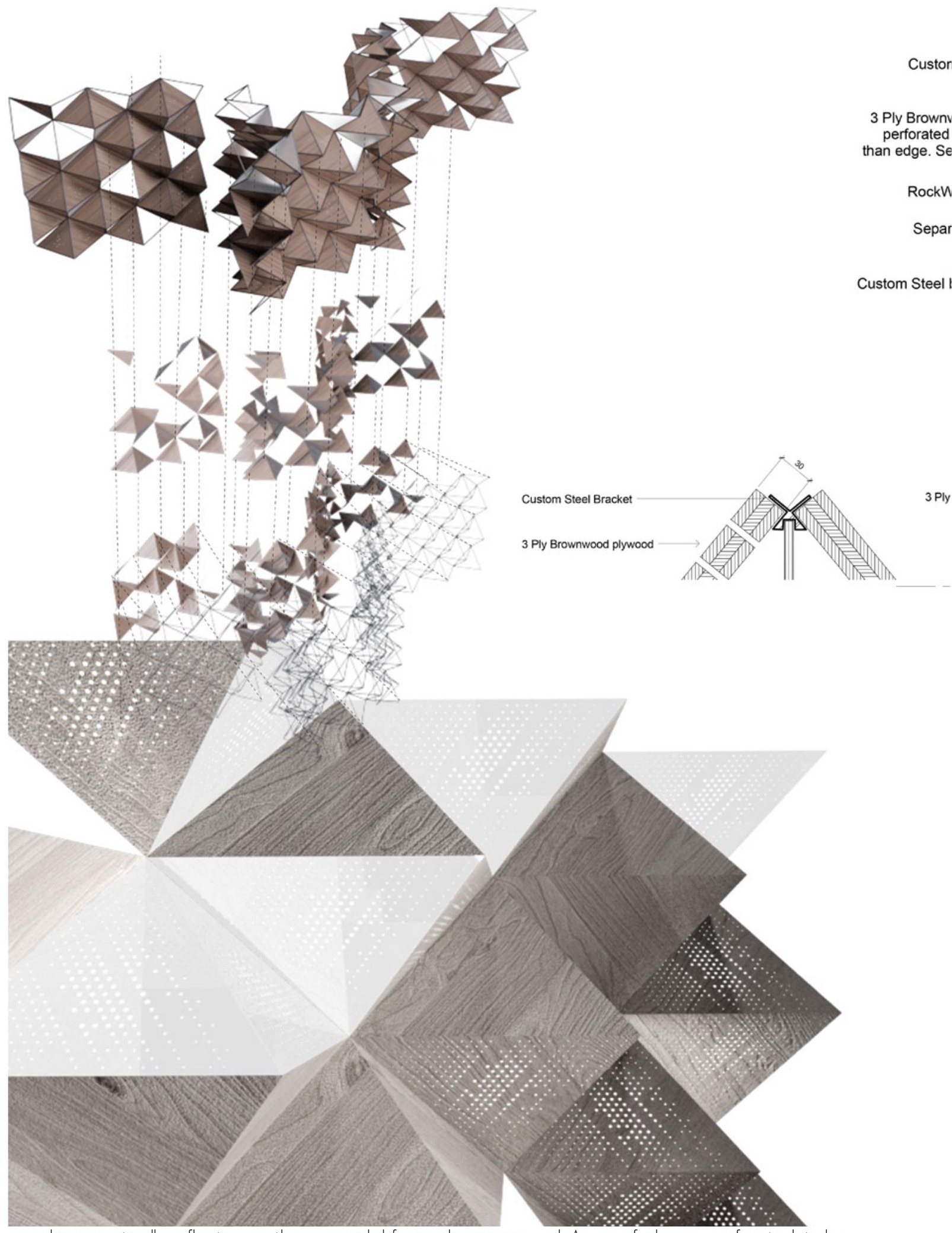

Figure 11.20 Plywood is acoustically reflective so the pyramidal forms disperse sound. Areas of ply are perforated, to be acoustically transparent, and the volume behind filled with rockwool to absorb sound. Some panels are detailed as frosted glazing so that visual connection between staff and patrons is maintained. An etched perforated pattern has been specified on these glazed panels to encourage unity across the wall. Through the implementation of visual and acoustic balance this interior wall forms a synthesis of the design ideas. 

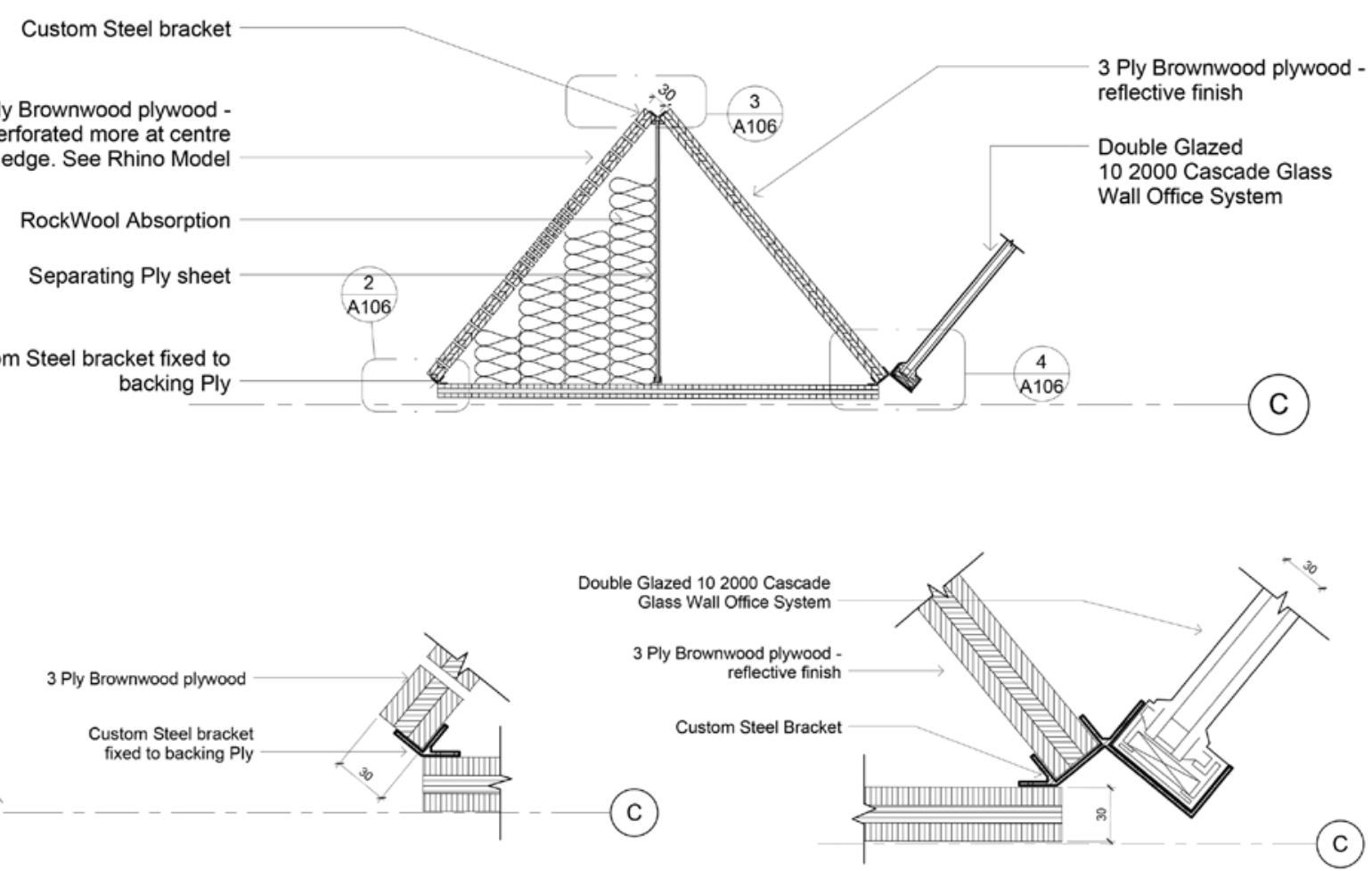

CHANGE

Triangle Depth

Number of Triangles/length

KEEP

Perforation size increases as distance to Centre decreases

FIND

$0.6 \mathrm{sec}$ T2O 


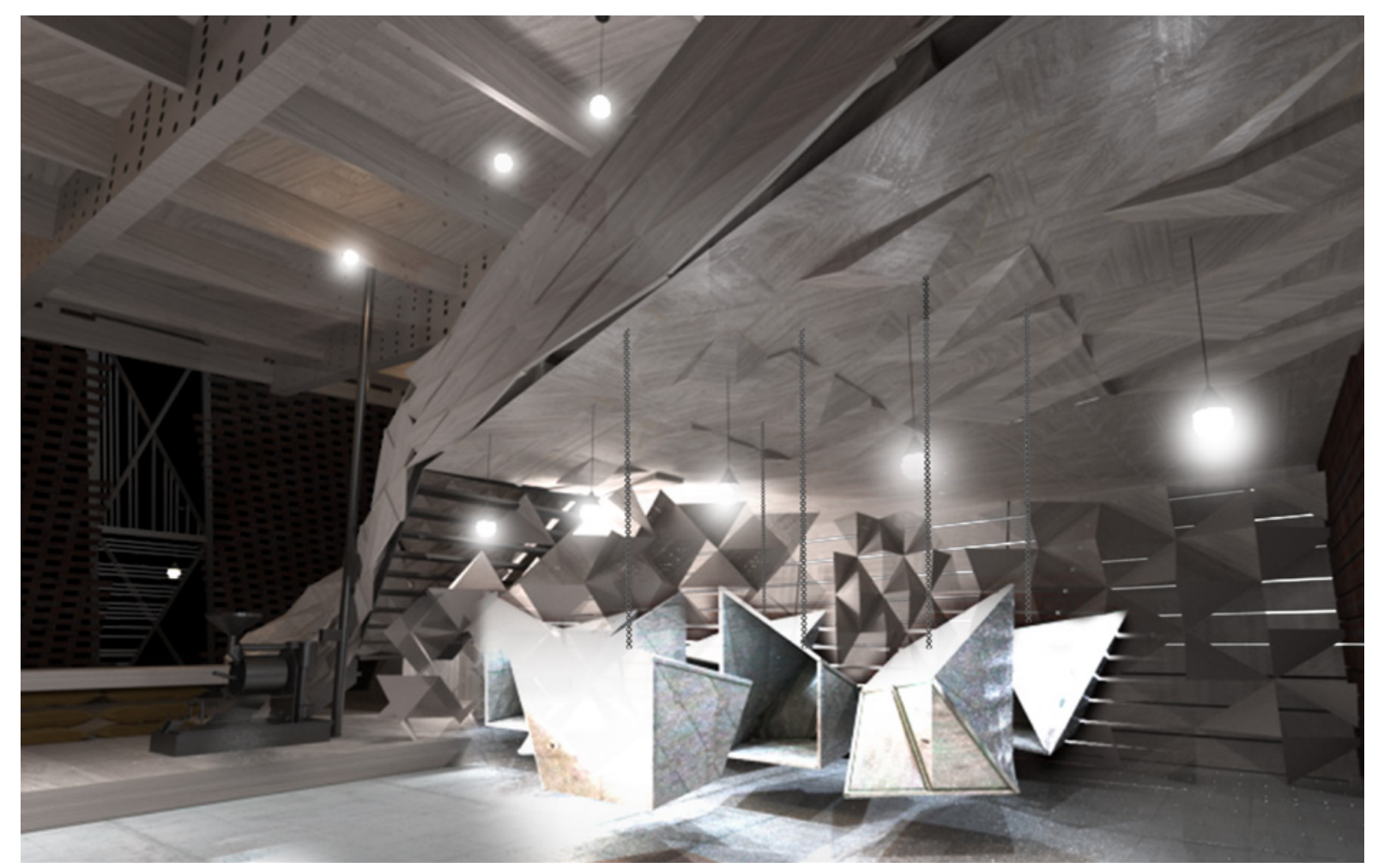

Figure 11.21 The wall alternates between glazed, perforated and solid panels along its extruded pyramidal face. The majority of the wall is plywood with some perforated panels that perform similarly as the beams.

\section{CONCLUSIONS}

Individual elements within the project express acoustic thinking through form and materiality. Each element has been created through an analogue design process, optimised by Galapagos. The plywood box beams, for example, were established within the knowledge that perforating plywood would create a perforated absorber but that shear forces are greater at the end of the beams than in the centre of the span. In response, an algorithm was written to find outcomes that reduce the maximum perforation radius closer to the end. This hybrid of parametric and more traditional architectural design produced informed architectural outcomes that were situated in human comfort. Furthermore, these results still reflect the designer restricting the loss of human connection in the outcome, as parametric design is often critiqued for. 



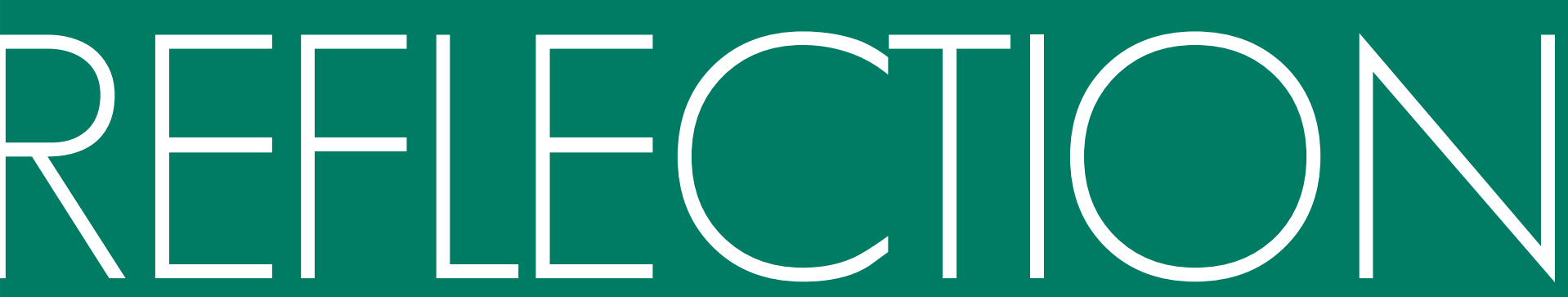




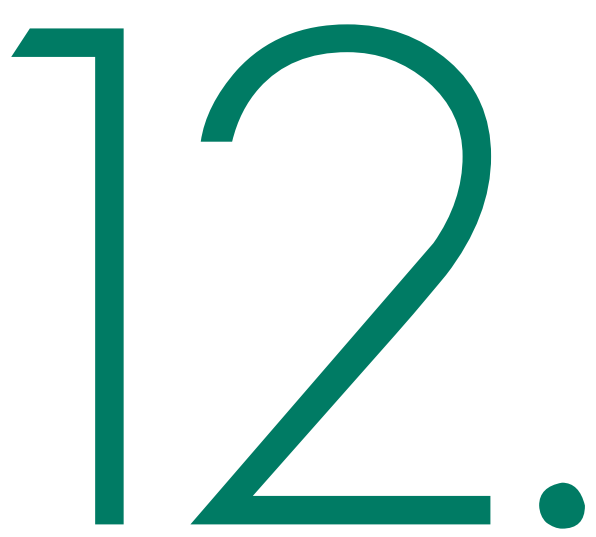

\section{Conclusions and Reflection}


This thesis section discusses the research proiect's conclusions on the success of:

- the design outcome,

- Pachyderm/Galapagos as a tool, - the holistic research (figure 12.1).

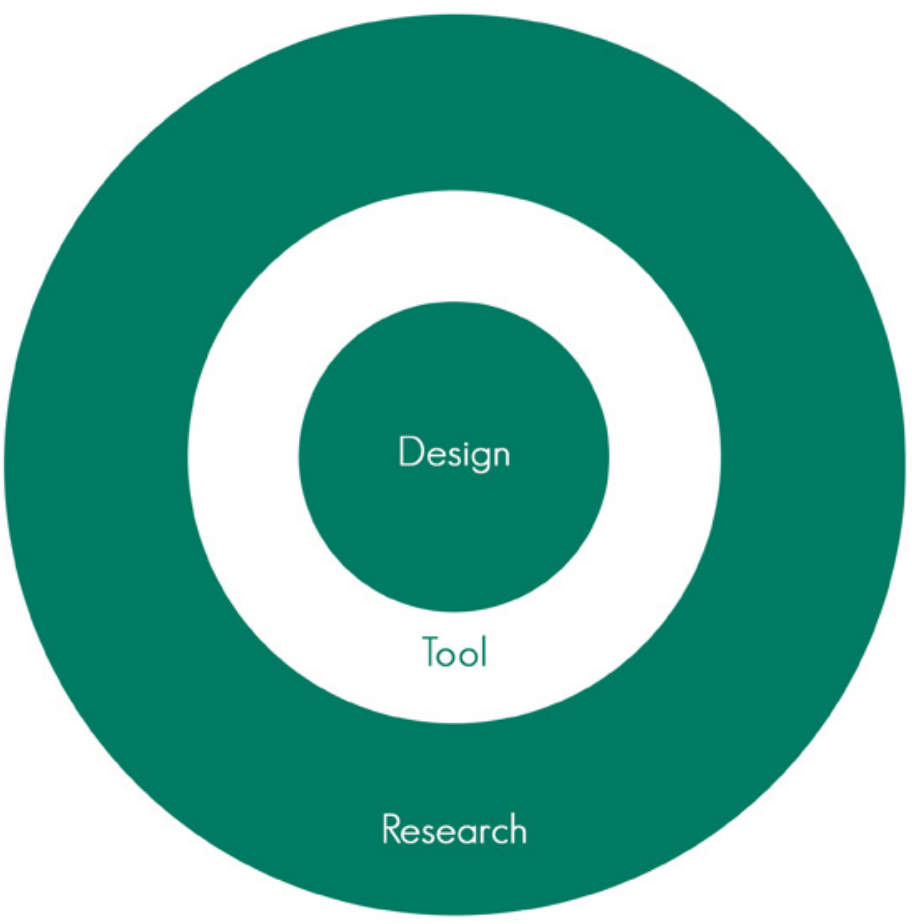

Figure 12.1 A diagram of the three project conclusions within each other with the design in the centre. The design conclusion evaluates the success of the design outcome and is within the tool conclusion. Similarly, the tool conclusion assesses the success of Pachyderm and Grasshopper and is within the Research conclusion. The overall research conclusions critically analyse the strengths and weaknesses of the project in respect to the other conclusions.

\section{DESIGN OUTCOME REFLECTION}

The degree of success of the case study project has been assessed on its ability to both satisfy the acoustic design goals and to produce a case study project that explores architectural acoustics.

\section{A DRIVING ACOUSTIC GOAL}

An RT goal of 0.7 seconds plus or minus 0.2 seconds has been found to be a driving measurement in design formation. This goal aligned with the suggestion set in standard
NZ/AS2107 of less than a second, and the 0.7 seconds result from the café tests. The case study project design was found to have a T30 of 0.7 seconds at $1000 \mathrm{~Hz}$, satisfying this RT goal. 


\section{CAFÉ DESIGN GOALS}

Design goals were developed from an analysis of the function of the existing cafe. Some significant design goals discussed in this section are:

- Achieving patron capacity numbers

- Creating multiple acoustic zones

- Implementing transparency

- Developing a visually intriguing façade

- Creating a "sprawling, eclectic and bustling" design

- Materiality

\section{PATRON CAPACITY NUMBERS}

The case study design seats 150 patrons with 100 seats inside and 50 in the courtyard slit, satisfying the goal of achieving the original café's patron capacity.

\section{ACOUSTIC ZONES}

Incorporating a variety of acoustic zones into the design has been concluded to increase patron enjoyment. An active zone, facilitating temporal relationships, has been contrasted to pockets of quiet space, catering to patrons who desire quiet and separation. The interior wall has been utilised in this division, creating acoustically different zones, with a difference in SPL and proximity to the grinder and kitchen.

It is difficult to evaluate the zones' success without a post-occupancy review to evalvate how patrons inhabit them. It is recommended that further study be undertaken to analyse if the environments are sufficiently acoustically distinct to satisfy the patrons. These tests could include a further subjective patron survey with accompanying SPL and EDT measurements from within the different zones.

The plywood counter is a successful design reaction to the potential separation of café through different zones (figure 12.2). 


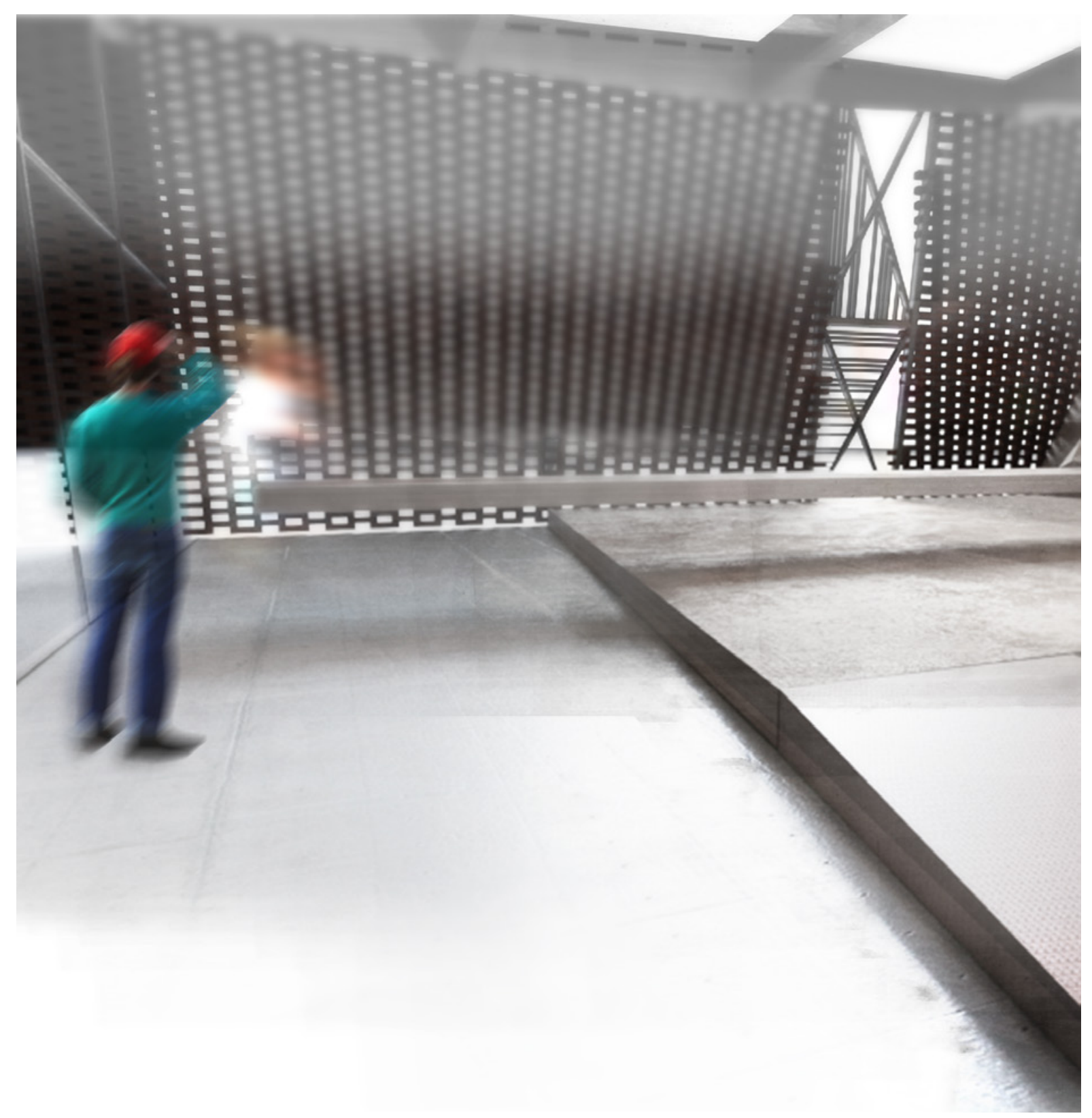

Figure 12.2 The counter cantilevers across the division acting as a bar leaner for temporary occupation, while winding up the stairs at the southern end. Eye heights and lines were explored through a variation of floor levels and the different chair and couch heights. Different eye-level lines have been found to create a sense of further 
IMPLEMENTING TRANSPARENCY

The design concept of transparency was communicated through lines of sight to an open kitchen and grinder.

\section{KITCHEN}

The consideration of sight lines to the kitchen communicates an importance of the food preparation ritual. The open kitchen can be seen by the majority of the café including the front and mezzanine areas (figure 12.3).

College Street

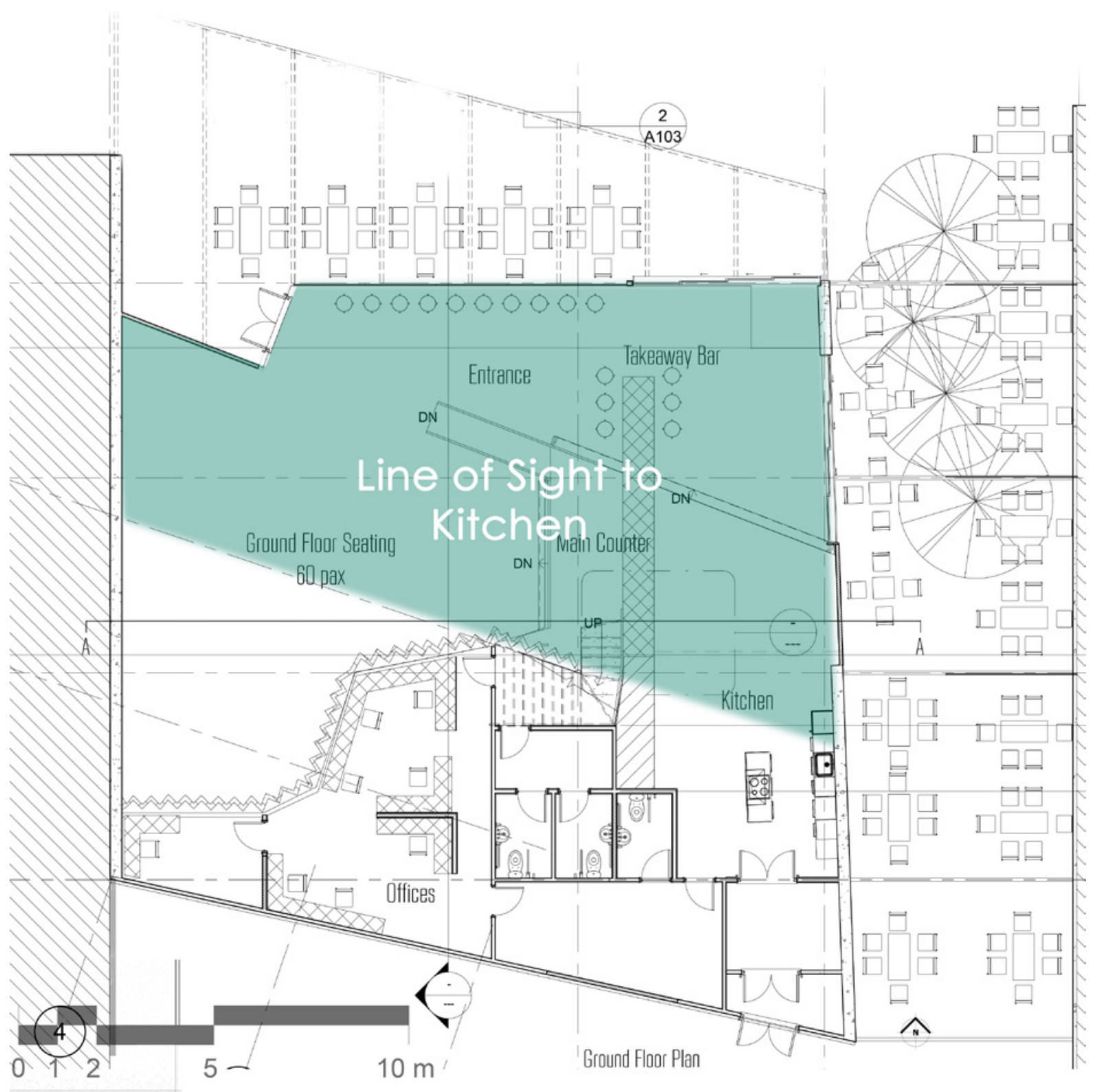

Figure 12.3 The kitchen produces its own cacophony of sounds which establishes an atmosphere. It is acknowledged that patrons looking for intimacy could find this noise distracting and so the interior wall has been positioned to mask it 
GRINDER

The relationship between stair and grinder connects the patrons to the role of the grinder in the coffee making process (figure 12.4). The ventilation exhaust was utilised as a structural member of the stair, unifying the two effectively (figure 12.5).

College Street

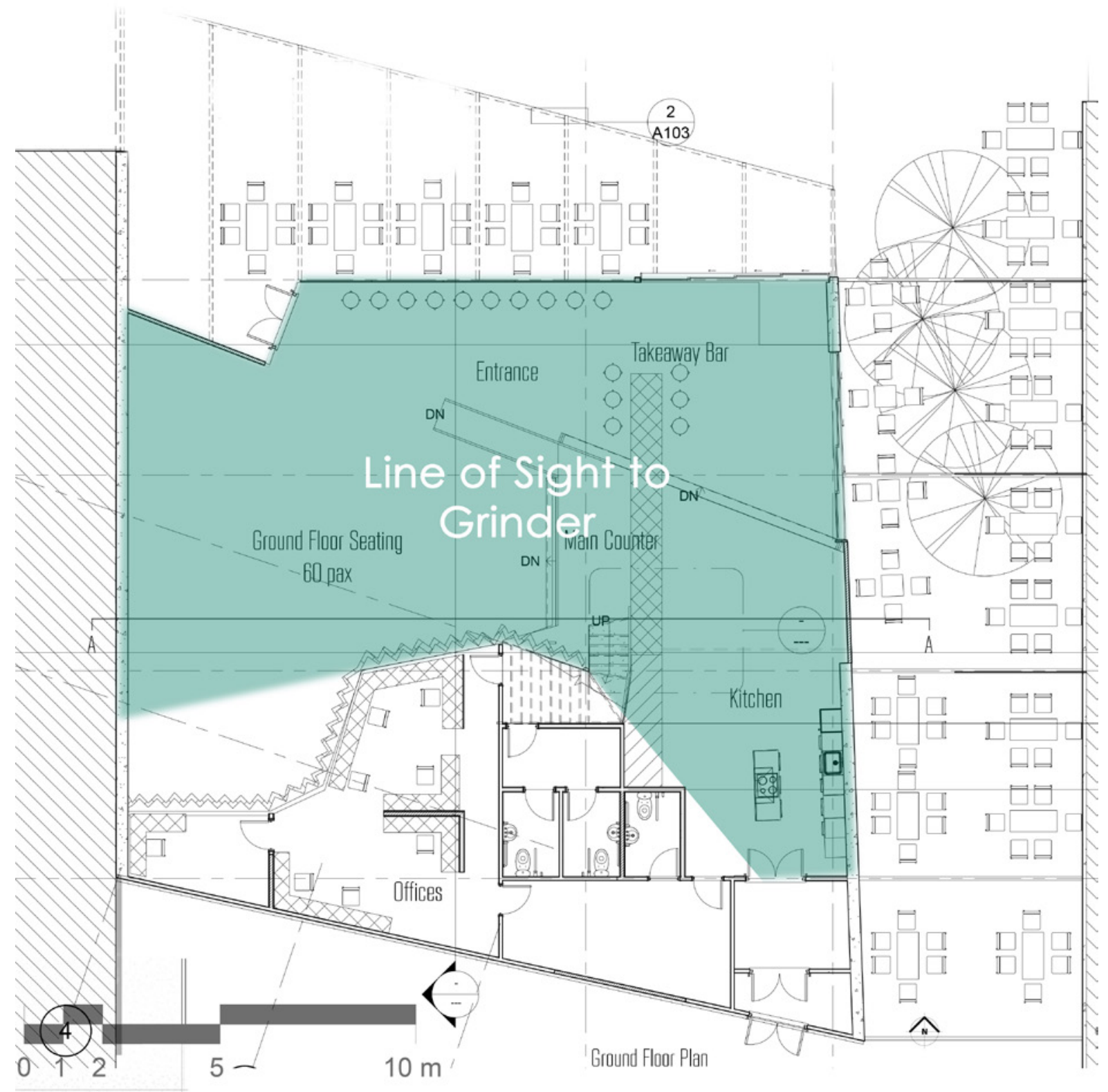

Figure 12.4 The grinder is visible by the majority of the cafe due to its central location and the shaping of internal walls. 


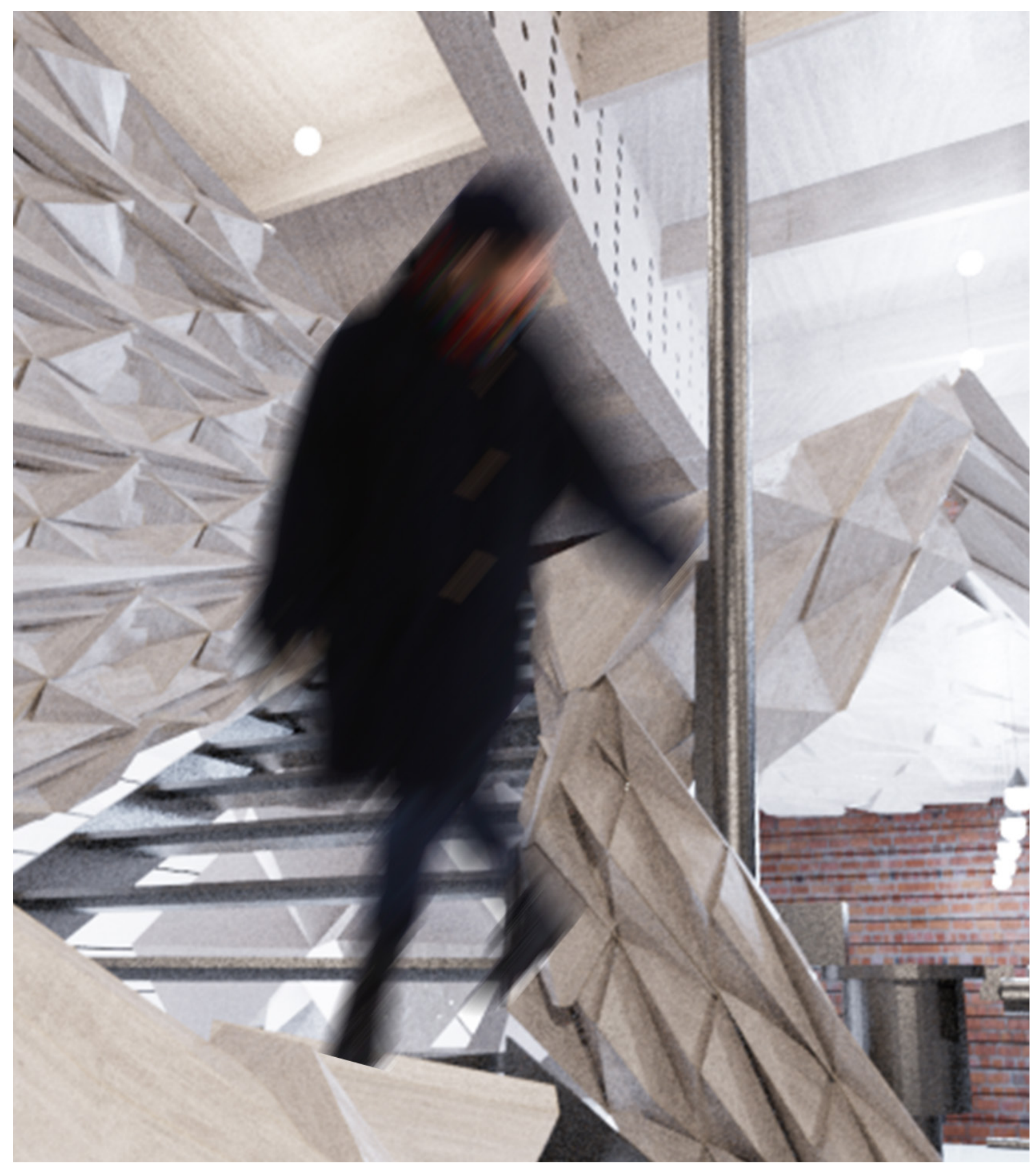

Figure 12.5 This integration of exhaust into structure also creates a haptic response, as a patron who runs their hand around the running grinder exhaust would feel the warmth of the steel, engaging them back to the grinder 
NTERIOR WALL

Transparency between patrons and the staff was established through the glazed panels of the interior wall. Through the implementation of a visual and acoustic synthesis this interior wall illustrates the project's architectural-acoustic amalgamation.

\section{FAÇADE DEVELOPMENT}

The façade design outcome contrasts from neighbouring buildings to draw pedestrians visual interest. The northern façade is cantilevered over the pathway while the main café space is pulled back to create an outdoor area (figure 12.6 - 12.8).

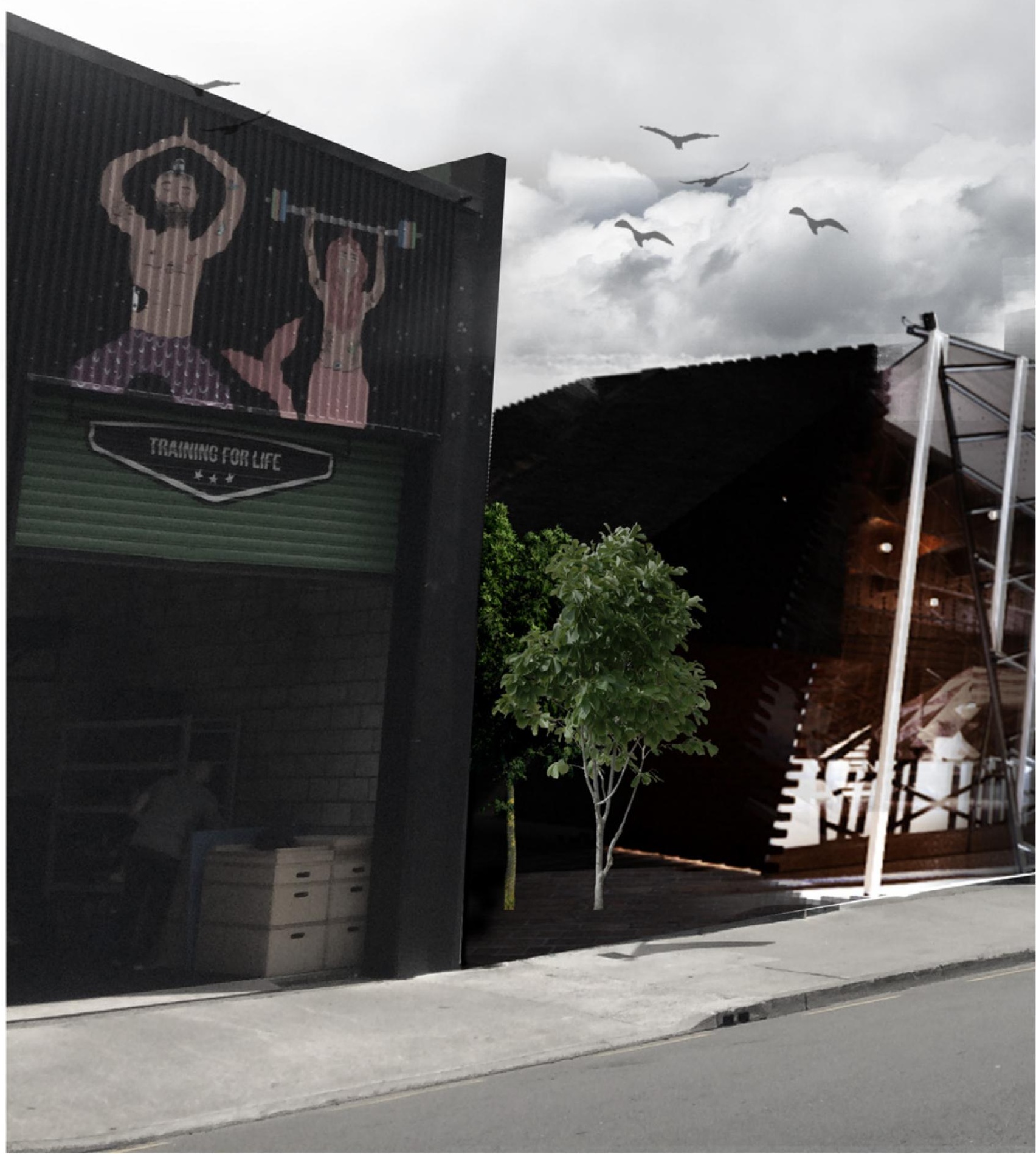

Figure 12.6 A landscaped step back contrasts from the monolithic neighbouring façade and creates an active street front, useful for drawing in patrons, or passively as a shelter from rain and wind. This design gesture could have been emphasised through further exploration of a circulation connection between the outdoor area at the 


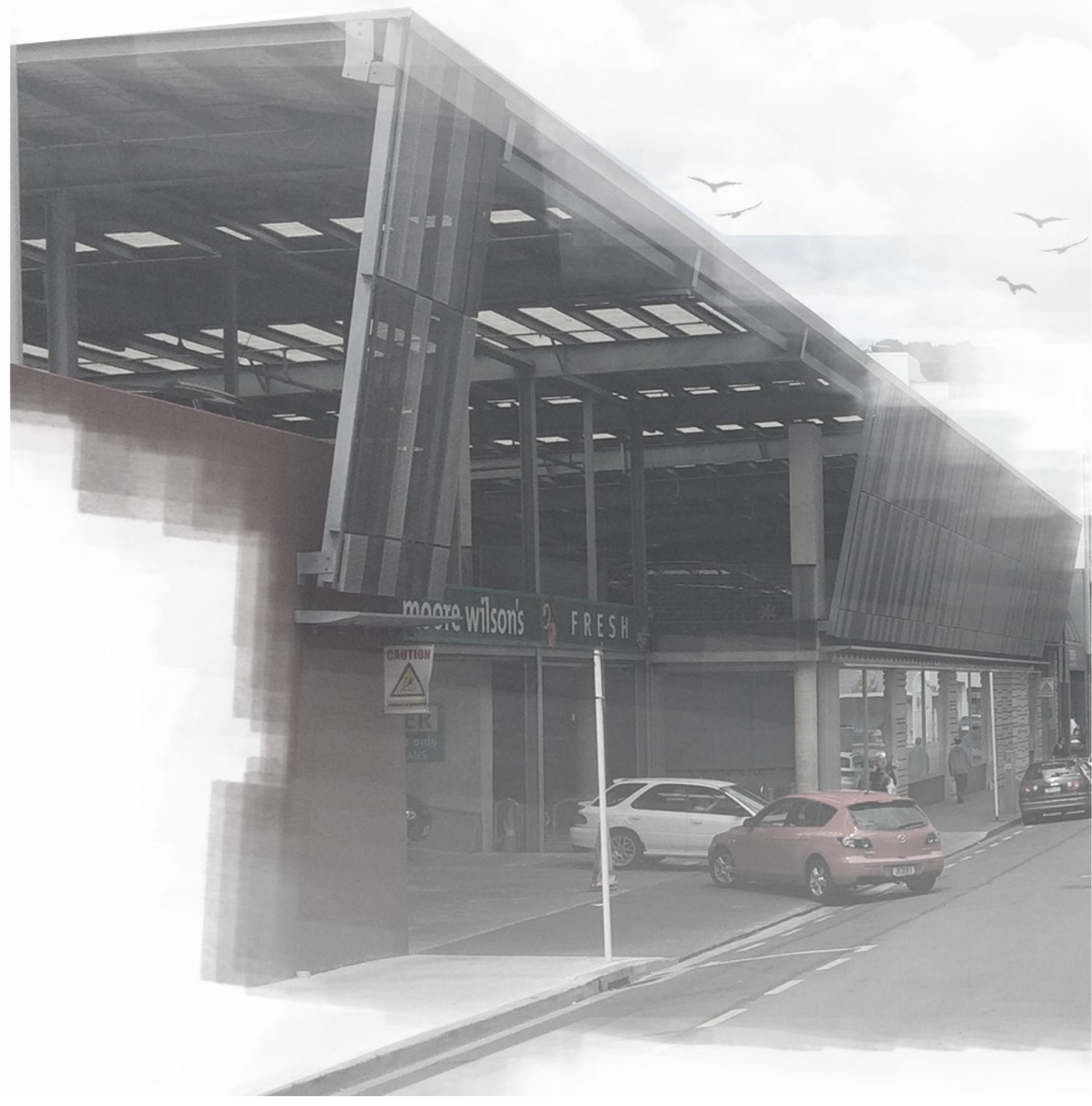

Figure 12.7 The facade responds in conversation to "Moore Wilson's" supermarket across the road 


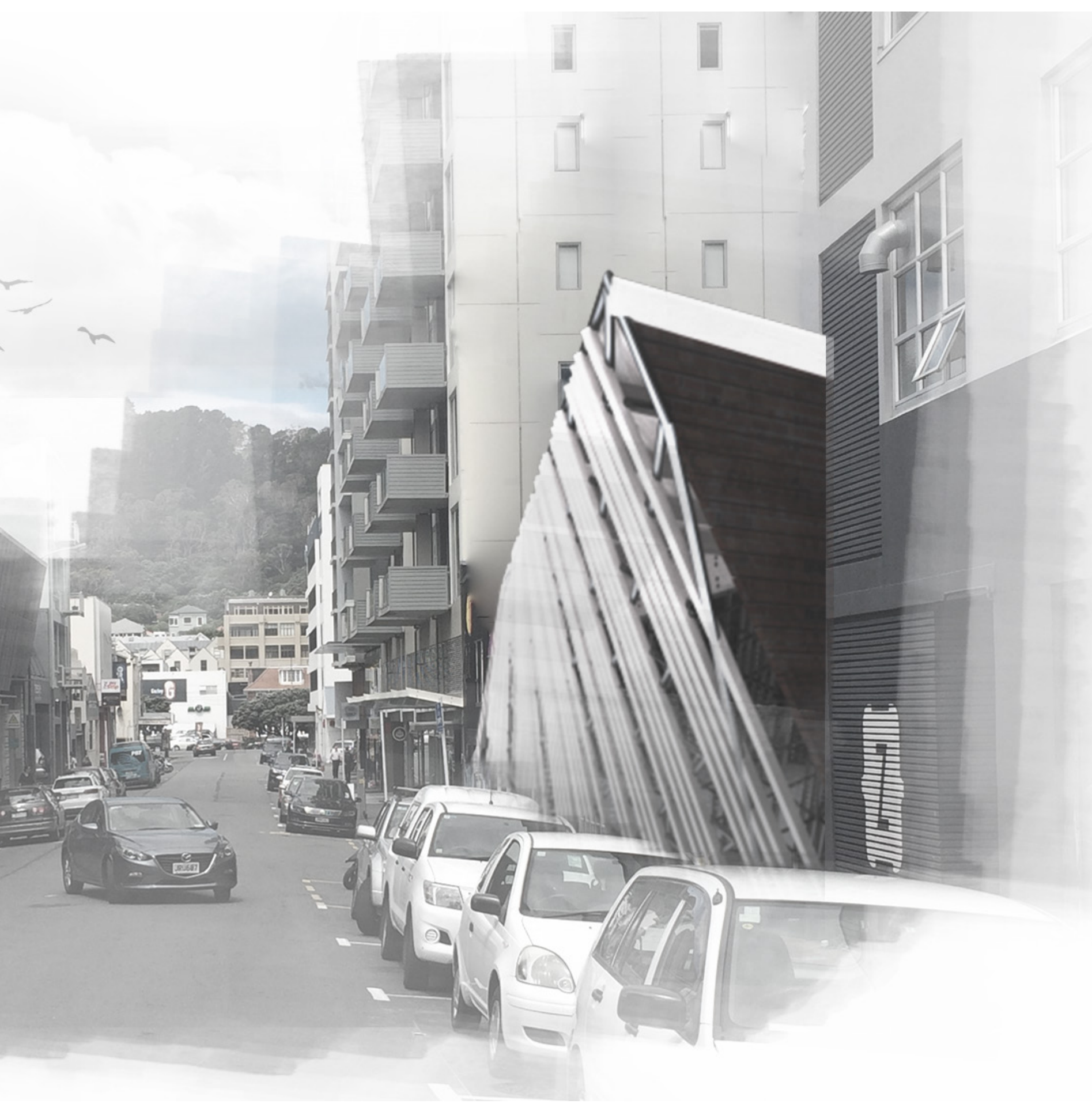




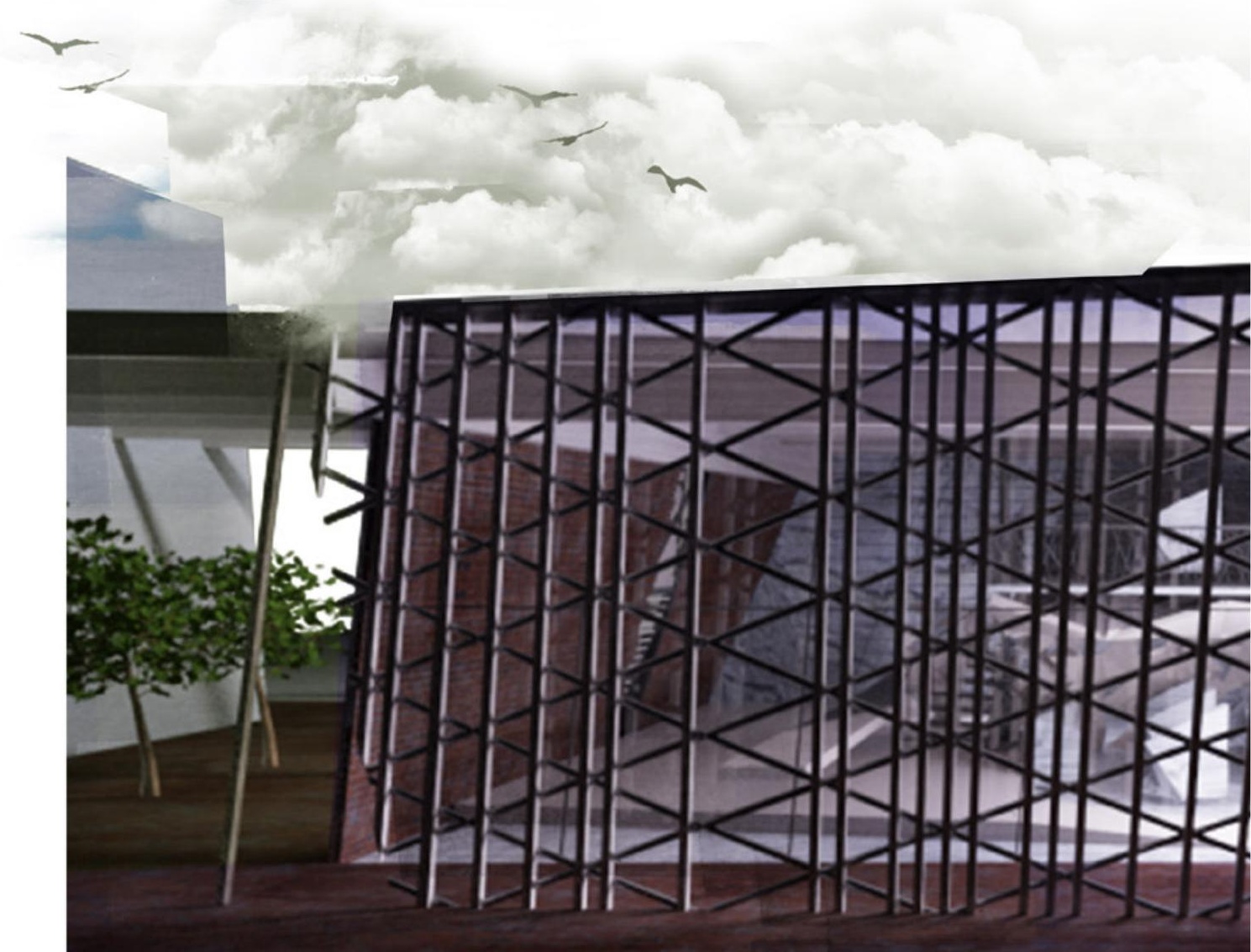

Figure 12.8 The rhythmic slats of the facade 


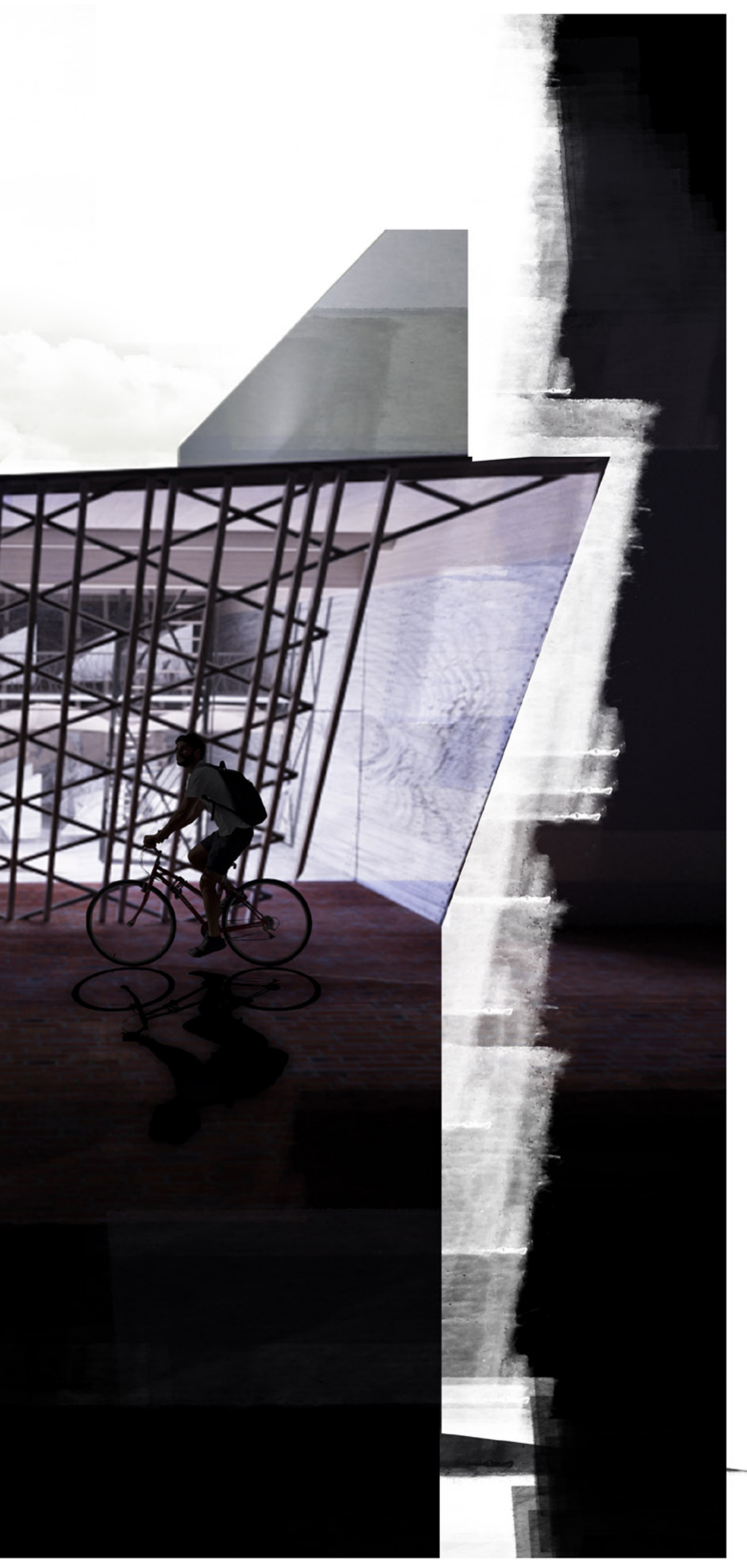


CREATING A "SPRAWLING, ECLECTIC AND BUSTLING" DESIGN

The design successfully implements outdoor spaces with street exposure to create a "sprawling, eclectic and bustling" environment. However, the main café space design could have been more effective through inclusions of intimate areas. The adaptive plan space is successful, yet, the space lacks the corners that inspire creative outcomes that are indicative of Te Aro culture. Intimacy was instead created through the design of furniture.

\section{MATERIALITY}

The material palette of the design could have been further developed. Ply was elected to illustrate its acoustic versatility through perforations. However, other materials could have achieved a similar acoustic result but different architectural one.

\section{OVERALL}

The major elements of the shell, interior wall, slat façade, furniture and plywood box beams were acoustically optimised using Pachyderm. These elements are architecturally engaging, specific to the site and are acoustically considered, combining aesthetics and function. Illustrating this potential for synthesis when considered early in design is the objective of this case study project design.

An auralisation was completed to test the success of the design. An auralisation is a method of representing a sound environment aurally. This convolved recording can provide the listener with a sense of acoustic atmosphere that visual images cannot. An auralisations for the design and the origina Cafe 5 were compared (figure 12.0) (see attached digital file). The auralisations illustrated a higher speech intelligibility and lower reverberance in the design cafe, further supporting the architectural and acoustical success of the design.

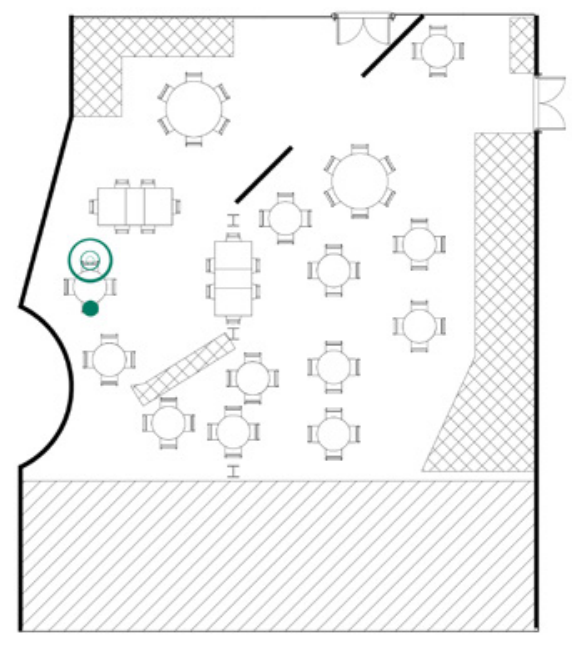

Orginal Cate
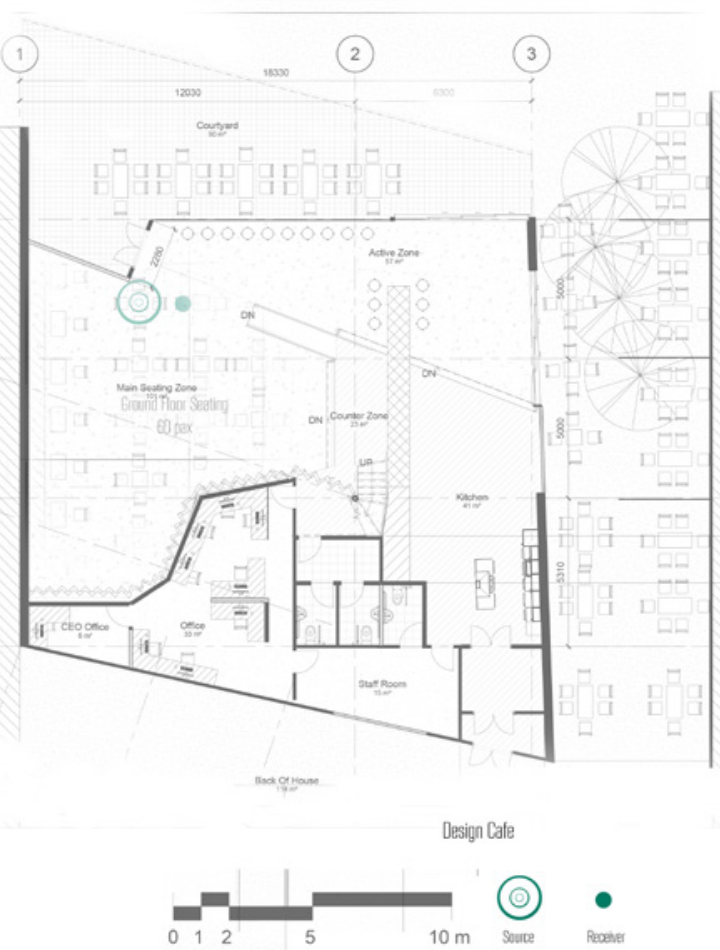

Figure 12.9 Source and Receiver locations for the auralisation are shown in green 


\section{TOOL REFLECTION}

It has been previously concluded that the design illustrates that acoustics can form the inspiration for architectural design, through Galapagos and Pachyderm. This section examines the accuracy of the Pachyderm to assess if it is producing useful information for a designer in the early design phase.

To assess Pachyderm, a validation study was conducted and suggested that Pachyderm can accurately simulate RT. In this assessment, the original cafe was modelled in Rhino and its $\mathrm{T30}$ was simulated. This $\mathrm{T30}$ was compared to the T2O recorded on site to understand the difference in readings. $A$ T30 was compared to a T2O as Pachyderm does not currently produce a T20, and "for assessment of typical café noise the T2O and the T30 values would be very comparable, and no significant errors would likely emerge for substituting one for the other" (Halstead).
The simulated RT at $1000 \mathrm{~Hz}$ (mid-frequency) was 0.85 seconds, while the original recording on site was 0.87 seconds (figure 12. 10). Pachyderm simulated results with an error of 0.02 seconds, a margin that could be deemed insignificant at the early design phase. This finding suggests that the performance of the newly-generated geometry can be predicted with some confidence and advocates for Pachyderm's ability to calculate acoustics in simulated architecture. However, this was a case study project so further research is required to understand the software's limitations in method, scale and complexity.

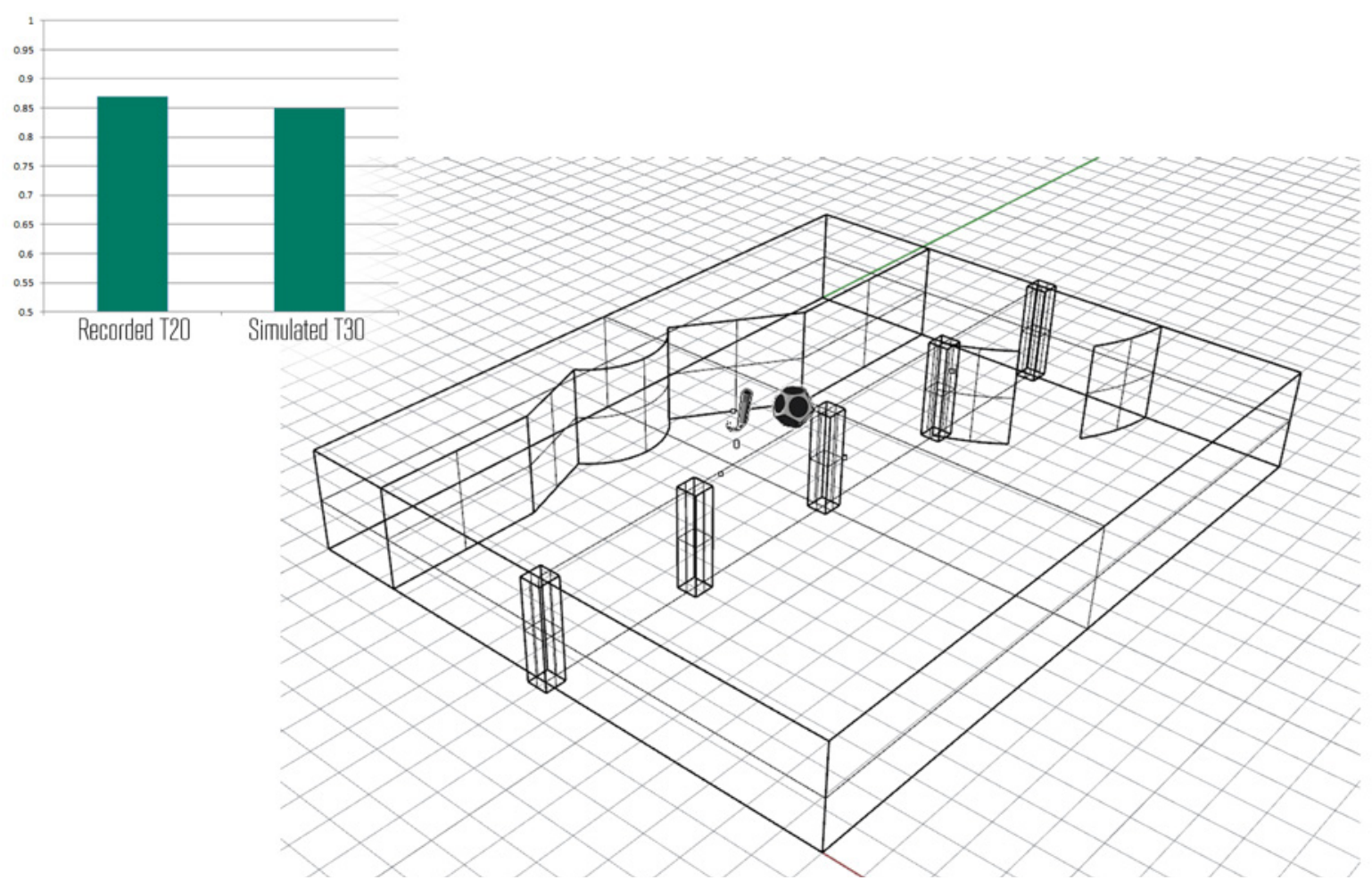

Figure 12.10 Digital model of the original Cafe 5 showing the source and receiver and the simulated T30 
Material scattering coefficients are one limitation of Pachyderm. Materials have inherent scattering properties, in that some rougher materials scatter sound over a larger area than smooth surfaces. This scattering significantly impacts the RT calculation (Wang, Rathsam, and Ryherd). When initially modelling the existing café, Pachyderm simulated an RT of 2 seconds, above the 0.8 seconds recorded in the café. This result is incorrect and was caused by Pachyderm's default $0 \%$ material scattering. If the room has little scatting, sound rays travel around the room without passing the receiver producing the excessive RT seen in the initial results. The simulated RT was reduced by increasing the scattering coefficients of the surfaces to represent furniture and other scattering objects. It is recommended that templates are created and further work is undertaken to quantify scattering coefficients. 
RESEARCH OUTCOME REFLECTION

In contrast to the design conclusions, the degree of success of the research project was judged on the research's ability to satisfy its three objectives and answer the research question of:

\section{How can parametric design add acoustic quality to an architectural design?}

\section{OBJECTIVE 1}

Identify key objective acoustic parameters that influence the creation of effective café space

The research project identified objective acoustic measurements through the physical testing of cafes. This testing was largely successful, producing a range of measurements and subjective patron options. However, sample size and fluctuations in volume were two testing limitations and are discussed in this reflection.

\section{SAMPLE SIZE}

The small sample size of café and patrons meant that only general conclusions could be made. Using a stratified sampling method of cafes from Legge et al.'s research was effective as it created a range of cafes, yet, the sample size of patrons surveyed per café should have been higher. Five patrons allowed only a rough overview of the patron opinions and meant that information gained from this test had to be generalised to all of the five cafes rather than accessing each individual cafe.

\section{FLUCTUATIONS IN VOLUME}

The ambient volume within the cafe altered over the survey period. This changing acoustic environments suggests that patrons who answered the survey at one point were potentially exposed to a different acoustic condition to others, influencing their opinions. It is recommended for further study that SPL be recorded as the survey is completed so any change in SPL could be compared.
Ambient noise heard when conducting the IRIS unoccupied study could have impacted the measurements recorded. Unfortunately, as a staff member was setting up the café while the recordings were undertaken, it was unrealistic in this study to expect silence. However, in an attempt to minimise the effect of this noise, if abrupt background noise was produced during the recording, such as a scrape of a chair on the floor, the recording was repeated.

SPLs from four out of the six cafes recorded agreed with Legge et al.'s measurements, however, recordings in Café 4 and 6 were significantly different. This variation in Café 4 and 6 could be explained by the two cafes' quiet environments. Managers can often respond to quiet spaces by increasing the music volume to establish ambience. This decreases the consistency of the measures as the ambient volume alters depending on the preference of the manager, which can change on the day. In contrast, a louder café can be more regular as the ambient volume is regulated by the café's capacity. Further testing on multiple days and times would have reduced these inconsistencies.

Café 5 recorded the longest RT, highest SPL, and lowest enjoyment rating, reinforcing the relationship between these three elements. Enioyment was concluded to be influenced by SPL and SPL was concluded to be influenced by RT (Whitlock and Dodd, 424). These variables were controlled by specifying a target design RT for Galapagos to solve towards. This use of an acoustic parameter meets $\mathrm{Ob}$ jective 1 .

\section{OBJECTIVE 2}

Use acoustic parameters to digitally inform the creation of a café design

RT, SPL and STI were found to be useful in the creation of acoustic-specific form. When optimising using Galapagos, general measurements such as RT were most successful 
during the early design phases where there was a lower level of design resolution. In contrast, measurements such as STI were more effective when designing at the human scale. This research project successfully addresses Objective 2 through the development of an optimised, functional and aesthetic café design (see Design Outcome Reflection).

\section{OBJECTIVE 3}

Assess if current parametric software produces meaningful information for the designer

This section evaluates Pachyderm and Galapagos as form drivers and their relevance to the design industry. Through the completion of the first two objectives, this research project found that Pachyderm can create architectural outcomes with the same target measurement. As, these simulated measurements can be predicted by Pachyderm with some confidence (Tool Reflection), Pachyderm was deemed to be able to communicate meaningful information to its user in the early design phase to drive the design.

Pachyderm and Galapagos have the potential to better the architectural acoustic design industry, however, should be accessible to its users. The Grasshopper platform is complex for new users to understand: allowing for flexibility amongst experienced users and confusion for beginning ones. In an attempt to reduce the complexity of the algorithms, "clusters" of components were created in this project. These clusters reduce the flexibility of the definitions, but increased the learning curve for public and professionals without parametric training (figure 12.11). It is recommended through further study, to explore different stakeholders' needs (whether these are architects, engineers, property managers or café owners) and how the software could intuitively respond to them.

\section{OVERALL}

Through an integrated parametric and analogue process, the case study project produced architecture that not only met acoustic criteria but harnessed form to sculpt sound. No two surfaces generated by Galapagos were parallel reducing the "flutter effects" that decrease STI. This integrated process produced a functional design that is successful from an acoustic and architectural perspective.

When given design agency, acoustics can successfully drive design. Instead of simply applying absorption to flat surfaces, the convex curves on the north and east facades disperse sound through form. These convex curves suggest that effective acoustics can be an aesthetic driver. One that betters the architectural outcome, not hinders it.

This research was successful as it questions the current practice of acoustics within architecture through the exploration of an extended design process. It assesses new methodologies to promote a synthesis of architectural acoustics. This project advocates for a shift in ideology from space-determined acoustics, to acoustic-determined spaces. 

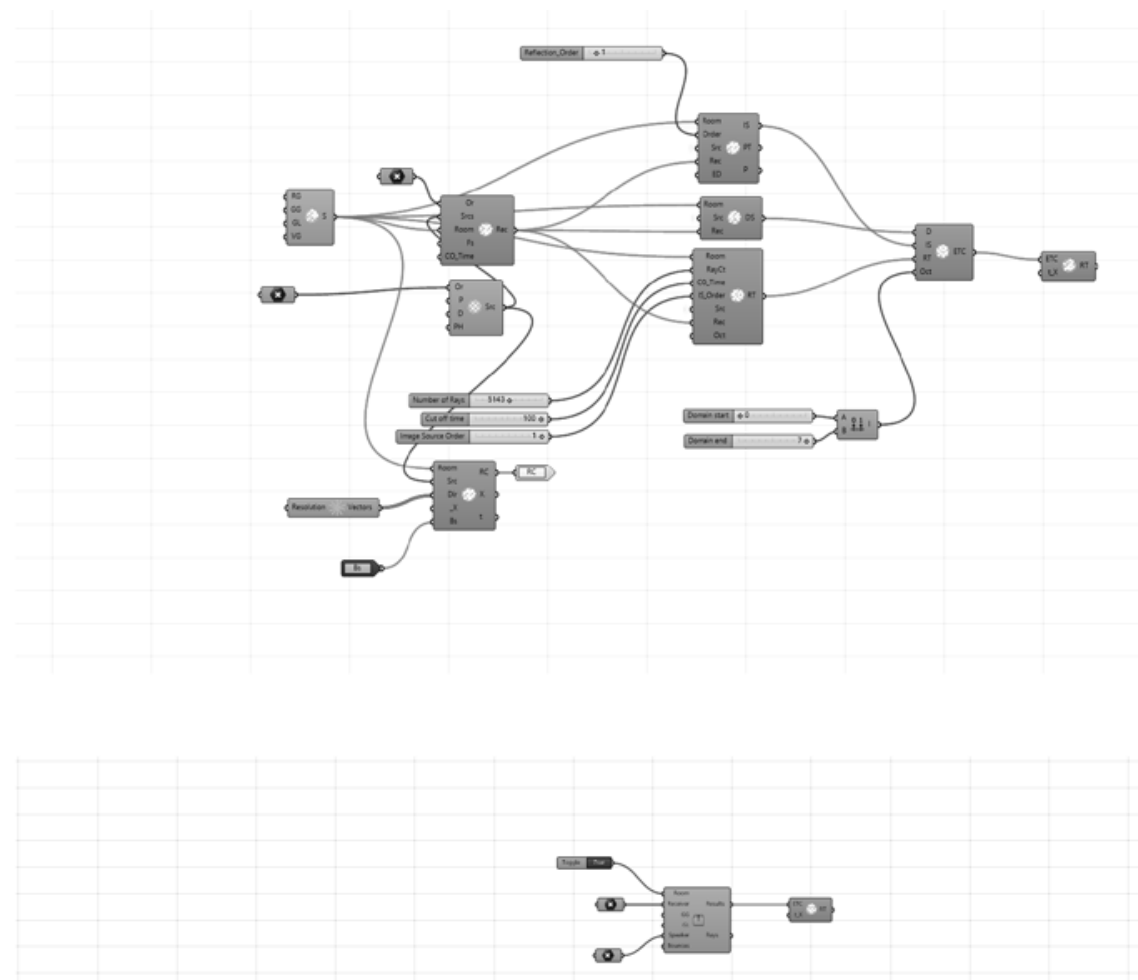

Figure 12.11 The Pachyderm simulation script indicates the visual difference between the original (top) and the clustered (bottom). The top script has more controls and therefore flexibility for advanced users. However, in contrast the clustered bottom script is the same script but packaged into one component with less inputs. This packaging is more accessible for new technicians.

\section{FINAL REMARKS}

This research process has taught me a lot. It has been a massive project that connected many different elements, people and thoughts.

Undertaking this research, I have learnt about the highly practical (hauling around a life-sized mannequin (HATS) for cafe testing) and the theoretical (discussing psychoacoustics effects with supervisors).

I have learnt about how I work best and how to play to my strengths, while still acknowledging my weaknesses and developing them.
I have learnt about time management and self-management. How I naturally manage my time well, but could divide a project into smaller sections, each with a set process goals that guide the task to completion on time and to my standards.

Undertaking this research has taught me a lot, but most of all I learnt how I would like to situate myself within the industry. 


\section{WORKS CITED}

AS/NZS 2107 (2000). Acoustics: Recommended Design Sound Levels and Reverberation times for

Building Interiors. Sydney/Wellington: Standards Australia/New Zealand, 2000. Print.

ArchDaily. "Cave Restaurant / Koichi Takada Architects." ArchDaily. N.p., 13 Apr. 2010. Web. 1 Mar. 2016.

Barron, Michael. Auditorium Acoustics and Architectural Design. 2nd ed. Hoboken: Taylor and Francis, 2009. Print.

Beranek, Leo Leroy. Concert and Opera Halls. Published for the Acoustical Society of America through the American Institute of Physics, 1996. Print.

Blesser, Barry, and Linda-Ruth Salter. Spaces Speak, Are You Listening?: Experiencing Aural Architecture. MIT press, 2009. Print.

Charleson, Andrew. RESIST. N.p., 2015. Print.

Christie, LH, and JRH Bell-Booth. "Acoustics in the Hospitality Industry: A Subjective and Objective Analysis." (2006): n. pag. Print.

Dezeen. "Blue Frog Lounge by Serie Architects." Dezeen. N.p., 27 Feb. 2008. Web. 1 Mar. 2016

Dalenbäck, B.-I. CATT-Acoustic. CATT. Print.

Echenagucia, T.I.M. et al. "Architectural Acoustic and Structural Form." Journal of the International Association for Shell and Spatial Structures 49.159 (2008): 181 - 186. Print.

Egan, M. David. Architectural Acoustic Workbook. Ed. Charles W. Tilley. Massachusetts: n.p., 2000. Print.

Gracey, Bill. "Speech : Definitions, Terms, Units and Measurement." Speech Definitions, Terms, Units and Measurement : Acoustic Glossary. N.p., n.d. Web. 25 Feb. 2017. <http://www.acoustic-glossary.co.uk/speech.hłm>.

Halstead, Miklin. Implementing an Intangible. 22 Feb. 2017. Email.

Kahn, Louis. "Architecture Is the Thoughtful Making of Spaces." Perspecta (1957): 2-3. Print.

Mandel, Theo. The elements of the user of The the interface design. Vol. 20. New York: Wiley, 1997.

National Research Council (U.S.). Building Research Institute. Noise Control in Buildings: A Research Correlation Conference Conducted by the Building Research Institute. New York, N.Y: National Academies, 1959. Print.

Pelzer, S., M. Aretz, and M. Vorländer. "Quality Assessment of Room Acoustic Simulation Tools by 
Comparing Binaural Measurements and Simulations in an Optimized Test Scenario." Proceedings of Forum Acusticum. N.p., 2011. 1529- 1534. Web.

Rutten, David. Galapagos. N.p. Print.

Schmidt, A.M.D., and P.H. Kirkegaard. "From Architectural Acoustics to Acoustical Architecture Using Computer Simulation." Building Acoustics 12.2 (2005): 85-98. Web.

Schumacher, Patrik. "Parametricism: A New Global Style for Architecture and Urban Design." Architectural Design 79.4 (2009): 14-23. Print.

Van Der Harten, Arthur. Pachyderm Acoustical Simulation. N.p., 2015. Print.

Vlaun, NJV. "Sound Working Environments: Optimizing the Acoustic Properties of Open Plan Workspaces Using Parametric Models." (2015): n. pag. Print.

Vorländer, M. "Computer Simulations in Room Acoustics: Concepts and Uncertainties." Journal of the Acoustical Society of America 133.3 (2013): 1203-1213. Web.

Wang, Lily M, Jonathan Rathsam, and Steven Ryherd. "Interactions of Model Detail Level and Scattering Coefficients in Room Acoustic Computer Simulation." (2004): n. pag. Print.

Whitlock, J. "Understanding the Lombard Effect." (2012): n. pag. Print.

Whitlock, James, and George Dodd. "Classroom Acoustics-controlling the Cafe Effect... Is the Lombard Effect the Key." Proceedings of ACOUSTICS, Christchurch, New Zealand (2006): 20-22. Print.

Wright, Oliver et al. "The Role of Acoustical Design within Architectural Design in the Early Design Phase." World Academy of Science, Engineering and Technology, International Journal of Civil, Environmental, Structural, Construction and Architectural Engineering 10.6 (2016): 780-785. Print. 


\section{IMAGES CITED}

All figures not listed are author's own

Figure 1.1 Wright, Oliver et al. "The Role of Acoustical Design within Architectural Design in the Early Design Phase." World Academy of Science, Engineering and Technology, International Journal of Civil, Environmental, Structural, Construction and Architectural Engineering 10.6 (2016): 780-785. Print.

Figure 2.1 Glazzard, Paul. WW1 Acoustic Mirrors. 2007. Kilnsea. Wikipedia. Web. 24 Feb. 2017. <https://en.wikipedia.org/wiki/Acoustimirror\#/media/File:WW1AcousticMirrorKilnsea(PaulGlazzard)Jan2007.jpg?.

Figure 2.4 Petit, Fram. Blue Frog Lounge. 2008. Mumbai. Dezeen. Web. 24 Feb. 2017. <https://www.dezeen.com/2008/02/27/blue-frog-lounge-by-serie-architects/>.

Figure 2.7 Rees, Sharrin. Cave Restaurant. 2009. Sydney. Archdaily. Web. 24 Feb. 2017. $<h t t p: / / w w w . a r c h d a i l y . c o m / 56011 /$ cave-restaurant-koichi-takada-architects?.

Figure 2.8 Supawood. "Supaslat Maxi Beam Lightweight Beams." Supawood Architectural Lining Systems. N.p., n.d. Web. 23 Feb. 2017. <http://supawood.com.au/ supawood-products/supaslat-maxi-beam?.

Figure 3.1 Echenagucia, T.I.M. et al. "Architectural Acoustic and Structural Form." Journal of the International Association for Shell and Spatial Structures 49.159 (2008): $181-186$. Print.

Figure 3.2 Echenagucia, T.I.M. et al. "Architectural Acoustic and Structural Form." Journal of the International Association for Shell and Spatial Structures 49.159 (2008): $181-186$. Print.

Figure 3.3 Vlaun, NJV. "Sound Working Environments: Optimizing the Acoustic Properties of Open Plan Workspaces Using Parametric Models." (2015): n. pag. Print. 


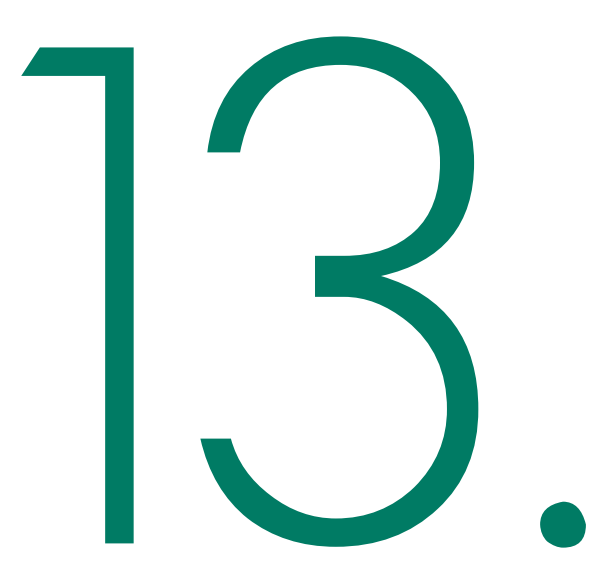

Appendices 


\section{APPENDIX A -TERMNOLOGY}

\section{SOUND PRESSURE LEVEL}

The Sound Pressure Level is the pressure created by the sound wave, but is more commonly understood to be how loudly something is heard, its volume. The SPL can be measured in $\mathrm{dB}$ or $\mathrm{dBA}$, with the $\mathrm{dBA}$ or A-weighted, SPL being weighted to the frequencies that humans hearing louder. Decibels are centred around the human ear with the reference value, $\mathrm{OdB}$, the quietest sound we can hear (Barron, 11). In a context, conversational speech has a level of around 50 $d B$, while a very loud sound of $120 \mathrm{~dB}$ causes pain in the ears and could cause deafness if experienced often (Barron, 11). Specifically for cafés, a recommendation of $45 \mathrm{dBA}$ and a maximum of $50 \mathrm{dBA}$ are set by the standard AS/NZS 2107 (2000).

\section{REVERBERATION TIME}

The acoustic response of a room is highly dependent on how the form shapes the sound energy within it. The decay of sound as energy reverberates around the room is known as terminal reverberation. The Reverberation Time (RT) is defined as the time for the sound level to decay to one millionth of its energy, or commonly understood as the time to decay 60dBA (Barron, 28). Barron states that if the RT is too long "one sound can be rendered inaudible (i.e. masked) by an earlier louder sound" (Barron, 18). This masking leads to a "muddy" impression of the space and a decrease in Speech Intelligibility. However, designing with RT is a balancing act, with Barron continuing to say that with a too short RT "the sound quality becomes too stark, like listening in the open air" (Barron, 18). Balancing these two extremes is one example of how acoustic design informs design direction. A café is recommended to have a 0.6 to 0.8 second RT which allows for some carrying of the sound, but still a high clarity. This is towards the right hand side of the scale and so a plot more like the right was expected.

\section{SPEECH TRANSMITTING INDEX (STI)}

The Speech Intelligibility Index is the subjective reference of the ease of speech comprehension. It is measured between .1 and 1.0 with 1.0 being a high speech intelligibility or Speech Transmission Index (STI).

The RT is the time taken for an impulse to decay $60 \mathrm{~dB}$ or from hearing. The longer this RT, the more sound energy there is reflecting around the room. In a recording studio, there is an emphasis on reducing reflections as much as possible and so the RT is very short, 0.2 seconds. This can be compared to the 2.5 second recommended RT of a concert hall. This is because a more live environment is desired in a concert hall, with the room itself projecting and carrying the sound.

\section{BACKGROUND INFORMATION}

Light energy travels around a room similarly to sound energy, thus making it an effective metaphor for visualising acoustics. While this is not completely true due to the complexity of different frequencies, and therefore wavelengths, it is a useful allusion.

When forming spaces, it is important to consider reflections. Flat and shiny surfaces reflect sound much like a mirror does light. If two mirrors are sat facing each other multiple reflections are seen. Similarly, if two surfaces are parallel then sound energy can be reflected back and forth creating a "flutter effect" that decreases the speech intelligibility. The distance between walls is significant as the further the sound travels between the walls the longer it takes before it is received back at the starting location. If this time is more than 50 milliseconds after the direct sound then this is heard as an echo which muddies speech articulation.

Materiality is one way of decreasing this muddying effect, as different materials absorb, transmit and scatter sound differently. Sound energy that hits absorptive material is decreased as energy is absorbed by the material and covered from sound energy. 
Sound can also be scattered by a material, much like the way that light is reflected off a rough surface. Matt surfaces have a high scattering coefficient so light is reflected over a less condensed area and no image is seen. This occurs with sound as well, however, due to the different frequencies there is a variety of scattering. Furthermore, each material has a unique signature which is called its absorption and scattering coefficient. These coefficients are important to consider when designing the treatment of a particular frequency of sound.

To increase the transfer of sound between two points it is important to maintain a clear line of sight. Much like trying to see through an obstacle, high frequency sound will be reflected off any obstruction resulting in a muffled result. Furthermore, to preserve acoustic condition it is important to isolate the space from exterior sources. This means that exterior noise such as road or plan noise should be monitored and reduced.
Rough surfaces scatter sound more than flat and shiny surface. However, sound has many different frequencies (or pitches), and therefore wavelengths. The variety in wavelengths is substantial with an $8,000 \mathrm{~Hz}$ sound producing a $43 \mathrm{~mm}$ wavelength, and a $50 \mathrm{~Hz}$ sound, a $6.8 \mathrm{~m}$ wavelength. This size difference influences the relative "roughness" of surfaces for each frequency. Chairs scatter sound significantly due to the relatively difference between chair height and floor height. It can be seen that the scattering increases from $30 \%$ at $125 \mathrm{~Hz}$ to a maximum of $70 \%$ at $4,000 \mathrm{~Hz}$. This increase in scattering at higher frequencies is caused by the shorter wavelengths and so the relative difference in height between the chair and ground is larger. 


\section{APPENDIX B \\ - CAFE TESTING METHOD}

\section{UNOCCUPIED TESTING:}

AIM:

To investigate empty café spaces to understand how architecture influences the acoustic environment. Testing will produce acoustics measurement results such as EDT, T2O LF and $\mathrm{C} 80$ and three dimensional IRIS plots

\section{EQUIPMENT:}

Laptop with IRIS 2.0

Omnidirectional dodecahedron

TetraMic

IRIS kit

\section{METHOD:}

- Elect three receiver locations and two source locations

- Set up the source and receiver in the first source (ST) and receiver (RT) location. Note: ensure that the side with the "CORE" logo of the TetraMic - the positive X-direction - should be directed to the source - this orientates the 3D plot. The complete set up is shown in figure 13.1.

- Connect the MOTU 4pre to the Laptop and run a lead from Line 4 to the loudspeaker. Run a STP Cat5e cable from the CBM to the PPA

See manufacturer's website for complete instructions

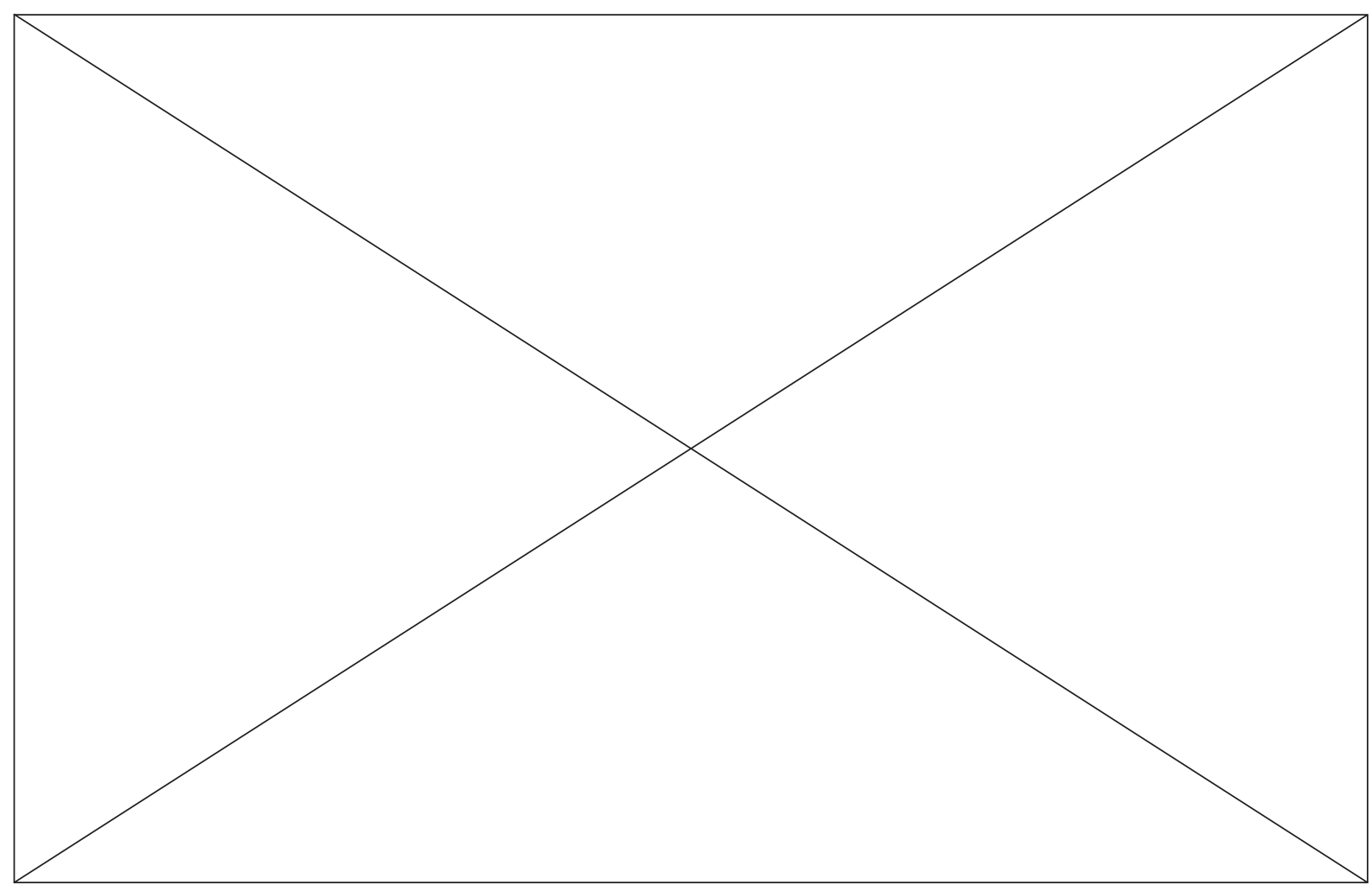

Figure 13.1 IRIS microphone stand set up

Image redacted for online submission, see physical submission for image 
OCCUPIED TESTING - PATRON SURVEY

AIM

To gain subjective feedback from patrons about the acoustic performance of the cafe.

EQUIPMENT

- Laptop and Tablet with internet connection

- Qualtrics Software

\section{METHOD}

- Create questionnaire on Oualtrics (see Appendix C for full questions) and "open" survey to public with a link

- Approach patrons in café noting time and café location.

- Introduce background on the research purpose and present patron with background sheet

- Gain permission from patron o participate within the study.

- Present Patron with a consent form to sign.

- Leave patron to complete survey

- Continue until five patrons per café have completed the survey
OCCUPIED TESTING - CONVERSATION

\section{AIM}

To investigate the Cafe Effect within cafes. To recorded the change in ambient sound level over a ten-minute recording time.

\section{EOUIPMENT}

Head And Torso Simulator (HATS)

MPA Side Microphone

Headset Microphone

\section{METHOD}

- Set up the MPA side microphone a neighbouring table. This records the ambient SPL

- Set up the both the right and left ear microphones on the Head and Torso Simulator across the table. This records the SPL received by a patron sitting across the table from the sound source

- Set up a headset microphone on yourself to record your source level SPL

- Connect all four microphone outputs to a four track recorder. This recorder records the four tracks simultaneously to a SD card 


\section{APPENDIX C}

\section{- SURVEY OUESTIONS}

\section{Implementing an Intangible: A Parametric Realisation of Café Acoustics}

What influenced your choice of Café? Order these influences from 1 (most important) to 9 (least important)

\begin{tabular}{lll}
\hline Location & \\
\hline Price & 2 \\
\hline Vibe/Atmosphere \\
- Cafe Size \\
- Fusic \\
Food \\
Coffee \\
- No Reason
\end{tabular}

- Other

You rated Vibe/Atmosphere highly. Please describe what atmosphere is to you?

You rated Other highly. Please state the influence

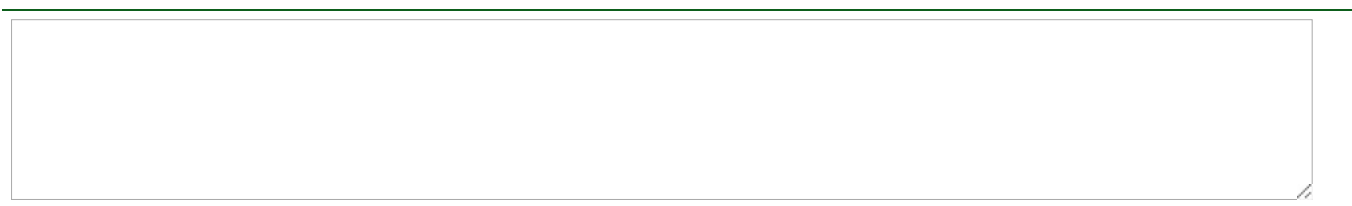

Did you come to this cafe for a quiet or a loud cafe experience? Drag the slider to indicate your preference

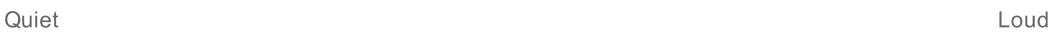

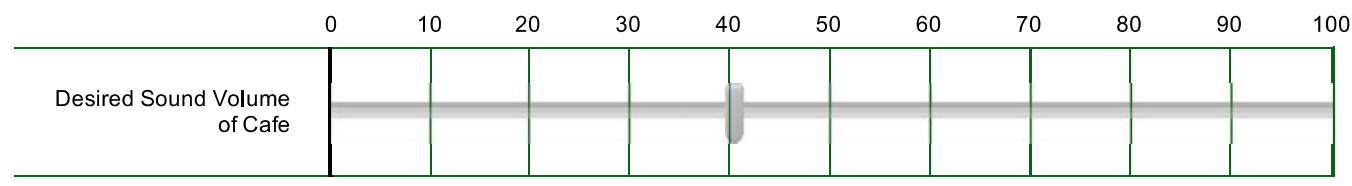

Where are you seated? 

Inside - by a wall
Inside - in a corne
Inside - in the centre of the room
Outside

Did you choose this table in the café? Please select No if you were taken by wait staff to this table
Yes
No

Why did you choose this table in the café?
Privacy
Near a window
Near a wal
More quiet
More loud
Other

What contributes the most to the noise of the cafe?

- Kitchen Noise

- Music

- Other Users talking

- Coffee Machine

- Road Noise

- Other Noises

Please rate your ability to converse easily with your companion/s

$\begin{array}{ccccc}\text { Poor } & \text { Average } & \text { Ok } & \text { Good } & \text { Excellent } \\ & \bigcirc & \bigcirc & \bigcirc & \end{array}$

If your conversation is impair, is it because of background sound?

Never Sometimes About half the time

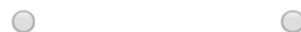

()

Most of the time

○

Always

Is your attention ever diverted by other patron's conversations?

\begin{tabular}{|c|c|c|c|c|}
\hline Never & Sometimes & About half the time & Most of the time & Always \\
\hline$\bigcirc$ & 0 & $\bigcirc$ & $\bigcirc$ & O \\
\hline
\end{tabular}


Please rate your ability to hear others at your table

\begin{tabular}{ccccc}
\hline Poor & Average & Ok & Good & Excellent
\end{tabular}

Please rate your ability to be heard by others at your table

\begin{tabular}{ccccc}
\hline Poor & Average & Ok & Good & Excellent \\
Please rate your ability to hear yourself & & & & \\
\hline Poor & Average & Ok & Good & Excellent
\end{tabular}

Poor Average

○

(

O

Please rate your degree of privacy that you experience (where 1 represents the ability for people from other tables to hear you and 5 is where you feel no one can)

\begin{tabular}{|c|c|c|c|c|}
\hline Poor Privacy & Average & Ok & Good & Excellent Privacy \\
\hline$\bigcirc$ & $\bigcirc$ & $\bigcirc$ & $\bigcirc$ & O \\
\hline \multicolumn{5}{|c|}{ Overall, please rate your enjoyment of this café } \\
\hline Poor & Average & Ok & Good & Excellent \\
\hline$\bigcirc$ & $\bigcirc$ & $\bigcirc$ & $\bigcirc$ & $\bigcirc$ \\
\hline
\end{tabular}




\section{APPENDIX D - RESUITS}

OUANTITATIVE DATA:

Background Sound Pressure levels $\left(\mathrm{L}_{\text {Aea }}\right)$

Every cafe had a higher SPL than the recommendation in AS/NZS 2107 (2000) aligning with Christie and Bell-Booth's research. The AS/NZS 2107 (2000) standard is used to design acoustic environments towards a recommended ambient sound level. The recommended unoccupied sound level set out in AS/NZS 2107 (2000) for a "coffee bar" is:

$$
\begin{gathered}
\mathrm{L}_{\text {Aeq }} \text { of } 45 \mathrm{dBA} \\
\text { Maximum of } 50 \mathrm{dBA} \text {. }
\end{gathered}
$$

These $L_{\text {Aea }} s$ are for unoccupied cafes, however, if a recommended Signal to Noise Ratio (SNR) of $10 \mathrm{dBA}$ is applied then $55 \mathrm{dBA}$ - 60dBA occupied can be estimated. Café 1 and 5 are more than 10dBA above this maximum with escalated Cafe Effect and decreased patron comfort (figure 13.2).
The SPL results showed agreement with Legge et al.'s results. SPL recordings taken by Legge et al. at the same cafes (grey bars) are comparable to the SPL taken in this study with the exception of café 4 and 6 . Café 4 and 6 were significantly different from by Legge et al.'s previously recorded average which suggested that these results were abnormalities. Both Legge et al. and this study measured the cafes at the busiest time of day, however, this variation of days and subsequent acoustic conditions could account for the differences in SPL for café 4 and 6 .

\section{Average Sound Pressure Levels}

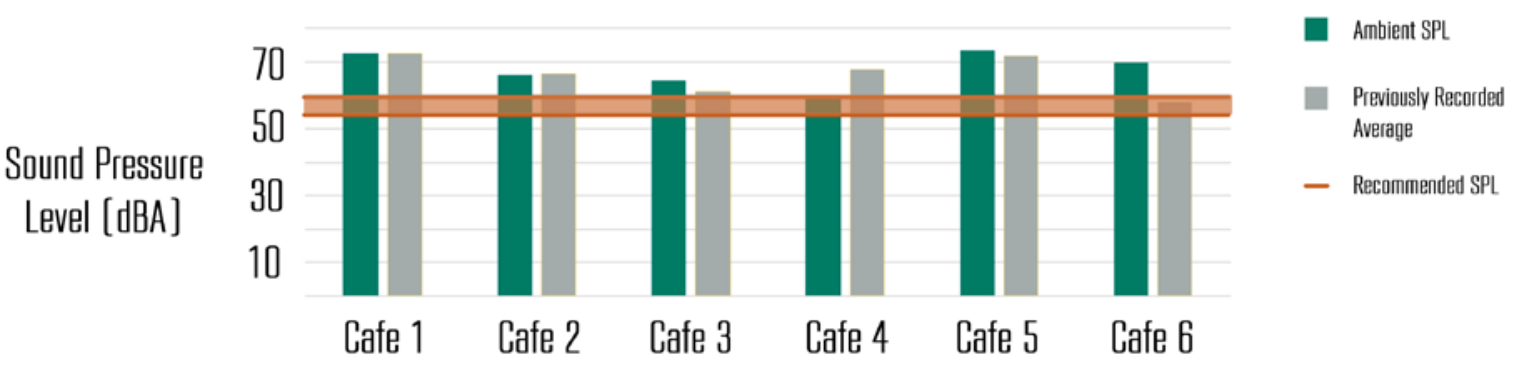

Figure 13.2 Comparison of SPL in the six cafes tested 
REVERBERATION TIME (T2O)

All T2Os were within the recommended maximum RT of 1 second set by AS/NZS 2107 (2000) (figure 13.3). However, decreasing the RT was identified by Whitlock and Dodd as an effective approach for maintaining a high Speech Intelligibility (1).

RTs were graphed against SPLs to show no significant correlation (figure 13.4). A positive trend was expected with an increase in RT causing an increase of SPL. This hypothesis was formed from the understanding that the higher the RT, the more the sound reverberates around the room, stimulating the Cafe
Effect. However, when reviewing the graph there is no clear relationship between RT and SPL. This is because of the outliers measured for café 4 and 6 . Legge et al.'s SPL were graphed against this research's recorded RT to show a linear trend.

\section{Reverberance [Т२०]}

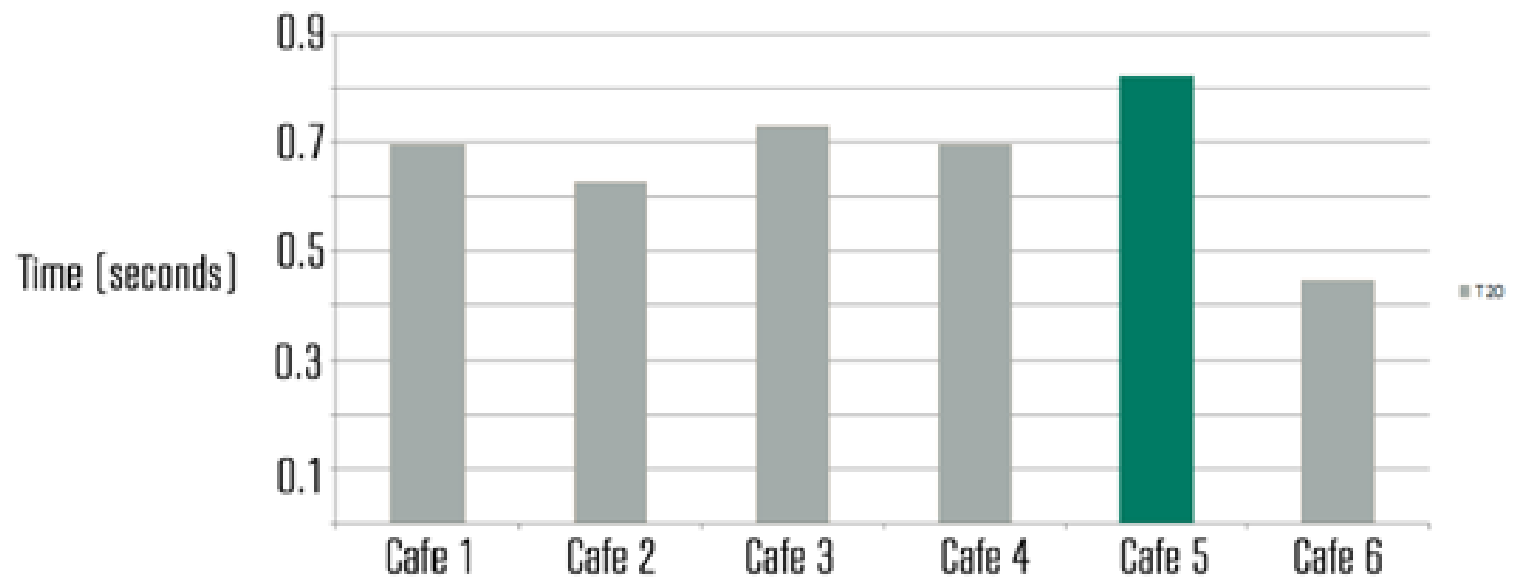

Figure 13.3. RT comparison of the six cafes 

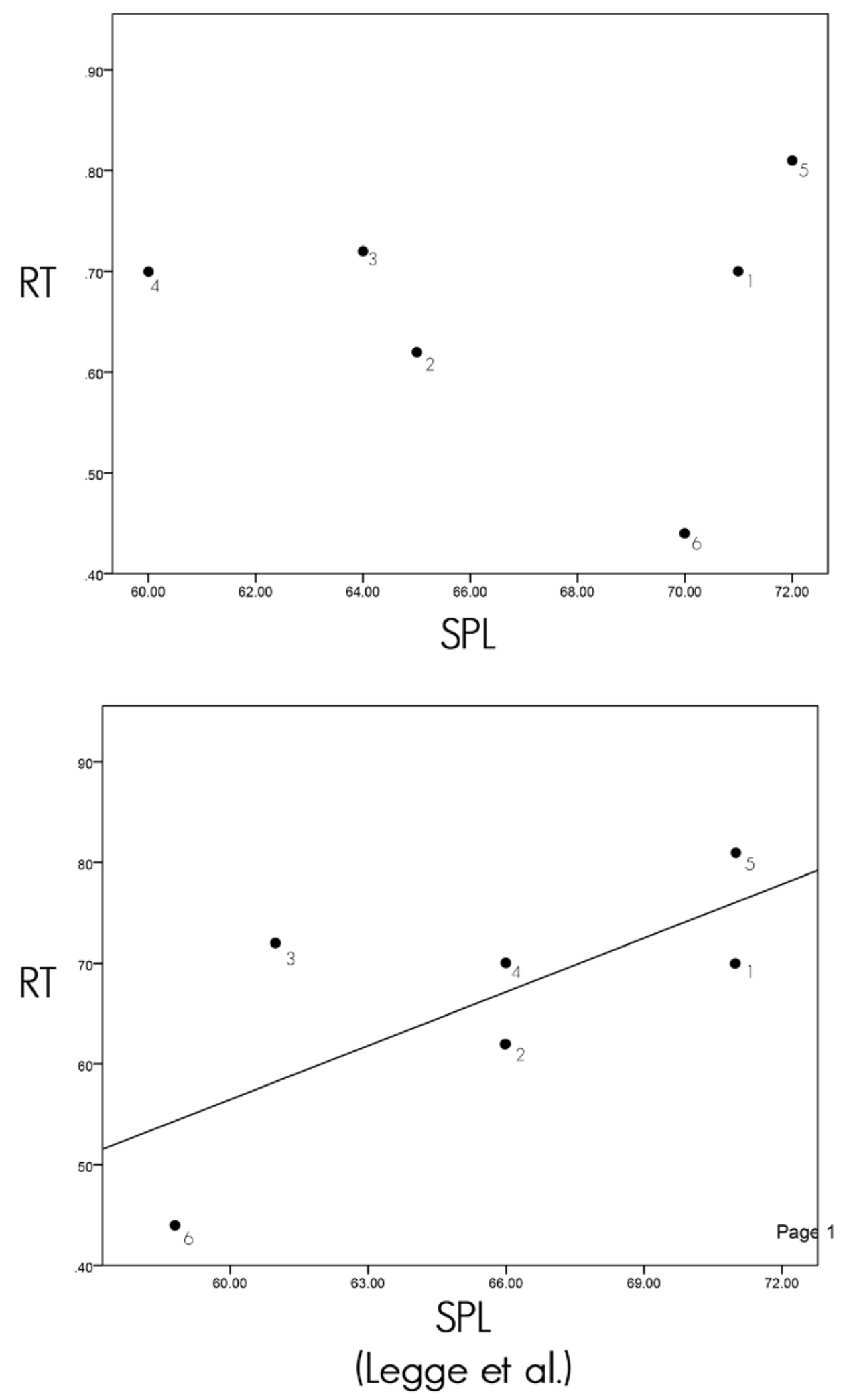

Figure 13.4. SPL and RT comparison for result taken from this research (top) and Legge et al.'s research (bottom) 


\section{IRIS OBSERVATIONS}

The IRIS plots in Figure 13.5 results show dominant long blue and light blue rays, representing a significant amount of late energy lafter 50 and 100 milliseconds respectively). Late energy decreases the clarity of the space as the reverberant energy is received after the 50ms threshold of human hearing for speech. This results in a slurring of words and subsequently lower speech intelligibility.
These blue rays are long relative to the direct (red) ray, suggesting that the late reflections are significant. The plots are roughly symmetrical with a full ring of blue rays. This means that reflections are received from behind, and to the side of the receiver, rather than just in front. This suggests a highly diffuse room. 


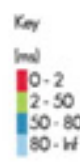
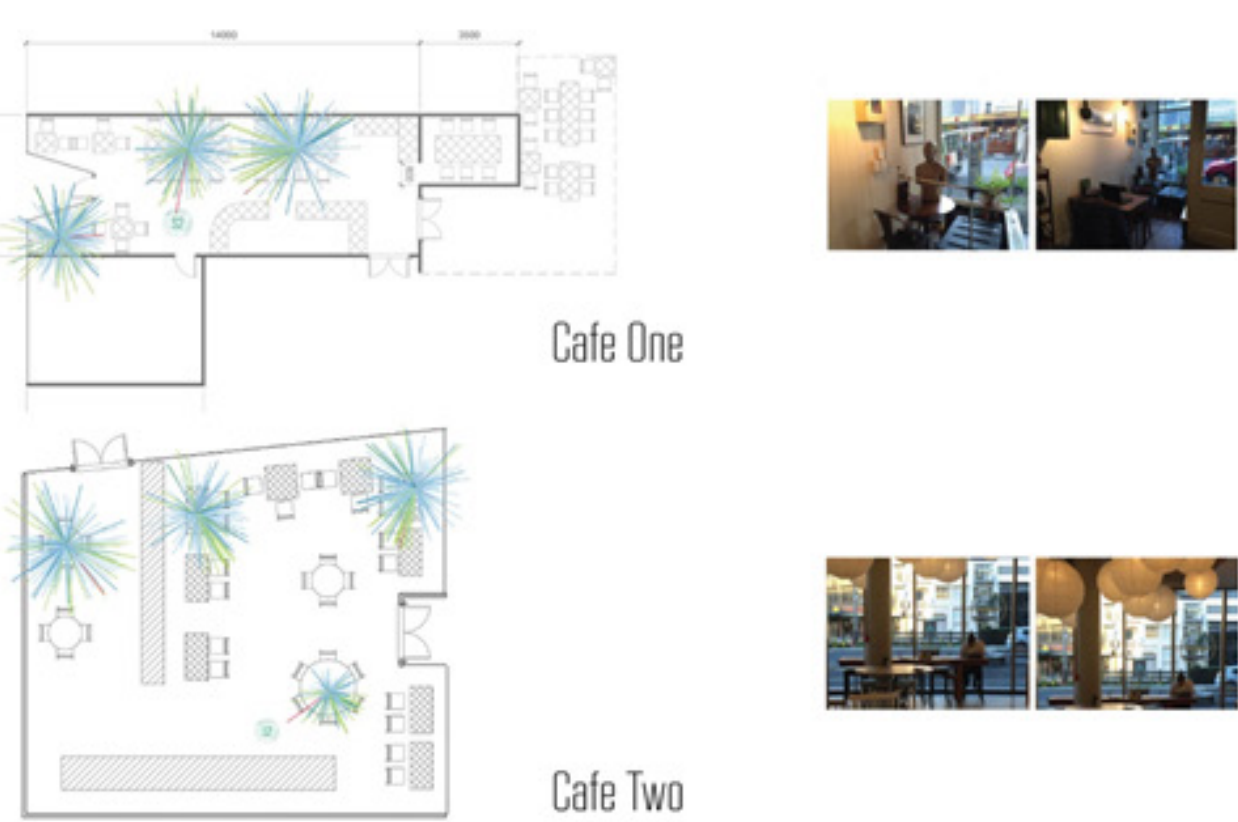

Cafe One

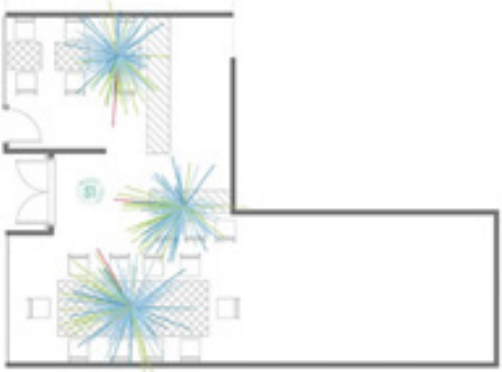

Cafe Two
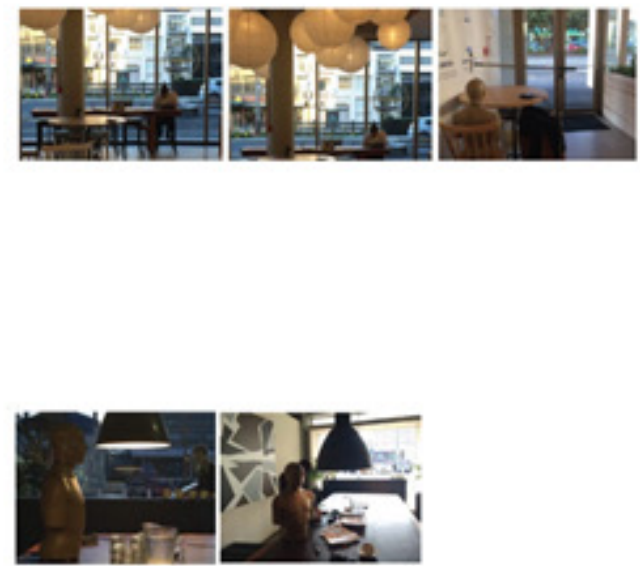

Cafe Three
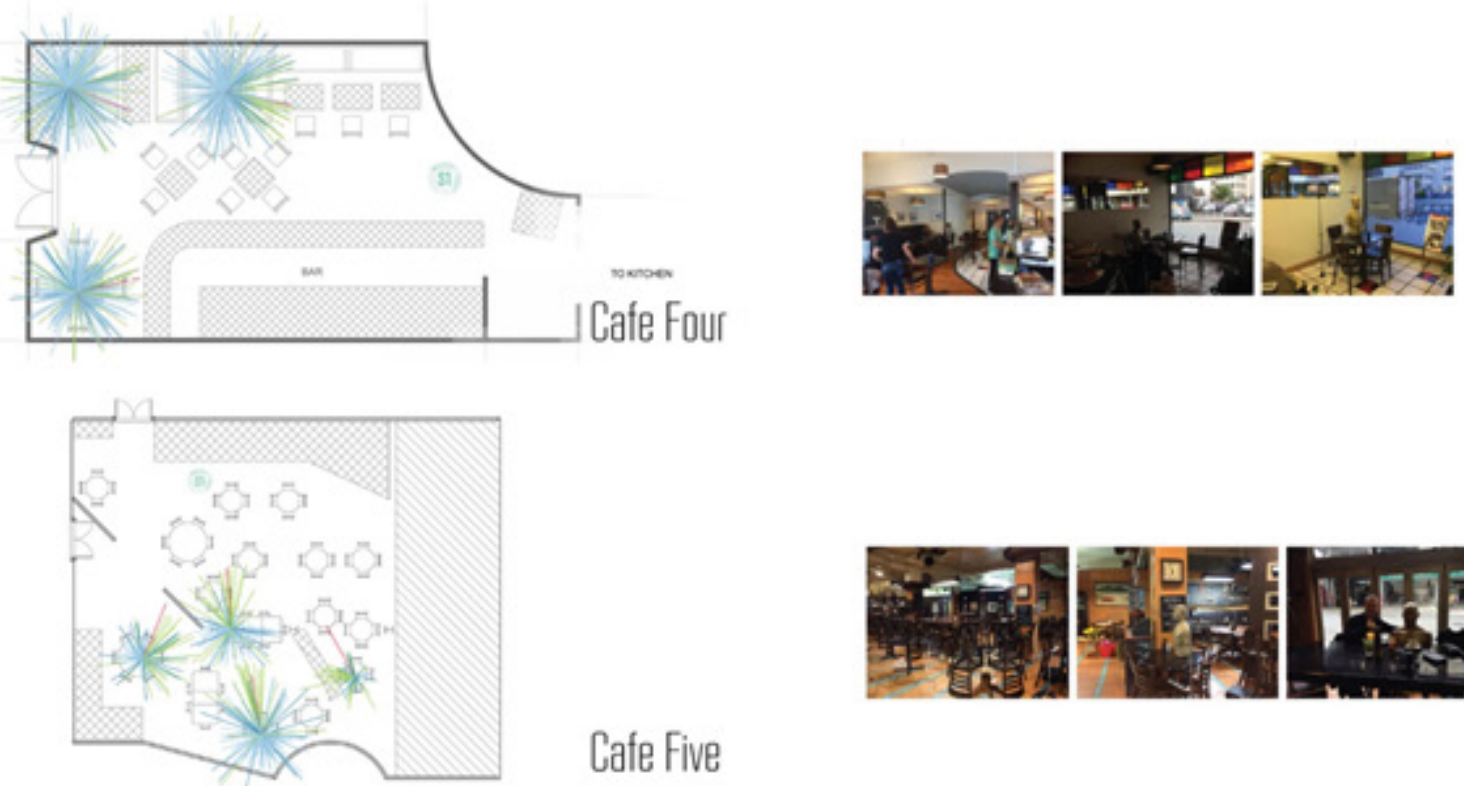

Cafe Five
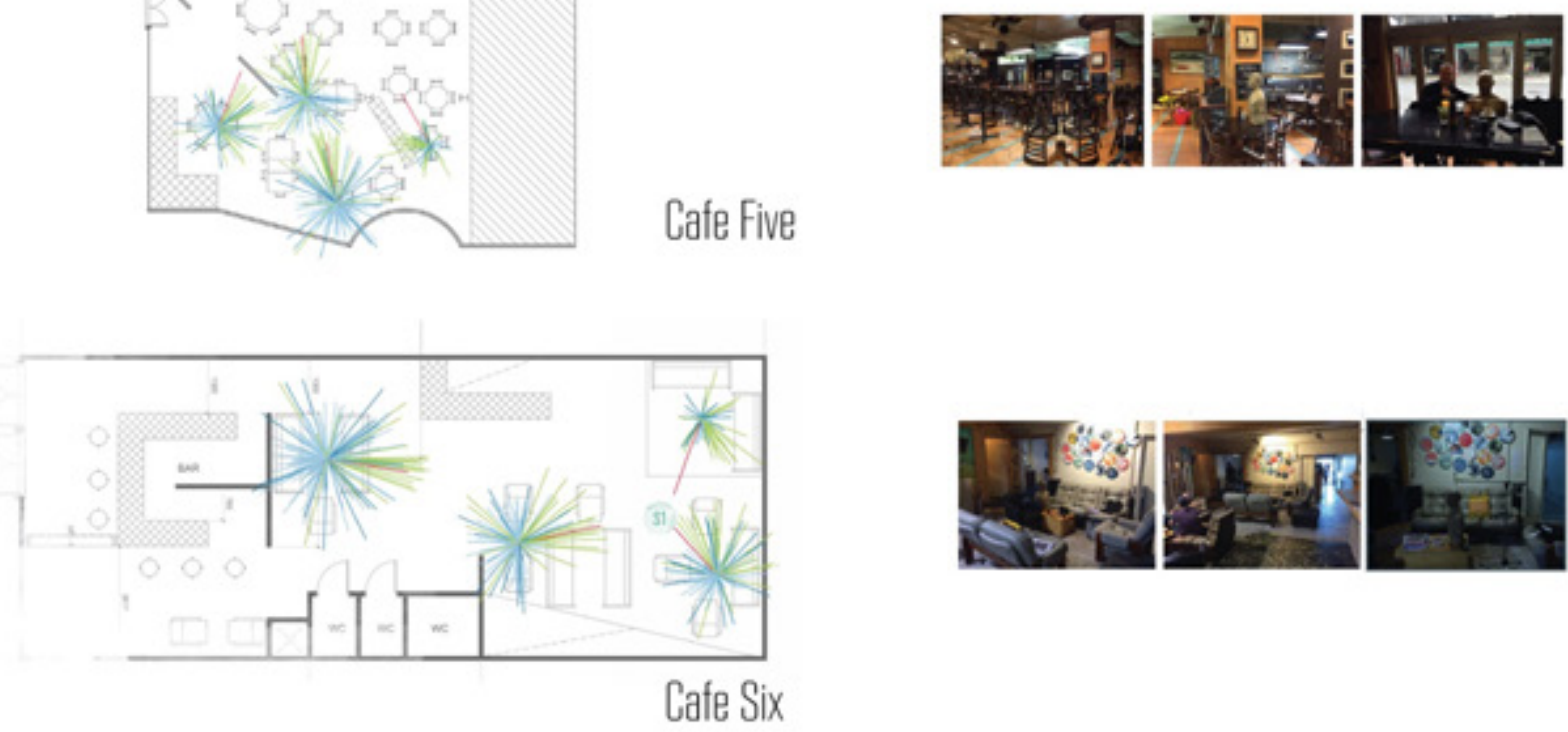

Figure 13.5 IRIS 3D plot results 


\section{OUALITATIVE DATA:}

30 patrons of the six cafés were asked a range of questions that gauged influences on their café experience. The patron survey gained subjective data that drew conclusions to accompany the objective data completed in the quantitative study.

Patrons were asked to scale the experienced volume between 0\% (quiet) and 100\% (loud).
Patrons were also asked to rate their ability on a five-level Likert scale to hear themselves, hear others and be heard by others at their table. These three questions shared a correlation significant at the 0.01 level. The three correlated results constructed the "Holistic Communication" measure. The ability of the patron to holistically communicate decreased linearly as the experienced volume increased (figure 13.6)

\section{Holistic Communication*}

Holistic Communication

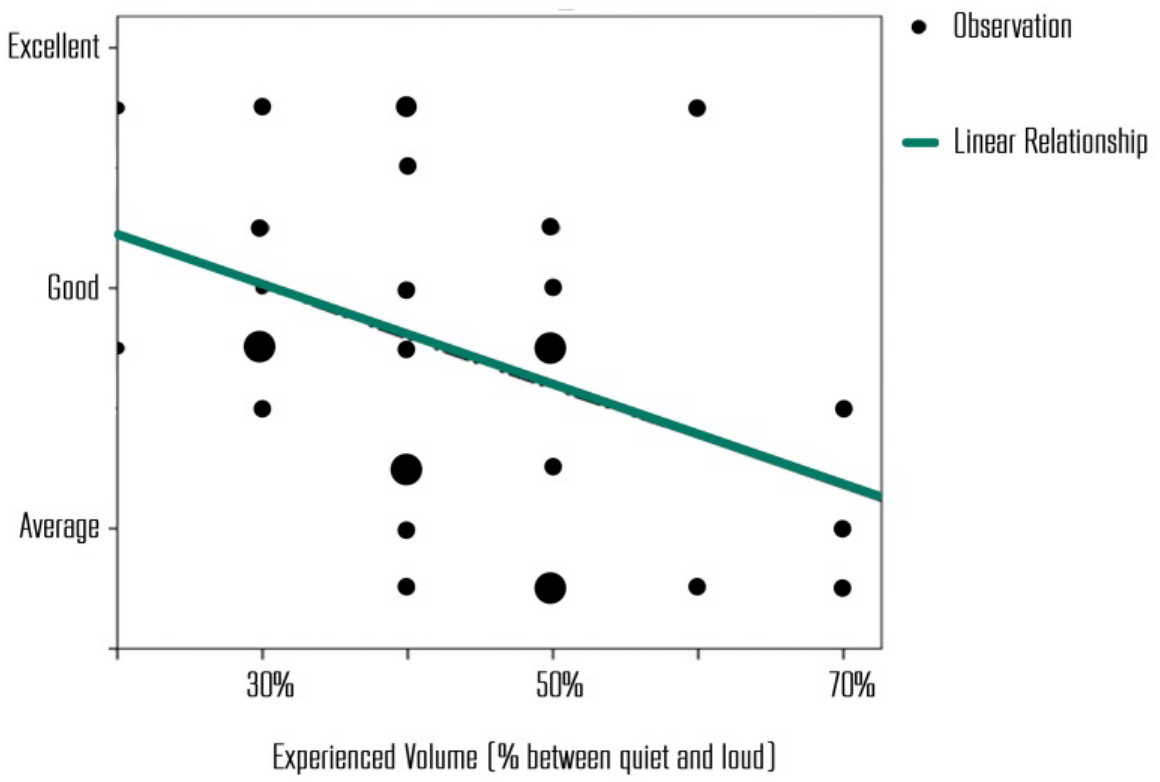

*Holistic Communication is the ability to hear others, self and be heard b

Figure 13.6 Holistic communication plotted against subjective experienced volume 
Unlike the Holistic Communication result, the overall Enjoyment of the café experience was not a linear regression (figure 13.7). The patrons were asked to rate their overall enjoyment of the café considering all of the previous questions that they answered. This overall enjoyment was graphed against the experienced volume to show their relationship. Overall enjoyment increased and then decreased quadratically as the volume increased.

The mean enjoyment ratings of all six cafes was above "good", however, Café 5 was rated the lowest (figure 13.8).
Patrons' Expected Volume was contrasted against the Experienced Volume to gauge if the café catered to its clients (figure 13.9). In the graph above, the first bar represents the mean Expected Volume and the second represents that mean Experienced Volume. The three cafés with the highest difference between Expected Volume and experienced Volume also had the lowest overall enioyment levels.

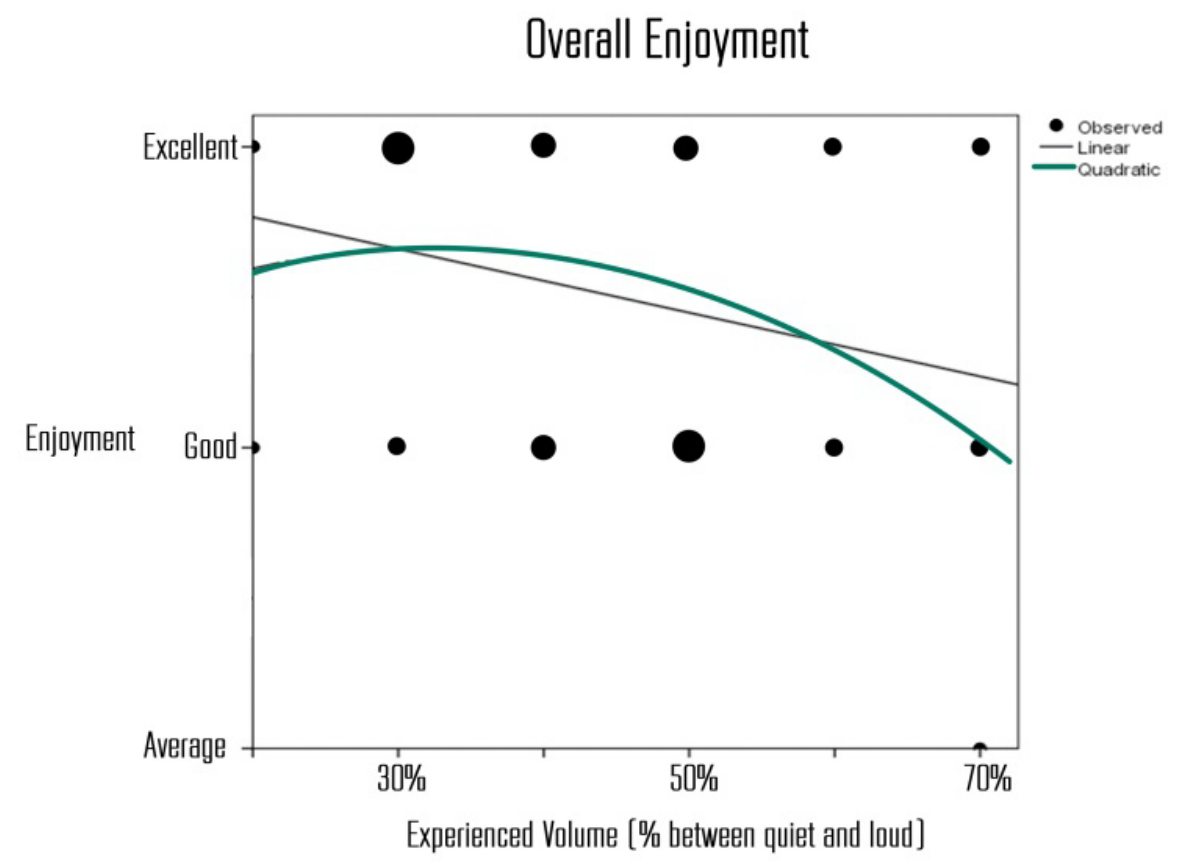

Figure 13.7 Overall patron enioyment plotted against subjective experienced volume 
Overall Customer Enjoyment

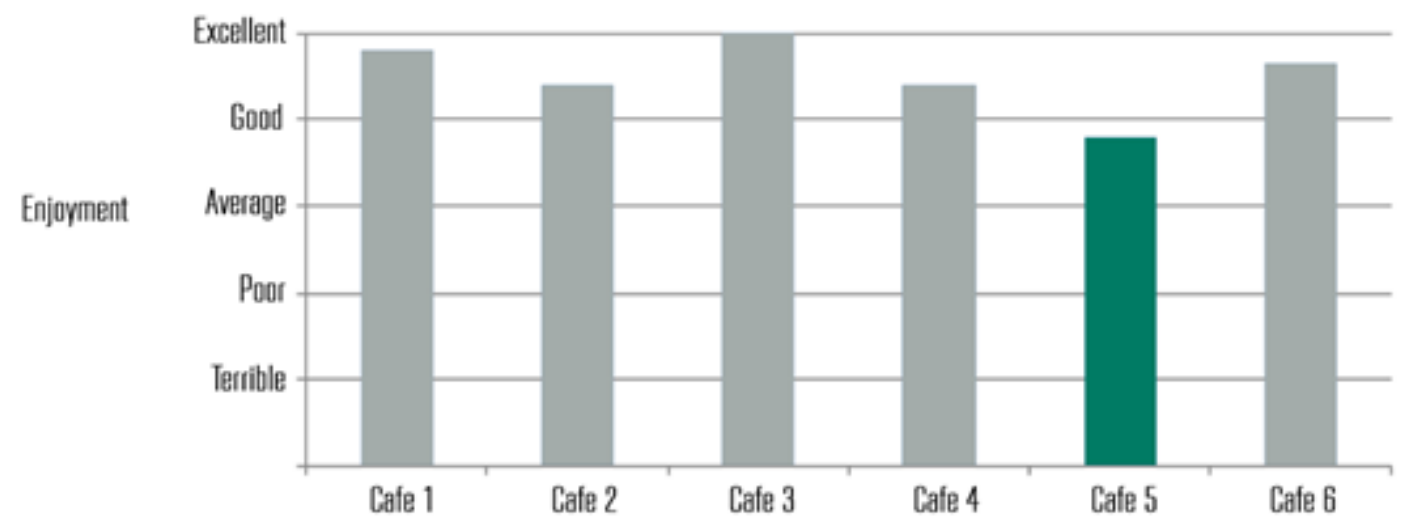

Figure 13.8 Comparison of patron enjoyment for the six cafes

\section{Expected Volume vs Actual Volume Perceived}

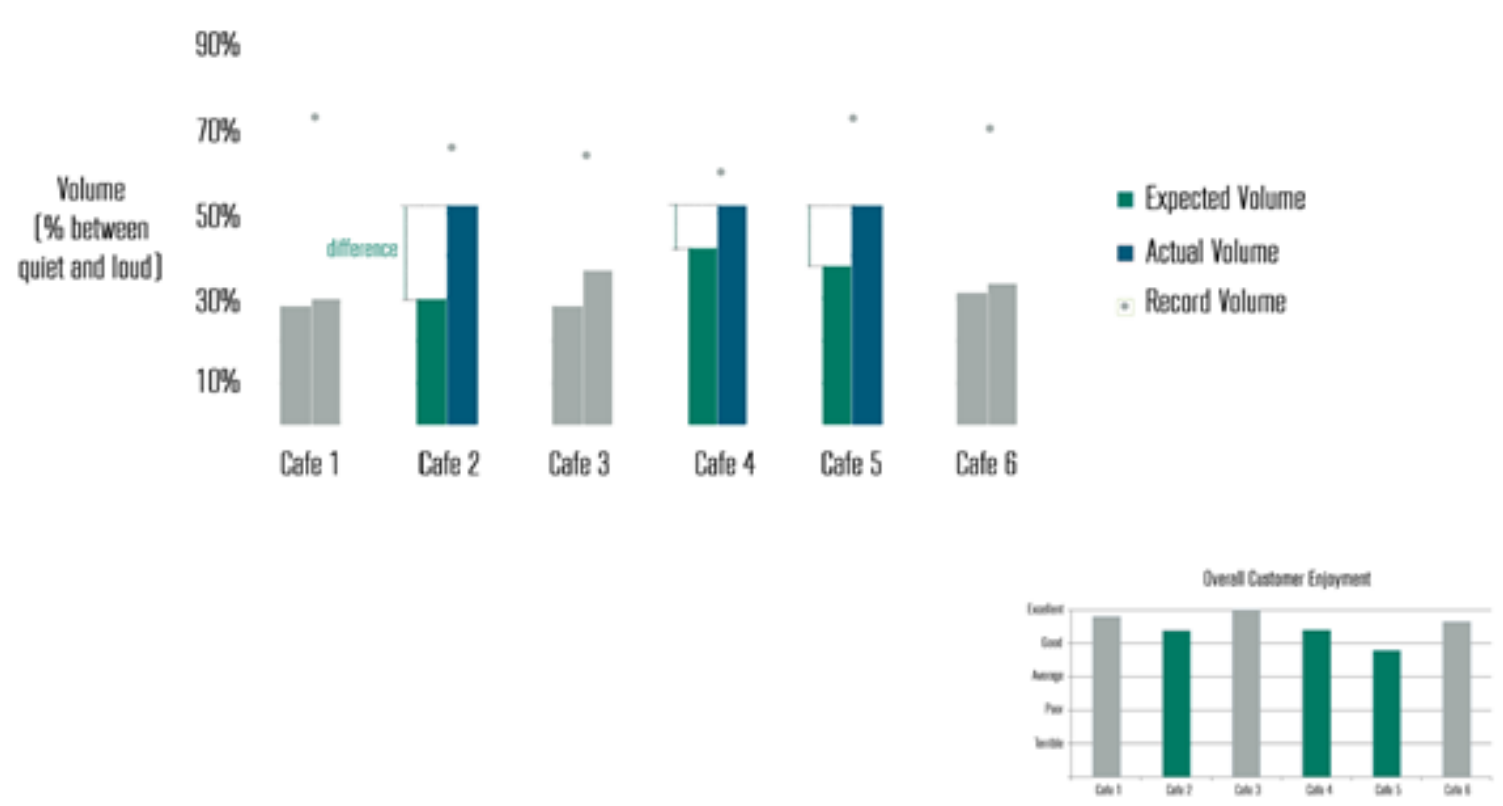

Figure 13.9 Comparison of expected and experienced volumes for the six cafes 